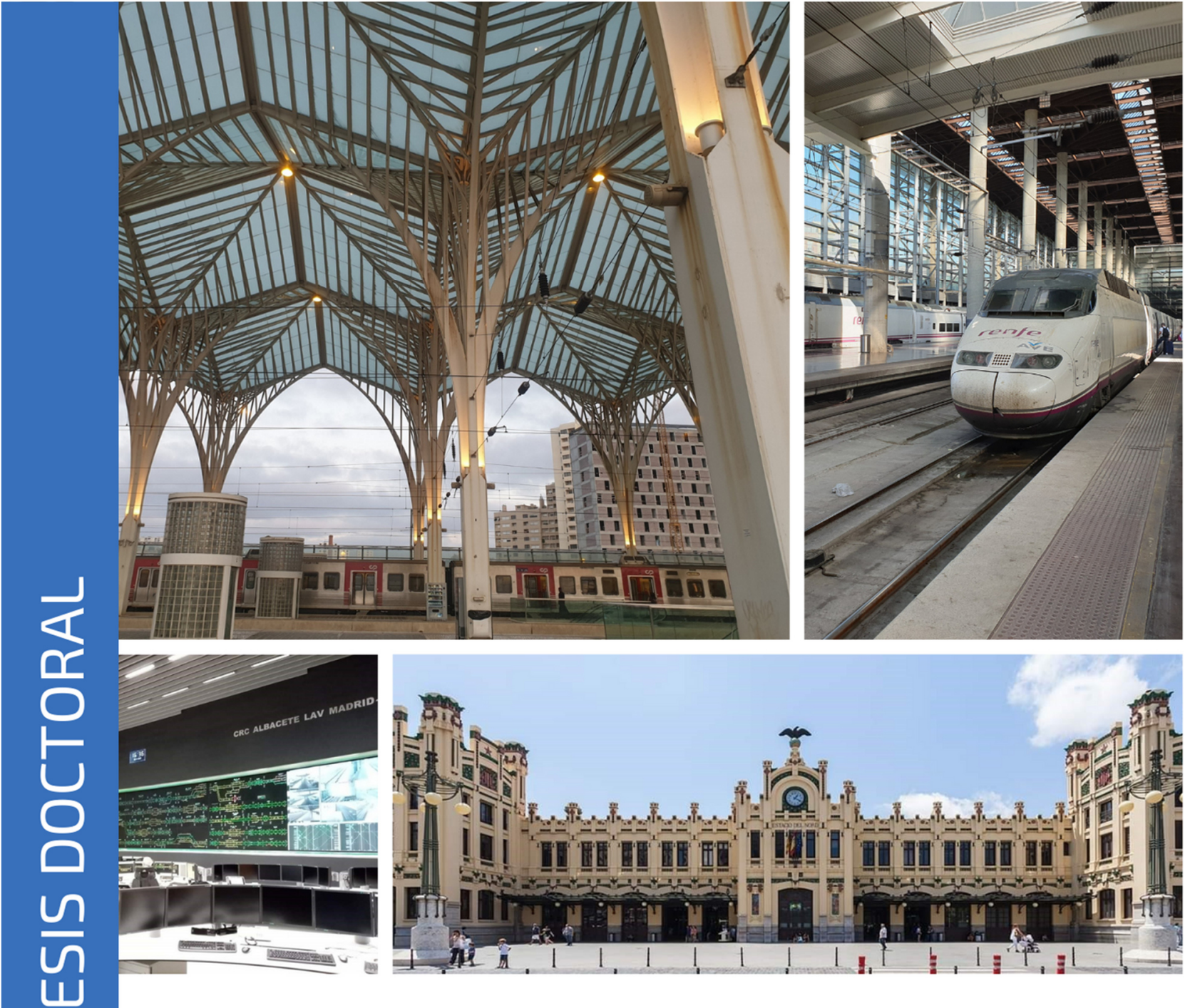

UNIVERSITAT
POLITËCNICA
DE VALĖNCIA

DOCTORANDO: JUAN B. FONT TORRES

DIRECTORES: Prof. Dr. RICARDO INSA FRANCO

Prof. Dr. PAULO FONSECA TEIXEIRA

ESCUELA DE DOCTORADO

PROGRAMA DE DOCTORADO EN INFRAESTRUCTURAS DE TRANSPORTE Y TERRITORIO

\title{
ESTUDIO DE LOS CÁNONES POR USO DE ESTACIONES DE VIAJEROS EN EL CONTEXTO DEL SISTEMA FERROVIARIO EUROPEO
}


Portada: Estación de Lisboa Oriente, Estación de Madrid Puerta de Atocha, Puesto de Mando de LAV Madrid-Levante, Estación de Valencia Nord. Elaboración propia.

Contraportada: Pórtico Línea Aérea de Contacto. Estación de Oropesa del Mar. Elaboración propia. 
A mi esposa Rosa.

A mis hijos, Sergio e Iván. 
"Me lo contaron y lo olvidé, lo vi y lo entendí, lo hice y lo aprendí." Confucio, siglos $\vee$ y VI a. c. 


\section{AGRADECIMIENTOS}

Antes tengo que reconocer que ha sido duro el camino seguido hasta la consecución de esta Tesis Doctoral. La elaboración de esta Tesis ha demostrado que existe algo más que un simple vínculo académico entre personas sino una muestra de apoyo, ánimo y satisfacción en su desarrollo y consecución.

A los doctores miembros del Tribunal de esta Tesis y a los Evaluadores por sus sabias observaciones y reflexiones.

A los miembros de la Comisión Académica del Programa del Doctorado y en especial al doctor Alfredo García.

A los doctores Ricardo Insa y Paulo F. Teixeira, directores de esta Tesis y al doctor Alberto García, personas a la que quiero demostrar mi agradecimiento por sus conocimientos y pasión por el ferrocarril. Sus pasos me hacen recordar palabras de Antonio Gaudí: "Para hacer las cosas bien hace falta, primero, amarlas, y segundo, la técnica". Sus más que amplios conocimientos sobre ferrocarriles y su visión práctica son un ejemplo a seguir.

A Juan B. Cano, subdirector de Estaciones Este de ADIF, por haberle conocido, de forma casual, en tierras sorianas y confiar en mí así como por su inestimable ayuda a la hora de confeccionar este trabajo.

A José Antonio Sebastián, Jefe de Estaciones del Ámbito de Valencia por sus consejos y confianza.

A Manuel Tomás por sus buenos consejos, trabajar contigo es un aprendizaje continuo.

A José Luis y Martín por su interés hacia mi persona.

A Paco, entonces Jefe de Edificación de ADIF, que me recibió no como jefe, haciéndome sentir como en mi casa, por ser un profesional y líder y del que he aprendido mucho. Ahora embarcado en el proyecto Haramain en Arabia Saudí. Mis mejores deseos en su nueva labor.

A mis compañeros de la Jefatura de Edificación de ADIF, Mar, Rodrigo, Carmen, y en especial a Dani, por ser como es, más que un compañero y haberme enseñado todo en el nuevo destino en Valencia tras la llegada de Soria procedente de la Subdirección de Circulación.

A mis compañeros Carlos, Javier, José y José María, responsables de Circulación de Soria que tanto me enseñaron y aconsejaron en mis comienzos en esta casa ferroviaria durante mi primer año. 
A mis amigos Ana, José, a su hijo Carlos por estar siempre ahí, para lo bueno y para lo malo.

A Esperanza, Pepe y sus hijos Lidia y Pepe, por sus ánimos e interés en mis estudios y sobre todo en los momentos más duros, sois mi familia murciana.

A Juan, Juan Carlos y José Vicente por su interés y apoyo.

A Cristina y sus hijos Rómulo, Cristina y María, aun estando en Madrid, no hay distancia.

A Cristina, Carlos y sus hijos Cristina y Carlos por estar ahí cuando los necesitas.

A Pilar, mi médica preferida, Miguel Ángel, Paco, Celia, Rosa, Noelia y Ramón por ser como son.

A Miguel por sus palabras de ánimo e interés hacia mi persona. Siempre apoyándome. Eres como un padre para mí.

A José Ramón Albiol y Luis Ballester, amigos y doctores, por sus consejos y ánimos en la consecución del presente trabajo.

A David Romero, amigo y doctor, gracias por tu ayuda.

A los doctores Rosa Arroyo, Pablo Salvador y Pablo Martínez por su ayuda y "soportarme" con mis dudas y sobre todo su paciencia antes de las tutorías. Especial mención al doctor Ignacio Villalba por sus ayudas y consejos.

No puedo olvidar al personal de la Unidad de Reanimación 2 de la UCl del Hospital La Fe de Valencia por tensar la línea delgada existente entre la vida y la muerte que delimita el COVID y no permitir que la cruzara en ningún momento. Toda gratitud es poca para estos ángeles de la guarda,

A mis hijos Sergio e Iván, por soportar mi ausencia durante mis estudios y por supuesto a Rosa, mi esposa, que, aplicando la jerga ferroviaria, mostrarme siempre la señal de paso siempre en "vía libre" nunca en "parada", y nunca "a vía desviada" en cuanto a objetivos y tiempo dedicado en mis estudios y trabajos, sin ellos no habría llegado hasta aquí.

Gracias, mil gracias.......

Deo Juvante... 


\section{RESUMEN}

El canon por uso de la infraestructura ferroviaria utiliza una gran diversidad de variables, pero no hay ningún administrador que aplique más del $35 \%$ de los conceptos existentes para tarificar sus servicios. La mayoría de los sistemas de tarificación comparten algunos parámetros, tales como la categoría de la línea, diferenciando el uso de líneas principales, secundarias y otras. Estas variables aplicadas recuperan los costes marginales y los costes variables correspondientes a la operación, mantenimiento y renovación.

En los corredores ferroviarios internacionales, a pesar de la legislación existente que obliga a una convergencia de enfoque para un sistema basado en costes directos, sigue existiendo esa falta de convergencia, no sólo en los niveles de cánones, sino también en las formulaciones, las variables y parámetros de fijación de precios variando de país a país, representando un problema.

Los cánones analizados en la tarificación por uso de las estaciones de viajeros muestran que existen administradores que aplican el uso de estaciones de viajeros directamente en el canon por uso de la infraestructura, siendo determinado en el momento de realizar la reserva del surco correspondiente. Las variables empleadas en la conceptualización de las categorías de las estaciones presentan variedad en las subcategorías empleadas en la clasificación.

Ante esto no es posible simplificar la formulación empleada para el cálculo de los cánones por los países estudiados en busca de una expresión común aplicable para conseguir eliminar una de las barreras en la red ferroviaria europea.

Respecto a la problemática de la tarificación por uso de las estaciones de viajeros en líneas de alta velocidad: caso de estudio línea Madrid-Levante, los ingresos por uso de las estaciones de transporte de viajeros, proviene con mayor porcentaje del canon, canon basado en el número de circulaciones que tienen origen/destino o parada comercial y en el número de viajeros subidos/bajados en cada una de ellas. En cuanto al canon aplicado a las circulaciones es dispar entre las estaciones de la línea, siendo más bajo en las estaciones que no son origen-destino, es decir en aquellas estaciones que tienen paradas intermedias. Los ingresos procedentes del canon son insuficientes para equilibrar el balance económico total pero sí que cubre más allá de los costes directos imputables a la explotación, no siguiendo la Directiva europea de la que emana que sólo se recuperará mediante 
cánones aquellos costes relacionados directamente con la explotación ferroviaria.

Ante el futuro escenario del ferrocarril en España con la entrada al mercado nacional de los nuevos operadores ferroviarios es necesaria reformar la Ley del Sector Ferroviario con el objetivo de modificar el sistema mediante el que se fijan los cánones. Este cambio supone separar esta tasa de los Presupuestos Generales del Estado y permitir que los administradores de infraestructuras puedan establecer con total libertad bonificaciones en los cánones para, expresamente, incentivar el transporte. Esta flexibilización permitiría reducir el importe que cada operadora paga por usar la infraestructura e instalaciones, traduciéndose en un incremento de las circulaciones, aumento de los ingresos del administrador y en una reducción de las tarifas de transporte de viajeros y mercancías. Por contrapartida está la financiación de los servicios comerciales operados por el operador actual en las líneas convencionales, el resultado positivo de los servicios prestados por la empresa en Alta Velocidad, después de la liquidación de los correspondientes cánones compensa los resultados negativos de todos los demás negocios de viajeros y de mercancías, caso no aplicado a los nuevos operadores y que "a priori" entran en el mercado con esta ventaja. 


\section{RESUM}

El cànon per ús de la infraestructura ferroviària utilitza una gran diversitat de variables, però no hi ha cap administrador que aplicació més del $35 \%$ dels conceptes existents per a tarifar els seus serveis. La majoria dels sistemes de tarifació comparteixen alguns paràmetres, com ara la categoria de la línia, diferenciant l'ús de línies principals, secundàries i altres. Aquestes variables aplicades recuperen els costos marginals i els costos variables corresponents a l'operació, manteniment i renovació.

En els corredors ferroviaris internacionals, malgrat la legislació existent que obliga a una convergència d'enfocament per a un sistema basat en costos directes, continua existint aqueixa falta de convergència, no sols en els nivells de cànons, sinó també en les formulacions, les variables i paràmetres de fixació de preus variant de país a país, representant un problema.

Els cànons analitzats en la tarifació per ús de les estacions de viatgers mostren que existeixen administradors que apliquen l'ús d'estacions de viatgers directament en el cànon per ús de la infraestructura, sent determinat en el moment de realitzar la reserva del solc corresponent. Les variables emprades en la conceptualització de les categories de les estacions presenten varietat en les subcategories emprades en la classificació.

Davant això no és possible simplificar la formulació emprada per al càlcul dels cànons pels països estudiats a la recerca d'una expressió comuna aplicable per a aconseguir eliminar una de les barreres en la xarxa ferroviària europea.

Respecte a la problemàtica de la tarifació per ús de les estacions de viatgers en línies d'alta velocitat: cas d'estudi línia Madrid-Llevant, els ingressos per ús de les estacions de transport de viatgers, prové amb major percentatge del cànon, cànon basat en el nombre de circulacions que tenen origen/destine o parada comercial i en el nombre de viatgers pujats/baixats en cadascuna d'elles. Quant al cànon aplicat a les circulacions és dispar entre les estacions de la línia, sent més baix en les estacions que no són origen-destine, és a dir en aquelles estacions que tenen parades intermèdies. Els ingressos procedents del cànon són insuficients per a equilibrar el balanç econòmic total però si que cobreix més enllà dels costos directes imputables a l'explotació, no seguint la Directiva europea de la qual emana que només es recuperarà mitjançant cànons aquells costos relacionats directament amb l'explotació ferroviària. 
Davant el futur escenari del ferrocarril a Espanya amb l'entrada al mercat nacional dels nous operadors ferroviaris és necessària reformar la Llei del Sector Ferroviari amb l'objectiu de modificar el sistema mitjançant el qual es fixen els cànons. Aquest canvi suposa separar aquesta taxa dels Pressupostos Generals de l'Estat i permetre que els administradors d'infraestructures puguen establir amb total lliberteu bonificacions en els cànons per $a$, expressament, incentivar el transport. Aquesta flexibilització permetria reduir l'import que cada operadora paga per usar la infraestructura i instal lacions, traduint-se en un increment de les circulacions, augment dels ingressos de l'administrador i en una reducció de les tarifes de transport de viatgers i mercaderies. Per contrapartida està el finançament dels serveis comercials operats per l'operador actual en les línies convencionals, el resultat positiu dels serveis prestats per l'empresa en Alta Velocitat, després de la liquidació dels corresponents cànons compensa els resultats negatius de tots els altres negocis de viatgers i de mercaderies, cas no aplicat als nous operadors i que "a priori" entren en el mercat amb aquest avantatge. 


\section{ABSTRACT}

The charge for the use of railway infrastructure uses a great diversity of variables, but there is no administrator that applies more than $35 \%$ of the existing concepts to price its services. Most of the charging systems share some parameters, such as the category of the line, differentiating the use of main, secondary, and other lines. These applied variables recover the marginal costs and the variable costs corresponding to the operation, maintenance, and renovation.

In international rail corridors, despite the existing legislation that requires a convergence of approach for a system based on direct costs, this lack of convergence continues to exist, not only in the levels of fees, but also in the formulations, the variables and pricing parameters varying from country to country, representing a problem.

The charges analysed in the charging for the use of passenger stations show that there are administrators who apply the use of passenger stations directly to the charge for use of the infrastructure, being determined at the time of booking the corresponding path. The variables used in the conceptualization of the station categories present a variety in the subcategories used in the classification.

Given this, it is not possible to simplify the formulation used for the calculation of charges by the countries studied in search of a common expression applicable to achieve the elimination of one of the barriers in the European rail network.

Regarding the problem of charging for the use of passenger stations on highspeed lines: case study of the Madrid-Levante line, income from the use of passenger transportation stations comes with a higher percentage of the charge, charge based on the number of circulations that have origin / destination or commercial stop and the number of passengers getting on / off in each one of them.

As for the charge applied to circulations, it is uneven between the stations of the line, being lower in the stations that are not origin-destination, that is, in those stations that have intermediate stops. The income from the canon is insufficient to balance the total economic balance, but it does cover beyond the direct costs attributable to the exploitation, not following the European Directive from which it emanates that only those costs directly related to the exploitation will be recovered through royalty's railway. 
Given the future scenario of the railway in Spain with the entry into the national market of the new railway operators, it is necessary to reform the Law of the Railway Sector with the aim of modifying the system by which fees are set. This change involves separating this rate from the General State Budgets and allowing infrastructure managers to freely establish discounts on fees to expressly encourage transportation. This flexibility would make it possible to reduce the amount that each operator pays to use the infrastructure and facilities, translating into an increase in traffic, an increase in the administrator's income and a reduction in passenger and freight transport rates. On the other hand, there is the financing of the commercial services operated by the current operator on conventional lines, the positive result of the services provided by the company in High Speed, after the settlement of the corresponding fees, offsets the negative results of all other businesses of travellers and freight, a case not applied to new operators and that "a priori" enter the market with this advantage. 


\section{ÍNDICE}

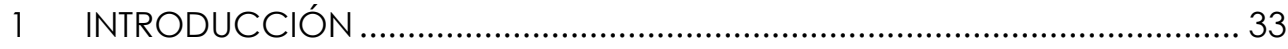

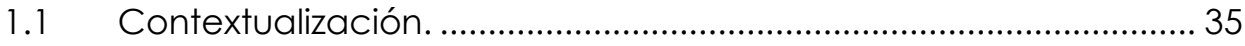

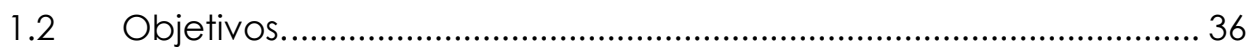

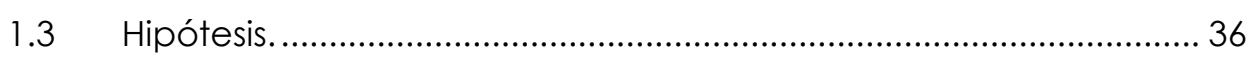

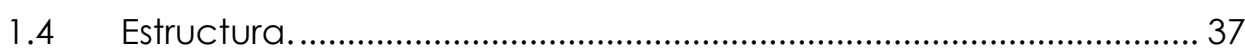

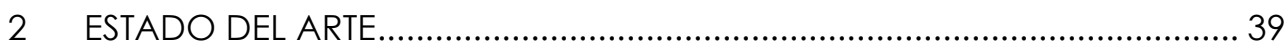

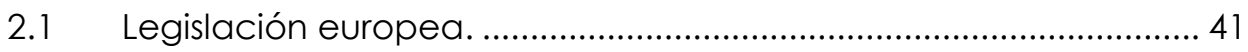

2.2 Cánones por uso de la infraestructura ferroviaria europea.

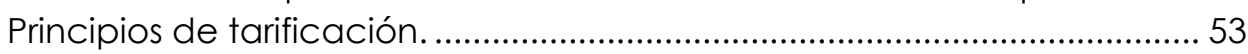

2.3 Canon por uso de estaciones. ......................................................... 59

3 EL CANON POR USO DE ESTACIONES DE VIAJEROS EN EL CONTEXTO DE LA TARIFICACIÓN POR USO DE LA INFRAESTRUCTURA EN EUROPA .................63

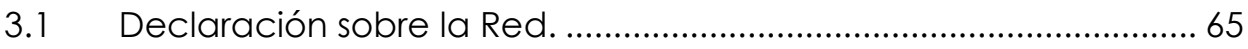

3.2 Estructura del canon por uso de la infraestructura. ........................66

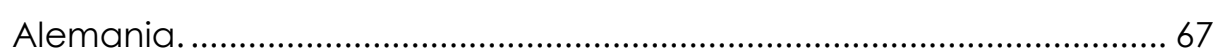

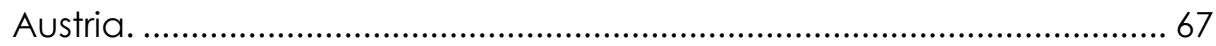

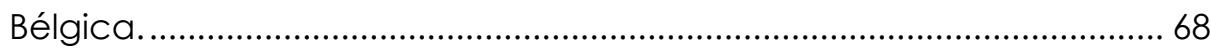

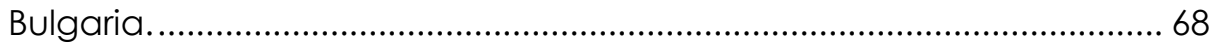

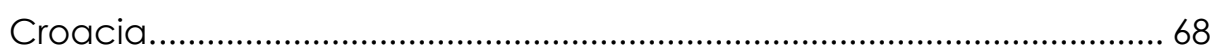

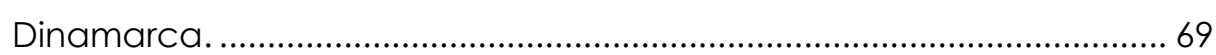

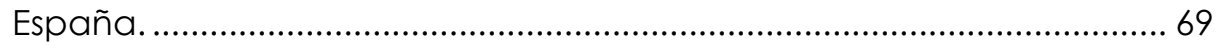

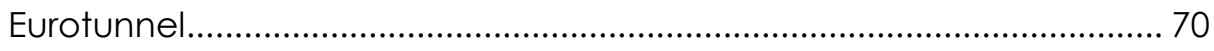

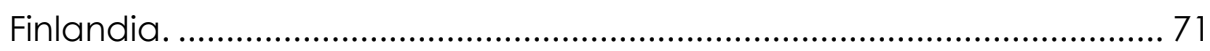

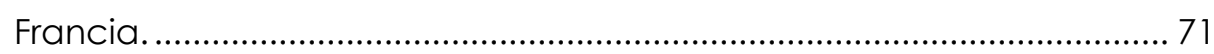

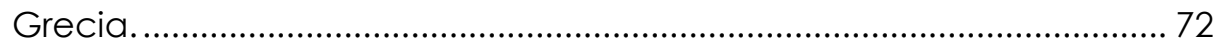

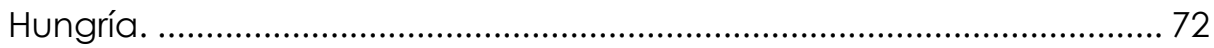

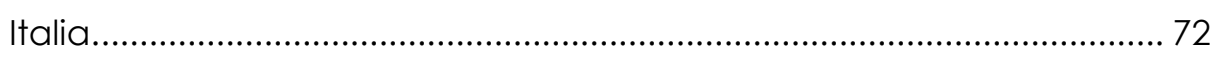

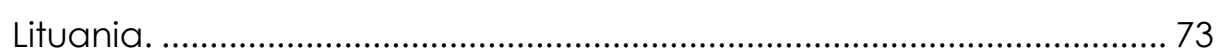

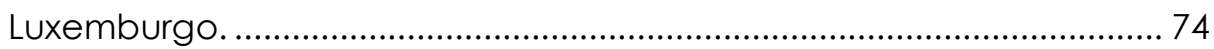




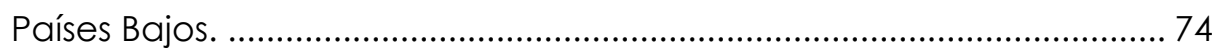

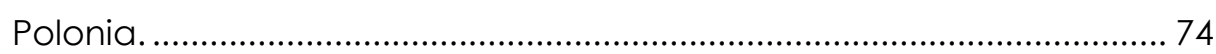

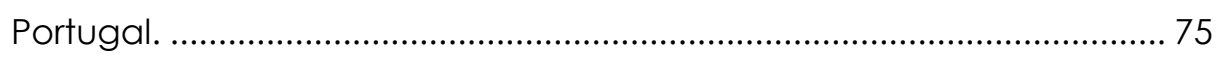

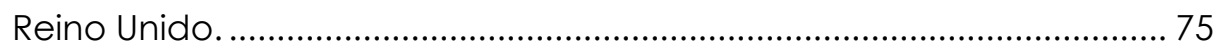

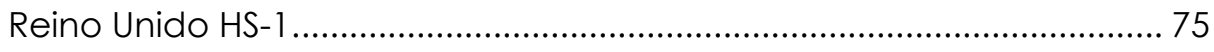

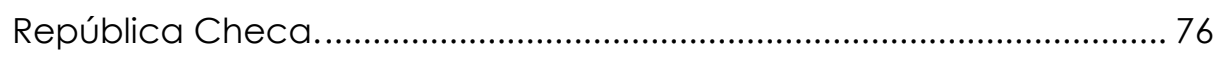

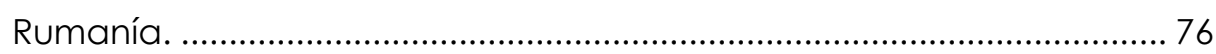

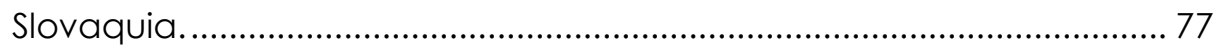

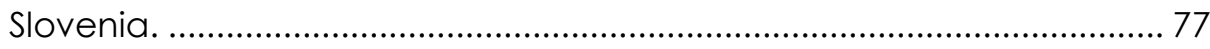

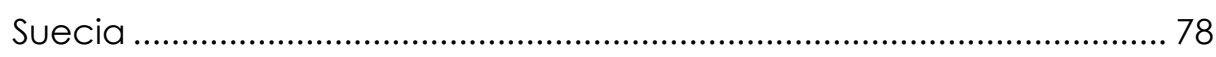

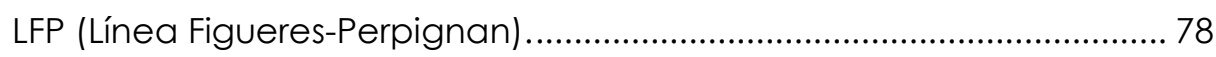

3.3 Estructura del canon por uso de estaciones de viajeros................ 79

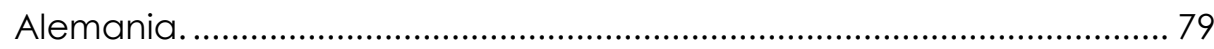

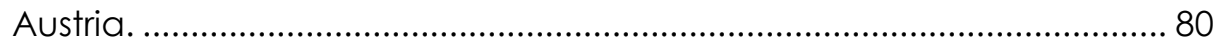

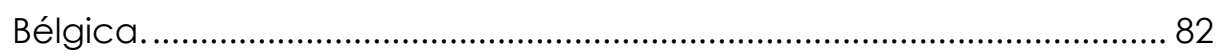

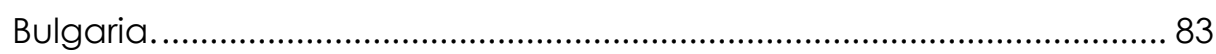

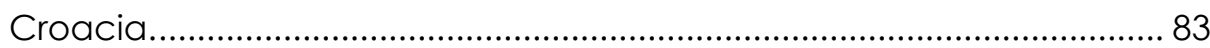

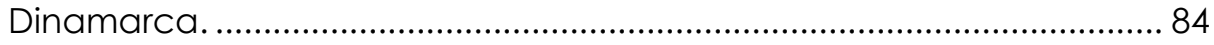

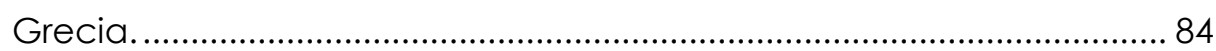

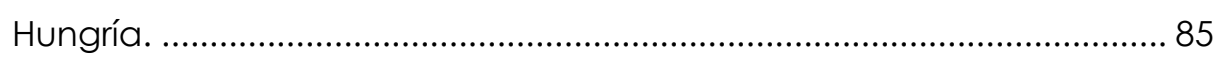

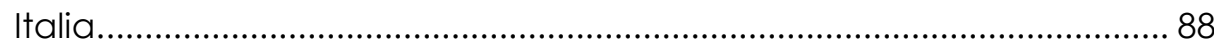

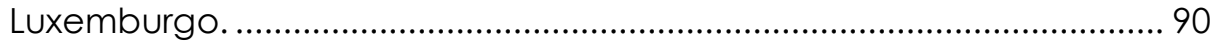

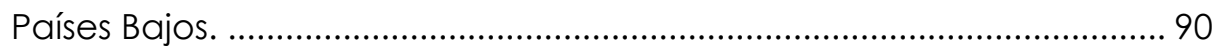

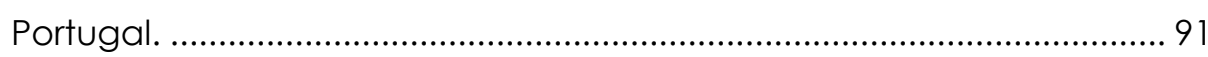

3.4 Estudio comparativo detallado de los cánones aplicados por uso de estaciones de viajeros en España y Francia............................................. 94

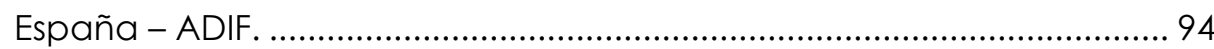

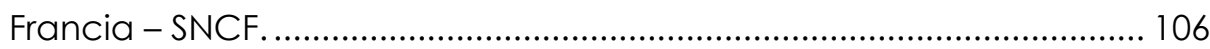

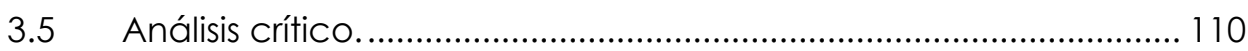

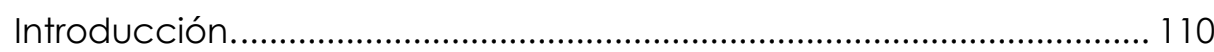

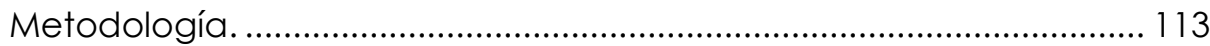


Reflexiones respecto a las Declaraciones sobre la Red.

Reflexiones respecto a los cánones aplicados por uso de la infraestructura.

Reflexiones respecto al canon por utilización de las estaciones de viajeros.

Reflexiones respecto al uso de estaciones de los administradores de la infraestructura español y francés.

4 PROBLEMÁTICA DE LA TARIFICACIÓN POR USO DE LAS ESTACIONES DE VIAJEROS EN LÍNEAS DE ALTA VELOCIDAD: CASO DE ESTUDIO LÍNEA MADRIDLEVANTE 135

4.1 Problemática de la inversiones en líneas de Alta Velocidad. ..... 137

Costes de construcción 137

Costes de amortización. 141

Costes financieros. 142

Costes corrientes. 143

Costes ambientales. 146

Beneficios económico-sociales. 147

Viabilidad económica de las líneas de alta velocidad...... 148

4.2 Uso de las estaciones línea de Alta Velocidad Madrid-Levante e ingresos asociados en concepto de canon.

Introducción 151

Clasificación de las estaciones. 154

Cálculo del canon por utilización de las estaciones de transporte de viajeros.

4.3 Costes asociados al uso de estaciones en la línea de Alta Velocidad Madrid-Levante. Tramo Madrid-Valencia.

4.4 Discusión sobre los niveles de canon por uso de estaciones en la línea Madrid-Valencia.

4.5 Nuevo escenario con la entrada de nuevos operadores ferroviarios en la línea de Alta Velocidad Madrid-Levante (Tramo MadridValencia)

Introducción

Estudio del nuevo escenario. 
Consideraciones ante la situación actual de la línea de alta velocidad Madrid-Levante.

Consideraciones ante la liberación de las líneas de alta velocidad Madrid-Levante

Reflexiones respecto a la explotación en la actual infraestructura.

Valor de la infraestructura.

Reflexiones de los efectos de la tarifa en los costes de la infraestructura durante la explotación. 188

Reflexiones ante la interoperabilidad del material rodante. 190

Reflexiones ante la financiación de servicios comerciales en líneas convencionales. 192

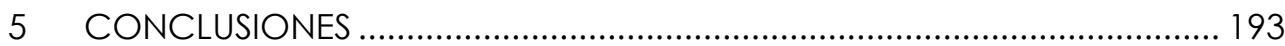

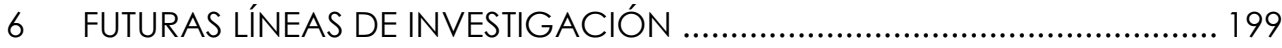

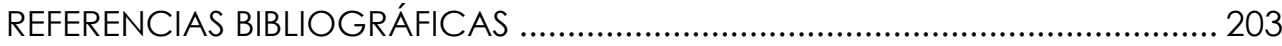

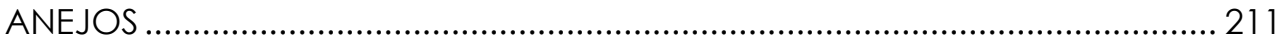

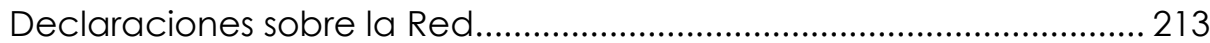




\section{INDICE DE TABLAS}

Tabla 1. Objetivos Directiva 2001/14/CE. Elaboración propia.

Tabla 2. Requisitos Directiva 2001/14/CE. Elaboración propia.

Tabla 3. Resumen de la normativa europea sobre ferrocarril. Elaboración

propia.

Tabla 4. Clasificación por sistema de canon. Elaboración propia a partir de

Charge4Rail2017.

Tabla 5. Categorías de las estaciones alemanas. Fuente: DB Netze AG. .... 79

Tabla 6. Servicios ofertados en estaciones de viajeros por ÖBB-Infrastruktur

AG. Elaboración propia.

Tabla 7. Factor según tipo de parada en estaciones. Fuente: Infrabel. ...... 82

Tabla 8. Coeficiente "tipo de tren" para el canon por uso de estaciones.

Fuente: $H Z ̌$ Infrastruktura.

Tabla 9. Categoría de las estaciones. Fuente: OSE.

Tabla 10. Parámetros e influencia \% para la determinación de los puntos de embarque de viajeros desde el punto de vista del viajero. Fuente: VPE. .... 86

Tabla 11. Valores determinantes de la calidad. Fuente: VPE.

Tabla 12. Tarifa aplicada por tipo de parada y categoría de la estación.

Fuente: ProRail.

Tabla 13. Tarifa aplicada por categoría de estación. Fuente:

Infraestructuras de Portugal.

Tabla 14. Tarifa aplicada por superficies utilizadas en estación. Fuente:

Infraestructuras de Portugal.

Tabla 15. Valores de índice "K" para la clasificación de estaciones. Fuente:

ADIF.

Tabla 16. Canon por uso de estaciones Categoría 6. Fuente: ADIF. ........... 100

Tabla 17. Canon por uso de estaciones de viajeros categorías 1 a 5. Fuente:

ADIF.

Tabla 18. Canon por uso de cambiador de ancho. Fuente: ADIF. 101

Tabla 19. Canon por estacionamiento en estaciones sin operaciones.

Fuente: ADIF.

Tabla 20. Tipo de estacionamiento aplicado al canon por uso de andenes.

Fuente: ADIF.

Tabla 21. Canon por estacionamiento para otras operaciones. Fuente:

ADIF.

Tabla 22. Coeficiente de rendimiento K. Fuente: ADIF.

104

Tabla 23. Canon por componentes por uso de vías de apartado. Fuente:

ADIF.

Tabla 24. Precios de los servicios básicos en estaciones de viajeros. Fuente:

ADIF. 
Tabla 25. Precios por servicios auxiliares. Fuente: ADIF. 105

Tabla 26. Canon básico aplicado por uso de estaciones y andenes por

SNCF. 108

Tabla 27. (a) Cánones analizados por países (a). Fuente: UIC Charge4Rail (Teixeira et al. 2017).

Tabla 28. (b) Cánones analizados por países (a). Fuente: UIC Charge4Rail

(Teixeira et al. 2017).

Tabla 29. Canon para circulaciones O-D en líneas convencionales por km.

Fuente: UIC Charge4Rail (Teixeira et al. 2017)

Tabla 30. Cuantía promedio de los cánones aplicados en circulaciones $O-D$ por líneas convencionales por km-tren. Fuente: UIC Charge4Rail (Teixeira et al. 2017).

Tabla 31. Canon para circulaciones O-D en líneas de alta velocidad por km. Fuente: UIC Charge4Rail (Teixeira et al. 2017.

Tabla 32. Cuantía promedio de los cánones aplicados en circulaciones O-D por líneas de alta velocidad por km-tren. Fuente: UIC Charge4Rail (Teixeira et al. 2017).

Tabla 33. Conceptos aplicados en el canon por uso de estaciones de viajeros. Elaboración propia.

Tabla 34. Categorías de las estaciones de viajeros. Elaboración propia... 128 Tabla 35. Variables empleadas en la categorización de las estaciones.

Elaboración propia.

Tabla 36. Cánones aplicados en el ámbito de estaciones por ADIF y SNCF.

Elaboración propia.

Tabla 37. Tabla ejemplo de los porcentajes aplicados en estaciones de Francia. Elaboración propia a partir de datos de Mobilités Gares \& Connexions.

Tabla 38. Coste de inversión LAV Madrid-Barcelona-Figueres. Fuente: ADIF 2009-2010.

Tabla 39. Costes de inversión LAV Madrid-Levante. Fuente: ADIF 2009-2010.

Tabla 40. Coste de inversión LAV Madrid-Sur España. Fuente: ADIF 2009-

2010.

Tabla 41. Costes de inversión de LAV Madrid-Centro España-Asturias-

Galicia. Fuente: ADIF 2009-2010.

Tabla 42. Costes de construcción estaciones línea. Fuente: Adif 2009-2010.

Tabla 43. Años amortización elementos infraestructura. Fuente: Informe de auditoría de las cuentas anuales ADIF Ejercicio 2017.

Tabla 44. Resumen de costes infraestructura. Fuente: García Álvarez, 2014. 
Tabla 45. Divisiones imputables para el cálculo de costes subyacentes.

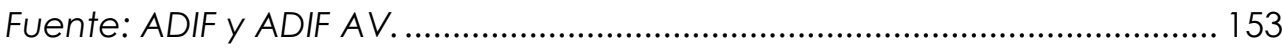

Tabla 46. Valores de índice "K" para la clasificación de estaciones. Fuente:

ADIF. 155

Tabla 47. Categoría de las estaciones ADIF Alta Velocidad tramo Madrid-

Valencia, Línea Madrid-Levante. Fuente: ADIF.

Tabla 48. Tarifa aplicada por estaciones y tipo de parada. Fuente: ADIF. 157

Tabla 49. Conceptos presupuestarios de las estaciones. Fuente: ADIF 2018

Tabla 50. Circulaciones y Viajeros. Elaboración propia. Fuente: ADIF 2018.

Tabla 51. Canon por Circulaciones y Viajeros. Elaboración propia. Fuente:

ADIF 2018.

Tabla 52. Costes directos en estaciones. Elaboración propia. Fuente: ADIF

2018.

Tabla 53. Cuantía mínima por estaciones. Elaboración propia.

Tabla 54. Amortización de las estaciones de la línea. Elaboración propia.

Tabla 55. Cuantía en € del canon mínimo con amortización. Elaboración

propia.

Tabla 56. Cuantía en € del canon actual con amortización. Elaboración

propia.

Tabla 57. Capacidad marco. Fuente Adif AV.

Tabla 58. Variación en la capacidad actual y ofertada. Fuente Adif AV. 174 Tabla 59. Configuración de la capacidad marco propuesta. Fuente Adif

AV.

Tabla 60. Estimación de demanda de viajeros. Fuente: Adif.

Tabla 61. Frecuencia de circulaciones por sentido ante el nuevo escenario.

Elaboración propia.

Tabla 62. Fragmento de Hoja de Ruta Madrid-Puerta de Atocha-Bif.

Torrejón de Velasco. Fuente: ADIF.

Tabla 63. Longitud de andenes de la estación Joaquín Sorolla. Fuente: ADIF.

Tabla 64. Incompatibilidad de las series de Renfe Operadora y las líneas de

AV. Elaboración propia. Fuente: García Álvarez (2019).

191

Tabla 65. Características técnicas líneas ferroviarias gestionadas por ADIF.

Elaboración propia.

Tabla 66 . Canon por tipo de línea DB Netze AG. Elaboración propia ...... 214

Tabla 67. Factores aplicados por tipo de tren DB Netze AG. Elaboración

propia

Tabla 68. Factor aplicable por incumplimiento de la velocidad mínima DB

Netze AG. 
Tabla 69. Suplemento por carga DB Netze AG.

Tabla 70. Cánones aplicables por ÖBB-Infrastruktur AG............................ 217

Tabla 71. Clasificación de locomotoras eléctricas ÖBB-Infrastruktur AG. .. 218

Tabla 72. Clasificación de locomotoras de vapor ÖBB-Infrastruktur AG. ... 218

Tabla 73. Clasificación de locomotoras diésel ÖBB-Infrastruktur AG. ......... 219

Tabla 74. Clasificación unidades autopropulsadas eléctricas ÖBB-

Infrastruktur AG.

Tabla 75. Clasificación unidades autopropulsadas diésel ÖBB-Infrastruktur

AG.

Tabla 76. Obtención del coeficiente por tipo de circulación (Ptj) Infrabel.

Tabla 77. Obtención del coeficiente Cli Infrabel........................................ 221

Tabla 78. Obtención del coeficiente C2i Infrabel.......................................... 221

Tabla 79. Obtención del coeficiente Cij Infrabel. .......................................... 221

Tabla 80. Obtención del coeficiente Hij Infrabel. .......................................... 221

Tabla 81. Obtención del coeficiente Tij Infrabel. .......................................... 222

Tabla 82. Valores de "T" para trenes de viajeros HZ Infrastruktur. ................. 224

Tabla 83. Valores de "T" para trenes de mercancías HZ Infrastruktur. ........ 224

Tabla 84. Valores del coeficiente "L" HZ Infrastruktur. .................................. 225

Tabla 85. Clasificación de las líneas ferroviarias ADIF. ................................. 227

Tabla 86. Canon de acceso a líneas ferroviarias tipo A ADIF. .................... 227

Tabla 87. Canon de acceso al resto de líneas ferroviarias ADIF.................. 228

Tabla 88. Características de los tipos de servicio y tipos de tren ADIF........ 228

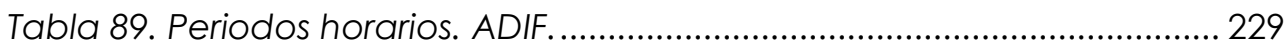

Tabla 90. Canon por reserva de capacidad ADIF. ....................................... 229

Tabla 91. Clasificación de las líneas ferroviarias ADIF. ................................... 230

Tabla 92. Características de los servicios y tipos de tren ADIF. ..................... 230

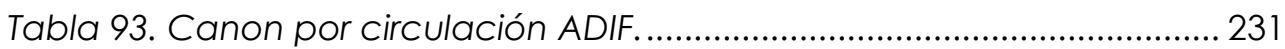

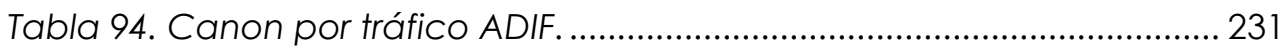

Tabla 95. Canon de acceso a la línea de Alta Velocidad ADIF. ................ 232

Tabla 96. Periodos horarios línea Alta Velocidad ADIF. ................................. 232

Tabla 97. Características de los servicios y tipos de tren ADIF. ..................... 233

Tabla 98. Clasificación de las líneas de Alta Velocidad ADIF. ...................... 233

Tabla 99. Canon por reserva de capacidad líneas de Alta Velocidad ADIF.

234

Tabla 100. Canon por circulación en líneas de Alta Velocidad ADIF......... 234

Tabla 101. Canon por tráfico en líneas de Alta Velocidad ADIF................. 235

Tabla 102. Periodo horario para trenes de mercancías Eurotunnel. ........... 237

Tabla 103. Cánones aplicados a trenes de mercancías Categoría 1

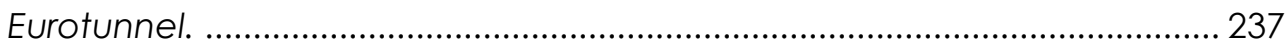

Tabla 104. Cánones aplicados a trenes de mercancías Categoría 2

Eurotunnel. 
Tabla 105. Cánones aplicados a trenes de mercancías Categoría 3

Eurotunnel.

Tabla 106. Cánones aplicados a trenes de mercancías Categoría 4 238

Eurotunnel.

Tabla 107. Cánones aplicados a trenes de mercancías Categoría 5

Eurotunnel. 238

Tabla 108. Periodo horario para trenes de viajeros Eurotunnel. 238 Tabla 109. Cánones aplicados a trenes de viajeros Categoría 1 Eurotunnel.

Tabla 110. Cánones aplicados a trenes de viajeros Categoría 2 Eurotunnel. 239

Tabla 111. Cánones aplicados a trenes de viajeros Categoría 3 Eurotunnel. 239

Tabla 112. Cánones aplicados a trenes de viajeros Categoría 4 Eurotunnel.

Tabla 113. Cánones aplicados por VR Group............................................... 240

Tabla 114. Clasificación de las líneas ferroviarias SNCF. .............................. 241

Tabla 1 15. Coeficientes horarios SNCF. ....................................................... 241

Tabla 116. Coeficientes para el cálculo del canon por reserva en trenes de

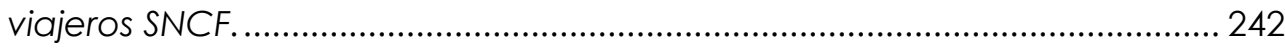

Tabla 117. Coeficientes para el cálculo del canon por circulación trenes de viajeros SNCF.... 243

Tabla 1 18. Canon por suministro de energía eléctrica para tracción trenes de viajeros SNCF. 243

Tabla 119. Canon de Acceso SNCF.... 243

Tabla 120. Coeficientes para el cálculo del canon por reserva en trenes de mercancías SNCF. 244

Tabla 121. Coeficiente C5 a aplicar a trenes de mercancías por líneas convencionales SNCF. 244 Tabla 122. Coeficientes para el cálculo del canon por circulación trenes de mercancías SNCF. 244

Tabla 123. Canon por suministro de energía eléctrica tracción trenes de mercancías SNCF.

Tabla 124. Coeficiente kq según línea/tramo OSE.

245

Tabla 125. Coeficiente $L_{2}$ según periodo horario.

246

Tabla 126. Periodos horarios en estaciones OSE.

247

Tabla 127. Periodos horarios en estaciones de ancho métrico OSE. .......... 247

Tabla 128. Tiempo ideal por tramos OSE......................................................... 248

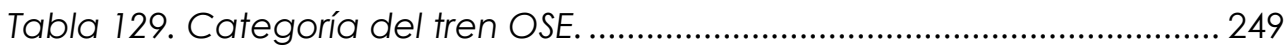

Tabla 130. Categoría del tren ancho métrico OSE....................................... 250

Tabla 131. Canon por reserva de capacidad MÁV Zrt- GYSEV Zrt.............. 251

Tabla 132. Canon por categoría de la línea y tipo de tren MÁV Zrt. .......... 251 
Tabla 133. Canon por tonelada kilómetro y tipo de tren MÁV Zrt.

Tabla 134. Canon por categoría de la línea y tipo de tren GYSEV Zrt........ 251

Tabla 135. Canon por tonelada kilómetro y tipo de tren GYSEV Zrt............ 252

Tabla 136. Cánones de acceso y de uso RFI.................................................. 252

Tabla 137. Cálculo de coeficientes "M" para obtener el canon por uso RFI.

Tabla 138. Estaciones de nudo para el cálculo de " $\Psi$ " RFI.......................... 253

Tabla 139. Coeficiente horario " $\varphi$ " RFI. ........................................................ 254

Tabla 140. Cánones que forman el paquete mínimo de acceso Lietuvos

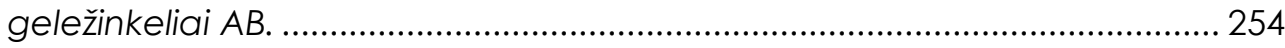

Tabla 141.Canon por tratamiento administrativo de la reserva de

capacidad ACF.

Tabla 142. Factor pi para trenes de mercancías para el cálculo del coste

de operación ACF.

Tabla 143. Factor pi para locomotoras aisladas para el cálculo del coste de operación ACF.

Tabla 144. Factor pi para trenes de viajeros remolcados para el cálculo del

coste de operación ACF.

Tabla 145. Factor pi para trenes de viajeros autopropulsados para el

cálculo del coste de operación ACF.

Tabla 146.Factor ßj para el cálculo del coste de operación ACF. ............. 257

Tabla 147. Coeficiente de rigidez $Y_{j} A C F$.

Tabla 148. Corredores europeos que discurren por los Países Bajos ProRail

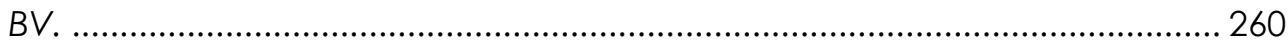

Tabla 149. Canon por circulación para trenes de mercancías ProRail. .... 260

Tabla 150. Canon por circulación para otros trenes ProRail........................ 261

Tabla 151. Canon por circulación para trenes que circulan por la línea

Betuwe ProRail.

Tabla 152. Parámetros definitorios de la categoría de la línea para trenes

de viajeros PKP.

262

Tabla 153. Parámetros definitorios de la categoría de la línea para trenes

de mercancías PKP.

Tabla 154. Canon de acceso para trenes de viajeros condicionado a WASH UP Network Rail.

Tabla 155. Canon de acceso para trenes de mercancías Network Rail. .. 265 Tabla 156. Canon fijo para trenes de viajeros por tipo de vehículo Network

Rail. 266

Tabla 157. Canon fijo para trenes de mercancías por tipo de vehículo Network Rail.

Tabla 158. Canon para trenes no programados Network Rail..................... 266

Tabla 159. Canon por transporte de carbón Network Rail........................... 267

Tabla 160. Canon para aplicar al transporte de carbón Network Rail....... 267 
Tabla 161. Canon por transporte de residuos de centrales nucleares

Network Rail.

Tabla 162. Canon IRC para trenes de viajeros HS 1....................................... 268

Tabla 163. Canon OMRC para trenes de viajeros HS 1................................... 269

Tabla 164. Valores de K1, K2 y K3 para el canon de adjudicación de capacidad SžDC.

Tabla 165. Clasificación de las líneas CFR. ..................................................... 272

Tabla 166. Elementos del canon de acceso CFR. ...................................... 272

Tabla 167. Canon U li por asignación de capacidad ZSR............................ 275

Tabla 168. Canon U2i por ordenación y gestión tráfico ZSR.......................... 275

Tabla 169. Canon U3i por uso de la infraestructura ZSR. ............................... 275

Tabla 170. Valores de Cvp para el cálculo del canon de circulación SZI. 277

Tabla 171. Valores de Pi para el cálculo del canon de circulación SZI...... 278

Tabla 172. Valores de FVV para el cálculo del canon de circulación SZI. . 279

Tabla 173. Canon por acceso de la red ferroviaria Trafikverket.................. 280

Tabla 174. Canon por reserva de capacidad Trafikverket............................ 280

Tabla 175. Canon por emisiones del material rodante Trafikverket. ........... 280

Tabla 176. Canon por reserva de capacidad estándar y especial TP Ferro.

Tabla 177. Canon por reserva de capacidad urgente TP Ferro. ................. 284

Tabla 178. Canon por reserva de capacidad trenes de mercancías

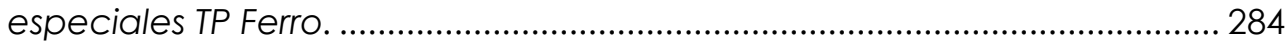

Tabla 179. Canon por circulación de trenes de viajeros TP Ferro................. 284

Tabla 180. Canon por circulación de trenes de mercancías TP Ferro. ....... 285

Tabla 181. Canon por circulación locomotoras aisladas y trenes de mercancías TP Ferro. 


\section{ÍNDICE DE GRÁFICOS}

Gráfico 1. Cánones aplicados según Directiva 200 1/14/EC. Elaboración

propia.

Gráfico 2. Relación entre el canon y la velocidad comercial. Fuente:

Sánchez Borrás, 2009.

Gráfico 3. Relación entre el canon y la velocidad comercial. Fuente:

Charge4Rail.UIC.

Gráfico 4. Porcentaje del canon por uso de estaciones. Fuente: UIC Study

on Railway Station and Auxiliary Charges in Europe Final Report 2017.

Gráfico 5. Porcentaje del canon por uso de estaciones en trenes larga distancia. Fuente: UIC Study on Railway Station and Auxiliary Charges in Europe Final Report 2017.

Gráfico 6. Clasificación por sistema de canon. Fuente: Charge4Rail2017.. 66 Gráfico 7. Estructura del canon ÖBB-Infrastruktur AG por uso de estaciones de viajeros. Elaboración propia.

Gráfico 8. Distribución de áreas en una estación según SNCF. 107 Gráfico 9. Rango de precios de parada por categoría de estaciones. Fuente: Declaraciones sobre la Red 2020. Elaboración propia.

Gráfico 10. Detalle del rango de precios de parada por categoría de estaciones. Fuente: Declaraciones sobre la Red 2020. Elaboración propia.

Gráfico 11. Canon por km líneas convencionales. Fuente: UIC Charge4Rail

(Teixeira et al. 2017).

Gráfico 12. Canon total por km en líneas de alta velocidad. Fuente: UIC Charge4Rail (Teixeira et al. 2017).

Gráfico 13. Cánones aplicados por país. Elaboración propia.

Gráfico 14. Matriz de variables aplicadas en el cálculo de los cánones por países. Elaboración propia.

Gráfico 15. Canon por uso de estaciones en Francia. Elaboración propia.

Gráfico 16. Canon por uso de estaciones en España. Elaboración propia.

Gráfico 17. Resultado financiero línea AV en España año 2014. Fuente:

García Álvarez

Gráfico 18. Canon por utilización de instalaciones de servicio. Elaboración

propia.

Gráfico 19. Fases del modelo de costes empleado por Adif y Adif Alta

Velocidad según art.97 de la Ley del Sector Ferroviario. Elaboración propia. 
Gráfico 20. Fases del modelo de costes empleado por Adif y Adif Alta Velocidad según art.98 de la Ley del Sector Ferroviario. Elaboración propia.

Gráfico 21. Viajeros por estaciones. Elaboración propia a partir de datos de ADIF.

Gráfico 22. Circulaciones por estaciones. Elaboración propia a partir de datos de ADIF.

Gráfico 23. Canon anual por uso de estaciones de viajeros. Elaboración

propia a partir de datos de ADIF 2018. .

Gráfico 24. Costes de las estaciones. Elaboración propia a partir de datos

de ADIF 2018.

Gráfico 25. Costes directos en miles de € por estaciones. Elaboración

propia. Fuente: ADIF.

Gráfico 26. Comparativa canon estaciones. Elaboración propia............... 167

Gráfico 27. Canon mínimo aplicable por viajero. Elaboración propia. ..... 169

Gráfico 28. Canon mínimo aplicable por circulación. Elaboración propia.

Gráfico 29. Reducción del canon realizado por RFI. Fuente: Texeira 2019.172

Gráfico 30. Ingresos de RFI por cánones. Fuente: Texeira 2019. 173

Gráfico 31. Estimación de la demanda de viajeros a partir de 2011 . Fuente:

ADIF

Gráfico 32. Previsión de circulaciones y frecuencias a partir de 2019.

Elaboración propia. 176

Gráfico 33. Troncalidad de la red de alta velocidad. Fuente: García Álvarez (2011). 182

Gráfico 34. Interferencia en las circulaciones en Madrid-Puerta de Atocha.

Fuente: ADIF. 186

Gráfico 35. Disposición de vías de estacionamiento en la estación de Joaquín Sorolla. Fuente: ADIF. 187 Gráfico 36. Importancia relativa de las variables críticas en el VAN. Fuente: Álvarez García, González Franco, Rubio García (2015), Jaro (2011).......... 188 Gráfico 37. Cambios en los costes operativos y totales de la infraestructura al cambiar las tarifas. Fuente: Álvarez García, González Franco, Rubio García (2015). 189

Gráfico 38. Cambios en el margen financiero y en el margen económico social. Fuente: Álvarez García, González Franco, Rubio García (2015). .... 190 Gráfico 39. Contribución del AVE a la financiación de servicios comerciales de Renfe. Fuente: García, 2019. 
ESTRUCTURA

Y CONTENIDO 
La presente Tesis está compuesta por 6 capítulos:

- El capítulo 1, formado por la contextualización, objetivos, hipótesis planteadas y la estructura del documento.

El capítulo 2, estado del arte, hace referencia a la legislación y los principios de tarificación empleados en Europa.

- El capítulo 3 muestra como está contextualizado el canon por uso de estaciones en el canon por uso de la infraestructura.

- El capítulo 4 analiza la problemática de la tarificación por uso de las estaciones de viajeros en las líneas de alta velocidad, concretamente en el caso de la línea Madrid-Valencia en la actualidad y ante la liberalización de esta línea al transporte de viajeros a los nuevos operadores ferroviarios a partir de diciembre de 2020.

- El capítulo 5 muestra las conclusiones obtenidas.

- El capítulo 6 expone las futuras líneas de investigación. 
1 INTRODUCCIÓN 


\subsection{Contextualización.}

La Unión Europea, dentro de su política de convertir al ferrocarril en un modo de transporte competitivo decidió acometer una serie de reformas en materia ferroviaria para facilitar la apertura de los mercados ferroviarios nacionales de transporte al transporte internacional, en régimen de libre competencia, facilitando la interoperabilidad del transporte ferroviario entre países europeos y garantizando un trato justo, transparente y no discriminatorio.

Entre las reformas en materia ferroviaria y que se describen en el apartado 2.1 de esta Tesis, se realizó la separación de actividades de administración de la infraestructura de las actividades propias de la explotación, así como la apertura del transporte ferroviario en régimen de libre competencia, lo que desembocó en la aparición de una nueva conexión en el sistema de producción entre la infraestructura y operación.

El administrador de la infraestructura proporciona acceso a las instalaciones de la red ferroviaria a las empresas ferroviarias contra el pago en concepto de acceso y de uso de la infraestructura, así como de aquellos servicios complementarios que sean inherentes al transporte ferroviario. Los operadores ferroviarios para poder operar por la red ferroviaria europea deben cumplir una serie de requisitos legales, técnicos y económicos. Entre los requisitos económicos figuran una serie de cánones a abonar a los administradores de la infraestructura ferroviaria de los países por donde circula la composición ferroviaria.

El presente estudio pretende abordar la problemática de la tarificación de la infraestructura ferroviaria a la luz de la legislación comunitaria y sus objetivos, discutiendo en particular el canon por uso de estaciones de viajeros. 


\subsection{Objetivos.}

El objetivo principal de este trabajo académico es el estudio de las cánones empleados por los administradores de la infraestructura ferroviaria para estimar el canon por uso de estaciones de viajeros en el contexto de la tarificación por uso de la infraestructura en Europa.

Como objetivos secundarios y necesarios para el desarrollo de esta Tesis se realiza un análisis de cómo son aplicados estos cánones por los distintos administradores ferroviarios, cuáles son los componentes y variables utilizadas tanto por uso de la infraestructura como por uso de las estaciones de viajeros, discusión sobre los componentes y variables utilizadas en el canon por uso de estaciones, comparando variables empleadas y reflexión sobre los incentivos a corto medio y largo plazo estudiando el caso francés y español.

Para profundizar en el estudio se ha empleado el caso de la línea de Alta Velocidad Madrid-Levante (tramo Madrid-Valencia) para discutir la importancia e impacto del canon por uso de las estaciones. Para ello se tienen en cuenta el canon actual aplicado y los costes directos imputables a la explotación ferroviaria así como el efecto del canon actual aplicado el en el marco de la competitividad del ferrocarril, sobre todo a partir de la entrada de los nuevos operadores ferroviarios en España.

\subsection{Hipótesis.}

Se plantea la hipótesis que tras el estudio de cada administración ferroviaria es posible simplificar mediante eliminación, agrupación o nueva formulación el cálculo de los cánones, haciendo más sencilla la circulación de cualquier composición ferroviaria por la red europea.

En el caso de estudio de la línea de Alta Velocidad Madrid-Valencia se analiza, partiendo de los cánones aplicados y de los resultados económicos de cada estación, una reducción del canon tras aplicar solamente los costes directamente imputables a la explotación, tal como emana la legislación Europa y así obtener un canon mínimo que pueda cubrir dichos costes. 


\subsection{Estructura.}

Con el fin de cumplir los objetivos previstos, este trabajo de investigación se ha desarrollado en 3 fases. Estas fases han sido desarrolladas de forma consecutiva.

En la primera fase se realiza un análisis de las directivas y reglamentos de la legislación europea y su transposición a cada país.

La segunda fase está basada en la obtención de matrices de las variables aplicadas en los cánones por uso de la infraestructura y el canon por uso de estaciones de viajeros tras el estudio de las Declaraciones sobre la Red realizando un estudio comparativo de los cánones aplicados por España y Francia por uso de estaciones de viajeros.

En la tercera fase se realiza el cálculo que analiza la problemática de la tarificación por uso de las estaciones de Alta Velocidad en la línea MadridLevante, tramo Madrid-Valencia, realizando una exposición de los costes soportados así como el cálculo por uso de la infraestructura. Esta fase termina con el uso de las estaciones en esta línea de Alta Velocidad así como el planteamiento ante la nueva situación frente al escenario de la entrada de los nuevos operadores ferroviarios.

Estas fases permiten obtener las conclusiones así como formular nuevas líneas de investigación. 
2 ESTADO DEL ARTE 


\subsection{Legislación europea.}

La Unión Europea dentro de su política de transportes incluye una legislación con el objetivo del establecimiento y promoción de políticas en el sector ferroviario, implementada posteriormente en la legislación nacional de cada Estado miembro, para conseguir un transporte eficiente y competitivo con otros modos de transporte abriendo los mercados ferroviarios a la competencia de forma transparente y no discriminatoria.

- La Directiva 91/440/CEE, adoptada en 1991, especifica el objetivo de facilitar la adaptación de los ferrocarriles comunitarios a las necesidades del mercado único y aumentar su eficacia mediante:

- La garantía de la autonomía de gestión de las empresas ferroviarias;

- La separación de la gestión de la infraestructura ferroviaria y de la explotación de los servicios de transporte de las empresas ferroviarias, siendo obligatoria la separación contable, y voluntaria la separación orgánica o institucional;

- El saneamiento de la estructura financiera de las empresas ferroviarias;

- La garantía de acceso a las redes ferroviarias de los Estados miembros, para las agrupaciones internacionales de empresas ferroviarias, así como para las empresas ferroviarias que efectúen transportes internacionales de mercancías.

- La Directiva 95/19/CEE, cuyo objeto es definir los principios y procedimientos que deben seguirse para la adjudicación de las capacidades de la infraestructura ferroviaria y la percepción de los correspondientes cánones de utilización relativos a las empresas ferroviarias establecidas o que se establecerán en la Unión y a las agrupaciones internacionales que constituyan, cuando dichas empresas y agrupaciones efectúen los servicios a que se refiere el artículo $10^{1}$ de la Directiva 91/440/CEE.

\footnotetext{
${ }^{1}$ Artículo 10.- Se reconocerá a las agrupaciones internacionales el derecho de acceso y de tránsito en los Estados miembros en que estén establecidas las empresas ferroviarias que las constituyan, así como el derecho de tránsito en los demás Estados miembros para prestaciones de servicios de transporte internacionales en las conexiones entre los Estados miembros en que estén establecidas las empresas que constituyan dichas agrupaciones. A las empresas ferroviarias comprendidas en el ámbito de aplicación del artículo 2 se les concederá el derecho de acceso, en condiciones equitativas, a la infraestructura de los demás Estados miembros a efectos de la explotación de servicios de transportes combinados internacionales de mercancías. Las agrupaciones internacionales y las empresas ferroviarias que efectúen transportes combinados internacionales de mercancías celebrarán los acuerdos
} 
Al objeto de hacer posible la revitalización del ferrocarril y avanzar en el proceso de liberalización ferroviaria, la Comisión Europea aprobó un conjunto de disposiciones agrupadas en "Primer Paquete Ferroviario", e integrado por tres Directivas, 2001/12/CE, 2001/13/CE y 2001/14/CE, posteriormente se agregó la Directiva 2001/16/CE relacionada con la interoperabilidad del sistema ferroviario transeuropeo.

El Primer Paquete Ferroviario (Directivas 2001/12/CEE, 2001/13/CEE Y 2001/14/CEE), estableció los principios que sirven de base para definir el sistema tarifario mediante la aplicación de cánones por uso de la infraestructura ferroviaria:

- La Directiva 2001/12/CEE, que modifica a la Directiva 91/440/CEE, se implantó con fines de reformar estructuralmente las empresas ferroviarias existentes mediante las siguientes directrices:

- Fijar al administrador de infraestructura como un organismo encargado de la instalación y el mantenimiento de la infraestructura, tareas que podrán incluir la gestión de los sistemas de control y de seguridad. Este organismo deberá de gozar de independencia de gestión.

- Separar orgánica e institucional entre la gestión de la infraestructura y la explotación, siendo obligatoria la separación de las funciones básicas (asignación de surcos, decisiones sobre percepción de cánones, concesión de licencias y certificados de seguridad, establecimiento de normas y reglas de seguridad), que no podrán ser realizadas por un prestador de servicios ferroviarios.

- Apertura del mercado de los servicios internacionales de mercancías.

- La Directiva 2001/13/CE, que amplía lo dispuesto en la Directiva 95/18/CEE, sobre concesión de licencias a las empresas garantizando un trato justo, transparente y no discriminatorio.

- La Directiva 2001/14/CE, que derogó la Directiva 95/19 CEE, se refiere a la adjudicación de la capacidad de la infraestructura, la aplicación de cánones por su utilización y la certificación de la seguridad y en ella se realiza:

administrativos, técnicos y financieros necesarios con los administradores de la infraestructura ferroviaria utilizada, con el fin de resolver las cuestiones de regulación y de seguridad del tráfico relativas a los servicios de transporte internacional a que se refieren los apartados 1 y 2 . Las normas por las que se rijan dichos acuerdos deberán ser no discriminatorias. 
- La definición de los derechos de las empresas ferroviarias y del administrador de infraestructuras en cuanto a la adjudicación de capacidades.

- Establecimiento del procedimiento para solucionar los conflictos en las solicitudes de capacidades y los problemas vinculados a la escasez de capacidad.

- La función de adjudicación de la capacidad será ejercida por un organismo independiente, que podrá ser el administrador de infraestructuras cuando sea independiente de toda empresa operadora ferroviaria.

- Por lo que se refiere a la percepción de cánones por utilización de la infraestructura, la tarificación se calculará sobre los costes marginales (los costes directamente vinculados a la explotación de los ferrocarriles). Estos cánones serán fijados y percibidos por un organismo independiente, generalmente el administrador de infraestructuras cuando éste no dependa de las empresas ferroviarias

- El administrador de infraestructuras publicará un documento de declaración sobre la red que contendrá las características de la infraestructura puesta a disposición de las empresas ferroviarias, las condiciones de acceso a dicha infraestructura, los principios de tarifación, los criterios y normas de adjudicación de capacidad, así como los procedimientos y plazos que han de respetarse.

- Bajo esta Directiva el sistema de cánones y adjudicación de capacidad quedan agrupados bajo la siguiente estructura:

- Canon por uso de la infraestructura.

- Canon por acceso a las instalaciones de servicios.

- Canon por prestación de servicios de las instalaciones.

- Canon por acceso a servicios auxiliares.

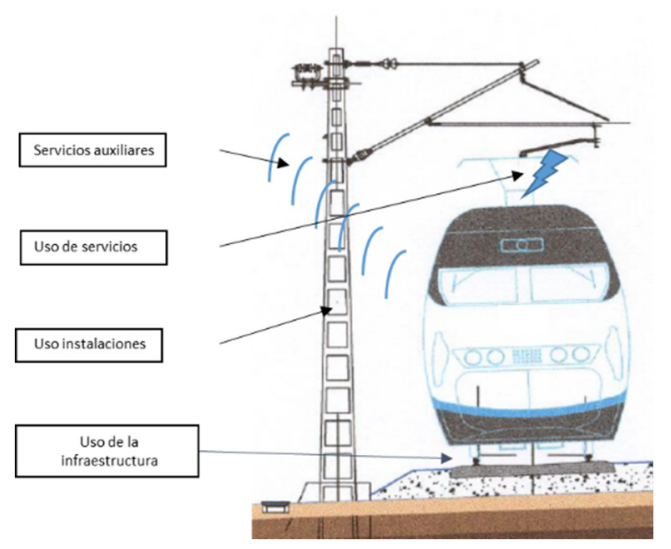

Gráfico 1. Cánones aplicados según Directiva 2001/14/EC. Elaboración propia. 
Las tablas siguientes muestran los objetivos y obligaciones definidas en la Directiva 2001/14/CE:

\begin{tabular}{|c|c|c|}
\hline \multicolumn{2}{|r|}{ Artículo } & Objetivo \\
\hline 5 & $\begin{array}{l}\text { "Para garantizar la transparencia y el acceso no } \\
\text { discriminatorio a la infraestructura de todas las empresas } \\
\text { ferroviarias Toda la información necesaria para utilizar los } \\
\text { derechos de acceso se publicará en una Declaración de la } \\
\text { Red". }\end{array}$ & Transparencia \\
\hline 10 & $\begin{array}{l}\text { "La revitalización de los ferrocarriles europeos (...) exige una } \\
\text { competencia intermodal justa entre ferrocarril y carretera, en } \\
\text { particular teniendo debidamente en cuenta los diferentes } \\
\text { efectos externos (...)". }\end{array}$ & Equidad intermodal \\
\hline 11 & $\begin{array}{l}\text { "Los regímenes de tarificación deberían permitir un acceso } \\
\text { igual y no discriminatorio a todas las empresas y procurar, en } \\
\text { la medida de lo posible, satisfacer las necesidades de todos } \\
\text { los usuarios y tipos de tráfico de manera equitativa y no } \\
\text { discriminatoria". }\end{array}$ & $\begin{array}{l}\text { Acceso no } \\
\text { discriminatorio }\end{array}$ \\
\hline 12 & $\begin{array}{l}\text { "En el marco establecido por los Estados miembros, los } \\
\text { sistemas de tarificación y de asignación de capacidad } \\
\text { deben alentar a los gestores de infraestructuras ferroviarias a } \\
\text { optimizar el uso de su infraestructura". }\end{array}$ & $\begin{array}{l}\text { Incentivo a la } \\
\text { eficiencia operativa }\end{array}$ \\
\hline 15 & $\begin{array}{l}\text { "Es conveniente que las empresas ferroviarias y el gestor de } \\
\text { la infraestructura reciban incentivos para reducir al mínimo } \\
\text { las perturbaciones y mejorar el rendimiento de la red". }\end{array}$ & $\begin{array}{l}\text { Incentivo a la } \\
\text { fiabilidad. }\end{array}$ \\
\hline 16 & $\begin{array}{l}\text { "Los sistemas de cánones (...) deben permitir una } \\
\text { competencia leal en la prestación de servicios ferroviarios". }\end{array}$ & $\begin{array}{l}\text { Enfoque orientado a } \\
\text { la competencia. }\end{array}$ \\
\hline 17 & $\begin{array}{l}\text { "Es importante tener en cuenta las necesidades } \\
\text { empresariales tanto de los solicitantes como del } \\
\text { administrador de la infraestructura". } \\
\end{array}$ & $\begin{array}{l}\text { Orientación } \\
\text { empresarial. }\end{array}$ \\
\hline 23 & $\begin{array}{l}\text { "Diferentes usuarios tendrán un impacto diferente en la } \\
\text { capacidad de la infraestructura". }\end{array}$ & $\begin{array}{l}\text { Diferenciación } \\
\text { de acuerdo con } \\
\text { especificidades. }\end{array}$ \\
\hline 25 & $\begin{array}{l}\text { "Los sistemas de tarificación deben tener en cuenta los } \\
\text { efectos de la creciente saturación de la capacidad de } \\
\text { infraestructura y, en última instancia, la escasez de } \\
\text { capacidad". }\end{array}$ & $\begin{array}{l}\text { Consideración de la } \\
\text { saturación y escasez. }\end{array}$ \\
\hline 32 & $\begin{array}{l}\text { "Es importante minimizar las distorsiones de la competencia } \\
\text { que puedan surgir, ya sea entre infraestructuras ferroviarias o } \\
\text { entre modos de transporte, a partir de diferencias } \\
\text { significativas en los principios de tarificación". }\end{array}$ & $\begin{array}{l}\text { Coherencia } \\
\text { (principios de } \\
\text { tarificación). }\end{array}$ \\
\hline 33 & $\begin{array}{l}\text { "Es deseable definir los componentes del servicio de } \\
\text { infraestructura que son esenciales para permitir que un } \\
\text { operador proporcione un servicio y que debe } \\
\text { proporcionarse a cambio de los cargos mínimos de acceso". }\end{array}$ & $\begin{array}{l}\text { Definición de tipos de } \\
\text { cargas. }\end{array}$ \\
\hline 34 & $\begin{array}{l}\text { "La inversión en infraestructuras ferroviarias es deseable y los } \\
\text { sistemas de tarificación de las infraestructuras deben } \\
\text { proporcionar incentivos para que los administradores de } \\
\text { infraestructuras realicen inversiones apropiadas cuando sean } \\
\text { económicamente atractivos". }\end{array}$ & $\begin{array}{l}\text { Incentivo a la } \\
\text { inversión. }\end{array}$ \\
\hline 35 & $\begin{array}{l}\text { "Cualquier esquema de carga enviará señales económicas } \\
\text { a los usuarios. Es importante que esas señales a las empresas } \\
\text { ferroviarias sean coherentes y las lleven a tomar decisiones } \\
\text { racionales". }\end{array}$ & $\begin{array}{l}\text { Consistencia } \\
\text { (inversiones) }\end{array}$ \\
\hline
\end{tabular}




\begin{tabular}{|c|c|c|}
\hline 36 & $\begin{array}{l}\text { "Para permitir el establecimiento de niveles apropiados y } \\
\text { justos de tarifas de infraestructura, los administradores deben } \\
\text { registrar y establecer la valoración de sus activos y desarrollar } \\
\text { una comprensión clara de los factores de costo en el } \\
\text { funcionamiento de la infraestructura". }\end{array}$ & $\begin{array}{l}\text { Relación con los } \\
\text { costes. }\end{array}$ \\
\hline 37 & $\begin{array}{l}\text { "Es conveniente garantizar que se tengan en cuenta los } \\
\text { costes externos al tomar decisiones de transporte". }\end{array}$ & Sostenibilidad. \\
\hline 38 & $\begin{array}{l}\text { "Es importante garantizar que las tarifas del tráfico } \\
\text { internacional sean tales que permitan al ferrocarril satisfacer } \\
\text { las necesidades del mercado; la tarificación de las } \\
\text { infraestructuras debe fijarse al coste que se incurre } \\
\text { directamente como consecuencia de la explotación del } \\
\text { servicio ferroviario" }\end{array}$ & $\begin{array}{l}\text { Relación con los } \\
\text { costes. }\end{array}$ \\
\hline 39 & $\begin{array}{l}\text { "(...) es deseable que cualquier sistema de tarificación de la } \\
\text { infraestructura permita al tráfico utilizar la red ferroviaria que } \\
\text { pueda y al menos, pagar el coste adicional que impone". }\end{array}$ & Equidad intermodal \\
\hline 40 & $\begin{array}{l}\text { "Una infraestructura ferroviaria es un monopolio natural. Por } \\
\text { lo tanto, es necesario proporcionar a los administradores de } \\
\text { infraestructuras incentivos para reducir costes y gestionar } \\
\text { eficientemente su infraestructura". }\end{array}$ & $\begin{array}{l}\text { Incentivo a la } \\
\text { rentabilidad }\end{array}$ \\
\hline $42 \mathrm{~A}$ & $\begin{array}{l}\text { "Los descuentos permitidos a las empresas ferroviarias deben } \\
\text { referirse a los ahorros reales de costes administrativos } \\
\text { experimentados (...)". }\end{array}$ & $\begin{array}{l}\text { Relación con los } \\
\text { costes (descuentos) }\end{array}$ \\
\hline $42 B$ & $\begin{array}{l}\text { "(...) los descuentos también pueden utilizarse para promover } \\
\text { el uso de la infraestructura. }\end{array}$ & $\begin{array}{l}\text { Incentivos para la } \\
\text { eficiencia operativa } \\
\text { (descuentos) }\end{array}$ \\
\hline 43 & $\begin{array}{l}\text { "Es conveniente que las empresas ferroviarias y el gestor de } \\
\text { la infraestructura reciban incentivos para reducir al mínimo } \\
\text { las perturbaciones de la red". }\end{array}$ & $\begin{array}{l}\text { Incentivo a la } \\
\text { eficiencia } \\
\text { operacional }\end{array}$ \\
\hline 44 & $\begin{array}{l}\text { "La asignación de capacidad se asocia con un coste para } \\
\text { el administrador de la infraestructura, cuyo pago debe ser } \\
\text { requerido". }\end{array}$ & $\begin{array}{l}\text { Relación con los } \\
\text { costes }\end{array}$ \\
\hline
\end{tabular}

Tabla 1. Objetivos Directiva 2001/14/CE. Elaboración propia.

\begin{tabular}{|c|l|c|}
\hline \multicolumn{1}{|c|}{ Artículo } & Requisito \\
\hline \multirow{8}{*}{4.4} & $\begin{array}{l}\text { "Salvo cuando se establezcan disposiciones específicas } \\
\text { con arreglo al párrafo 2 del artículo 8, los administradores } \\
\text { de infraestructuras velarán por que el sistema de } \\
\text { tarificación en uso se base en los mismos principios en } \\
\text { toda su red". }\end{array}$ & $\begin{array}{c}\text { Uniformidad de los } \\
\text { principios de } \\
\text { tarificación }\end{array}$ \\
\hline \multirow{8}{*}{8.5} & $\begin{array}{l}\text { "Los gestores de infraestructuras velarán por que la } \\
\text { aplicación del sistema de tarificación de lugar a tasas } \\
\text { equivalentes y no discriminatorias para las diferentes } \\
\text { empresas ferroviarias que prestan servicios de naturaleza } \\
\text { equivalente en el mercado (...)". }\end{array}$ & $\begin{array}{c}\text { Cargos no } \\
\text { discriminatorios para } \\
\text { las diferentes } \\
\text { empresas ferroviarias }\end{array}$ \\
\hline $\begin{array}{l}\text { "Para evitar la discriminación, se garantizará que las } \\
\text { cargas medias y marginales de un determinado } \\
\text { administrador de la infraestructura para usos } \\
\text { equivalentes de su infraestructura sean comparables y } \\
\text { que los servicios comparables en el mismo segmento de } \\
\text { mercado estén sujetos a los mismos gastos. El gestor de } \\
\text { infraestructuras deberá demostrar en la declaración de } \\
\text { la red que el sistema de tarificación cumple estos } \\
\text { requisitos en la medida en que ello pueda hacerse sin } \\
\text { revelar información empresarial confiable". }\end{array}$ & $\begin{array}{c}\text { Gastos equivalentes } \\
\text { por usos equivalentes } \\
\text { de la infraestructura y }\end{array}$ \\
servicios comparables \\
\hline
\end{tabular}




\begin{tabular}{|c|c|c|}
\hline 7.3 & $\begin{array}{l}\text { "(...) las tarifas por el paquete de acceso mínimo y el } \\
\text { acceso de vía a las instalaciones de servicio se } \\
\text { establecerán al coste que se incurre directamente como } \\
\text { resultado de la operación del servicio de trenes". }\end{array}$ & $\begin{array}{l}\text { Enfoque de costes } \\
\text { marginales }\end{array}$ \\
\hline $7.5 \mathrm{~A}$ & $\begin{array}{l}\text { "La tarifa de infraestructura puede modificarse para tener } \\
\text { en cuenta el coste de los efectos ambientales causados } \\
\text { por el funcionamiento del tren. Dicha modificación se } \\
\text { diferenciará en función de la magnitud del efecto } \\
\text { causado (...). }\end{array}$ & $\begin{array}{l}\text { Diferenciación según } \\
\text { magnitud }\end{array}$ \\
\hline $7.5 \mathrm{~B}$ & $\begin{array}{l}\text { "(...) la imposición de costes medioambientales que } \\
\text { suponga un aumento de los ingresos globales del } \\
\text { administrador de infraestructuras se autorizará, si dicha } \\
\text { tarificación se aplica a un nivel comparable a los modos } \\
\text { de transporte competidores". }\end{array}$ & $\begin{array}{l}\text { Aplicación a modos } \\
\text { de transporte } \\
\text { competidores }\end{array}$ \\
\hline $7.6 \mathrm{~B}$ & $\begin{array}{l}\text { "(...) las magnitudes relativas de las tarifas de } \\
\text { infraestructura estarán relacionadas con los costes } \\
\text { atribuibles a los servicios". }\end{array}$ & $\begin{array}{c}\text { Relación entre cargas } \\
\text { y costes atribuibles a } \\
\text { los servicios }\end{array}$ \\
\hline $8.1 \mathrm{~A}$ & $\begin{array}{l}\text { "(...) El sistema de tarificación respetará los incrementos } \\
\text { de productividad alcanzados por las empresas } \\
\text { ferroviarias (...)". }\end{array}$ & $\begin{array}{l}\text { Respeto al aumento } \\
\text { de la productividad } \\
\text { de la empresa } \\
\text { ferroviaria }\end{array}$ \\
\hline $8.1 \mathrm{~B}$ & $\begin{array}{l}\text { "(...) el nivel de las cargas no debe excluir la utilización de } \\
\text { infraestructuras por segmentos de mercado que pueden } \\
\text { pagar al menos el coste directamente incurrido como } \\
\text { consecuencia de la explotación de los servicios } \\
\text { ferroviarios, más una tasa de rendimiento que el } \\
\text { mercado puede soportar". }\end{array}$ & $\begin{array}{l}\text { Sin exclusión de los } \\
\text { segmentos de } \\
\text { mercado capaces de } \\
\text { pagar su coste } \\
\text { marginal }\end{array}$ \\
\hline 8.2 & $\begin{array}{l}\text { "En el caso de proyectos de inversión específicos (...), el } \\
\text { administrador de infraestructuras podrá fijar o seguir } \\
\text { fijando tasas más elevadas sobre la base de los costes a } \\
\text { largo plazo de dichos proyectos si aumentan la eficiencia } \\
\text { y / o la rentabilidad (...)". }\end{array}$ & $\begin{array}{l}\text { Condiciones para } \\
\text { imponer cotizaciones } \\
\text { para proyectos } \\
\text { específicos de } \\
\text { inversión }\end{array}$ \\
\hline $9.2 \mathrm{~A}$ & $\begin{array}{l}\text { "Con excepción del párrafo } 3 \text { del artículo 9, los } \\
\text { descuentos se limitarán al ahorro real del coste } \\
\text { administrativo para el administrador de la infraestructura } \\
\text { (...)". }\end{array}$ & $\begin{array}{l}\text { Limitado al ahorro en } \\
\text { costes administrativos }\end{array}$ \\
\hline $9.2 \mathrm{~B}$ & $\begin{array}{l}\text { "(...) Al determinar el nivel de descuento, no se pueden } \\
\text { tener en cuenta los ahorros de costes ya internalizados en } \\
\text { la tasa percibida". }\end{array}$ & $\begin{array}{c}\text { Ya no se pueden } \\
\text { incorporar los ahorros } \\
\text { de costes } \\
\text { internalizados }\end{array}$ \\
\hline $9.3 \mathrm{~A}$ & $\begin{array}{l}\text { "Los administradores de infraestructuras pueden } \\
\text { introducir sistemas disponibles para todos los usuarios de } \\
\text { la infraestructura (...)". }\end{array}$ & $\begin{array}{l}\text { Disponibilidad para } \\
\text { todos los usuarios }\end{array}$ \\
\hline $9.3 \mathrm{~B}$ & $\begin{array}{l}\text { "Los gestores de infraestructuras pueden introducir } \\
\text { esquemas (...) que concedan descuentos limitados en el } \\
\text { tiempo (...)". }\end{array}$ & $\begin{array}{l}\text { Limitación en el } \\
\text { tiempo }\end{array}$ \\
\hline $9.3 \mathrm{C}$ & $\begin{array}{l}\text { "Los gestores de infraestructuras pueden introducir } \\
\text { sistemas (...) para fomentar el desarrollo de nuevos } \\
\text { servicios ferroviarios o descuentos que fomenten el uso } \\
\text { de líneas considerablemente infrautilizadas". }\end{array}$ & $\begin{array}{l}\text { Fomento de nuevos } \\
\text { servicios ferroviarios }\end{array}$ \\
\hline 9.5 & $\begin{array}{l}\text { "Se aplicarán regímenes de descuento similares para } \\
\text { servicios similares". }\end{array}$ & $\begin{array}{l}\text { Descuentos similares } \\
\text { para servicios similares }\end{array}$ \\
\hline
\end{tabular}




\begin{tabular}{|c|c|c|}
\hline $11.1 \mathrm{~A}$ & $\begin{array}{l}\text { "Los sistemas de tarificación de las infraestructuras se } \\
\text { aplicarán a través de un plan de ejecución (...)". }\end{array}$ & $\begin{array}{l}\text { Implementación de } \\
\text { un esquema de } \\
\text { rendimiento }\end{array}$ \\
\hline $11.1 \mathrm{~B}$ & $\begin{array}{l}\text { "Los sistemas de tarificación de infraestructuras (...) } \\
\text { alentarán a las empresas y al Administrador de } \\
\text { infraestructuras para minimizar las perturbaciones y } \\
\text { mejorar el rendimiento de la red ferroviaria (...)". }\end{array}$ & $\begin{array}{c}\text { Mejora del } \\
\text { rendimiento operativo } \\
\text { de la red }\end{array}$ \\
\hline 11.2 & $\begin{array}{l}\text { "Los principios básicos del sistema de prestaciones se } \\
\text { aplicarán en toda la red". }\end{array}$ & $\begin{array}{l}\text { Uniformidad del } \\
\text { esquema de } \\
\text { rendimiento }\end{array}$ \\
\hline 12 & $\begin{array}{l}\text { "Los administradores de infraestructuras pueden imponer } \\
\text { una tasa adecuada por la capacidad que se solicita, } \\
\text { pero no se utiliza. Este cargo deberá proporcionar } \\
\text { incentivos para el uso eficiente de la capacidad (...)". }\end{array}$ & $\begin{array}{l}\text { Incentivos para el uso } \\
\text { eficiente de la } \\
\text { capacidad }\end{array}$ \\
\hline
\end{tabular}

Tabla 2. Requisitos Directiva 2001/14/CE. Elaboración propia.

La Directiva 2001/16/CE tiene por finalidad establecer las condiciones que deben satisfacerse para permitir la interoperabilidad de los sistemas ferroviarios, las "Especificaciones Técnicas de Interoperabilidad" (ETI). Estas disposiciones se aplican a las líneas de la Red Transeuropea de transporte y al material rodante que circula por estas líneas.

El Segundo Paquete Ferroviario destinado a revitalizar el ferrocarril mediante la construcción rápida de un espacio ferroviario integrado. Las cinco acciones previstas en este primer documento se apoyaban en las orientaciones del Libro Blanco de 2001 sobre la política de transportes, con el objetivo de reforzar la seguridad, la interoperabilidad, la apertura del mercado del transporte ferroviario de mercancías y la creación de una Agencia Ferroviaria Europea encargada de dirigir la labor técnica en material de seguridad e interoperabilidad.

Estas cinco acciones legislativas se detallan a continuación:

- La Directiva 2004/50/CEE define la interoperabilidad como la capacidad de circular indistintamente por cualquier sección de la red ferroviaria. Esta Directiva constituye un escalón más para hacer operativos los distintos sistemas técnicos ferroviarios existentes en la $U E$, eliminando las barreras técnicas y reglamentarias que limitan la explotación a nivel internacional. Para ello, incide en la mejora de las Especificaciones Técnicas de Interoperabilidad (ETI), que será elaboradas por la Agencia Ferroviaria Europea, obliga a los Estados a publicar y actualizar anualmente un registro de infraestructuras y otro de material rodante. 
- La Directiva 2004/51/CEE que modifica la 91/440/CE, al adelantar las fechas de los derechos de acceso a las infraestructuras ferroviarias para las empresas. Se establece que los servicios de transporte ferroviario internacional de mercancías que discurran por la red transeuropea quedarán liberalizados antes del 1 de enero de 2006, y un año después los que se realicen dentro de cada país. Asimismo, propone para 2010 la apertura del mercado de los servicios de transporte internacional de viajeros.

- El Reglamento 881/2004/CEE, crea la Agencia Ferroviaria Europea, responsable de la seguridad y la interoperabilidad ferroviaria a nivel europeo. La Agencia asistirá a la Comisión Europea $u$ a los Estados miembros, desde el punto de vista técnico en los temas referentes a interoperabilidad y seguridad y elaborará la reglamentación técnica común.

- La Directiva 2005/47/CEE aborda aspectos de las condiciones de trabajo de los trabajadores móviles que realicen servicios de interoperabilidad transfronteriza en el sector ferroviario. Esta Directiva avala el acuerdo alcanzado entre la Comunidad de los Ferrocarriles Europeos (CER) y la Federación Europea de Trabajadores del Transporte (EFT). En cuanto a la competencia por los viajeros en el mercado internacional, la normativa sobre las Obligaciones de Servicio Público (Directiva 2007/58/UE), así como aspectos de interoperabilidad (Directiva 2007/59/CEE) queda agrupada en el Tercer Paquete Ferroviario.

- La Directiva 2012/34/UE, texto refundido de los paquetes ferroviarios, proporciona una única directiva por la que se establece un espacio ferroviario único.

El 12 de junio de 2015 fue aprobado el Reglamento 2015/909/UE en el que se establecen las modalidades de cálculo de los costes directos, costes directamente imputables a la explotación del servicio ferroviario, a efectos de fijar los cánones de acceso mínimo y de acceso a infraestructuras que conectan con instalaciones de servicios.

Los costes directos se calcularán como la diferencia entre, por un lado, los costes de prestación de los servicios del paquete de acceso mínimo y del acceso a infraestructuras que conectan con instalaciones de servicio y, por otro, los costes no elegibles. 
El administrador de infraestructuras no incluirá los costes siguientes (costes inelegibles) en el cálculo de los costes directos del conjunto de la red:

- los costes fijos relacionados con la puesta a disposición de un tramo de línea que el administrador de infraestructuras debe sufragar incluso en ausencia de circulación de trenes;

- los costes no relacionados con pagos efectuados por el administrador de infraestructuras; los costes o centros de costes que no estén relacionados directamente con la prestación de los servicios del paquete de acceso mínimo o con el acceso a infraestructuras que conectan con instalaciones de servicio;

- los costes de adquisición, venta, desmantelamiento, descontaminación, nueva puesta en cultivo o alquiler de tierras $u$ otros activos fijos;

- los gastos generales a escala de la red, incluidos los de salarios y pensiones;

- los costes de financiación;

- los costes relacionados con el progreso o la obsolescencia tecnológicos;

- los costes de los activos intangibles;

- los costes de los sensores de vía y de los equipos de comunicación y dispositivos de señalización situados en vía que no sean directamente imputables a la explotación del servicio ferroviario;

- los costes de los equipos de información, comunicación o telecomunicación no situados en vía;

- los costes relacionados con incidencias de fuerza mayor, accidentes y perturbaciones de servicio específicos, sin perjuicio de lo dispuesto en el artículo $35^{2}$ de la Directiva 2012/34/UE;

- los costes de los equipos de alimentación eléctrica para el suministro de corriente de tracción que no sean directamente imputables a la explotación del servicio ferroviario; los costes directos de la explotación de los servicios ferroviarios que no utilizan equipos de alimentación eléctrica no incluirán los costes de utilización de tales equipos;

\footnotetext{
2 Los sistemas de cánones por la utilización de infraestructuras deberán incentivar a las empresas ferroviarias y al administrador de infraestructuras a reducir al mínimo las perturbaciones y a mejorar el funcionamiento de la red ferroviaria a través de un sistema de incentivos. Dicho sistema podrá incluir la imposición de penalizaciones por acciones que perturben el funcionamiento de la red, la concesión de indemnizaciones a las empresas que las sufran y la concesión de primas a los resultados mejores de lo previsto.
} 
- la parte de los costes de mantenimiento y renovación de infraestructuras civiles que no sea directamente imputable a la explotación del servicio ferroviario;

- los costes relacionados con la transmisión de la información mencionada en el anexo $\| 3$, punto 1 , letra f), de la Directiva 2012/34/UE, salvo que sean imputables a la explotación del servicio ferroviario;

- los costes administrativos derivados de los sistemas de cánones diferenciados contemplados en el artículo 31, apartado 5, y en el artículo 32, apartado 4, de la Directiva 2012/34/UE;

- la amortización no determinada por el deterioro efectivo de las infraestructuras debido a la explotación del servicio ferroviario;

El administrador de infraestructuras calcula los costes unitarios directos medios del conjunto de la red dividiendo los costes directos del conjunto de la red por el número total de kilómetros-vehículo, kilómetros-tren o toneladas- kilómetro brutas previsto o explotado con carácter efectivo.

Los administradores de infraestructuras podrán modular los costes directos para tomar en consideración los distintos grados de desgaste de las infraestructuras con arreglo a uno o varios de los parámetros siguientes:

- longitud del tren y/o número de vehículos del tren;

- masa del tren;

- tipo de vehículo, en particular su masa no suspendida;

- velocidad del tren; velocidad del tren;

- potencia de tracción de la unidad motriz;

- peso por eje y/o número de ejes;

- número registrado de planos en las ruedas o uso efectivo de equipos de protección contra deslizamientos;

- rigidez longitudinal de los vehículos y fuerzas horizontales que impactan en la vía;

- potencia eléctrica consumida y medida o comportamiento dinámico de los pantógrafos o patines de contacto como parámetro para fijar los cánones por el desgaste del hilo de contacto o del carril electrificado;

- parámetros de vía, en particular los radios; cualquier otro parámetro relacionado con el coste, cuando el administrador de infraestructuras pueda demostrar al organismo regulador que los valores de tal parámetro, incluida su variación, cuando proceda, se midan y registren de manera objetiva.

\footnotetext{
${ }^{3}$ Cualquier otra información necesaria para introducir o explotar el servicio para el que se ha concedido capacidad.
} 
El administrador podrá calcular los costes unitarios directos mediante una modelización econométrica o de ingeniería de costes rigurosamente documentada, siempre y cuando pueda demostrar al organismo regulador que los costes unitarios directos incluyen solo los costes directos de la explotación del servicio ferroviario.

Un punto de referencia de 2 Euros por tren-km para un tren de 1.000 toneladas quedó establecido en el Reglamento 2015/909/CE, por encima del cual el cálculo del coste directo debe estar debidamente justificado.

Los costes directos deben totalizar menos del $15 \%$ de los costes de mantenimiento y renovación, o deben ser menores que la suma del $10 \%$ de costes de mantenimiento y $20 \%$ de los costes de renovación, pudiendo aumentar estos porcentajes no más del doble de los valores anteriores. 


\begin{tabular}{|l|l|l|}
\hline PAQUETE & NORMATIVA & MEDIDAS PRINCIPALES \\
\hline
\end{tabular}

\begin{tabular}{|c|c|c|}
\hline $\begin{array}{c}\text { Primer } \\
\text { Paquete } \\
\text { Ferroviario }\end{array}$ & $\begin{array}{l}\text { Directiva } 2001 / 13 / C E \\
\text { Directiva } 2001 / 14 / C E \\
\text { Directiva } 2001 / 16 / C E\end{array}$ & $\begin{array}{l}\text { - Independencia de gestión del } \\
\text { administrador de infraestructuras } \\
\text { - Liberalización del transporte } \\
\text { internacional de mercancías } \\
\text { - Ampliación de licencias nacionales a } \\
\text { todo el ámbito comunitario } \\
\text { - Adjudicación de capacidad, cánones y } \\
\text { seguridad. } \\
\text { - Interoperabilidad del transporte } \\
\text { ferroviario }\end{array}$ \\
\hline
\end{tabular}

\begin{tabular}{|c|c|c|}
\hline & Directiva 2004/49/CE & $\begin{array}{l}\text {-Medidas de seguridad, Interoperabilidad } \\
\text { y creación de la Agencia }\end{array}$ \\
$\begin{array}{c}\text { Segundo } \\
\text { Paquete } \\
\text { Ferroviario }\end{array}$ & $\begin{array}{c}\text { Directiva 2004/50/CE } \\
\text { Directiva 2004/51/CE } \\
\text { Reglamento CE } \\
881 / 2004\end{array}$ & -Apertura transporte de mercancías: \\
& \multicolumn{2}{|c|}{ Internacionales:1/1/2006 } \\
\hline
\end{tabular}

\begin{tabular}{|c|c|l|}
\hline & Directiva 2007/58/CE & - Liberalización transporte internacional \\
de viajeros: 1/1/2010 \\
Tercer & Directiva 2007/59/CE & \\
Paquete & Reglamento & - Certificación de maquinistas \\
Ferroviario & $2007 / 1370 / C E$ & \\
& Reglamento & \\
& $2007 / 1371 / C E$ & - Derechos y Obligaciones de los viajeros \\
\hline
\end{tabular}

\begin{tabular}{|c|c|l|}
\hline & $\begin{array}{c}\text { Directiva 2016/797/UE } \\
\text { Directiva 2016/798/UE } \\
\text { Reglamento (UE) }\end{array}$ & $\begin{array}{l}\text {-Liberalización de transporte nacional de } \\
\text { viajeros:14/12/2020 }\end{array}$ \\
Cuarto & $2016 / 796$ & -Licitación obligatoria de servicios OSP: a \\
partir de 2023 \\
Paquete & Directiva & \\
& $2016 / 2370 / U E$ & \\
& $\begin{array}{c}\text { Reglamento (UE) } \\
2016 / 2337\end{array}$ & -Imparcialidad en la gobernanza de las \\
& infraestructuras ferroviarias \\
& Reglamento (UE) & \\
\hline
\end{tabular}

Tabla 3. Resumen de la normativa europea sobre ferrocarril. Elaboración propia. 


\subsection{Cánones por uso de la infraestructura ferroviaria europea. Principios de tarificación.}

Los ingresos que obtiene el administrador de la infraestructura provienen mayoritariamente de los cánones abonados por el operador de transporte por el uso de sus instalaciones (vías, estaciones, instalaciones de electrificación...). Es obvio que condiciona el comportamiento de los operadores y es objeto de múltiples estudios y discusiones sin llegar a una solución y aplicación eficiente.

El canon se trata de una transferencia dentro del sistema, es decir, el operador paga al administrador con el objetivo de cubrir una serie de servicios que realiza. Este canon influye en la cuenta de resultados por lo que el canon es parte en la formación del precio final que pagan los viajeros y parte en la demanda. El canon aparece como elemento común entre la actividad de transporte y la actividad de gestión de la infraestructura, siendo clave en la cuenta de resultados, constituyendo un coste para el operador y un ingreso para el gestor de la infraestructura.

El canon es una herramienta básica para la competitividad del ferrocarril en relación con otros modos de transporte, pues, un elevado canon pagado por el operador obliga a éste repercutir o trasladar este coste a los viajeros, lo que supone una pérdida de competitividad.

Los sistemas de tarificación implementados en cada país han tenido como resultado un conjunto con diferentes estructuras y fórmulas, que, aplicada a cada sistema de cánones, dan lugar a una variedad considerable de niveles de componentes y variables entre los países de la Unión Europea.

Desde la separación vertical en los ferrocarriles europeos, se utilizaron dos tipos de filosofías como base para la determinación de los costes, una por medio de los costes marginales y otra por medio de los costes totales.

El administrador de infraestructuras, además de buscar la eficiencia económica también tiene que alcanzar el equilibrio financiero evitando costes excesivos. La fijación de precios debe garantizar el acceso justo a las empresas $u$ operadores ferroviarios, proporcionando recursos e incentivos para la mejora de la capacidad. 
El sistema de cánones debe cumplir los siguientes requisitos de acuerdo con ECMT4:

- No discriminatorios, se debe tratar de la misma manera todas las solicitudes con ofertas idénticas.

- Transparente, los requisitos de los administradores de infraestructuras deben ser conocidos por todos los candidatos.

- Atractivo, dentro de los límites de capacidad de la infraestructura en cuestión.

- Recuperación de costes, es decir, el canon debe permitir alcanzar los objetivos financieros.

- Reflexivo, basado en datos cuantificables que permitan el cálculo de sus variables.

La regulación de precios está condicionada por el marco legislativo de la Unión Europea, estableciendo las condiciones sobre el equilibrio financiero del negocio y sobre los principios básicos de fijación de precios, que derivan en la determinación de los cánones. De acuerdo con el marco europeo, la mayoría de los países han adoptado normas de fijación directa de precios basadas en costes, pero estos costes están por debajo del nivel del coste total por lo que, mediante la firma de acuerdos marco, los administradores consiguen el equilibro financiero. Existen sistemas de precios para guiar las decisiones de tal manera que se alcance un uso más eficiente de los recursos escasos, por los que en consecuencia el sistema de tarifas de acceso debe servir para mejorar la utilización de la capacidad disponible, garantizando los derechos de uso de los servicios. Pero este objetivo no es el único al que pueden acceder los sistemas de cánones por uso de la infraestructura, también se puede configurar para recuperar un determinado nivel de costes, optimizar la gestión de la red, orientar las decisiones de inversión o fomentar las ganancias de productividad en la operación y el mantenimiento de la infraestructura (ECMT, 1998).

No existe un principio de fijación de precios que pueda cumplir todos los objetivos al mismo tiempo, debido a las características particulares del negocio de los administradores. La cantidad de costes fijos hace que sea incompatible alcanzar la eficiencia óptima y la recuperación de costes al mismo tiempo. Si los costes fijos se recuperan a través de un canon fijo, existe el riesgo de discriminación de los nuevos participantes, y así sucesivamente por lo que la selección de un principio de fijación de precios implica una compensación entre objetivos alternativos de fijación de precios de infraestructura.

${ }^{4}$ European Conference of Ministers of Transport. 
A su vez, esta elección de objetivos que impulsarán la selección de un principio de fijación de precios se deriva de los objetivos políticos y reglamentarios establecidos para el mercado de la infraestructura ferroviaria (Fernández, 2008).

La elección de los principios de fijación de precios debe hacerse teniendo en cuenta otros modos de transporte, evitando la discriminación e impulsando la eficiencia de todo el sistema, además de existir limitaciones derivadas que modifican estos principios. Los precios de acceso establecidos en la práctica raramente o nunca 'igualan' su óptimo teórico. Sin embargo, se espera que las implicaciones producidas por tales "desviaciones" no sean tan costosas, como el esfuerzo e inversión requeridos para establecer los precios de acceso más cerca del 'óptimo' (Houpis, 2004).

Según los criterios empleados para recuperar los costes de la infraestructura existen dos fórmulas para establecer el canon por uso de la infraestructura: la primera fijando el canon primeramente para después compensar la diferencia entre los ingresos obtenidos y el gasto mediante ayudas del Estado y la segunda estableciendo el canon como resultado de la diferencia entre los costes y las ayudas que aporta el correspondiente Estado.

La amplia gama de principios de fijación de precios permitida por dicho marco legal, desde la recuperación de los costes marginales hasta los costes totales, se ha manifestado en la disparidad de filosofías adoptadas por los administradores de infraestructuras.

El ECMT (2005, p.30) los clasificó en tres categorías:

- Mediante el Coste Marginal.

El coste marginal (MC) es el coste impuesto por cada usuario, sea empresa ferroviaria $u$ operador, al administrador de la infraestructura como usuario de ésta, generando un coste al circular un tren por la infraestructura como el desgaste, la congestión del tramo en cuestión, la escasez de capacidad, así como externalidades como son los costes medioambientales, ruido y accidentes.

- Mediante el Coste Marginal con recargos.

El coste marginal con recargos $(\mathrm{MC}+$ ) se basa en los principios del coste marginal, pero al que se le aplican recargos con la finalidad de disminuir las ayudas del Estado. Este sistema es aplicado si existen restricciones presupuestarias. 
Basado en la aplicación del principio de tarificación Ramsey5 (1927), principio complicado de aplicar debido al requerimiento un gran conocimiento de la elasticidad de la demanda de las empresas operadoras, información difícil de conseguir al tratarse de información estratégica de las empresas.

- Mediante Costes Totales con contribución del Estado.

El sistema de costes totales con contribución del Estado (FC-) consiste en determinar el canon directamente como la diferencia entre todos los costes y la contribución del Estado. Para ello hay que conocer los costes marginales para no obtener una tarifa excesivamente baja y poder realizar una recuperación de los costes de forma más eficiente.

De acuerdo con García Álvarez \& Fernández Arévalo (2011) los costes incurridos en el sector ferroviario se pueden resumir en:

- Costes de operación, costes relacionados con el movimiento, incluyendo también los costes de capital del operador.

- Costes de operación de la infraestructura (mantenimiento, gestión del tráfico, etc.).

- Costes de capital de la infraestructura.

- Otros costes (congestión, ambientales, accidentes...).

Decidir sobre el nivel de recuperación de los costes de la infraestructura a través del canon es una tarea compleja y ámbito de numerosas discusiones. Existen diferentes estructuras de canon que permiten recuperar o cubrir parte de los costes por lo tanto la cuantía influye en las decisiones de los operadores. El canon no corresponde a una tarifa fija y única, sino que es un conjunto de tarifas que tratan de obtener los objetivos marcados por el administrador por lo que su definición es compleja y diferente según el país que se trate. Resumiendo existen cánones fijos, variables o mixtos, aunque también se pueden clasificar también se pueden clasificar en cánones al coste marginal, cánones ligados a cubrir total o parcialmente los costes incurridos por el gestor de la infraestructura o los cánones ligados a la capacidad de pago. Un canon fijo es independiente de cuánto se use la infraestructura, el pago que realiza el operador es exclusivo al hecho de poder utilizar la infraestructura, incentiva el uso de la infraestructura, cuanto mayor uso se haga de la misma mayor reducción del coste por unidad producida.

\footnotetext{
5 Principio de tarificación basado en la reducción de los efectos de los impuestos, por lo que éstos debían ser mayores con los bienes con una demanda inelástica y más pequeños que la demanda elástica. Este principio se extendió para minimizar la pérdida de bienestar social cuando hay una pérdida de cobertura del déficit.
} 
Pero constituye una barrera de entrada a nuevos pequeños operadores, ya que tienen menos capacidad de hacer uso de la infraestructura. Los cánones variables están íntimamente relacionados con el desgaste que sufre la infraestructura por uso que los operadores, recuperan la totalidad o parte de los costes del administrador y potencian el uso de la Infraestructura. Debe distinguirse entre el canon variable destinado a recuperar el coste marginal y el canon variable destinado a recuperar una parte o la totalidad de los costes fijos de la infraestructura.

Según Sánchez Borrás (2009) el canon variable para recuperar costes marginales recupera los costes marginales ligados a la circulación de los trenes y al uso que hacen de la infraestructura cubriendo el coste adicional que supone la circulación de un nuevo tren o servicio. Si no existe ninguna distorsión en el mercado, el canon óptimo es el que iguala precio y coste marginal a corto plazo (first best charging). Así mismo estudia 100 relaciones diferentes dentro de la red ferroviaria europea determinando el canon para cada una de ellas y, analiza las características de sistema de precios implementado por los países que operan líneas de alta velocidad. Entre las conclusiones a las que llega, se destaca el análisis que realiza entre la cuantía del canon y la velocidad comercial, estableciendo una relación entre la velocidad media y el canon obtenido del análisis de la red ferroviaria europea de las mencionadas relaciones tomando la siguiente forma:

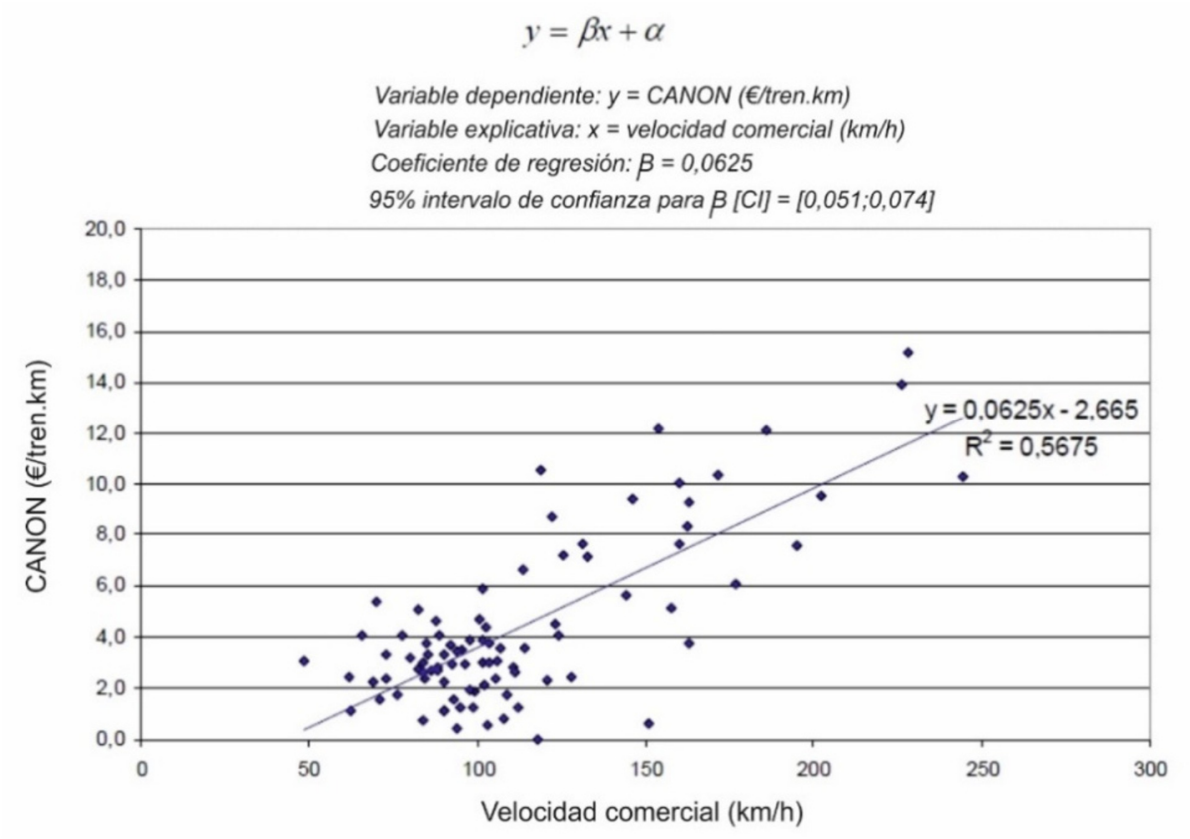

Gráfico 2. Relación entre el canon y la velocidad comercial. Fuente: Sánchez Borrás, 2009. 
Del gráfico anterior, según González Franco, se obtiene dicha relación entre la cuantía del canon y la velocidad comercial:

$$
\text { Canon }=0,0625 * \text { Velocidad Comercial }(\mathrm{km} / \mathrm{h})-2.665
$$

Según García Álvarez \& Fernández Arévalo (2011), el coste marginal se suele situar en torno al 10-20\% de los costes totales, por lo que, solo se cubriría una parte pequeña del coste total. Esto supone que la parte que no cubre el canon tenga que ser financiada a través de impuestos o mediante subvenciones.

Los cánones variables para recuperar los costes fijos tienen como fin cubrir los costes fijos que no puede cubrir el Estado e incorpora una tarifa por encima del coste marginal de forma que cubra como mínimo parte de ellos.

Los cánones basados en la capacidad de pago se aplican en base al principio de valoración de Ramsey. Se asigna un canon en función del coste marginal al que se le añade recargos que se estiman en función de la elasticidad de la demanda. Se basa en cobrar precios más altos a aquellos operadores con demanda más por lo que el administrador obtiene mayores ingresos con el mínimo impacto sobre la demanda.

La fijación del canon a partir del principio de Ramsey permite determinar el canon de forma eficiente pero presenta el gran inconveniente que su implementación requiere de un gran conocimiento del mercado (elasticidad de la demanda).

En estudios realizados recientemente por Teixeira et al (2017) sigue confirmándose un aumento del nivel de canon con la velocidad comercial, aunque cada vez con menor correlación, hecho que se produce en parte por la evolución de la tarificación por uso de infraestructura en líneas de alta velocidad.

En la figura siguiente se representan las circulaciones Origen-Destino en líneas convencionales con unas tarifas aplicadas menores a $10 €$ por trenkilómetro así como circulaciones en líneas de alta velocidad. Como era de esperar los datos muestran que cuanto mayor es la velocidad comercial la tarifa por tren-kilómetro también aumenta. 


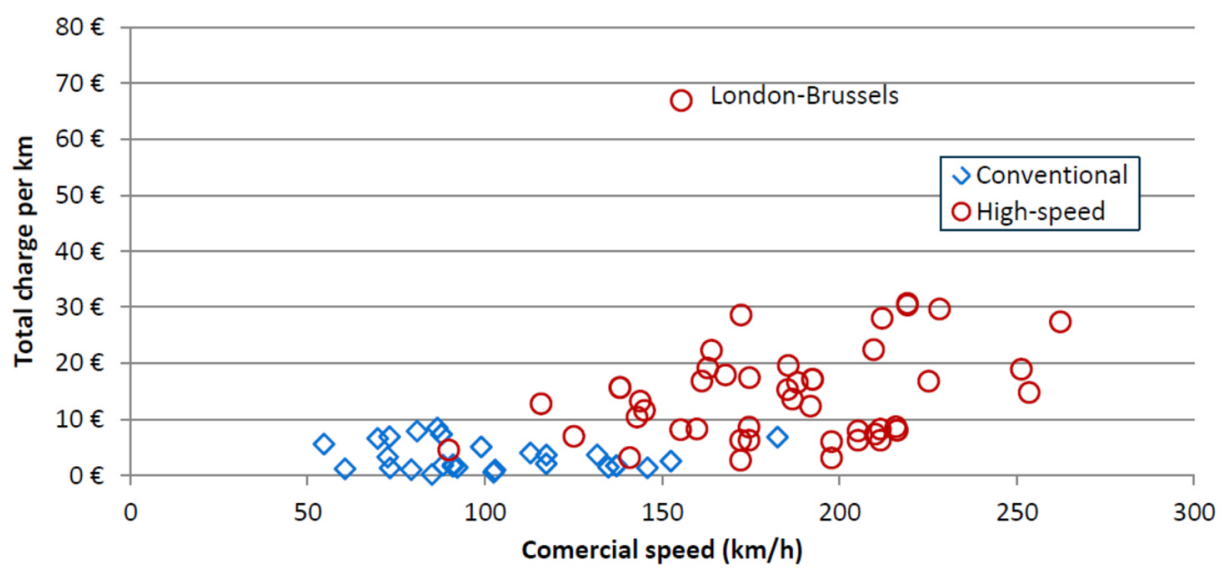

Gráfico 3. Relación entre el canon y la velocidad comercial. Fuente: Charge4Rail.UIC.

\subsection{Canon por uso de estaciones.}

La Directiva 2012/34/UE del Parlamento Europeo y del Consejo, de 21 de noviembre de 2012, por la que se establece un espacio ferroviario europeo único, fija los principios y procedimientos aplicables para la determinación y percepción de cánones por la utilización de infraestructuras ferroviarias y para la adjudicación de capacidad de estas.

Con el objetivo de definir las modalidades de cálculo de los costes directamente imputables a la explotación del servicio ferroviario, a efectos de fijar los cánones de acceso mínimo y de acceso a infraestructuras que conectan con instalaciones de servicio, la Comisión Europea publicó el Reglamento de Ejecución (UE) 2015/909 relativo a las modalidades de cálculo de los costes directamente imputables a la explotación del servicio ferroviario.

Para la cuantificación del canon por utilización de las estaciones de viajeros, modalidad incluida en el canon por utilización de las instalaciones de servicio, no es de aplicación dicho Reglamento para poder determinar los costes recuperables.

A pesar de haber sido tratada en numerosos estudios la problemática referente a los cánones aplicados por uso de la infraestructura son escasos los estudios referentes a los cánones empleados por utilización de instalaciones de servicio, en particular por uso de estaciones. 
Quiero destacar el estudio minucioso realizado por Teixeira et al. (2013) para UIC donde se analiza el peso del uso de estaciones dentro del total del canon, haciendo una diferenciación entre países, tipo de servicio e incluso periodo horario. Entre las conclusiones obtenidas y referente a los cánones por uso de las estaciones, estos representan, en términos relativos, un papel importante en los sistemas tarifarios totales por uso de la infraestructura.

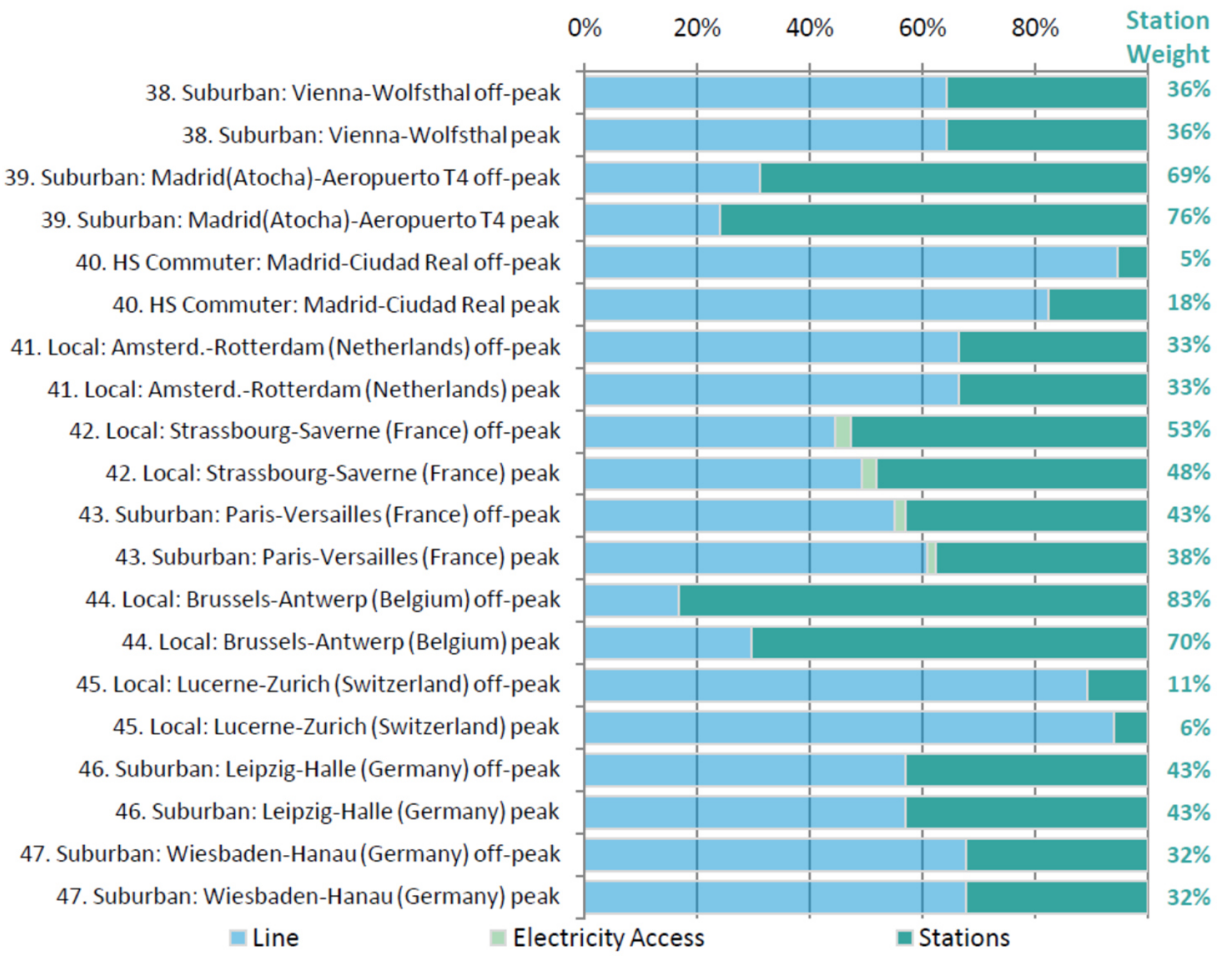

Gráfico 4. Porcentaje del canon por uso de estaciones. Fuente: UIC Study on Railway Station and Auxiliary Charges in Europe Final Report 2017.

En este análisis, el canon por estaciones representa un papel importante para los trenes de cercanías y regionales. Para los trenes regionales, pueden representar más del $83 \%$ del total del canon de la infraestructura, como en el caso de Bélgica a pesar de ser fuera de hora punta, mientras que el porcentaje más bajo de las líneas evaluadas se encuentra en Suiza (6-11\%).

Para las líneas de cercanías, una línea española muestra un $76 \%$ de la carga total durante hora punta, mientras que una línea de alta velocidad desvela un $18 \%$ del canon total durante el mismo periodo horario. 


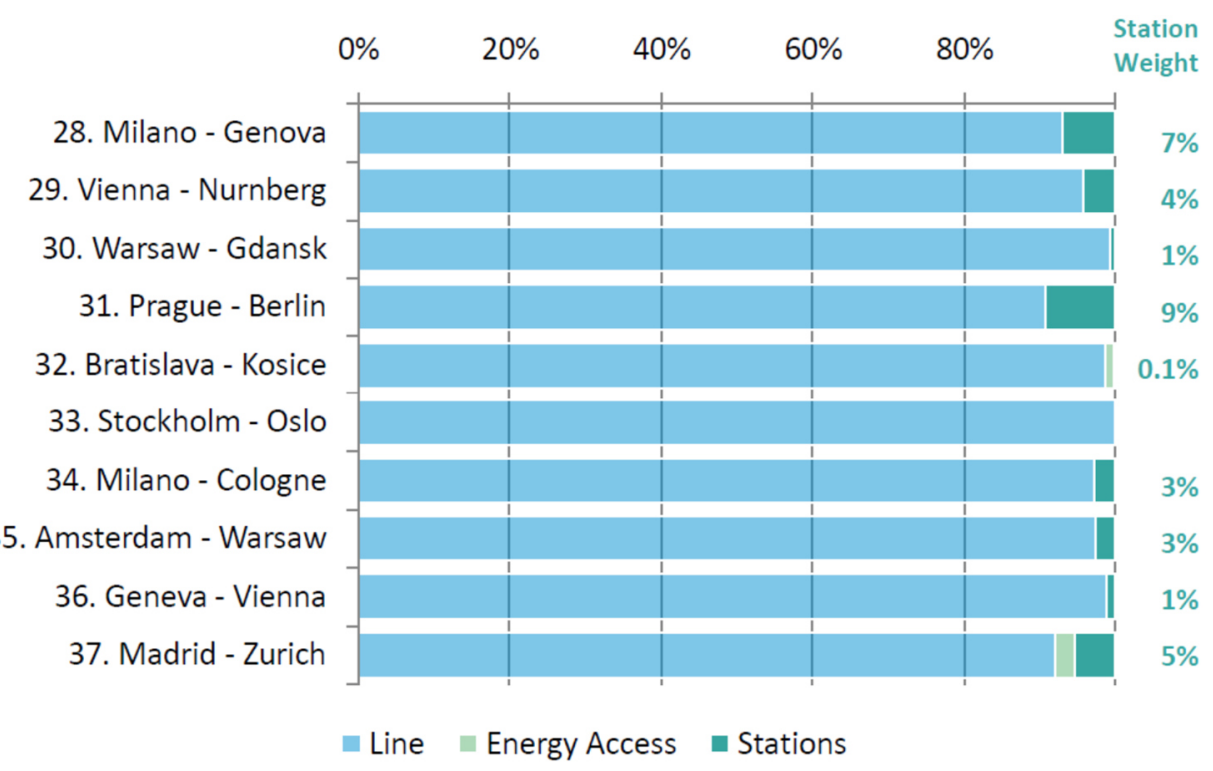

Gráfico 5. Porcentaje del canon por uso de estaciones en trenes larga distancia. Fuente: UIC Study on Railway Station and Auxiliary Charges in Europe Final Report 2017.

Para el caso de trenes tipo de larga distancia el peso del canon por uso de estaciones sobre el total del canon es inferior al 10\%. El número de paradas es relativamente pequeño en comparación con la distancia total de la ruta lo que hace que no sea significativo. 
3 EL CANON POR USO DE ESTACIONES DE VIAJEROS EN EL CONTEXTO DE LA TARIFICACIÓN POR USO DE LA INFRAESTRUCTURA EN EUROPA 


\subsection{Declaración sobre la Red.}

Los datos necesarios para el cálculo de los cánones por uso de la infraestructura ferroviaria y por utilización de estaciones de viajeros son obtenidos de las Declaraciones sobre la Red del año 2017 de los administradores de cada país. Es el documento que expone las características de la infraestructura puesta a disposición de las empresas ferroviarias 6 y candidatos $^{7}$, contiene información sobre las condiciones de acceso a la misma detallándose las normas generales, plazos, procedimientos y criterios relativos a los sistemas de cánones y adjudicación de capacidad 8 así como la información necesaria para cursar una solicitud de capacidad de infraestructura. El marco legal se fundamenta en los Reglamentos y Directivas de la Unión Europea y su trasposición a la legislación nacional. Tienen carácter vinculante entre las empresas ferroviarias o candidatos y los administradores de infraestructura en cuanto a derechos y obligaciones, llevando implícita la aceptación de los derechos y obligaciones contenidos. La estructura es coherente con el índice común fijado por Rail Net Europe' cuyo objetivo es que todos los candidatos y empresas ferroviarias puedan acceder a los documentos similares en los diferentes países, disponiendo de la misma información y ubicación, facilitando el acceso a la infraestructura, especialmente en la programación de tráficos internacionales. La estructura es la siguiente:

Capítulo 1: Información General.

Capítulo 2: Condiciones de Acceso.

Capítulo 3: Descripción de las Infraestructuras Ferroviarias.

Capítulo 4: Adjudicación de Capacidades.

Capítulo 5: Servicios.

Capítulo 6: Régimen Económico y Tributario.

Mapas y anexos.

\footnotetext{
6 Empresas Ferroviarias: Entidades titulares de la licencia de empresa ferroviaria cuya actividad principal consiste en prestar servicios de transporte de viajeros o de mercancías por ferrocarril. Deberán aportar la tracción. Así mismo se consideran empresas ferroviarias aquellas que aporten exclusivamente la tracción.

7 Candidatos: Agrupaciones empresariales internacionales, administraciones públicas con competencias en materia de transporte ferroviario, consignatarios, cargadores, empresas transportistas y operadores de transporte que tengan interés comercial en adquisición de capacidad.

8 Adjudicación de capacidad: Otorgamiento, por el administrador de infraestructuras ferroviarias, del derecho a servirse de capacidad de infraestructura ferroviaria.

9 RailNet Europa (RNE) fue creado en enero de 2004 por iniciativa de un grupo de administradores de infraestructuras ferroviarias europeos y organismos de adjudicación (IMS ( ABS). Como una asociación sin ánimo de lucro de los administradores de infraestructuras y los organismos de adjudicación, que se dedica a facilitar el tráfico internacional en la Infraestructura Ferroviaria Europea.
} 


\subsection{Estructura del canon por uso de la infraestructura.}

El estudio realizado de las Declaraciones sobre la Red y sus documentos anexos muestran que el sistema de cánones se puede clasificar en cuatro tipologías atendiendo a su complejidad.

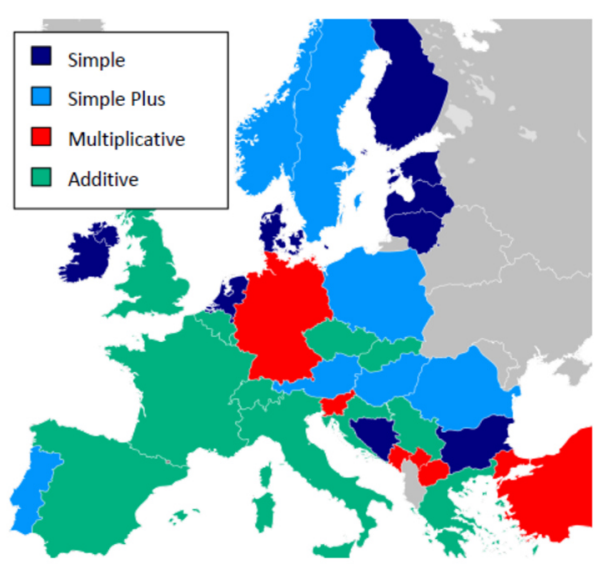

Gráfico 6. Clasificación por sistema de canon. Fuente: Charge4Rail2017.

Estas cuatro tipologías son, dependiendo del sistema empleado, las siguientes:

- Simple, sistema que utiliza una o dos unidades (tren.km, tonelada.km).

- Simple-Plus, que emplea una o dos variables clave, pudiendo contener más parámetros.

- Multiplicativo, usa un canon base multiplicado por una serie de factores.

- Aditivo, sistema complejo formado por la suma de fórmulas distintas.

\begin{tabular}{|l|l|}
\hline \multicolumn{1}{|c|}{ Tipo de sistema } & \multicolumn{1}{c|}{ País } \\
\hline Simple & $\begin{array}{l}\text { Bulgaria, Dinamarca, Finlandia, Lituania, Países Bajos, Reino } \\
\text { Unido, }\end{array}$ \\
\hline Simple Plus & Austria, Hungría, Polonia, Portugal, Suecia \\
\hline Multiplicativo & Alemania, Eslovenia \\
\hline Aditivo & $\begin{array}{l}\text { Bélgica, Croacia, República Checa, Francia, Grecia, } \\
\text { Rumanía, Italia, Luxemburgo, Serbia, Eslovaquia, España, } \\
\text { Suiza, HS I }\end{array}$ \\
\hline
\end{tabular}


Alemania.

DB Netze obtiene sus cánones según el tipo de línea, clasificada en función del tráfico y velocidad máxima permitida. Los multiplicadores varían según la utilización de la línea, por tipo de servicio, tipo de tren, así como la aplicación de unas penalizaciones por circular a velocidades inferiores a 50 $\mathrm{km} / \mathrm{h}$ y aplicación de cargos adicionales por transportes de mercancías superiores a 3.000 toneladas o por impacto ambiental.

$$
C_{D B N E T Z E}=\alpha(T I) * \beta(T t, T S, V m, Q e x)+M r
$$

\author{
Siendo: \\ CDBNETZE Canon administrador alemán \\ $\alpha \quad$ Precio por kilómetro de tramo \\ Tl Tipo de línea \\ $\beta \quad$ Factores multiplicadores \\ Ts Tipo de servicio \\ Tt Tipo de tren \\ Vm Velocidad mínima (si $V<50 \mathrm{~km} / \mathrm{h})$ \\ Qex $\quad$ Sobrecarga trenes de mercancías (si $Q>3.000 t$ ) \\ Mr Impacto ambiental trenes de mercancías (si >90\% de TSI)
}

Austria.

OBB Infrastruktur aplica el canon por tren-km que varía según la línea y tipo de servicio y un canon por tonelada-km transportada al que se suma un suplemento por tipo de tracción empleado en la circulación.

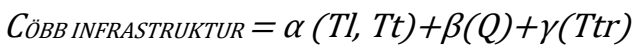

Siendo:
CöBB INFRASTRUKTUR
$\alpha$
$T I$
$T t$
$\beta$
$Q$
$\gamma$
$T t r$

Canon administrador austríaco
Precio por kilómetro de tramo
Tipo de línea
Tipo de tren
Precio por tonelada bruta kilómetro
Carga
Precio por kilómetro
Tipo de tracción


Bélgica.

Infrabel utiliza un sistema de factores en los que se diferencia por tipo de tren, tipo de línea (diferenciando por el equipamiento técnico con el que está equipada), la carga de la composición, así como el horario de circulación del tren.

$$
C_{\text {INFRABEL }}=\alpha^{*} \beta(T t, \text { Tlop, Tleq, } Q, H)
$$

Siendo:

$\begin{array}{ll}\text {C}_{\text {INFRABEL }} & \text { Canon administrador belga } \\ \alpha & \text { Precio por kilómetro de tramo } \\ \beta & \text { Factores multiplicadores } \\ T t & \text { Tipo de tren } \\ \text { Tlop } & \text { Tipo de línea (operacional) } \\ \text { Titeq } & \text { Tipo de línea (equipamiento técnico) } \\ Q & \text { Carga de la composición } \\ H & \text { Horario de circulación }\end{array}$

Bulgaria.

El administrador búlgaro aplica su canon de forma simple, en función de tren-km y por tonelada-kilómetro.

$$
C_{N R I C}=\alpha+\beta(Q)
$$

Siendo:

$C_{N R I C} \quad$ Canon administrador búlgaro

$\alpha \quad$ Precio por kilómetro

$\beta \quad$ Precio por tonelada kilómetro

Q Carga de la composición

Croacia.

El canon en Croacia varía según la importancia de la línea, tipo de servicio, la carga, así como el uso de tecnología basculante en las composiciones. 
Siendo:

$\begin{array}{ll}\text { CHZ INFRASTRUKTURA } & \text { Canon administrador croata } \\ \alpha & \text { Precio por kilómetro } \\ \beta & \text { Factores multiplicadores } \\ T s & \text { Tipo de servicio } \\ T t & \text { Tipo de tren } \\ Q e x & \text { Sobrecarga trenes de mercancías }(\text { si } Q>1.500 t) \\ T b c & \text { Uso de tecnología basculante }(0,20) \\ T I & \text { Tipo de línea }\end{array}$

Dinamarca.

El sistema danés emplea una tarifa plana por tren-km y un recargo por uso del puente de Öresund y la línea de enlace Storebaelt.

$$
C_{B A N E D A N M A R K}=\alpha(T S)+\beta
$$

Siendo:

$\begin{array}{ll}\text { CBANEDANMARK } & \text { Canon administrador danés } \\ \alpha & \text { Precio de acceso } \\ T S & \text { Tipo de servicio } \\ \beta & \text { Precio por uso de las líneas Storebaelt y Öresund }\end{array}$

España.

Adif y Adif Alta Velocidad utilizan el sistema resultante de la suma del canon de acceso, canon por reserva, canon por tráfico. El canon de acceso varía de según km-tren anuales, el canon por reserva depende del tipo de servicio, tipo de línea y hora del día.

El canon por tráfico, aplicado sólo a servicios de viajeros, depende del número de asientos ofertados, tipo de servicio, tipo de línea y horario.

$$
C_{A D I F}=\alpha(T l, V t)+\beta(T l, T t, H)+\gamma(T l, T t, H)+\delta(T l, T t, H) * \text { plazas/tren }
$$


Siendo:

$\begin{array}{ll}\text { CADIF } & \text { Canon administrador español } \\ \alpha & \text { Precio de acceso } \\ T I & \text { Tipo de línea } \\ V t & \text { Volumen de tráfico } \\ \beta & \text { Precio por reserva } \\ T I & \text { Tipo de línea } \\ T t & \text { Tipo de tren } \\ H & \text { Horario } \\ \gamma & \text { Precio por circulación } \\ T I & \text { Tipo de línea } \\ T t & \text { Tipo de tren } \\ H & \text { Horario } \\ \delta & \text { Precio por tráfico (sólo a trenes de viajeros) } \\ T I & \text { Tipo de línea } \\ T t & \text { Tipo de tren } \\ H & \text { Horario }\end{array}$

Eurotunnel.

El canon varía según la frecuencia de los trenes. El canon de reserva y el canon de acceso depende de la hora, velocidad y tipo de tren circulado.

$$
C_{\text {EUROTUNNEL }}=\alpha(T t, V, H)+\beta(T t, V, H)
$$

Siendo:

$\begin{array}{ll}\text { CEUROTUNNEL } & \text { Canon administrador túnel bajo Canal de la Mancha } \\ \alpha & \text { Precio de acceso } \\ T t & \text { Tipo de tren } \\ V & \text { Velocidad del tren } \\ H & \text { Horario } \\ \beta & \text { Precio por reserva } \\ T t & \text { Tipo de tren } \\ V & \text { Velocidad } \\ H & \text { Horario }\end{array}$


Finlandia.

El administrador determina el canon en base a toneladas-km y un recargo por uso de una sección de línea determinada debido a la necesidad de recuperar los costes de construcción.

$$
C_{\text {Liikennevirasto }}=\alpha(T t)+\beta(T t, T t r)
$$

Siendo:

$\begin{array}{ll}\text { C Liikennevirasto } & \text { Canon administrador finlandés } \\ \alpha & \text { Precio de acceso } \\ T t & \text { Tipo de tren } \\ \beta & \text { Precio por circulación } \\ T t & \text { Tipo de tren } \\ T t r & \text { Tipo de tracción }\end{array}$

Francia.

SNCF Reseau suma un canon de reserva y un canon por tipo de tren. Se aplican cánones especiales en algunos tramos. El canon de reserva varía según el tipo de línea, horario de circulación, el origen o destino en Paris, uso de líneas de alta velocidad por trenes regionales, según el tipo de tren.

$C_{S N C F R E S E A U}=\alpha(T l, T t){ }^{*} \beta(H, T S, V m)+\gamma(T t)+\delta(T l, T t, H)$

Siendo:

$\begin{array}{ll}\text { CSNCFRESEAU } & \text { Canon administrador francés } \\ \alpha & \text { Precio de reserva } \\ T 1 & \text { Tipo de línea } \\ T t & \text { Tipo de tren } \\ \beta & \text { Factores multiplicadores } \\ H & \text { Horario } \\ T s & \text { Tipo de servicio } \\ V m & \text { Velocidad media (trenes de mercancías) } \\ \gamma & \text { Precio para trenes de viajeros } \\ T t & \text { Tipo de tren } \\ \delta & \text { Precio por circulación (trenes de viajeros) }\end{array}$




\section{Grecia.}

El administrador griego utiliza el canon formado por dos componentes: gestión de tráfico y mantenimiento de la línea. La gestión de tráfico se obtiene mediante un coeficiente de capacidad y un coeficiente de horario. El canon por mantenimiento de la línea se obtiene multiplicando el precio base por un coeficiente de calidad que varía según línea y un coeficiente que depende del número de ejes, más y velocidad máxima.

$$
\operatorname{CoSE}=\alpha^{*} \beta(T I, H, V, Q e j)
$$

Siendo:

$\begin{array}{ll}\text { COSE } & \text { Canon administrador griego } \\ \alpha & \text { Precio básico } \\ \beta & \text { Factores multiplicadores } \\ T I & \text { Tipo de línea } \\ H & \text { Horario } \\ V & \text { Velocidad } \\ \text { Qej } & \text { Carga por eje }\end{array}$

Hungría.

Los dos administradores ferroviarios húngaros aplican un canon de reserva por tren-km y tonelada-km, variando según la importancia de la línea y el tipo de tren. Existe una bonificación por uso del sistema ETCS.

$$
C_{M A ́ V V P E}=\alpha+\beta(T I, T t)
$$

Siendo:

$\begin{array}{ll}\text { CMÁV-VPE } & \text { Canon administradores húngaros } \\ \alpha & \text { Precio reserva de capacidad } \\ \beta & \text { Factores multiplicadores } \\ T I & \text { Tipo de línea } \\ T t & \text { Tipo de tren }\end{array}$

Italia.

El canon por uso de la línea consiste en un canon de acceso y un canon por uso de la infraestructura. El canon de acceso para líneas principales es una tarifa plana, siendo el máximo en líneas secundarias y cero para líneas de alta velocidad. 
El canon de uso de la infraestructura es calculado por tren-km, multiplicando un cargo fijo por factores que dependen de la velocidad del tren, grado de saturación de la línea y un factor por desgaste en función de la masa del tren, velocidad y número de pantógrafos. La variable nodo es una cantidad fija determinada por minuto y que varía con el horario de circulación y la detención o no de un tren en una estación principal.

$$
C_{R F I}=\alpha(T I, N)+\beta(T I)^{*} \gamma(V, \text { Traf, } Q, \text { Pant }, H)
$$

\title{
Siendo:
}

$\begin{array}{ll}C_{R F I} & \text { Canon administrador italiano } \\ \alpha & \text { Precio de acceso } \\ T I & \text { Tipo de línea } \\ N & \text { Nodo ferroviario } \\ \beta & \text { Precio de uso } \\ T I & \text { Tipo de línea } \\ \gamma & \text { Factores multiplicadores } \\ V & \text { Velocidad } \\ T r a f & \text { Nivel de congestión } \\ Q & \text { Carga } \\ \text { Pant } & \text { Número de pantógrafos } \\ H & \text { Horario }\end{array}$

Lituania.

Utiliza un canon base consistente en la reserva de capacidad por tren-km y un canon por uso de catenaria

$$
C_{\text {Lietuvos geležinkeliai } A B}=\alpha+\beta(Q)+\Gamma
$$

\section{Siendo:}

CLietuvos geležinkeliai $A B$
$\alpha$
$\beta$
$Q$
$\Gamma$

\author{
Canon administrador lituano \\ Precio de reserva de capacidad \\ Precio de uso \\ Carga \\ Uso de catenaria.
}


Luxemburgo.

ACF aplica un sistema aditivo de dos partes, con canon de uso de infraestructura, que varía según tipo de tren, masa de la composición y un canon que grava la escasez de capacidad en la línea.

$$
C_{A C F}=\alpha^{*} \beta(T t, Q c o, T s)
$$

Siendo:

$\begin{array}{ll}C_{A C F} & \text { Canon administrador luxemburgués } \\ \alpha & \text { Precio de uso } \\ \beta & \text { Factores multiplicadores } \\ T t & \text { Tipo de tren } \\ Q c o & \text { Masa total de la composición } \\ T S & \text { Tipo de servicio }\end{array}$

Países Bajos.

ProRail emplea un canon basado en la masa del tren.

$$
C_{\text {PRORAIL }}=\alpha(Q C O)
$$

Siendo:

CPRORAIL Canon administrador holandés

$\alpha \quad$ Precio de uso

Qco Masa total de la composición

Polonia.

El canon polaco depende de la masa del tren, categoría de la línea y la circulación por líneas electrificadas.

$$
C_{P K P}=\alpha(T l, T t, Q C O)
$$

Siendo:

$\begin{array}{ll}\text { CPKP } & \text { Canon administrador polaco } \\ \alpha & \text { Precio de uso } \\ T I & \text { Tipo de línea } \\ T t & \text { Tipo de tren } \\ \text { Qco } & \text { Masa total de la composición }\end{array}$


Portugal.

El sistema tarifario portugués aplica un precio base por tren-km que varía según el tipo de línea, tipo de tren y el uso de líneas electrificadas.

$$
C_{I P}=\alpha(T t, T t r . T I)
$$

Siendo:

$\begin{array}{ll}C_{I P} & \text { Canon administrador portugués } \\ \alpha & \text { Precio de uso } \\ T t & \text { Tipo de tren } \\ T t r & \text { Tipo de tracción } \\ T I & \text { Tipo de línea }\end{array}$

Reino Unido.

Network Rail utiliza el sistema de franquicias, lo que requiere a los operadores realizar grandes desembolsos para el acceso. Existe un canon variable tren-millas al que se le añade el uso de líneas electrificadas, un canon por reserva de capacidad, variable dependiendo del día de la semana, así como el tipo de material rodante empleado.

$$
C_{\text {NETWORK RAIL }}=\alpha(O p, H)+\beta(T t, T m r)
$$

Siendo:

$\begin{array}{ll}\text {C}_{\text {NETWORKRALL }} & \text { Canon administrador británico } \\ \alpha & \text { Precio de acceso } \\ \text { Op } & \text { Operador ferroviario } \\ H & \text { Horario } \\ \beta & \text { Precio por uso } \\ T t & \text { Tipo de tren } \\ \mathrm{Tmr} & \text { Tipo de material rodante }\end{array}$

Reino Unido HS-1.

HS-1 emplea cánones aplicados en función del tiempo empleado por las circulaciones para asegurar que los trenes están aplicando la velocidad máxima de la red. Las variables dependen del tipo de utilice la infraestructura. 


$$
C_{H S 1}=\alpha(\text { Tram })+\beta(R P I+1,1 \%)+\gamma(\text { Tram }, T t)
$$

Siendo:

\begin{tabular}{ll}
\multicolumn{1}{c}{ CHS1 } & Canon administrador británico alta velocidad \\
\multicolumn{1}{c}{$\alpha$} & Precio de acceso (IRC) \\
Tram & Tramo del recorrido \\
$\beta$ & Precio de acceso (OMRC) \\
$R P I$ & Canon fijo aplicado por la ORR \\
$\gamma$ & Precio por reserva \\
Tram & Tramo del recorrido \\
$T t$ & Tipo de tren
\end{tabular}

República Checa.

El administrador checo aplica un canon por reserva y otro por uso de capacidad, dependiendo de la longitud del recorrido y número de días al año por el que se solicita la reserva de capacidad. El uso de capacidad depende de tren-km y de tonelada-km.

$$
C_{S \check{D} D}=\alpha+\beta(H)
$$

Siendo:

$\begin{array}{ll}C_{S Z ̌ D C} & \text { Canon administrador checo } \\ \alpha & \text { Precio de reserva } \\ \beta & \text { Precio de uso } \\ H & \text { Horario }\end{array}$

Rumanía.

Su sistema está compuesto por dos partes, un canon por tonelada-km y otra por tren-km. EL canon por tonelada-km varía según el tipo de línea y si es electrificada, mientras que el canon por tren-km varía sólo por tipo de línea. 


$$
C_{C F R}=\alpha(T I) * \beta(Q e x)
$$

Siendo:

$\begin{array}{ll}C_{C F R} & \text { Canon administrador rumano } \\ \alpha & \text { Precio de uso } \\ T I & \text { Tipo de línea } \\ \beta & \text { Factores multiplicadores } \\ \text { QeX } & \text { Sobrecarga }\end{array}$

Slovaquia.

Formado por un canon de reserva por tren-km, una parte fija por gestión de tráfico y por uso teniendo en cuanta la masa de la composición.

$$
C_{\check{Z} S R}=\alpha(T I)+\beta(T I)+\gamma(T I, Q c o m)
$$

Siendo:

$\begin{array}{ll}C_{\check{Z} S R} & \text { Canon administrador eslovaco } \\ \alpha & \text { Precio por asignación de capacidad } \\ T I & \text { Tipo de línea } \\ \beta & \text { Precio por tráfico } \\ \gamma & \text { Precio por uso } \\ \text { Qcom } & \text { Masa total de la composición }\end{array}$

Slovenia.

El sistema multiplicativo de este administrador está formado por el producto de un precio base, un coeficiente por tipo de tren, categoría de la línea y por potencia de la unidad de tracción empleada.

$$
\text { C Slovenske Železnice }=\alpha * \beta(T t, Q c o m, T I, P \text { tr })
$$

Siendo:

C Slovenske Železnice Canon administrador esloveno

a Precio por uso

Tt Tipo de tren

Qcom Masa total de la composición ferroviaria

TI Tipo de línea

Ptr Potencia unidad de tracción 
Incluye una parte base tonelada.km, dependiente de la carga por eje, una parte por tipo de línea, por tren-km, en zonas de alto tráfico por viajero y una por emisiones dependiendo del tipo de monitorización empleada en las unidades de tracción.

Como parte especial de canon figura el uso de la parte sueca del puente de Öresund y que es aplicable solamente a los trenes de mercancías

$$
C_{\text {Trafikverket }}=\alpha(T t, Q e j)+\beta(\text { Ntraf })+M(T t r, T m t)
$$

\section{Siendo:}

$C_{\text {Trafikverket } \quad \text { Canon administrador sueco }}$

a Precio de acceso

Tt Tipo de tren

Qej $\quad$ Carga por eje

$\beta \quad$ Precio por acceso

Ntraf Nivel de congestión

M Precio ambiental

Ttr Tipo de tracción

Tmt Tipo de motorización unidad de tracción

LFP (Línea Figueres-Perpignan).

Se basa en un canon por reserva determinado por el horario de circulación de la composición y un cargo fijo por uso de este tramo internacional de alta velocidad.

$$
C_{L F P}=\alpha(T t, H)+\beta(T t, H)
$$

Siendo:

$C_{L F P} \quad$ Canon administrador sección internacional Francia-España

$\alpha$

Tt

H

$\beta$

Precio de reserva

Tipo de tren

Horario

Precio por uso 


\subsection{Estructura del canon por uso de estaciones de viajeros.}

En este apartado se va a analizar el canon aplicado por los administradores de la infraestructura por uso de las estaciones de viajeros. Para ello se han analizado los países siguientes: Alemania, Austria, Bélgica, Bulgaria, Croacia, Dinamarca, Grecia, Hungría, Italia, Luxemburgo, Países Bajos y Portugal. España y Francia se analizan más exhaustivamente en el apartado 5 de este trabajo académico.

Alemania.

DB Station und Service AG aplica el canon en base al número de paradas realizadas. Se basa en una clasificación de 7 categorías según los servicios prestados realizando la distinción entre el tipo de servicio que realiza el tren, corta o larga distancia, y según la situación geográfica de la estación.

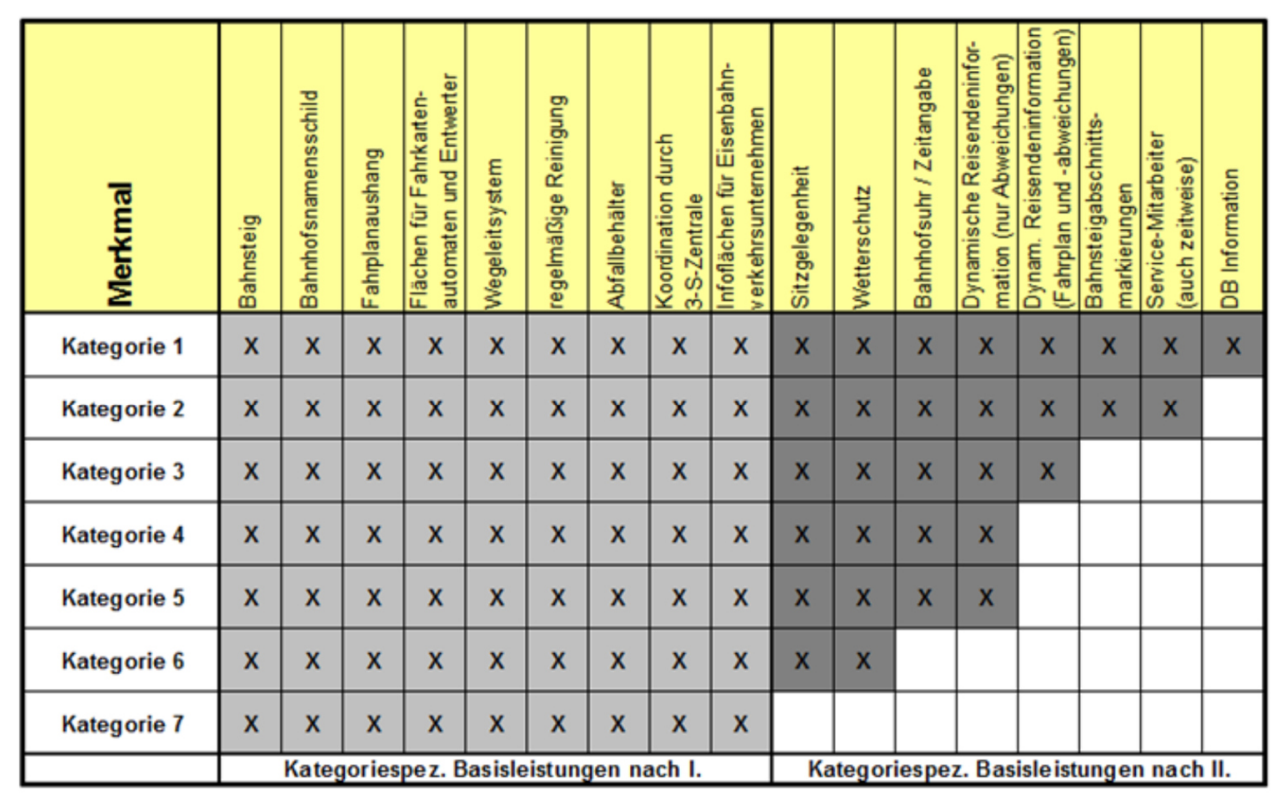

Tabla 5. Categorías de las estaciones alemanas. Fuente: DB Netze AG. 
Austria.

El servicio de ÖBB-Infrastruktur AG comprende la autorización del uso de la estación en relación con las paradas de los trenes en la estación.

La duración de la parada en la estación es definida en el horario de forma previa. La parada en la estación incluye los siguientes servicios básicos:

- Embarque y desembarque de trenes, incluidos los transbordos.

- Transbordos entre trenes y acceso a áreas de transporte público pertenecientes a otras entidades y accesos a la estación.

Las estaciones de viajeros están categorizadas de acuerdo con el número de viajeros diarios que soportan:

- Categoría 1+:> 65.000 pasajeros por día.

- Categoría 1:> 20.000 a 65.000 pasajeros por día

- Categoría 2:> 8.000 a 20.000 pasajeros por día

- Categoría 3:> 4.000 a 8.000 pasajeros por día

- Categoría 4:> 2.000 a 4.000 pasajeros por día

- Categoría 5:> 500 a 2.000 pasajeros por día

- Categoría 6: Hasta 500 pasajeros por día

Los servicios prestados en las estaciones dependen de la categoría de la estación y se muestran en la tabla siguiente y esto son:

- Acceso y uso de los andenes.

- Sistema de orientación.

- Información a viajeros.

- Puntos de información estática.

- Puntos de atención al viajero.

- Espacios para máquinas de ticketing y máquinas canceladoras.

- Limpieza. 


\begin{tabular}{|c|c|c|c|c|c|c|c|}
\hline Categoría & $1+$ & 1 & 2 & 3 & 4 & 5 & 6 \\
\hline viajeros. día & $>65.000$ & $\begin{array}{c}>20.000 \mathrm{a} \\
65.000\end{array}$ & $\begin{array}{c}>8.000 \mathrm{a} \\
20.000\end{array}$ & $\begin{array}{c}>4.000 \mathrm{a} \\
8.000\end{array}$ & $\begin{array}{l}>200 \mathrm{a} \\
4.000\end{array}$ & $\begin{array}{c}>500 \mathrm{a} \\
2.000\end{array}$ & $\begin{array}{c}\text { hasta } \\
500\end{array}$ \\
\hline Servicios básicos & & & & & & & \\
\hline $\begin{array}{l}\text { Uso de escaleras } \\
\text { mecánicas }\end{array}$ & & & & & & & \\
\hline Servicio de vigilancia & & & & & & & \\
\hline $\begin{array}{c}\text { Punto de } \\
\text { Información }\end{array}$ & & & & & & & \\
\hline
\end{tabular}

\section{Canon por}

servicios básicos

Servicios con

suplemento

No ofertado

Tabla 6. Servicios ofertados en estaciones de viajeros por ÖBB-Infrastruktur AG. Elaboración propia.

También es aplicado un factor dependiendo del número de andenes disponibles en la estación, quedando definidos en los grupos siguientes:

- $\quad 1$ a 2 andenes $=1$

- $\quad 3$ a 4 andenes $=1,1$

- $\quad 5$ a 7 andenes $=1,2$

- 8 o más andenes $=1,3$

Los cánones adicionales contemplados son:

- Servicios a viajeros con movilidad reducida.

- Actividades de venta y apoyo publicitario.

- Publicidad.

- WI-FI en estaciones y a bordo.

- Objetos perdidos.

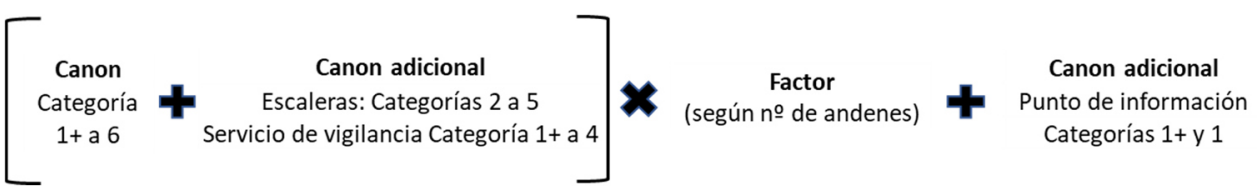

Gráfico 7. Estructura del canon ÖBB-Infrastruktur AG por uso de estaciones de viajeros. Elaboración propia. 
Bélgica.

Las estaciones están gestionadas por SNCB, sociedad anónima belga responsable del diseño, construcción, renovación, mantenimiento y gestión de 552 estaciones de ferrocarril. Aunque Infrabel no opera las estaciones de viajeros, los andenes se consideran parte de la infraestructura, por lo que a Infrabel se debe solicitar acceso a los mismos a la vez que se solicita la reserva de capacidad para la circulación de un tren.

Las 552 estaciones se clasifican en cinco categorías:

- TOP 4: Son las tres estaciones donde se detienen los trenes internacionales de pasajeros (Bruselas-Sur, Amberes-Central y LiejaGuillemins) y el aeropuerto de Bruselas - estación Zaventem. Estas 4 estaciones forman una categoría separada por una infraestructura y actividades específicas relacionadas con la seguridad.

- 20,000 +: Estaciones con más de 20.000 viajeros semanales.

- 10,000 +: Estaciones con un flujo de viajeros que varía entre 10.000 y 20.000 viajeros por semana.

- Otras estaciones: Estaciones con menos de 10.000 viajeros semanales.

- Estaciones sin personal.

Las tarifas se calculan en función del número de paradas planificadas diferenciando entre servicios realizados por trenes de viajeros nacionales o internacionales.

Los costes son los siguientes:

- Acceso a los edificios e instalaciones de la estación.

- Información a los viajeros.

- Asistencia para personas con movilidad reducida.

- Seguridad en estaciones y andenes.

En el canon por uso de infraestructura, Infrabel aplica un factor multiplicativo que varía según sea la parada realizada en estación de origen, estación destino o estación intermedia. En la tabla siguiente se muestra el valor de los factores a aplicar a los trenes de viajeros:

\begin{tabular}{cc} 
Tipo de parada & Factor Cu \\
\hline Estación origen & 4,00 \\
\hline Estación destino & 3,50 \\
\hline Estación intermedia & 3,00 \\
\hline
\end{tabular}

Tabla 7. Factor según tipo de parada en estaciones. Fuente: Infrabel. 
Bulgaria.

El canon por uso de las estaciones de viajeros está integrado en el canon por uso de la infraestructura. Se aplica un cargo adicional por uso de áreas en las propias estaciones definido por la clasificación de estas en 2 categorías. Cada categoría está dividida según la utilización de zonas cubiertas o zonas descubiertas.

\section{Croacia.}

$\mathrm{HŽ} \mathrm{Infrastruktura} \mathrm{permite} \mathrm{a} \mathrm{todas} \mathrm{las} \mathrm{empresas} \mathrm{ferroviarias} \mathrm{utilizar} \mathrm{las}$ estaciones, edificios y otras instalaciones necesarias para el embarque de viajeros, incluidos los elementos de información y ubicación de puntos de venta de billetes. No ofrece el servicio de precalentamiento y de aire acondicionado preliminar a los coches. El canon por uso de estaciones incluye el uso de andenes y otras áreas necesarias para el acceso de viajeros y el uso de pantallas de información, siendo aplicado por parada en la estación. El cálculo del canon se obtiene mediante la fórmula siguiente:

$$
\mathrm{Csm}=\mathrm{Ksm} \times \mathrm{Kvl} \times \mathrm{Cos}
$$

siendo:

Csm = Canon por uso de estaciones.

$\mathrm{Ksm}=$ Coeficiente estación .

$\mathrm{Kvl}=$ Coeficiente por tipo de tren

Cos $=$ Precio base

El coeficiente de estación Ksm se determina para cada estación por separado, teniendo en cuenta los siguientes parámetros:

- Importancia de la estación o parada en términos de transporte, geográficos y sociales.

- Dimensiones del andén y áreas construidas para el embarque de viajeros.

- Número de vías a lo largo de la superficie elevada de la estación / parada.

- Existencia de marquesinas.

- Existencia de equipos para información del viajero. 
El coeficiente de tipo de tren Kvl está determinado por la longitud del tren y equivale a:

\begin{tabular}{ccc}
$\begin{array}{c}\text { Coeficiente } \\
\text { Tipo de tren }\end{array}$ & Tipo de tren & Coef \\
\hline $\mathrm{KVl}_{1}$ & Eurocity, Euronight, Intercity, Rápido, Semi-rápido. & 1,91 \\
\hline $\mathrm{KVl}_{2}$ & Viajeros, transfronterizos & 0,89 \\
\hline $\mathrm{KVl}_{3}$ & Suburbano & 0,99 \\
\hline
\end{tabular}

Tabla 8. Coeficiente "tipo de tren" para el canon por uso de estaciones. Fuente: HŽ Infrastruktura.

\section{Dinamarca.}

Los costes por uso de estaciones de viajeros están integrados en el canon por uso de la infraestructura, siendo los servicios adicionales y auxiliares realizados directamente por las empresas ferroviarias.

Grecia.

El método empleado para el cálculo del canon se basa en la clasificación de las estaciones de viajeros y en las paradas en estación. Las estaciones de viajeros están divididas en dos categorías según la cantidad de viajeros anuales como criterio de clasificación.

La siguiente tabla enumera los cargos respectivos:

\section{Categoría de la Estación $\quad \epsilon /$ parada}

\begin{tabular}{cc}
\hline A & 1,50 \\
\hline B & 1,00 \\
\hline
\end{tabular}

Tabla 9. Categoría de las estaciones. Fuente: OSE. 
Hungría.

El organismo de asignación de capacidad ferroviaria y el organismo de aplicación de cánones es la oficina de asignación de capacidad ferroviaria (VPE). El canon por uso de estaciones de viajeros se contabiliza por el número de trenes que efectúan salida, parada o llegada a la estación, siendo el administrador ferroviario el encargado de la actividad de ticketing mediante su personal. El cargo es dependiente del número de billetes vendidos.

La categorización de las estaciones se determina según los parámetros siguientes (Tsz, i):

- Altura y longitud de andenes

- Tipo de acceso a los andenes.

- Información al viajero.

- Existencia de refugios y marquesinas en andenes.

- Características de los puntos de embarque de viajeros.

- Número de vías.

- Servicio de vigilancia.

- Existencia de vías electrificadas.

El valor de los factores aplicados y relacionados con la calidad del servicio (Szsz, j) se muestran a continuación:

- Índice de lugares de embarque de viajeros desde el punto de vista del uso de las instalaciones de las estaciones:

$$
\mathrm{V}_{s z}=\Sigma \Sigma_{T s z, \mathrm{i}} \times S_{z s z, j}
$$

Estos valores quedan determinados según la relación siguiente:

- $\quad \mathrm{y}_{\mathrm{sz}} \geq 0,56$, categoría I.

- $\quad 0,56>\mathrm{y}_{\mathrm{sz}} \geq 0,27$, categoría ll.

- $\quad 0,27>\mathrm{y}_{s z} \geq 0,19$, categoría III.

- $\quad \mathrm{y}_{s z}<0,22$, categoría IV. 
En las tablas siguientes se muestran los parámetros empleados y el porcentaje de influencia en la fórmula anterior para la definición de los puntos de embarque desde el punto de vista del viajero:

\begin{tabular}{|c|c|c|}
\hline Clave & Factores de calidad & (\%) \\
\hline 1 & Altura de andén & 15 \\
\hline 2 & Longitud de andén & 15 \\
\hline 3 & Tipo de acceso al andén & 10 \\
\hline 4 & Información en andén & 5 \\
\hline 5 & Información en edificio & 10 \\
\hline 6 & Marquesinas, refugios, etc. & 10 \\
\hline 7 & Conexiones intermodales & 5 \\
\hline 8 & Número de vías principales & 10 \\
\hline 9 & Tipo de instalación de seguridad & 5 \\
\hline 10 & Vías electrificadas & 5 \\
\hline 11 & Precalentamiento de trenes & 5 \\
\hline 12 & Acceso a instalaciones de servicio & 5 \\
\hline
\end{tabular}

Tabla 10. Parámetros e influencia \% para la determinación de los puntos de embarque de viajeros desde el punto de vista del viajero. Fuente: VPE.

Los valores de cada clave así como el factor multiplicador del nivel de calidad para los puntos de embarque de viajeros son los siguientes:

\begin{tabular}{|l|l|c|}
\hline \multicolumn{1}{|c|}{ Clave } & \multicolumn{1}{c|}{$\begin{array}{c}\text { Factor } \\
\text { multiplicador (\%) }\end{array}$} \\
\hline 1. Altura de andén \\
\hline "1" & Cota sobre raíl + 0 & 10 \\
\hline "2" & Cota sobre raíl + 15 & 25 \\
\hline ," & Cota sobre raíl + 30 & 50 \\
\hline "4" & Cota sobre raíl + 55-60 & 100 \\
\hline 2. Longitud del andén & 0 \\
\hline "," & Menos de 100 m. & 50 \\
\hline "," & De 101 a 199 m. & 90 \\
\hline "2" & De 200 a 299 m. & 100 \\
\hline "," & Más de 300 m. & 0 \\
\hline 3. Tipo de acceso al andén & 80 \\
\hline ",2" & Al mismo nivel & 100 \\
\hline ,"3" & Paso inferior O superior & \\
\hline \multicolumn{2}{|l|}{} \\
\hline
\end{tabular}




\begin{tabular}{|c|c|c|}
\hline \multicolumn{3}{|c|}{ 4. Información al viajero en andenes } \\
\hline , ," & Cartelería & 0 \\
\hline ,1" & Megafonía & 30 \\
\hline "2" & Video & 80 \\
\hline ,3" & Video+Audio & 100 \\
\hline \multicolumn{3}{|c|}{ 5. Información a los viajeros en el edificio } \\
\hline , ," & Sin información & 0 \\
\hline ", & Megafonía & 30 \\
\hline "2" & Información Visual & 60 \\
\hline ,", & Video+Audio & 100 \\
\hline \multicolumn{3}{|c|}{ 6. Protección climatológica } \\
\hline ,0" & Sin protección & 0 \\
\hline ", & Refugio & 30 \\
\hline 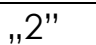 & Marquesina & 60 \\
\hline ,"3" & Sala de Espera & 70 \\
\hline ,13" & Sala de espera y Refugio & 90 \\
\hline ,23" & Sala de espera y Marquesina & 100 \\
\hline \multicolumn{3}{|c|}{ 7. Conexiones intermodales } \\
\hline , & Sin conexión & 0 \\
\hline "1" & Aparcamiento para bicicletas & 30 \\
\hline ,"2" & $P \& R$ & 40 \\
\hline ,12" & Aparcamiento bicicletas + P\&R & 60 \\
\hline , ,3" & Conexión con transporte público & 80 \\
\hline "13" & $\begin{array}{l}\text { Aparcamiento de bicicletas + } \\
\text { transporte público }\end{array}$ & 90 \\
\hline ,23" & P\&R + transporte público. & 90 \\
\hline "4" & $\begin{array}{l}\text { Aparcamiento de bicicletas + P\&R } \\
+ \text { transporte público }\end{array}$ & 100 \\
\hline \multicolumn{3}{|c|}{ 8. Número de vías principales } \\
\hline ,1" & De 1 a 2 & 0 \\
\hline ", & De 3 a 4 & 50 \\
\hline ,"3" & De 5 a 7 & 80 \\
\hline ,"4" & Más de 7 & 100 \\
\hline \multicolumn{3}{|c|}{ 9. Tipo de instalaciones de seguridad } \\
\hline ," & Sin instalaciones de seguridad & 0 \\
\hline ", & NBJF & 15 \\
\hline "2" & $\mathrm{KA}, \mathrm{KAE}$, EÁ & 25 \\
\hline ,"3" & KR & 35 \\
\hline ". & ER, SH, FM, VES & 80 \\
\hline , $5 "$ & $\begin{array}{l}\text { FOND, INT, D55, KA69, SZKA, WSSB, } \\
\text { KSW-90 }\end{array}$ & 90 \\
\hline ,6" & D70V, ESTW-ELEKTRA-D55 & 95 \\
\hline ,7" & D67, D70, SZT, ELEKTRA, SIMIS & 100 \\
\hline
\end{tabular}




\begin{tabular}{|c|c|c|}
\hline \multicolumn{3}{|c|}{ 10. Vías electrificadas } \\
\hline ,1" & No electrificada & 0 \\
\hline ,2" & Parcialmente electrificada & 50 \\
\hline ,3" & Electrificada & 100 \\
\hline \multicolumn{3}{|c|}{ 11. Precalentamiento de trenes } \\
\hline "O" & no & 0 \\
\hline "1" & si & 100 \\
\hline \multicolumn{3}{|c|}{ 12. Puntos de acceso para servicios } \\
\hline "0" & Sin puntos de acceso & 0 \\
\hline ,1" & De 1 a 2 & 60 \\
\hline "2" & 3 o más & 100 \\
\hline
\end{tabular}

Italia.

El canon por uso la infraestructura incluye el canon de estaciones. Este es aplicado como un componente, estructurado en un coeficiente que se aplica a las circulaciones que hacen uso de andenes siendo el resultante determinado por minutos de estacionamiento en las estaciones y por el horario en el que se realiza el estacionamiento.

La clasificación de las estaciones empleada por la Rete Ferroviaria Italiana está basada en 4 categorías: platino, oro, plata y bronce. Con estas categorías se establecen las tarifas por establecimiento de áreas de mostradores y taquillas, por colocación de máquinas de ticketing, así como por servicios de asistencia a personas de movilidad reducida. Estas categorías están establecidas en las características funcionales de las mismas:

- Categoría Platino: Más de 25.000 viajeros de media al día. Poseen servicios específicos para viajeros de alta velocidad. Estas estaciones son gestionadas por Grandi Stazioni Rail SpA, 100\% controlada por RFI. Desde noviembre de 2018 es la empresa encargada del mantenimiento, mejora y gestión de las catorce estaciones principales italianas (Bari Centrale, Bologna Centrale, Firenze Santa Maria Novella, Genova Brignole, Genova Piazza Principe, Milán Central, Nápoles Central, Palermo Central, Roma Termini, Roma Tiburtina, Turín Porta Nuova, Venecia Mestre, Venecia Santa Lucía y Verona Porta Nuova).

- Categoría Oro: Con más de 10.000 viajeros de promedio al día. También están gestionadas por Grandi Stazioni Rail SpA. 
- Categoría Plata: Incluye dos tipos:

* Estaciones con más de 2.500 viajeros de promedio al día y que gestiona directamente de RFI.

* Estaciones con una media diaria de más de 4.000 viajeros y sin edificio de viajeros abierto, no atendido por personal y sólo con servicios regionales o de cercanías. La gestión se lleva a cabo directamente por RFI aunque hay posibilidad de que se gestione a través de organismos institucionales o asociaciones sin fines de lucro a través de contratos a préstamo gratuitos.

- Categoría Bronce: Incluye pequeñas estaciones con más de 500 de promedio diario, sin edificio abierto, no atendido por personal y servicios sólo con servicios regionales o de cercanías. La gestión se realiza directamente por RFI 0 , a veces, se confía a organismos institucionales o asociaciones sin fines de lucro a través de contratos de préstamo gratuitos.

Los parámetros utilizados para determinar la categoría de cada estación se definen de acuerdo con los siguientes parámetros:

- Asistencia diaria: Obtenida por la cantidad de viajeros subidos/bajados y la cantidad de personas que, aunque no utilizan el servicio de transporte, entran en la estación (para compras, intercambio con otros tipos de transporte, turismo, etc.).

- Nivel del servicio de viajeros: Se considera la importancia del sistema en términos exclusivamente relacionados con el nivel de la oferta comercial de transporte y el número y tipo de trenes (trenes de alta velocidad, larga / media distancia, regional, cercanías).

- Áreas abiertas al público: Toma como referencia el tamaño del área total de las áreas abiertas al público (áreas comerciales como tiendas y áreas de exhibición, áreas de tránsito - subterráneos, túneles de tránsito, las áreas "operativas" (áreas que fuera de la estación, (aceras, entradas principales, vías, taquillas).

- Intermodalidad: Tiene en cuenta la presencia o ausencia de paradas de metro, terminales de autobuses urbanos / extraurbanos, paradas de tranvía, paradas de taxis, conexiones a aeropuertos desde la estación o en las inmediaciones, estacionamiento de vehículos automóviles, motocicletas y bicicletas. 
Luxemburgo.

El acceso a las estaciones de viajeros, edificios de estaciones y sus infraestructuras se incluye en el surco solicitado para una circulación destinada al transporte de viajeros.

El acceso a las vías desde los andenes se limita al tiempo estrictamente necesario para realizar las operaciones requeridas, como es el estacionamiento de un tren para su posterior salida de la estación, el embarque y el desembarque de viajeros, el cambio de locomotoras o del personal de tren o la modificación de su composición.

El canon por el acceso a las estaciones incluye el uso de los andenes, plataformas y áreas abiertas al público, incluidos ascensores y escaleras mecánicas. También incluye la información de trenes de acuerdo con las instalaciones disponibles. En caso de utilizar las vías como vías de apartado la tarifa se obtiene como el producto del precio único por vehículo y el número de días completos de uso de vías y basada en la longitud efectiva de la vía ocupada (en número de secciones de 20 m).

La tarifa asociada con climatización previa del material rodante se establece como el producto de una tarifa única y el número de vehículos (pre) calefactados o (pre) aire acondicionado.

Países Bajos.

La tarifa por uso de andenes depende de la categoría de la estación y el tipo de parada. ProRail divide en 5 categorías las estaciones teniendo en cuanta también el tipo de parada de los trenes:

\begin{tabular}{|c|c|c|c|}
\hline $\begin{array}{c}\text { Categoría de la } \\
\text { estación }\end{array}$ & \multicolumn{3}{|c|}{$\boldsymbol{\epsilon} /$ parada } \\
\cline { 2 - 4 } & A & B & C \\
\hline Stop & 0,55 & 0,91 & 1,12 \\
\hline Basic & 0,97 & 1,60 & 1,96 \\
\hline Plus & 1,56 & 2,59 & 3,18 \\
\hline Mega & 1,96 & 3,25 & 3,97 \\
\hline Catedral & 4,85 & 8,06 & 9,87 \\
\hline
\end{tabular}

Tabla 12. Tarifa aplicada por tipo de parada y categoría de la estación. Fuente: ProRail. 
La clasificación en estas 5 categorías se basa en el número estimado de viajeros subido/bajados con los valores umbral de menos de 1.000, 10.000, $25.000,75.000$ y más de 75.000 viajeros diarios.

El código de parada de tren aplicable $(A, B \circ C)$ se determina en función del tren según se detalla a continuación:

- Código de parada A: Tren para el transporte de viajeros que durante su ruta desde la estación inicial hasta la final de acuerdo con el horario se detiene en todas las estaciones o no se detiene en no más del $15 \%$ de ellas.

- Código de parada B: Tren de viajeros que durante su ruta desde el inicio hasta la estación final de acuerdo con el horario se detiene en un mínimo del $50 \%$ de estaciones o que forma parte de una serie de trenes de los cuales al menos el $90 \%$ se ejecuta en una composición con una oferta menor a 150 plazas.

- Código de parada C: Tren para el transporte de viajeros, no sujeto a ninguna condición con respecto al porcentaje de estaciones en las que no se realiza ninguna parada. determinado en el acuerdo de acceso a la infraestructura.

Portugal.

El canon por uso de estaciones está basado en las paradas comerciales realizadas por cada tren, de acuerdo con la tipología de la estación donde se realiza la parada comercial. Es aplicado por el uso de andenes así como por el acceso a la estación. La clasificación empleada está determinada por los siguientes parámetros:

* Flujo de pasajeros, relacionado con el volumen de viajeros subidos/bajados en la estación.

* Servicio ferroviario prestado, asociado con la diversidad de servicios ferroviarios prestados;

* Nivel de intermodalidad, es decir disponibilidad y condiciones de medios de transporte complementarios al servicio ferroviario.

* Relevancia, a través de criterios asociados con la cobertura y el alcance de la estación. 
Este valor se aplica como componente multiplicador en el canon de acceso a la red portuguesa. El cálculo para establecer el canon de acceso es el siguiente:

$$
T_{i=} C_{0} * C_{1} * C_{2} * C_{3} * C_{4} * C_{5} * C_{6}
$$

Siendo:

Ti - Tarifa de la Sección i

Co- Componente base.

$\mathrm{C}_{1}$ - Componente de control de tráfico.

$\mathrm{C}_{2}$ - Componente de instalaciones eléctricas.

$\mathrm{C}_{3}$ - Componente de valor operativo.

$\mathrm{C}_{4}$ - Componente de instalaciones de seguridad y telecomunicaciones.

$C_{5}$ - Componente de estación y costes asociados.

$\mathrm{C}_{6}$ - Tipo de componente de servicio.

\begin{tabular}{|c|c|}
\hline Categoría de la Estación & $\boldsymbol{\epsilon} /$ parada comercial \\
\hline A & 0,70 \\
\hline B & 0,49 \\
\hline H & 0,21 \\
\hline D & 0,05 \\
\hline
\end{tabular}

Tabla 13. Tarifa aplicada por categoría de estación. Fuente: Infraestructuras de Portugal.

La provisión de instalaciones operativas en cada estación se cobra de acuerdo con las áreas ocupadas de acuerdo con la categoría de la estación e independientemente del tipo de ocupación:

\begin{tabular}{|c|c|}
\hline Categoría de la Estación & $\boldsymbol{\epsilon}_{\text {mes }} / \mathbf{m}^{\mathbf{2}}$ \\
\hline $\mathrm{A}$ & 2,74 \\
\hline $\mathrm{B}$ & 1,93 \\
\hline $\mathrm{H}$ & 1,01 \\
\hline $\mathrm{D}$ & 0,22 \\
\hline
\end{tabular}

Tabla 14. Tarifa aplicada por superficies utilizadas en estación. Fuente: Infraestructuras de Portugal. 
La información al viajero por medio de teleindicadores se ejecuta por 20 minutos para la inserción en el sistema y 20 minutos para su eliminación, lo que totaliza 40 minutos para cada operación solicitada, para un tren y período específicos, que se cobran de acuerdo con el valor de coste de la mano de obra de un responsable de circulación en esta tarea. La tarifa aplicada a cada solicitud de prestación del servicio es de $18,18 €$, a lo que se aplica el IVA. Solicitud significa toda aquella que también implique la introducción de un nuevo mensaje, incluso si es igual contenido pero en un idioma diferente o una alteración de los mensajes existentes en el sistema.

Para los servicios de megafonía corresponde a la inserción de 90 segundos, por anuncio / mensaje y por parada de estación, que se tarifica de acuerdo con el valor de la mano de obra de un responsable de circulación. La tarifa aplicada a cada solicitud de prestación del servicio de anuncio es de 0,68 $€$, a lo que se aplica el IVA. 
3.4 Estudio comparativo detallado de los cánones aplicados por uso de estaciones de viajeros en España y Francia.

$$
\text { España - ADIF. }
$$

Las estaciones están gestionadas por la Dirección General de Negocio y Operaciones Comerciales perteneciente al organigrama del administrador de infraestructuras español.

Las estaciones de transporte de viajeros 10 están clasificadas en 6 categorías, las 5 primeras categorías corresponden con aquellas que prestan servicios interurbanos o de larga distancia. La clasificación de este grupo de estaciones es resultado de la aplicación de la siguiente fórmula:

$$
C=\sum_{i=1}^{5}(K i \cdot P i)
$$

La categoría de la estación se determina en función del valor C, perteneciendo a la categoría 1 las estaciones con valores $C>4$, a la categoría 2, las estaciones con valores C entre 3 y 4 , y así sucesivamente.

Son estaciones de categoría 6 las que no pertenecen a ninguna de las anteriores (no prestan servicios de larga distancia) o bien su índice $C<1,3$.

Para la obtención del valor de C se evalúan 5 criterios que determinan el valor Ki para posteriormente ponderarlos por el valor Pi:

1) Número de viajeros subidos/bajados de la estación.

2) Número de trenes con parada en la estación.

3) Tamaño de la estación, en función de los metros cuadrados de las áreas de uso público de la estación.

4) Intermodalidad de la estación, en función del número de enlaces con otros medios de transporte.

5) Ubicación y número de andenes.

\footnotetext{
10 Se identifican como Estaciones de Viajeros las estaciones que tienen parada comercial de trenes de transporte de viajeros.
} 
La tabla siguiente presenta los valores del índice $K$ en función de los diferentes parámetros:

\begin{tabular}{|c|c|c|c|c|c|c|}
\hline Criterio & $K=1$ & $K=2$ & $K=3$ & $K=4$ & $K=5$ & $\begin{array}{c}\text { Valor } \\
\mathrm{Pi}\end{array}$ \\
\hline \multirow{4}{*}{ Número de viajeros $(V)$} & $\begin{array}{c}\text { Viajeros larga distancia } \\
\text { e interurbanos }\end{array}$ & $\begin{array}{c}\text { Viajeros larga distancia } \\
\text { e interurbanos }\end{array}$ & $\begin{array}{c}\text { Viajeros larga distancia } \\
\text { e interurbanos }\end{array}$ & $\begin{array}{c}\text { Viajeros larga distancia } \\
\text { e interurbanos }\end{array}$ & $\begin{array}{c}\text { Viajeros larga distancia } \\
\text { e interurbanos }\end{array}$ & \multirow{4}{*}{0,30} \\
\hline & $V<150$ & $150<=V<750$ & $750<=V<2.000$ & $2.000<=V<10.000$ & $V>10.000$ & \\
\hline & Total viajeros & Total viajeros & Total viajeros & Total viajeros & Total viajeros & \\
\hline & $V<400$ & $400<=V<7.500$ & $7.500<=V<20.000$ & $20.000<=V<100.000$ & $V>100.000$ & \\
\hline Número de trenes $(\mathrm{T})$ & $T<25$ & $25<=\mathrm{T}<85$ & $85<=T<190$ & $190<=\mathrm{T}<500$ & $T>500$ & 0,25 \\
\hline Tamaño de la estación (S) & $S<2.500$ & $2.500<=S<5.000$ & $5.000<=S<10.000$ & $10.000<=S<50.000$ & $S>50.000$ & 0,25 \\
\hline Intermo-dalidad (I) & $\begin{array}{c}1<3 \\
\text { sin información } \\
\text { dedicada }\end{array}$ & $\begin{array}{c}\mid>=3 \\
\text { sin información } \\
\text { dedicada }\end{array}$ & $\begin{array}{c}I=4 \\
\text { con información } \\
\text { dedicada }\end{array}$ & $\begin{array}{c}1>4 \\
\text { con información } \\
\text { dedicada }\end{array}$ & $\begin{array}{c}1>4 \\
\text { con información } \\
\text { dedicada y tratarse } \\
\text { de un intercambiador }\end{array}$ & 0,10 \\
\hline $\begin{array}{l}\text { Ubicación y número } \\
\text { de andenes (U) }\end{array}$ & Resto situaciones & $\begin{array}{c}\text { En lineas tipo B } \\
\text { y } n .^{\circ} \text { andenes }>=3\end{array}$ & $\begin{array}{l}\text { En lineas tipo } A \\
\text { y } n .{ }^{\circ} \text { andenes }>=2\end{array}$ & $\begin{array}{l}\text { En capital provincia } \\
\text { o de Comunidad } \\
\text { Autónoma } \\
\text { yn. }{ }^{\circ} \text { andenes }>=2\end{array}$ & $\begin{array}{l}\text { En lineas tipo A } \\
\text { y capital provincia } \\
\text { o de Comunidad } \\
\text { Autónoma }\end{array}$ & 0,10 \\
\hline
\end{tabular}

Tabla 15. Valores de índice "K" para la clasificación de estaciones. Fuente: ADIF.

\section{Canon por servicios básicos.}

Se consideran aquellos servicios que se prestan y que se relacionan a continuación:

a) Las estaciones de transporte de viajeros, así como sus edificios e instalaciones conexas, incluidos los paneles de información sobre itinerarios y viajes así como los emplazamientos propios para la venta de billetes.

b) Las instalaciones técnicas y logísticas de mercancías.

c) Las estaciones de clasificación y las instalaciones de formación de trenes, incluidas las instalaciones para maniobras.

d) Las vías de apartado.

e) Las instalaciones de mantenimiento de los vehículos ferroviarios, a excepción de las instalaciones de mantenimiento pesado dedicadas a trenes de alta velocidad o a otros tipos de material rodante que requieran instalaciones específicas.

f) Otras instalaciones técnicas, tales como las instalaciones de lavado y limpieza.

g) Las instalaciones portuarias vinculadas a actividades ferroviarias. 
h) Las instalaciones de protección y socorro.

i) Las instalaciones de aprovisionamiento y suministro de combustible en dichas instalaciones.

j) Cambiadores de ancho y de ejes. Esta prestación no es obligatoria, siendo las disposiciones aplicables únicamente cuando el servicio sea ofrecido por el explotador.

Estos servicios se ofrecen de manera no discriminatoria a cualquier empresa ferroviaria o candidato que los solicite siendo su prestación recogidos en la siguiente clasificación, según el ámbito de aplicación de estos:

- Adjudicación de capacidad en las instalaciones que componen las Estaciones de Transporte de Viajeros: Vías, de apartado, de formación, maniobras, para otras operaciones comerciales en vías con andén y en vías sin andén, etc.

- Suministro de combustible.

- Acceso a los edificios y andenes en las Estaciones de Transporte de Viajeros (comprende la utilización por parte de los viajeros de las instalaciones comunes de las estaciones, accesos, vestíbulos, áreas de espera, etc.), así como los servicios de información, seguridad, confort, mantenimiento, limpieza, etc.

- Uso de soportes de información para viajes.

- Local para la prestación del servicio de venta de billetes e información.

- Espacio para elementos de ticketing.

- Locales para personal operativo de servicios a bordo de los trenes.

Canon por servicios complementarios.

Son servicios que se prestan para facilitar el funcionamiento del sistema ferroviario teniendo en cuenta que si el explotador de la instalación de servicio presta como servicios complementarios cualquiera de los servicios siguientes deberá prestarlos de manera no discriminatoria a cualquier empresa ferroviaria que los solicite. Estos servicios son el suministro de corriente de tracción, el precalentamiento de trenes de viajeros y contratos personalizados para control del transporte de mercancías peligrosas y asistencia a la circulación de convoyes especiales.

Actualmente no se ofertan estos servicios en el ámbito de las terminales de transporte de mercancías ni en el ámbito de las estaciones de transporte de viajeros gestionadas por ADIF. 
Canon por servicios auxiliares.

Son servicios que pueden solicitar las empresas ferroviarias al administrador o a otros prestadores.

El explotador de la instalación de servicio no tendrá obligación de prestar dichos servicios, pero si ofrece su realización a alguna empresa ferroviaria, deberá prestarlos de manera no discriminatoria a cualquier empresa ferroviaria que los solicite.

Los servicios auxiliares se prestan en las instalaciones de servicio, titularidad de ADIF a las empresas ferroviarias y otros candidatos y bajo el régimen de Derecho privado. Podrá prestar los servicios auxiliares recogidos en la siguiente clasificación:

- Espacios para efímeros, en los que la empresa ferroviaria podrá instalar este tipo de elementos, como expositores de estructura flexible, mostradores móviles u otros elementos similares. Los espacios destinados a este uso no están identificados en los planos de servicios comerciales a empresas ferroviarias y se analizan sus necesidades a través de sus peticiones. Para este tipo de elementos se procede su asignación según las posibilidades de la estación y criterios de prioridad.

- Espacios en andenes para equipamientos móviles de las empresas ferroviarias, como maquinaria de limpieza, plataformas de atención a personas con movilidad reducida, carretillas $u$ otros equipamientos para el catering y otros elementos similares para facilitar las operaciones en andenes. Para todas las empresas que lo solicitan se dimensiona el espacio a ocupar de forma proporcional a su volumen de negocio, medido por el número de trenes con parada en la estación. Para la adjudicación de los espacios se hace un reparto proporcional al número de trenes con parada en la estación de cada empresa, teniendo preferencia en la elección de los espacios la empresa con más trenes con parada en la estación.

- Punto de embarque equipado, con elementos tipo mostrador o similar que permite desarrollar los servicios a viajeros de control de acceso y embarque a trenes. Incluye el equipamiento y soporte informático necesario para conectarse a sus propios sistemas. El administrador de infraestructuras ferroviarias pone a disposición los distintos elementos para prestar estos servicios. 
Los espacios habilitados disponen de, al menos, una toma eléctrica para conexión de equipos informáticos, pantalla de ordenador para suministro de información, lector de código de barras, conexión para emisión de mensajes por megafonía local y conectividad para la conexión a sus propios sistemas.

- Punto de atención de última hora, tipo mostrador o similar destinados a desarrollar servicios por las EE. FF. de atención a clientes para servicios de asistencia de última hora. Incluye conectividad a sus propios sistemas. Las dimensiones del espacio a ocupar se establecen de forma proporcional a su volumen de negocio, medido por el número de trenes con parada en la estación. Para la adjudicación de los espacios se hace un reparto proporcional al número de trenes con parada en la estación teniendo preferencia en la elección de los espacios, la empresa con más trenes con parada en la estación. La solicitud se realiza junto con la solicitud de capacidad. En caso de que alguna empresa ya disponga, a la hora de hacer la solicitud de nuevos espacios, locales y/o servicios, de alguno consolidado por estar prestando servicio previamente, estos elementos se tienen en cuenta en las nuevas asignaciones, en el porcentaje que representen. Una vez asignado el servicio, los contratos establecidos al efecto con las empresas se considerarán criterios de prioridad de cara a nuevas solicitudes de otras.

- Taquillas en vestuario de uso compartido. Incluye el uso de las instalaciones y equipamientos comunes disponibles en el vestuario, que pueden compartirse con personal de otras empresas o del propio administrador. Para todas las empresas que lo soliciten las dimensiones del espacio a ocupar se calcula de forma proporcional a su volumen de negocio, medido por el número de trenes con parada en la estación. Para la adjudicación de las taquillas se hace un reparto proporcional al número de trenes con parada en la estación, teniendo preferencia en la adjudicación de espacios donde se sitúen la empresa con más trenes con parada en la estación. La solicitud de servicios se realiza junto con la solicitud de capacidad. En caso de que alguna empresa, a la hora de hacer la solicitud de nuevos espacios, locales y/o servicios, ya dispusiera de alguno consolidado por estar prestando servicio previamente, estos elementos se tendrán en cuenta en las nuevas asignaciones, en el porcentaje que representen. Una vez asignado el servicio, los contratos establecidos al efecto se consideran criterios de prioridad de cara a nuevas solicitudes. 
- Gestión de objetos perdidos, ADIF dispone en determinadas estaciones de un servicio de recogida de objetos perdidos encontrados en trenes que pondrá a disposición de las empresas ferroviarias.

Este servicio compatibilizará recursos y medios con el servicio de objetos perdidos propio de la estación y está disponible para todas las empresas que lo soliciten y tengan parada comercial en la estación.

- Salas VIP, en virtud de la demanda y dependiendo de la disponibilidad de locales para desarrollar la actividad en cada estación, Adif ofrece un servicio de Sala VIP gestionado por medios propios, o a través de terceros, en igualdad de condiciones a todas las empresas. Complementariamente se puede establecer contrato de alquiler de local a una empresa., en régimen comercial, para que la misma pueda ofrecer este servicio a sus clientes.

En las salas gestionadas por el administrador se facilita el acceso todas las empresas que lo soliciten, proporcionalmente al número de usuarios previamente acordado con cada empresa ferroviaria y a su volumen de negocio, medido en base al número de trenes con parada en la estación.

La solicitud de servicios se realiza junto con la solicitud de capacidad. En caso de que alguna E.F, a la hora de hacer la solicitud de nuevos espacios, locales y/o servicios, ya dispusiera de alguno consolidado por estar prestando servicio previamente, estos elementos se tendrán en cuenta en las nuevas asignaciones, en el porcentaje que representen.

Régimen tarifario.

\section{Por uso de estaciones}

El servicio se tarifica teniendo en cuenta la clasificación de la estación y el tipo de parada que efectúan las composiciones. Existen 6 categorías en total, perteneciendo a la categoría 6 las estaciones de cercanías, siendo su importe tarificado mensualmente por núcleo de cercanías donde este ubicada la estación, independientemente del número de circulaciones. En las tablas siguientes se muestra el canon establecido por uso de estaciones y categoría de la estación. 
Tanifa Canon por Utilización Estaciones de Viajeros Categoría 6

\begin{tabular}{|c|r|}
\hline Núcleo & Importe Mensual ( $\boldsymbol{)}$ \\
\hline Asturias & 12.851 \\
\hline Barcelona & 146.857 \\
\hline Bilbao & 29.945 \\
\hline Cádiz & 1.228 \\
\hline Madrid & 358.874 \\
\hline Málaga & 21.413 \\
\hline Murcia & 1.282 \\
\hline San Sebastián & 24.542 \\
\hline Santander & 1.630 \\
\hline Sevilla & 9.498 \\
\hline Valencia & 13.127 \\
\hline
\end{tabular}

Tabla 16. Canon por uso de estaciones Categoría 6. Fuente: ADIF.

\begin{tabular}{|c|c|c|c|c|}
\hline \multirow[t]{2}{*}{ Clasificación } & Parada & $\begin{array}{c}\text { Nacional / } \\
\text { Internacional }\end{array}$ & Interurbano & Urbano \\
\hline & \multicolumn{4}{|c|}{$€$ Parada Tren } \\
\hline \multirow{3}{*}{1} & DESTINO & 164,00 & 33,7842 & 8,1082 \\
\hline & INTERMEDIA & 63,78 & 13,1383 & 3,1532 \\
\hline & ORIGEN & 182,22 & 37,538 & 9,0091 \\
\hline \multirow{3}{*}{2} & DESTINO & 78,11 & 16,0904 & 3,8617 \\
\hline & INTERMEDIA & 30,38 & 6,2574 & 1,5018 \\
\hline & ORIGEN & 86,79 & 17,8782 & 4,2908 \\
\hline \multirow{3}{*}{3} & DESTINO & 75,2111 & 15,0422 & 3,6101 \\
\hline & INTERMEDIA & 29,2487 & 5,8497 & 1,4039 \\
\hline & ORIGEN & 83,5678 & 16,7136 & 4,0113 \\
\hline \multirow{3}{*}{4} & DESTINO & 33,483 & 6,6966 & 1,6072 \\
\hline & INTERMEDIA & 13,0212 & 2,6042 & 0,625 \\
\hline & ORIGEN & 37,2034 & 7,4407 & 1,7858 \\
\hline \multirow{3}{*}{5} & DESTINO & 13,4793 & 2,6959 & 0,647 \\
\hline & INTERMEDIA & 5,2419 & 1,0484 & 0,2516 \\
\hline & ORIGEN & 14,977 & 2,9954 & 0,7189 \\
\hline
\end{tabular}

Tabla 17. Canon por uso de estaciones de viajeros categorías 1 a 5. Fuente: ADIF. 


\section{Por uso de cambiadores de ancho.}

La cuantía se calcula mediante el producto de la tarifa unitaria por el número de pasos por la instalación.

\section{Tarifa Canon por Paso por Cambiadores de Ancho, Modalidad B}

$€ /$ Por Paso

$134,82 €$

Tabla 18. Canon por uso de cambiador de ancho. Fuente: ADIF.

Por uso de andenes para el estacionamiento de trenes para servicios comerciales de viajeros y otras operaciones.

Están establecidas dos tarifas:

- Por estacionamiento de trenes para servicios comerciales de viajeros sin otras operaciones: Establecidos 15 minutos durante el cual el canon no es aplicable.

A los efectos de cómputo del tiempo de estacionamiento en andenes no se consideran las paradas intermedias de un trayecto comercial, ni aquellos en los que el administrador decida la permanencia del tren en la vía de estacionamiento por gestión de tráfico. La cuantía del canon es el resultante de aplicar a cada tren la tarifa unitaria por el tiempo del estacionamiento en función de la categoría de la estación.

Tarifas Canon por Estacionamiento de Trenes para Servicios Comerciales sin otras operaciones, Modalidad C. 1

Tipo de Estacionamiento

\begin{tabular}{|c|c|c|c|}
\hline \multirow{2}{*}{ Categoría de Estaciones } & A & B & C \\
\cline { 2 - 4 } & \multicolumn{3}{|c|}{$€ /$ Tren } \\
\hline 1 & 2,2458 & 3,3688 & 4,4917 \\
\hline 2 & 1,1229 & 1,6998 & 2,2458 \\
\hline
\end{tabular}

Tabla 19. Canon por estacionamiento en estaciones sin operaciones. Fuente: ADIF.

\begin{tabular}{|c|l|}
\hline \multicolumn{2}{|c|}{ Tipo de Estacionamiento } \\
\hline A & Por cada 5 minutos adicionales o fracción entre $15 \mathrm{~min}$. y $45 \mathrm{~min}$. \\
\hline B & Por cada 5 minutos adicionales o fracción entre $45 \mathrm{~min}$. y $120 \mathrm{~min}$. \\
\hline C & Por cada 5 minutos adicionales o fracción a partir de los $120 \mathrm{~min}$. \\
\hline
\end{tabular}

Tabla 20. Tipo de estacionamiento aplicado al canon por uso de andenes. Fuente: ADIF. 
- Por estacionamiento de trenes para otras operaciones (Limpieza del tren interior $y / o$ exterior, operaciones de carga y descarga de servicios a bordo, utilización de tomas de agua, utilización de instalaciones de combustible, utilización de tomas eléctricas, utilización de instalaciones de vaciado WC y de otras análogas). La cuantía del canon es la resultante de aplicar la tarifa unitaria, determinada en función de la categoría de la estación y del tipo de operación a realizar en el tren, al número de operaciones de cada tipo realizadas durante el tiempo de estacionamiento. Es de aplicación de forma independiente a la tarifa anterior por la realización de operaciones a trenes durante el tiempo de estacionamiento.

Las operaciones realizadas en el tren se clasifican en dos tipos:

- Tipo A: Limpieza del tren interior y/o exterior mínima (frontales y cristales de puertas y ventanas).

- Tipo B: Por operaciones de carga y descarga de servicios a bordo, utilización de tomas de agua, utilización de instalaciones de combustible, utilización de tomas eléctricas, utilización de instalaciones de vaciado WC y de otras análogas.

Tarifas Canon Estacionamiento de Trenes para Otras Operaciones, Modalidad C. 2

\begin{tabular}{|c|c|c|c|}
\hline Categoría Estación & & Operación & Euros \\
\hline \multirow{2}{*}{ Tipo A } & $1-2$ & Limpieza de tren & 0,6818 \\
\cline { 2 - 4 } & Resto & Limpieza de tren & 0,5681 \\
\hline \multirow{2}{*}{ Tipo B } & $1-2$ & Carga y descarga a bordo del tren & 0,6722 \\
\cline { 2 - 4 } & Resto & Carga y descarga a bordo del tren & 0,5601 \\
\hline Por otras operaciones & & & 0,3947 \\
\hline
\end{tabular}

Tabla 21. Canon por estacionamiento para otras operaciones. Fuente: ADIF. 
Canon por Utilización de vías en otras instalaciones de servicio: de apartado, de formación de trenes y maniobras, de mantenimiento, lavado y limpieza, de suministro de combustible.

Los costes repercutibles en esta modalidad son los directamente imputables a la utilización de las vías en concepto de mantenimiento y reposición de las instalaciones. Se establece según tiempo de utilización de la vía de la instalación, de la vía con sus componentes básicos, como son la vía, la catenaria, los desvíos y el equipamiento adicional.

La cuantía de esta modalidad es la resultante de computar el importe por utilización de la vía completa autorizada, el importe asociado al equipamiento con el que está dotado esa vía y el importe del equipamiento opcional solicitado, aplicando el importe unitario de cada concepto por las unidades correspondientes, prorrateando para el periodo solicitado y afectado por el coeficiente de rendimiento en función del tiempo objeto de autorización (años, meses, días, horas), según la fórmula siguiente:

$$
\begin{gathered}
\text { Canon }=(C \text { base }+C \text { equipamiento }) \times T \times K \\
C_{\text {equipamiento }}=\left(\sum_{i=1}^{n} L_{i} * \text { Cequipamientos lineales } i\right)+\left(\sum_{i=1}^{n} n_{i}^{\mathbf{0}} * \text { equipamientos puntuales } i\right)
\end{gathered}
$$

Siendo:

$\mathrm{C}$ base $=\left(\right.$ Longitud de la vía $\left.\times \mathrm{C}_{\text {vía }}\right)+\left(\right.$ Longitud de catenaria $\left.\times \mathrm{C}_{\text {catenaria }}\right)+$ (n. ${ }^{\circ}$ desvíos $\times$ Cdesvio) .

$\mathrm{T}=\mathrm{N} .^{\circ}$ de años autorizados para periodos anuales.

$\mathrm{T}=\mathrm{N} .^{\circ}$ de meses autorizados $/ 12$ para periodos mensuales.

$\mathrm{T}=\mathrm{N} .^{\circ}$ de días autorizados $/ 365$ para periodos por días.

$\mathrm{T}=\mathrm{N} .^{\circ}$ de horas autorizadas $/ 8760$ para periodos por horas .

$\mathrm{K}=$ Coeficiente de rendimiento, que permite la aplicación de descuentos/recargos en función del tiempo objeto de autorización. 


\begin{tabular}{|c|c|}
\hline Período de uso continuado & Coeficiente de rendimiento K \\
\hline Por 4 años & 0,96 \\
\hline Por 3 años & 0,97 \\
\hline Por 2 años & 0,98 \\
\hline Por 1 año & 1,00 \\
\hline Por meses & 1,5 \\
\hline Periodo de uso puntual & Coeficiente de rendimiento K \\
\hline Por días & 2,00 \\
\hline Por horas & 2,50 \\
\hline
\end{tabular}

Tabla 22. Coeficiente de rendimiento K. Fuente: ADIF.

Canon por Utilización Vías de Apartado y Otros, Modalidad D

\begin{tabular}{|l|c|}
\hline \multicolumn{2}{|l|}{ Componentes base } \\
\hline C Vía & 5,402 euros/m de vía-año \\
\hline C Catenaria & 1,826 euros/m de catenaria-año \\
\hline C Desvío Tipo I (manual) & 564,755 euros/ud.-año \\
\hline C Desvío Tipo II (tele mandado) & $2.165,954$ euros/ud.-año \\
\hline
\end{tabular}

Tabla 23. Canon por componentes por uso de vías de apartado. Fuente: ADIF.

\begin{tabular}{|l|r|r|r|r|r|}
\hline & \multicolumn{5}{|c|}{$€ / \mathrm{m} 2 / \mathrm{mes}$} \\
\hline Categoría estación & \multicolumn{1}{|c|}{$\mathbf{1}$} & \multicolumn{1}{c|}{$\mathbf{2}$} & $\mathbf{3}$ & $\mathbf{4}$ & $\mathbf{5}$ \\
\hline Uso de soportes de información de viajes... & 3,73 & 3,73 & 3,73 & 3,73 & ---- \\
\hline $\begin{array}{l}\text { Local para venta de billetes e } \\
\text { información. }\end{array}$ & 19,69 & 16,54 & 12,79 & 9,90 & 5,58 \\
\hline $\begin{array}{l}\text { Locales para el personal operativo de } \\
\text { servicios a bordo }\end{array}$ & 11,81 & 9,93 & 7,67 & 5,94 & ---- \\
\hline & \multicolumn{5}{|c|}{$€ /$ mes/máquinas } \\
\hline Categoría estación & $\mathbf{1}$ & $\mathbf{2}$ & $\mathbf{3}$ & $\mathbf{4}$ & $\mathbf{5}$ \\
\hline Espacio para ticketing. & 210 & 151 & 105 & 75 & 54 \\
\hline
\end{tabular}

Tabla 24. Precios de los servicios básicos en estaciones de viajeros. Fuente: ADIF. 


\begin{tabular}{|c|c|c|c|c|c|}
\hline \multirow{2}{*}{ Espacios } & \multicolumn{4}{|c|}{ CATEGORIA DE LA ESTACIÓN } & \multirow{2}{*}{ Unidad } \\
\hline & 1 & 2 & 3 & 4 & \\
\hline \multirow{2}{*}{$\begin{array}{l}\text { Espacio para } \\
\text { efímeros }\end{array}$} & 746,25 & 537,75 & 477,75 & 298,50 & $\begin{array}{c}\text { HASTA } 4 M 2 \\
€ / M E S\end{array}$ \\
\hline & $1.243,75$ & 896,25 & 796,25 & 497,50 & $\begin{array}{c}\text { HASTA } 8 M 2 \\
€ / M E S\end{array}$ \\
\hline $\begin{array}{l}\text { Espacio en } \\
\text { andenes para } \\
\text { equipamientos }\end{array}$ & 1,77 & 1,49 & 1,15 & 0,89 & $€ / M 2$ / MES \\
\hline $\begin{array}{l}\text { Punto de } \\
\text { embarque } \\
\text { equipado }\end{array}$ & 40,00 & 40,00 & 40,00 & 40,00 & $\begin{array}{c}€ / M E S / \\
\text { MOSTRADOR }\end{array}$ \\
\hline $\begin{array}{l}\text { Punto atención } \\
\text { última hora }\end{array}$ & 20,00 & 20,00 & 20,00 & 20,00 & $\begin{array}{c}€ / M E S / \\
\text { MOSTRADOR }\end{array}$ \\
\hline $\begin{array}{l}\text { TAQUILLAS EN } \\
\text { VESTUARIO } \\
\text { COMPARTIDO }\end{array}$ & 15,00 & 15,00 & 15,00 & 15,00 & $\begin{array}{c}\text { MES / } \\
\text { TAQUILLA }\end{array}$ \\
\hline OBJETOS PERDIDOS & 550,00 & 300,00 & 175,00 & 125,00 & $€ / M E S$ \\
\hline
\end{tabular}

Tabla 25. Precios por servicios auxiliares. Fuente: ADIF. 
Francia-SNCF.

Las tarifas vinculadas en relación con las instalaciones de servicio de la red ferroviaria se establecen anualmente por SNCF Reseau y por SNCF Mobilités Gares \& Connexions. SNCF Mobilités Gares \& Connexions es subsidiaria de SNCF Réseau, con autonomía organizacional y financiera, constituida como sociedad anónima desde el 1 de enero de 2020 y garantiza la gestión unificada de las estaciones de viajeros junto a SNCF Réseau. Como objetivo es cubrir todos los costes previstos correspondiente a la prestación de los servicios en cada una de las áreas de gestión de estaciones.

Canon por servicios básicos.

Este canon es aplicado según el perímetro de gestión. Existen 56 perímetros agrupados en cinco categorías:

-Perímetro "TGA":

- Definido en base por el número de viajeros durante 2016 con más de 7 millones.

-Perímetro "A TVG":

- Estaciones con frecuencia mayor del $75 \%$ de trenes de alta velocidad y con menos del $50 \%$ de circulaciones de trenes regionales;

-Perímetro "a" de gestión para el conjunto funcional de otras estaciones por región.

-Perímetro "b", estaciones con servicios de trenes regionales.

-Perímetro "c", estaciones con trenes de viajeros de interés local (cercanías).

Este canon está formado por tres componentes, un componente base, un componente por uso de andenes y un componente por uso de puertas de embarque. Existe la excepción aplicada a las empresas que utilizan las infraestructuras que cruzan el Canal de la Mancha.

El componente por uso de puertas de embarque es aplicado de acuerdo con el número de títulos de transporte validados en los controles de acceso, es decir, por el número de viajeros que acceden a la estación como punto de origen del viaje. El precio es establecido según el área de gestión y determinado por los costes de inversión en equipos, equipamiento de información, mantenimiento y gestión del programa y los gastos de limpieza. 
Canon por servicios complementarios.

Este canon se fija de acuerdo con la ubicación del espacio donde se va a desarrollar la actividad. Las tarifas son aplicadas a todas las empresas ferroviarias, en las mismas condiciones y no están sujetos a negociación. Estas tarifas incluyen todos los costes aplicables y son aprobadas por ARAFER ${ }^{11}$ de forma anual. Estos costes se establecen a partir de una previsión de gastos según las actividades desarrolladas en las áreas como son la limpieza, servicio de seguridad, mantenimiento de ascensores y escaleras mecánicas, y según el programa de inversiones previstas para la propia estación. Para poder asignar los costes, las estaciones se encuentran estructuradas en zonas dependiendo su uso y finalidad.

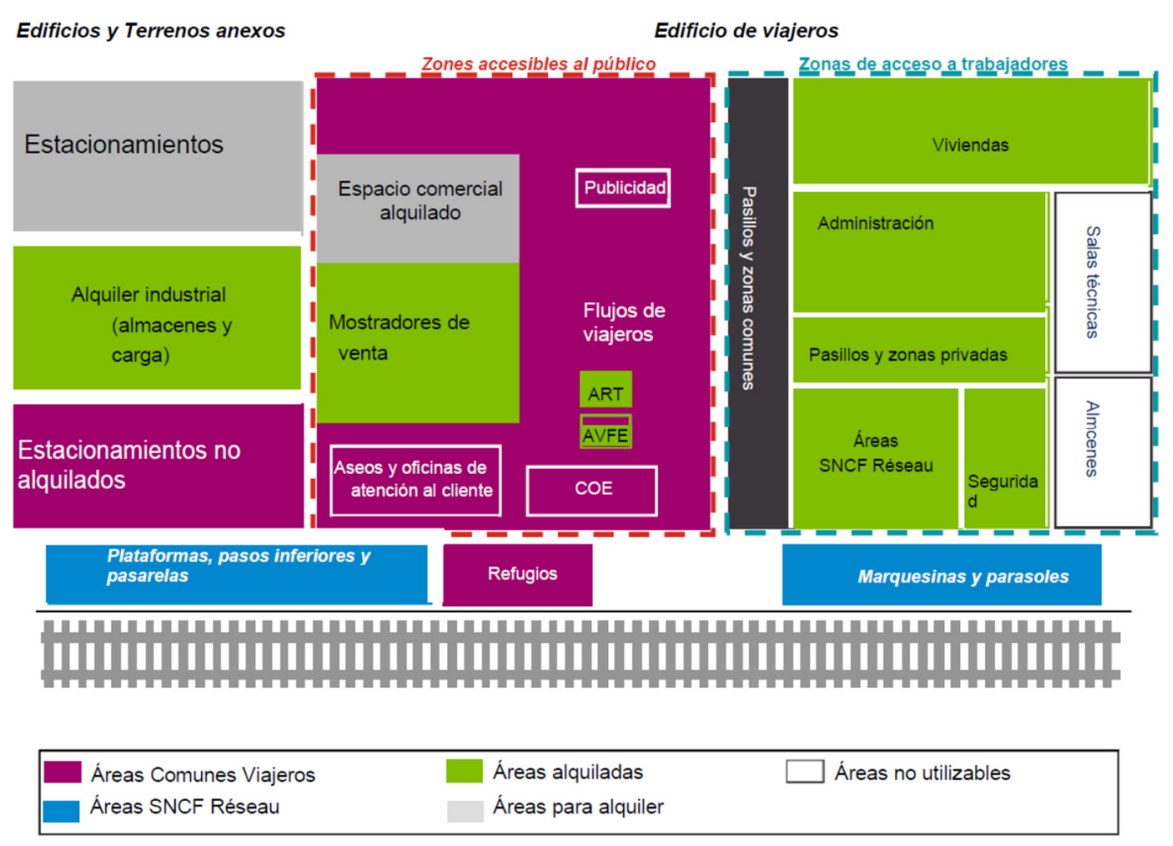

Gráfico 8. Distribución de áreas en una estación según SNCF.

Esta división permite definir superficies y poder asignar los costes correspondientes a imputar a cada agente interviniente.

Los activos fijos se clasifican por edificio y se asignan a cada estación para ser aplicados sus costes por $\mathrm{m}^{2}$ de superficie usado o prorrateado en el caso de superficies comunes.

11 Autorité de Régulation des Transports. 


\begin{tabular}{|c|c|c|c|c|c|c|c|c|c|}
\hline \multirow{3}{*}{ Área de Gestión } & \multicolumn{9}{|c|}{ Canon } \\
\hline & \multicolumn{2}{|c|}{ Otros trenes } & \multicolumn{2}{|c|}{$\begin{array}{l}\text { Trenes regionales } \\
\text { convencionales }\end{array}$} & \multirow[t]{2}{*}{ Área de Gestión } & \multicolumn{2}{|c|}{ Otros trenes } & \multicolumn{2}{|c|}{$\begin{array}{l}\text { Trenes regionales } \\
\text { convencionales }\end{array}$} \\
\hline & Base & Andenes & Base & Andenes & & Base & Andenes & Base & Andenes \\
\hline TGA AEROPUERTO CDG 2 TGV (excepto Transilien) & 151,24 & 16,57 & 84,02 & 16,57 & A NORMANDIE & 116,80 & 7,12 & 64,89 & 7,12 \\
\hline TGA AEROPUERTO CDG 2 TGV Transilien & & & 84,02 & 1,16 & A NOUVELLE AQUITAINE & 128,10 & 20,31 & 71,17 & 20,31 \\
\hline TGA BORDEAUX & 254,17 & 111,27 & 141,21 & 111,27 & A OCCITANIE & 112,48 & 11,21 & 62,49 & 11,21 \\
\hline TGA GRENOBLE & 112,21 & 9,85 & 62,34 & 9,85 & APACA & 79,59 & 4,19 & 44,22 & 4,19 \\
\hline TGA LILLE EUROPE & 282,35 & 18,70 & 156,86 & 18,70 & A PAYS DE LA LOIRE & 91,72 & 8,59 & 50,95 & 8,59 \\
\hline TGA LILLE FLANDRES & 120,83 & 12,16 & 67,13 & 12,16 & A TGV & 197,94 & 28,52 & 109,97 & 28,52 \\
\hline TGA LYON PART-DIEU & 106,10 & 8,89 & 58,94 & 8,89 & B AUV-RHONE ALPES & 19,11 & 3,43 & 10,62 & 3,43 \\
\hline TGA MARSEILLEST CHARLES & 190,73 & 11,07 & 105,96 & 11,07 & B BOURGOGNEFC & 32,00 & 4,44 & 17,78 & 4,44 \\
\hline TGA MONTPELLIER & 296,32 & 7,54 & 164,62 & 7,54 & B BREIAGNE & $\frac{15,42}{15,4}$ & 4,91 & 8,56 & 4,94 \\
\hline TGA NANCY & 125,72 & 5,58 & 69,85 & 5,58 & B CENTRE VAL DE LOIRE & 26,48 & 4,52 & 14,71 & 4,52 \\
\hline TGA NANTES & 145,80 & 15,74 & 81,00 & 15,74 & B GRAND EST & 14,57 & 3,80 & 8,09 & 3,80 \\
\hline TGA NICE & 163,18 & 36,36 & 90,65 & 36,36 & B HAUTS DE FRANCE & 19,75 & 3,39 & 10,97 & 3,39 \\
\hline TGA PARIS AUSTERLITZ & 959,96 & 85,25 & 533,31 & 85,25 & B ILE-DE-FRANCE & 21,98 & 1,39 & 12,21 & 1,39 \\
\hline TGA PARIS EST (excepto Transilien) & 310,82 & 32,93 & 172,68 & 32,93 & B NORMANDIE & 22,30 & 7,01 & 12,39 & 7,01 \\
\hline TGA PARIS EST Transilien & & & 172,68 & 13,48 & B NOUVELLE AQUITAINE & 25,40 & 8,74 & 14,11 & 8,74 \\
\hline TGA PARIS GAREDELYON - BERCY & 583,60 & 21,27 & 324,22 & 21,27 & B OCCIIANIE & 19,32 & 5,26 & 10,73 & 5,26 \\
\hline TGA PARIS MONTPARNASSE (excepto Transilien) & 397,19 & 21,29 & 220,66 & 21,29 & B PACA & 19,06 & 2,42 & 10,59 & $\frac{0,260}{2,42}$ \\
\hline TGA PARIS MONTPARNASSE Transilien & & & 220,66 & 5,06 & B PAYS DELA LOIRE & 13,96 & 4,94 & 7,76 & 4,94 \\
\hline TGA PARIS NORD (excepto Transilien) & 196,35 & 32,04 & 109,09 & 32,04 & C AUV-RHONE ALPES & 10,13 & 2,47 & 5,63 & 2,47 \\
\hline TGA PARIS NORD Transilien & 170,00 & & 109,09 & 8,39 & CBOURGOGNEFC & 7,82 & $\frac{2,47}{2,69}$ & $\frac{3,03}{4,35}$ & 2,69 \\
\hline TGA PARIS ST LAZARE (excepto Transilien) & 110,35 & 29,65 & 61,31 & 29,65 & CBRETAGNE & 4,55 & 2,48 & 2,53 & 2,48 \\
\hline TGA PARIS ST LAZARE Transilien & & & 61,31 & 6,46 & C CENTRE VAL DE LOIRE & 9,14 & 2,93 & 5,08 & 2,93 \\
\hline TGA RENNES & 166,27 & 16,74 & 92,37 & 16,74 & CGRAND EST & 5,82 & 2,43 & 3,23 & 2,43 \\
\hline TGA STRASBOURG & 108,18 & 9,40 & 60,10 & 9,40 & CHAUTS DE FRANCE & 7,07 & 2,70 & 3,93 & 2,70 \\
\hline TGA TOULOUSE & 238,84 & 12,36 & 132,69 & 12,36 & CILE-DE-FRANCE & 10,32 & 1,46 & 5,73 & 1,46 \\
\hline A AUV-RHONE ALPES & 126,08 & 10,12 & 70,04 & 10,12 & C NORMANDIE & 6,87 & 4,89 & 3,82 & 4,89 \\
\hline A BOURGOGNEFC & 94,31 & 7,94 & 52,40 & 7,94 & C NOUVELLE AQUITAINE & 6,99 & 3,18 & 3,88 & 3,18 \\
\hline A BRETAGNE & 96,51 & 8,93 & 53,62 & 8,93 & COCCITANIE & 9,36 & 3,71 & 5,20 & 3,71 \\
\hline A CENTRE VAL DELOIRE & 92,45 & 14,04 & 51,36 & 14,04 & CPACA & 7,33 & 2,76 & 4,07 & 2,76 \\
\hline A GRAND EST & 81,36 & 9,74 & 45,20 & 9,74 & CPAYS DE LA LOIRE & 7,75 & 3,82 & 4,30 & 3,82 \\
\hline A HAUTS DE FRANCE & 76,64 & 7,68 & 42,58 & 7.68 & & & & & \\
\hline
\end{tabular}

Tabla 26. Canon básico aplicado por uso de estaciones y andenes por SNCF. 


\subsection{Análisis crítico.}

Introducción.

Previo al análisis se realiza el estudio del sistema de cánones empleando primeramente las variables estudiadas en el estudio Charge4Rail 2017 realizado por Teixeira et al. (2017) para UIC, posteriormente tras la adición del canon respecto al uso de estaciones de viajeros, poder obtener un orden de magnitud de cada uno de ellos, sobre todo el de uso de estaciones de viajeros.

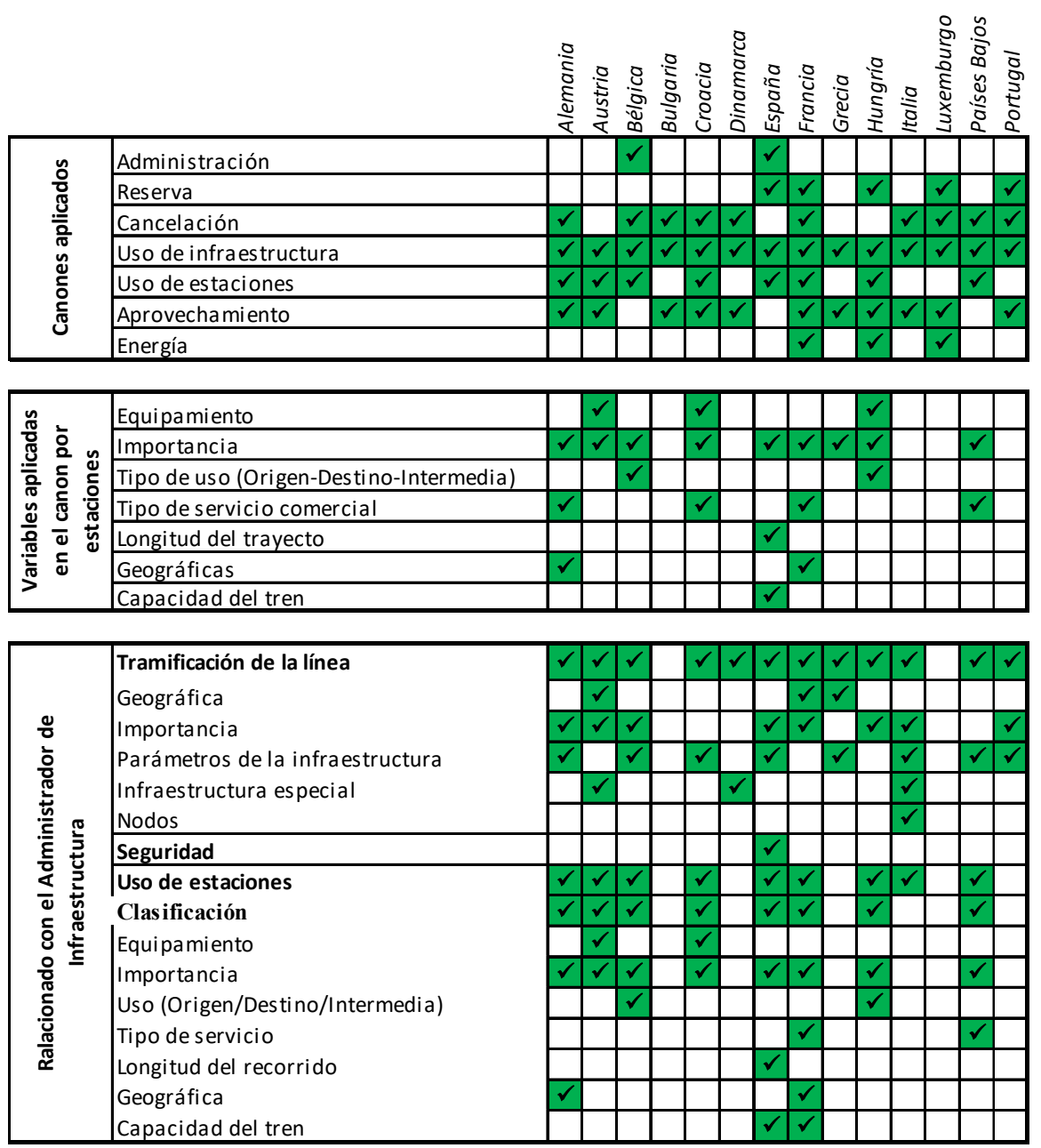

Tabla 27. (a) Cánones analizados por países (a). Fuente: UIC Charge4Rail (Teixeira et al. 2017). 


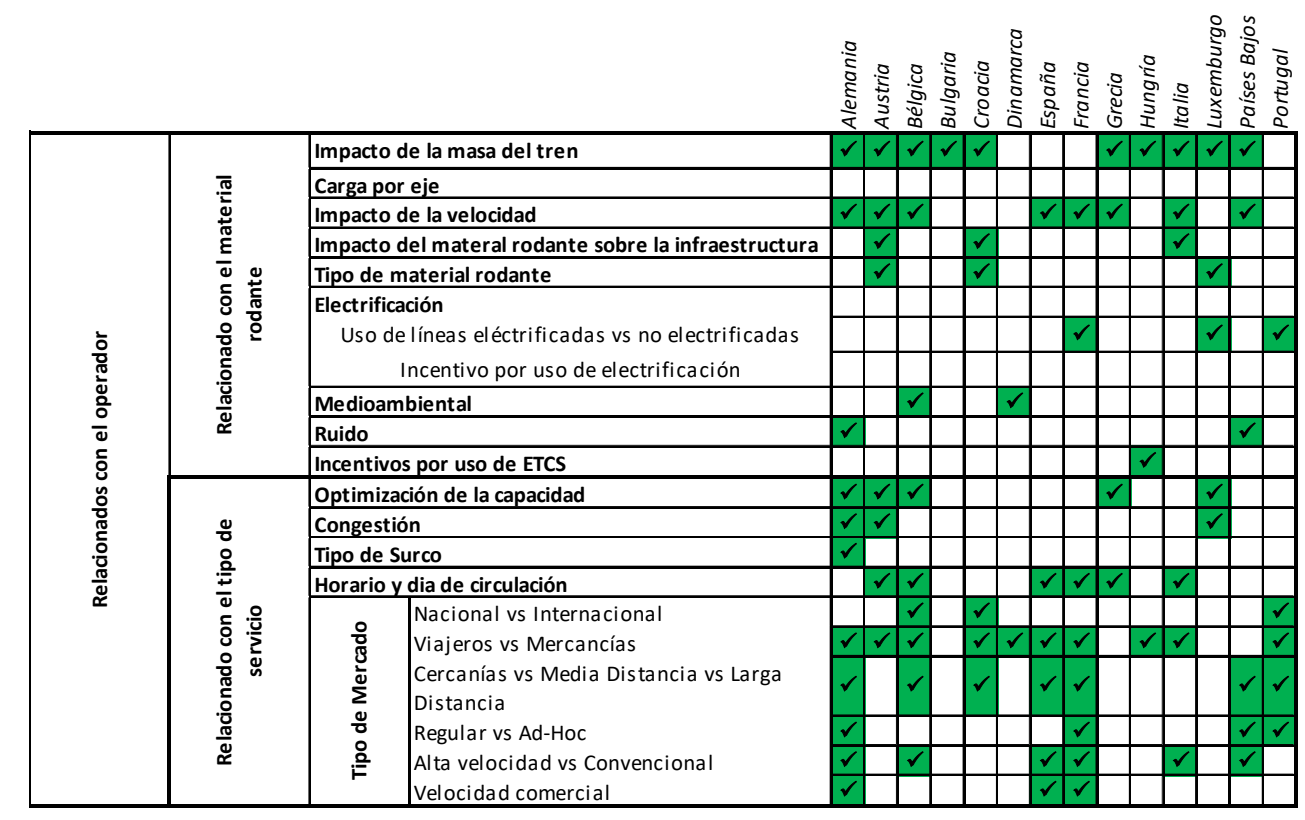

Tabla 28. (b) Cánones analizados por países (a). Fuente: UIC Charge4Rail (Teixeira et al. 2017).

Los cánones por uso de estaciones de viajeros están presentes en 9 de los 14 sistemas analizados siendo clasificadas en categorías a excepción de Italia que incluye el canon dentro del abonado por uso de la infraestructura. La variable más empleada es la de importancia de la estación siendo menor empleadas las clasificadas por equipamiento, uso, tipo de servicio o longitud de recorrido. Hay que destacar que los sistemas analizados de Francia y España muestran la mayor aplicación de variables para determinar el canon.

Es de reflexionar que los cargos que dependen del administrador de la infraestructura o del operador ferroviario presentan entre una y seis variables cada uno, lo que amplifica la complejidad a la hora de simplificar el sistema tarifario.

La estructura de los sistemas de tarificación empleados por los países aplica unos precios mínimos y máximos dependiendo de variables como son el tipo de tren, el tipo de línea, etc. 
De los 14 países estudiados 8 diferencian el precio según la clasificación por importancia de las estaciones, esta distinción permite comparar los precios de las estaciones a excepción de Bulgaria, Dinamarca Italia y Luxemburgo, que al contrario que los demás países que separan los cánones son aplicados directamente sobre el canon por uso de la infraestructura.

Rango de precios de parada según por categoría de estaciones

(€ parada)

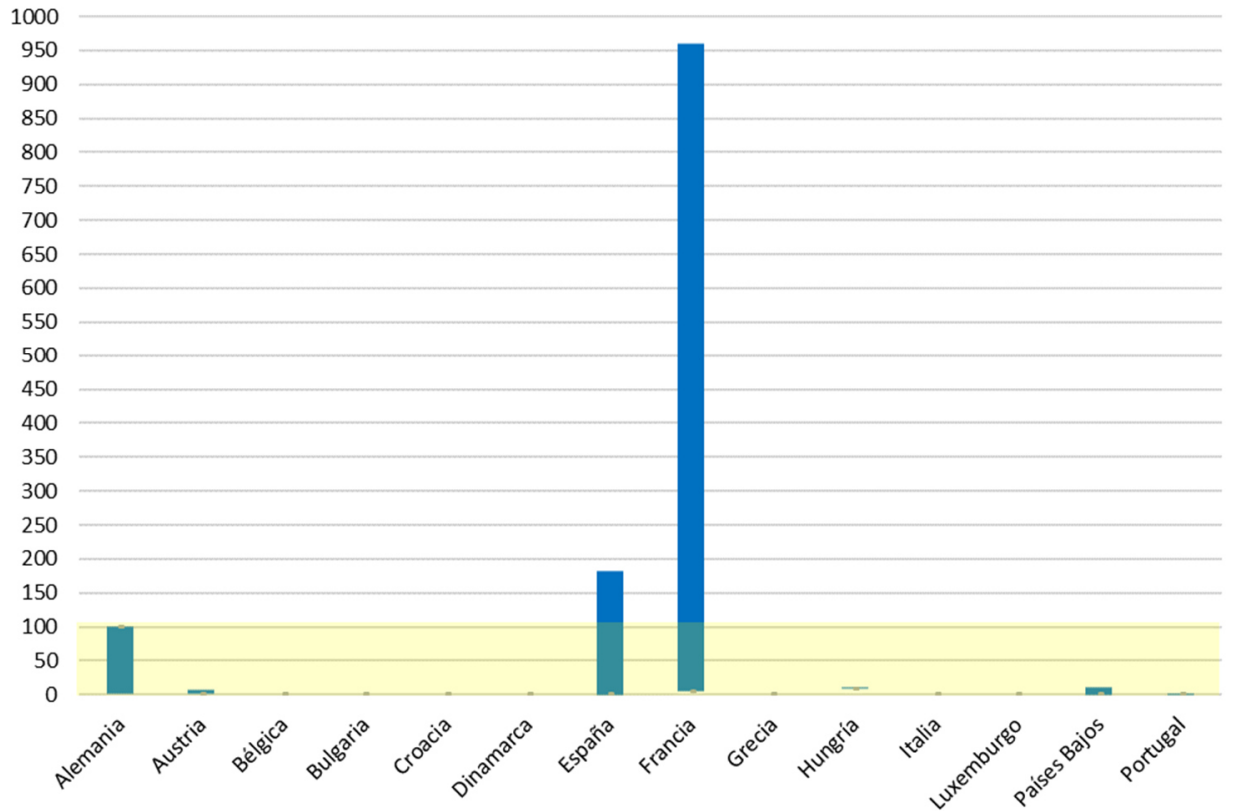

Gráfico 9. Rango de precios de parada por categoría de estaciones. Fuente: Declaraciones sobre la Red 2020. Elaboración propia.

De forma general en la comparación anterior se observa una gran diferencia de precio entre los países analizados, destacando notablemente los casos de España y Francia, donde el rango de precios es bastante más elevado. 
En el gráfico siguiente se muestra con detalle el resto de los países que debido al menor rango no es apreciada en la gráfica anterior:

Rango de precios de parada según por categoría de estaciones

(€ parada)

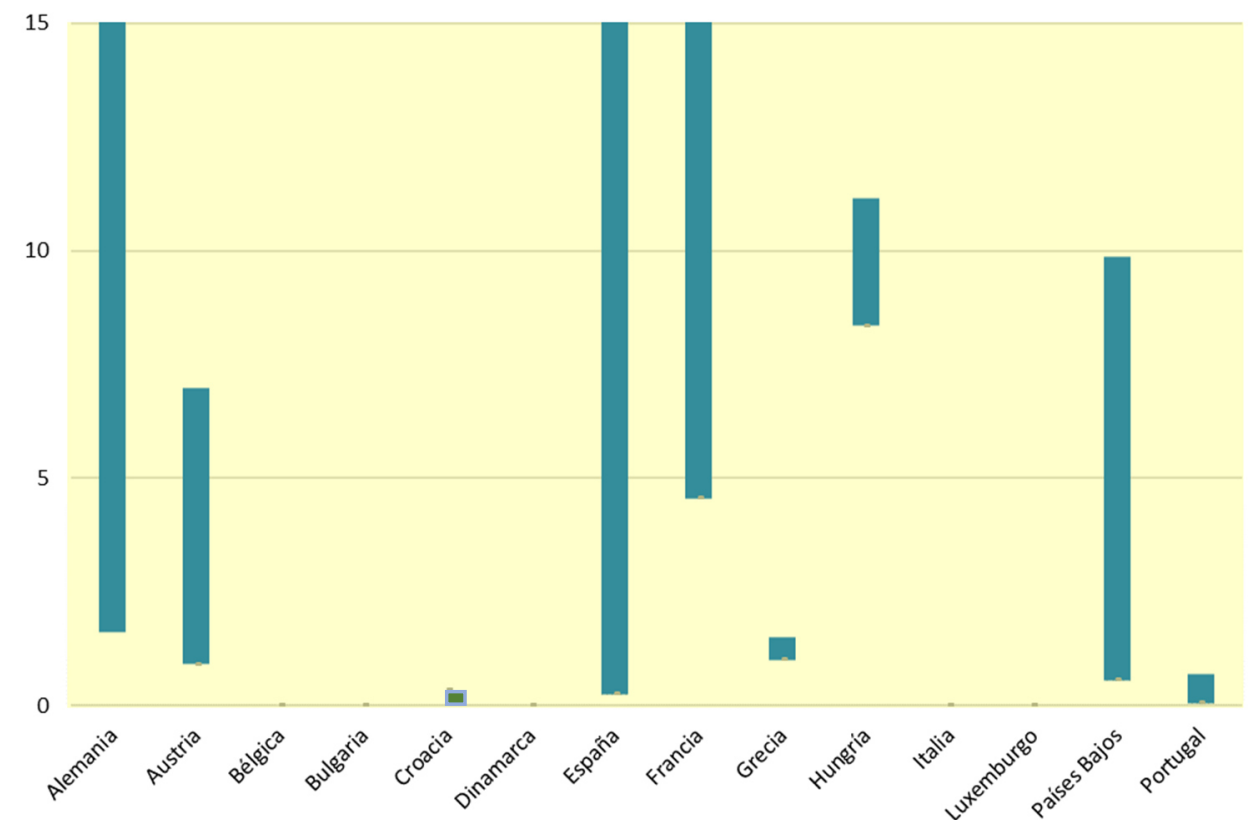

Gráfico 10. Detalle del rango de precios de parada por categoría de estaciones. Fuente: Declaraciones sobre la Red 2020. Elaboración propia.

Metodología.

La metodología utilizada en este estudio para elegir el conjunto de pares OD representativos sigue los criterios establecidos en el estudio UIC Charge4Rail de 2017, comparando circulaciones origen-destino tanto en líneas convencionales como en líneas de alta velocidad por separado.

Para la obtención del rendimiento de cada sistema empleado por país y poder realizar una comparación entre ellos se parte como modelo con los datos de una misma composición con las características correspondientes a un TGV Dúplex con 500 plazas, 200 metros de longitud y 447 toneladas de peso. 
Se han adoptado otros supuestos debido a la presencia de otras variables como son en el caso del número de plazas ocupadas. Se asume una ocupación del $65 \%$ lo que da una ocupación de 325 viajeros, en los países donde varía el canon dependiendo de la hora de circulación se toma como valor un horario de salida a las 8:00 y a las 18:00 horas, con el fin de obtener el canon por uso de infraestructura representativo.

Para la obtención de valores más comparables se han separado las circulaciones por líneas de convencionales y por líneas de alta velocidad.

\begin{tabular}{|c|c|c|c|c|c|c|c|}
\hline Origen-Destino & País & $\begin{array}{l}\text { Distancia } \\
\quad(\mathrm{km})\end{array}$ & $\begin{array}{c}\text { Uso de } \\
\text { Infraestructura }\end{array}$ & $\begin{array}{c}\text { Uso de } \\
\text { Estaciones }\end{array}$ & $\begin{array}{c}\text { Uso } \\
\text { Inst.Energía }\end{array}$ & Total & $€ \mathrm{~km}$ \\
\hline Vienna-Salzburg & AT & 311,7 & $1132.11 €$ & $15.81 €$ & $-€$ & $€ 1147.93 €$ & $3.68 €$ \\
\hline Sofia-Varna & BG & 543,6 & $518.40 €$ & $-€$ & $220.03 €$ & $€ 738.43 €$ & $1.36 €$ \\
\hline Prague-Brno & $\mathrm{CZ}$ & 253,8 & $255.10 €$ & $-€$ & $-€$ & $255,10 €$ & $1.01 €$ \\
\hline Copenhagen-Esbjerg & DK & 309,1 & $1130.23 €$ & $-€$ & $-€$ & $1130, .23$ & $3.66 €$ \\
\hline Tallinn-Narva & $\mathrm{EE}$ & 209,4 & $402.50 €$ & $-€$ & $-€$ & $€ \quad 402,50 €$ & $1.92 €$ \\
\hline Perpignan-Montpellier & FR & 158,8 & $807.34 €$ & $451.50 €$ & $84.64 €$ & $€ 1343.48 €$ & $8.46 €$ \\
\hline Helsinki-Turku & $\mathrm{Fl}$ & 193,0 & $116.87 €$ & $-€$ & $-€$ & $€ \quad 116.87 €$ & $0.61 €$ \\
\hline Freiburg Frankfurt & $\mathrm{DE}$ & 273,3 & $1764.30 €$ & $44.20 €$ & $-€$ & $€ 1808.50 €$ & $6.62 €$ \\
\hline Athens-Thessaloniki & GR & 493,4 & $715.78 €$ & $-€$ & $-€$ & $€ \quad 715.78 €$ & $1.45 €$ \\
\hline Budapest-Debrecen & $\mathrm{HU}$ & 219,0 & $350.06 €$ & $14.61 €$ & $40.89 €$ & $€ \quad 405.57 €$ & $1.85 €$ \\
\hline Belfast-Dublin & $\mathrm{IE}$ & 182,0 & $1438.69 €$ & $-€$ & $-€$ & $€ 1438.69 €$ & $7.90 €$ \\
\hline Bologna-Venice & IT & 182,7 & $600.87 €$ & $-€$ & $-€$ & $€ \quad 600.87 €$ & $3.29 €$ \\
\hline Riga-Rēzekne & LV & 219,4 & $1514.07 €$ & $-€$ & $-€$ & $€ 1514.07 €$ & $6.90 €$ \\
\hline Vilnius-Klaipeda & LT & 376,2 & $1692.37 €$ & $-€$ & $215.37 €$ & $€ 1907.75 €$ & $5.07 €$ \\
\hline Luxembourg & LU & 34,6 & $188.28 €$ & $-€$ & $5.68 €$ & $€ \quad 193.96 €$ & $5.61 €$ \\
\hline Oslo-Trondheim & NO & 551,8 & $114.75 €$ & $-€$ & $-€$ & $114.75 €$ & $0.21 €$ \\
\hline Warsaw-Katowice & $\mathrm{PL}$ & 319,1 & $477.63 €$ & $3.23 €$ & $-€$ & $480.85 €$ & $1.51 €$ \\
\hline Lisbon-Porto & PT & 336,4 & $709.28 €$ & $-€$ & $-€$ & $709.28 €$ & $2.11 €$ \\
\hline Bucharest-Timisoara & RO & 533,1 & $647.20 €$ & $0.44 €$ & $-€$ & $€ \quad 647.64 €$ & $1.21 €$ \\
\hline Barcelona-Valencia & ES & 343,8 & $1713.85 €$ & $643.11 €$ & $-€$ & $€ 2356.96 €$ & $6.86 €$ \\
\hline Gothenburg-Stockholm & SE & 457,0 & $639.78 €$ & $-€$ & $-€$ & $€ \quad 639.78 €$ & $1.40 €$ \\
\hline Geneva-Zurich & $\mathrm{CH}$ & 302,8 & $1211.17 €$ & $3.75 €$ & $-€$ & $€ 1214.92 €$ & $4.01 €$ \\
\hline Bratislava-Zilina & SK & 203,2 & $313.41 €$ & $1.04 €$ & $22.72 €$ & $€ \quad 337.16 €$ & $1.66 €$ \\
\hline Ljubljana-Maribor & SL & 155,8 & $161.79 €$ & $-€$ & $-€$ & $161.79 €$ & $1.04 €$ \\
\hline London-Newcastle & UK & 432,0 & $1099.56 €$ & $-€$ & $10.91 €$ & $€ 1110.48 €$ & $2.57 €$ \\
\hline Copenhagen-Stockholm & DK, & 729,2 & $1267.62 €$ & $-€$ & $-€$ & $€ 1267.62 €$ & $1.74 €$ \\
\hline Copenhagen-Malmo & DK, & 52,7 & $385.68 €$ & $-€$ & $-€$ & $€ \quad 385.68 €$ & $7.32 €$ \\
\hline
\end{tabular}

Tabla 29. Canon para circulaciones O-D en líneas convencionales por $\mathrm{km}$. Fuente: UIC Charge4Rail (Teixeira et al. 2017).

Los datos de este análisis muestran que la importancia del canon por uso de la infraestructura conformando la mayor parte de importe por kilómetro. El canon por uso de estaciones es insignificante mientras que el canon por uso de las instalaciones de energía de tracción representa una contribución importante en la tarifa total de infraestructura donde está presente ya que no es un canon común en los países estudiados. 
Las tarifas totales para cada circulación se han empleado para calcular el promedio del coste por kilómetro-tren de cada canon aplicado. En la tabla siguiente se observa la cuantía de cada uno:

\begin{tabular}{|c|c|c|c|c|c|c|}
\hline Origen-Destino & País & $\begin{array}{l}\text { Distancia } \\
(\mathbf{k m})\end{array}$ & $\begin{array}{c}\text { Uso de } \\
\text { Infraestructura }\end{array}$ & $\begin{array}{c}\text { Uso de } \\
\text { Estaciones }\end{array}$ & $\begin{array}{c}\text { Uso } \\
\text { Inst.Energía }\end{array}$ & $€ \mathrm{~km}$ \\
\hline Vienna-Salzburg & AT & 311,70 & 3,63 & 0,05 & & 3,68 \\
\hline Sofia-Varna & BG & 543,60 & 0,95 & & 0,40 & 1,36 \\
\hline Prague-Brno & $\mathrm{CZ}$ & 253,80 & 1,01 & & & 1,01 \\
\hline Copenhagen-Esbjerg & DK & 309,10 & 3,66 & & & 3,66 \\
\hline Tallinn-Narva & $\mathrm{EE}$ & 209,40 & 1,94 & & & 1,94 \\
\hline Perpignan-Montpellier & FR & 158,80 & 5,08 & 2,84 & 0,53 & 8,46 \\
\hline Helsinki-Turku & $\mathrm{Fl}$ & 193,00 & 0,61 & & & 0,61 \\
\hline Freiburg Frankfurt & DE & 273,30 & 6,46 & 0,16 & & 6,62 \\
\hline Athens-Thessaloniki & GR & 493,40 & 1,45 & & & 1,45 \\
\hline Budapest-Debrecen & $\mathrm{HU}$ & 219,00 & 1,60 & 0,07 & 0,19 & 1,85 \\
\hline Belfast-Dublin & $\mathrm{IE}$ & 182,00 & 7,90 & & & 7,90 \\
\hline Bologna-Venice & IT & 182,70 & 3,29 & & & 3,29 \\
\hline Riga-Rēzekne & LV & 219,40 & 6,90 & & & 6,90 \\
\hline Vilnius-Klaipeda & LT & 376,20 & 4,50 & & 0,57 & 5,07 \\
\hline Luxembourg & LU & 34,60 & 5,44 & & 0,16 & 5,61 \\
\hline Oslo-Trondheim & NO & 551,80 & 0,21 & & & 0,21 \\
\hline Warsaw-Katowice & $\mathrm{PL}$ & 319,10 & 1,50 & 0,01 & & 1,51 \\
\hline Lisbon-Porto & PT & 336,40 & 2,11 & & & 2,11 \\
\hline Bucharest-Timisoara & RO & 533,10 & 1,21 & 0,00 & & 1,21 \\
\hline Barcelona-Valencia & ES & 343,80 & 4,98 & 1,87 & & 6,85 \\
\hline Gothenburg-Stockholm & SE & 457,00 & 1,40 & & & 1,40 \\
\hline Geneva-Zurich & $\mathrm{CH}$ & 302,80 & 4,00 & 0,01 & & 4,01 \\
\hline Bratislava-Zilina & SK & 203,20 & 1,54 & 0,01 & 0,11 & 1,66 \\
\hline Ljubljana-Maribor & SL & 155,80 & 1,04 & & & 1,04 \\
\hline London-Newcastle & UK & 432,00 & 4,86 & & 0,03 & 4,89 \\
\hline Copenhagen-Stockholm & DK, SE & 729,20 & 1,74 & & & 1,74 \\
\hline Copenhagen-Malmo & DK, SE & 52,70 & 7,32 & & & 7,32 \\
\hline
\end{tabular}

Tabla 30. Cuantía promedio de los cánones aplicados en circulaciones O-D por líneas convencionales por km-tren. Fuente: UIC Charge4Rail (Teixeira et al. 2017).

En el gráfico siguiente y ordenados de mayor a menor se aprecia la diferencia en cuanto a las tarifas aplicadas por kilómetro tren en las circulaciones estudiadas: 


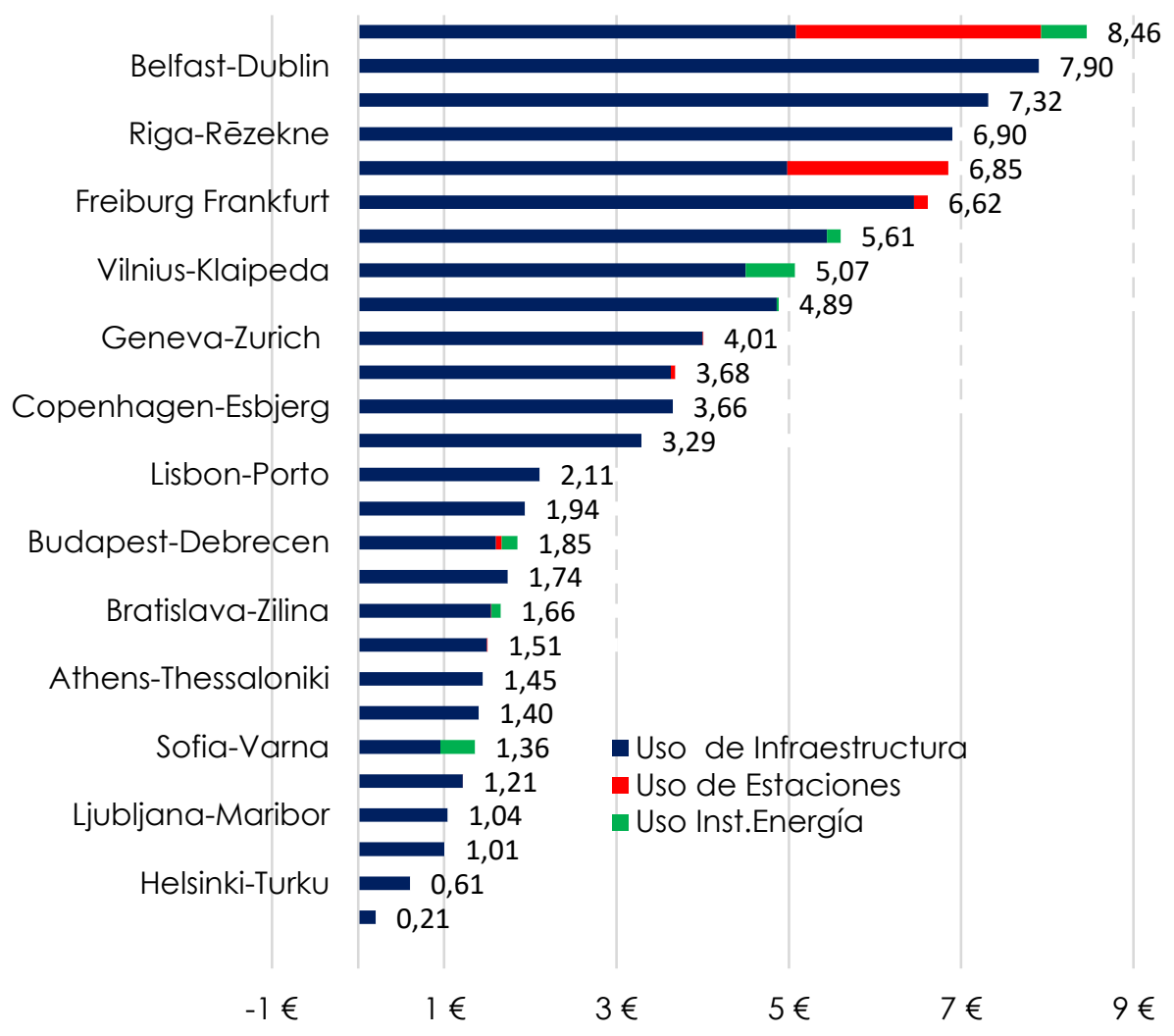

Gráfico 11. Canon por km líneas convencionales. Fuente: UIC Charge4Rail (Teixeira et al. 2017).

Como se puede observar y se confirma, el canon aplicado por uso de la infraestructura constituye el mayor porcentaje del total aplicado en los casos

A continuación se realiza el análisis para circulaciones Origen-Destino en líneas de alta velocidad. 


\begin{tabular}{|c|c|c|c|c|c|c|}
\hline Origen-Destino & $\begin{array}{l}\text { Distancia } \\
\quad \text { km }\end{array}$ & $\begin{array}{c}\text { Uso de } \\
\text { Infraestructura }\end{array}$ & $\begin{array}{c}\text { Uso de } \\
\text { Estaciones }\end{array}$ & $\begin{array}{c}\text { Uso de } \\
\text { Instalaciones } \\
\text { de Energía }\end{array}$ & Total & $\begin{array}{l}\text { Total por } \\
\text { km }\end{array}$ \\
\hline Brussels - Liege & 104,50 & $678,58 €$ & $167,74 €$ & & $846,32 €$ & $8,10 €$ \\
\hline Frankfurt - Cologne & 179,60 & $3.028,98 €$ & $46,72 €$ & & $3.075,70 €$ & $17,13 €$ \\
\hline Hannover - Berlin & 253,50 & $2.030,15 €$ & $43,50 €$ & & $2.073,65 €$ & $8,18 €$ \\
\hline Hannover - Frankfurt & 335,60 & $2.729,08 €$ & $52,05 €$ & & $2.781,13 €$ & $8,29 €$ \\
\hline Barcelona - Seville & $1.079,50$ & $8.502,04 €$ & $878,74 €$ & & $9.380,78 €$ & $8,69 €$ \\
\hline Madrid - Barcelona & 628,20 & $11.006,55 €$ & $878,74 €$ & & $11.885,29 €$ & $18,92 €$ \\
\hline Madrid - Seville & 470,40 & $6.913,19 €$ & $878,74 €$ & & $7.791,93 €$ & $16,56 €$ \\
\hline Madrid - Toledo & 75,10 & $193,36 €$ & $46,87 €$ & & $240,23 €$ & $3,20 €$ \\
\hline Madrid - Valencia & 390,30 & $5.671,27 €$ & $878,74 €$ & & $6.550,01 €$ & $16,78 €$ \\
\hline Lyon - Marseille & 320,60 & $3.879,89 €$ & $259,26 €$ & $224,74 €$ & $4.363,89 €$ & $13,61 €$ \\
\hline Paris - Bordeaux & 542,10 & $13.847,52 €$ & $522,65 €$ & $461,08 €$ & $14.831,25 €$ & $27,36 €$ \\
\hline Paris - Lille & 224,40 & $6.016,75 €$ & $469,00 €$ & $157,30 €$ & $6.643,05 €$ & $29,60 €$ \\
\hline Paris - Lyon & 427,40 & $12.210,46 €$ & $582,32 €$ & $299,61 €$ & $13.092,39 €$ & $30,63 €$ \\
\hline Paris - Marseille & 740,70 & $15.393,17 €$ & $690,30 €$ & $519,23 €$ & $16.602,70 €$ & $22,41 €$ \\
\hline Paris - Rennes & 363,70 & $5.675,93 €$ & $410,64 €$ & $254,95 €$ & $6.341,52 €$ & $17,44 €$ \\
\hline Paris - Strasbourg & 439,40 & $5.762,91 €$ & $433,47 €$ & $308,02 €$ & $6.504,40 €$ & $14,80 €$ \\
\hline Paris - Tours & 219,10 & $5.521,03 €$ & $456,11 €$ & $153,59 €$ & $6.130,73 €$ & $27,98 €$ \\
\hline Tours - Bordeaux & 315,80 & $8.341,12 €$ & $377,52 €$ & $299,60 €$ & $9.018,24 €$ & $28,56 €$ \\
\hline Torino - Milano 2017 & 130,90 & $1.131,12 €$ & & & $1.131,12 €$ & $8,64 €$ \\
\hline Torino - Milano 2018 & 130,90 & $823,74 €$ & & & $823,74 €$ & $6,29 €$ \\
\hline Milano - Florence 2017 & 320,90 & $2.651,15 €$ & & & $2.651,15 €$ & $8,26 €$ \\
\hline Milano - Florence 2018 & 320,90 & $2.019,52 €$ & & & $2.019,52 €$ & $6,29 €$ \\
\hline Florence - Rome 2017 & 257,10 & $805,18 €$ & & & $805,18 €$ & $3,13 €$ \\
\hline Florence - Rome 2018 & 257,10 & $1.554,25 €$ & & & $1.554,25 €$ & $6,05 €$ \\
\hline Rome - Naples 2017 & 229,20 & $1.825,92 €$ & & & $1.825,92 €$ & $7,97 €$ \\
\hline Rome - Naples 2018 & 229,20 & $1.442,59 €$ & & & $1.442,59 €$ & $6,29 €$ \\
\hline Amsterdam - Breda ${ }^{1}$ & 115,10 & $1.918,19 €$ & $17,92 €$ & & $1.936,11 €$ & $16,82 €$ \\
\hline Amsterdam - Brussels $^{1}$ & 214,30 & $2.644,79 €$ & $96,22 €$ & & $2.741,01 €$ & $12,79 €$ \\
\hline Lille - Brussels & 111,90 & $1.000,85 €$ & $364,73 €$ & $16,47 €$ & $1.382,05 €$ & $12,35 €$ \\
\hline Brussels - Cologne & 223,00 & $1.457,43 €$ & $102,88 €$ & & $1.560,31 €$ & $7,00 €$ \\
\hline Paris - Geneva & 550,50 & $9.892,94 €$ & $508,68 €$ & $375,18 €$ & $10.776,80 €$ & $19,58 €$ \\
\hline Zurich - Milano & 266,40 & $1.214,11 €$ & $2,00 €$ & & $1.216,11 €$ & $4,56 €$ \\
\hline Barcelona - Lyon & 699,90 & $8.110,79 €$ & $252,77 €$ & $369,78 €$ & $8.733,34 €$ & $12,48 €$ \\
\hline Barcelona - Paris & $1.085,30$ & $16.617,66 €$ & $638,81 €$ & $639,94 €$ & $17.896,41 €$ & $16,49 €$ \\
\hline Paris - Rome & $1.454,70$ & $16.011,05 €$ & $478,57 €$ & $414,34 €$ & $16.903,96 €$ & $11,62 €$ \\
\hline Paris - Amsterdam ${ }^{1}$ & 529,10 & $8.597,87 €$ & $200,49 €$ & $108,45 €$ & $8.906,81 €$ & $16,83 €$ \\
\hline Marseille - Amsterdam ${ }^{1}$ & $1.263,40$ & $18.690,38 €$ & $195,87 €$ & $448,58 €$ & $19.334,83 €$ & $15,30 €$ \\
\hline Paris - Hannover & 831,20 & $8.341,74 €$ & $212,48 €$ & $108,45 €$ & $8.662,67 €$ & $10,42 €$ \\
\hline Milano - Cologne & 837,40 & $6.166,28 €$ & $19,01 €$ & $0,00 €$ & $6.185,29 €$ & $7,39 €$ \\
\hline London - Brussels & 375,60 & $27.999 .77 €$ & $83,87 €$ & $61,79 €$ & $28.145,43 €$ & $74,93 €$ \\
\hline London - Brussels & 325,10 & $7.098,25 €$ & $83,87 €$ & $61,79 €$ & $7.243,91 €$ & $22,28 €$ \\
\hline
\end{tabular}

Tabla 31. Canon para circulaciones O-D en líneas de alta velocidad por km. Fuente: UIC Charge4Rail (Teixeira et al. 2017. 


\begin{tabular}{|c|c|c|c|c|}
\hline Origen-Destino & $\begin{array}{c}\text { Uso de } \\
\text { Infraestructura }\end{array}$ & $\begin{array}{l}\text { Uso de } \\
\text { Estaciones }\end{array}$ & $\begin{array}{c}\text { Uso } \\
\text { Inst.Energí } \\
\text { a }\end{array}$ & $€ \mathrm{~km}$ \\
\hline
\end{tabular}

\begin{tabular}{|c|c|c|c|c|}
\hline Florence - Rome 2017 & $3,13 €$ & $0,00 €$ & $0,00 €$ & $3,13 €$ \\
\hline Madrid - Toledo & $2,57 €$ & $0,62 €$ & $0,00 €$ & $3,20 €$ \\
\hline Zurich - Milano & $4,56 €$ & $0,01 €$ & $0,00 €$ & $4,56 €$ \\
\hline Florence - Rome 2018 & $6,05 €$ & $0,00 €$ & $0,00 €$ & $6,05 €$ \\
\hline Torino - Milano 2018 & $6,29 €$ & $0,00 €$ & $0,00 €$ & $6,29 €$ \\
\hline Milano - Florence 2018 & $6,29 €$ & $0,00 €$ & $0,00 €$ & $6,29 €$ \\
\hline Rome - Naples 2018 & $6,29 €$ & $0,00 €$ & $0,00 €$ & $6,29 €$ \\
\hline Brussels - Cologne & $6,54 €$ & $0,46 €$ & $0,00 €$ & $7,00 €$ \\
\hline Milano - Cologne & $7,36 €$ & $0,02 €$ & $0,00 €$ & $7,39 €$ \\
\hline Rome - Naples 2017 & $7,97 €$ & $0,00 €$ & $0,00 €$ & $7,97 €$ \\
\hline Brussels - Liege & $6,49 €$ & $1,61 €$ & $0,00 €$ & $8,10 €$ \\
\hline Hannover - Berlin & $8,01 €$ & $0,17 €$ & $0,00 €$ & $8,18 €$ \\
\hline Milano - Florence 2017 & $8,26 €$ & $0,00 €$ & $0,00 €$ & $8,26 €$ \\
\hline Hannover - Frankfurt & $8,13 €$ & $0,16 €$ & $0,00 €$ & $8,29 €$ \\
\hline Torino - Milano 2017 & $8,64 €$ & $0,00 €$ & $0,00 €$ & $8,64 €$ \\
\hline Barcelona - Seville & $7,88 €$ & $0,81 €$ & $0,00 €$ & $8,69 €$ \\
\hline Paris - Hannover & $10,04 €$ & $0,26 €$ & $0,13 €$ & $10,42 €$ \\
\hline Paris - Rome & $11,01 €$ & $0,33 €$ & $0,28 €$ & $11,62 €$ \\
\hline Lille - Brussels & $8,94 €$ & $3,26 €$ & $0,15 €$ & $12,35 €$ \\
\hline Barcelona - Lyon & $11,59 €$ & $0,36 €$ & $0,53 €$ & $12,48 €$ \\
\hline Amsterdam - Brussels ${ }^{1}$ & $12,34 €$ & $0,45 €$ & $0,00 €$ & $12,79 €$ \\
\hline Lyon - Marseille & $12,10 €$ & $0,81 €$ & $0,70 €$ & $13,61 €$ \\
\hline Paris - Strasbourg & $13,12 €$ & $0,99 €$ & $0,70 €$ & $14,80 €$ \\
\hline Marseille - Amsterdam ${ }^{1}$ & $14,79 €$ & $0,16 €$ & $0,36 €$ & $15,30 €$ \\
\hline Barcelona - Paris & $15,31 €$ & $0,59 €$ & $0,59 €$ & $16,49 €$ \\
\hline Madrid - Seville & $14,70 €$ & $1,87 €$ & $0,00 €$ & $16,56 €$ \\
\hline Madrid - Valencia & $14,53 €$ & $2,25 €$ & $0,00 €$ & $16,78 €$ \\
\hline Amsterdam - Breda ${ }^{1}$ & $16,67 €$ & $0,16 €$ & $0,00 €$ & $16,82 €$ \\
\hline Paris - Amsterdam ${ }^{1}$ & $16,25 €$ & $0,38 €$ & $0,20 €$ & $16,83 €$ \\
\hline Frankfurt - Cologne & $16,87 €$ & $0,26 €$ & $0,00 €$ & $17,13 €$ \\
\hline Paris - Rennes & $15,61 €$ & $1,13 €$ & $0,70 €$ & $17,44 €$ \\
\hline Madrid - Barcelona & $17,52 €$ & $1,40 €$ & $0,00 €$ & $18,92 €$ \\
\hline Paris - Geneva & $17,97 €$ & $0,92 €$ & $0,68 €$ & $19,58 €$ \\
\hline London - Brussels & $21,83 €$ & $0,26 €$ & $0,19 €$ & $22,28 €$ \\
\hline Paris - Marseille & $20,78 €$ & $0,93 €$ & $0,70 €$ & $22,41 €$ \\
\hline Paris - Bordeaux & $25,54 €$ & $0,96 €$ & $0,85 €$ & $27,36 €$ \\
\hline Paris - Tours & $25,20 €$ & $2,08 €$ & $0,70 €$ & $27,98 €$ \\
\hline Tours - Bordeaux & $26,41 €$ & $1,20 €$ & $0,95 €$ & $28,56 €$ \\
\hline Paris - Lille & $26,81 €$ & $2,09 €$ & $0,70 €$ & $29,60 €$ \\
\hline Paris - Lyon & $28,57 €$ & $1,36 €$ & $0,70 €$ & $30,63 €$ \\
\hline London - Brussels & $74,55 €$ & $0,22 €$ & $0,16 €$ & $74,93 €$ \\
\hline
\end{tabular}

Tabla 32. Cuantía promedio de los cánones aplicados en circulaciones O-D por líneas de alta velocidad por km-tren. Fuente: UIC Charge4Rail (Teixeira et al. 2017). 
Los valores obtenidos muestran que el canon por uso de la infraestructura sigue constituyendo la mayor parte del canon total. Los cánones por uso de las estaciones representan una contribución pequeña, aunque notable, resaltando el porcentaje en las circulaciones entre Lille-Bruselas y BruselasLieja con un porcentaje sobre el total del $26 \%$ y $20 \%$, respectivamente.

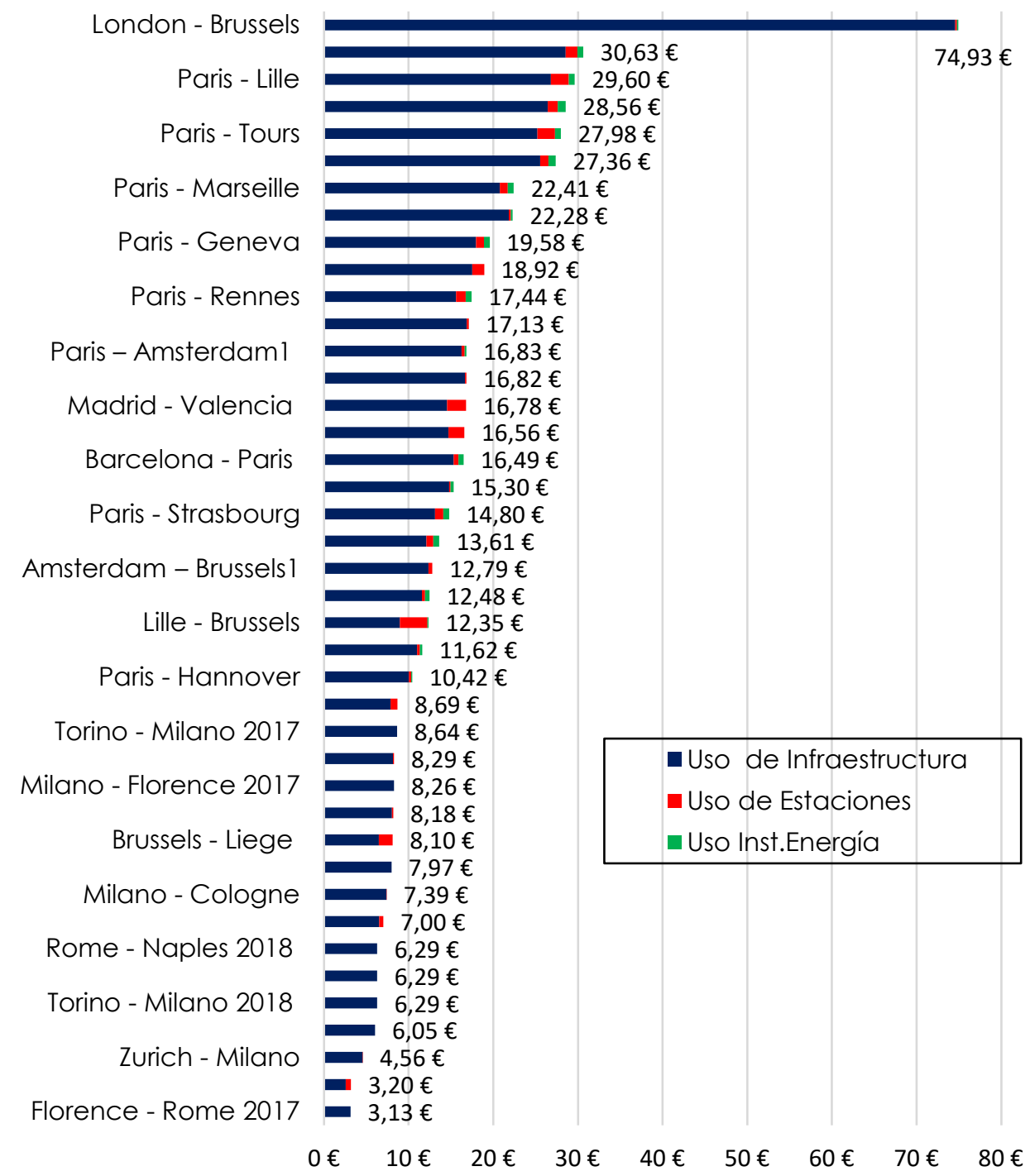

Gráfico 12. Canon total por km en líneas de alta velocidad. Fuente: UIC Charge4Rail (Teixeira et al. 2017). 
En el gráfico anterior, el importe por uso de la infraestructura aplicada a las circulaciones entre Londres-Bruselas se destaca por presentar el valor más elevado. El valor excepcionalmente alto se debe al cargo impuesto por el Eurotúnel. Si se omite esta tarifa del total por kilómetro muestra que está dentro de las tarifas comparable con otras relaciones como París-Marsella y París-Ginebra.

Tal como se ha mostrado en este apartado y dada la importancia del canon en la competitividad del ferrocarril de alta velocidad así como el futuro escenario ante la liberalización del transporte de viajeros es de interés trazar una serie de reflexiones sobre el canon por uso de las estaciones en el contexto de estas líneas en España, eligiendo para tal efecto el estudio el tramo Madrid-Valencia de la línea Madrid-Levante de alta velocidad.

\section{Reflexiones respecto a las Declaraciones sobre la Red.}

En primer lugar, hay que reseñar que la investigación ha ido en contra de dos dificultades relevantes.

La primera dificultad estriba al examinar las Declaraciones, carecen de una información detallada con respecto a su red ferroviaria, la mayoría no proporcionan suficiente información respecto a la tramificación de las líneas, en términos de identificación, sección y longitud, mientras que otros proporcionan mapas de baja calidad, lo que dificulta lectura de estos. La facilidad de lectura y comprensión de las Declaraciones sobre la Red varía de un país a otro, al igual que la disponibilidad e integridad de la información en inglés. En algunos casos, no existe versión en inglés del documento; mientras que en otros casos la información proporcionada es incompleta, lo que obliga a consultar anexos que se encuentran en el idioma nacional (alemán, danés, rumano, etc.). La segunda dificultad está con la alta dispersión y baja disponibilidad de la información así como la práctica real seguida por las administraciones ferroviarias nacionales con respecto a los incentivos buscados, los procedimientos de cálculo y asignación de costes.

En cuanto al sistema de tarificación, varios países proporcionan el canon y su precio en la propia Declaración sobre la Red y otros muestran parte de la información en diferentes documentos. Países, como Dinamarca, sólo informan de precios en documentos externos, dificultando la comprensión del sistema empleado, obligando a la consulta de múltiples fuentes con el fin de encontrar toda la información necesaria. 
Para superar estas dificultades en la medida de lo posible, esta investigación ha dedicado una atención especial a la recopilación de datos sobre las Declaraciones sobre la red de cada administrador ferroviario desarrollando la matriz con todas las variables aplicadas, aplicando los cánones en el caso concreto de la línea de alta velocidad Madrid-Valencia perteneciente a ADIF.

Reflexiones respecto a los cánones aplicados por uso de la infraestructura.

El estudio de las declaraciones sobre la red de los administradores da a conocer la existencia de diversos cánones aplicados con naturaleza distinta entre sí. La totalidad de los países cobran cánones relacionados con el concepto de uso de la infraestructura utilizando una gran diversidad de variables, siendo la más utilizada la variable tipo de línea, tipo de tren y horario de circulación, pero no hay ningún administrador que aplique más del $35 \%$ de los conceptos existentes para tarificar sus servicios. En los gráficos y matrices siguientes se muestran los cánones y las variables utilizadas en su cálculo por países:

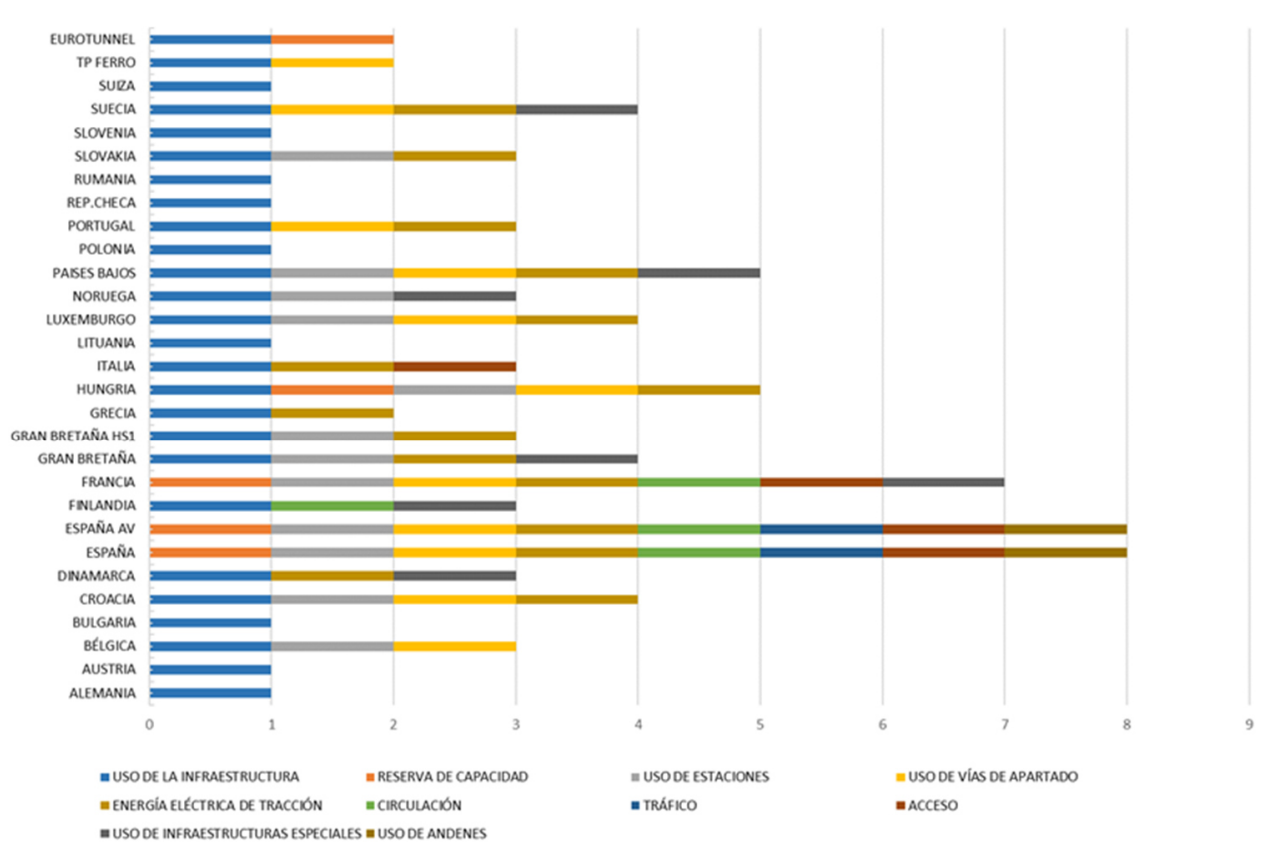

Gráfico 13. Cánones aplicados por país. Elaboración propia. 
Estas variables aplicadas recuperan los costes marginales y los costes variables correspondientes a la operación, mantenimiento y renovación. Tras examinar cada estructura de tarificación en profundidad existen administradores que no realizan una clara distinción entre los costes marginales y los márgenes de beneficio.

En los corredores ferroviarios internacionales, a pesar de la legislación existente que obliga a una convergencia de enfoque para un sistema basado en costes directos, sigue existiendo esa falta de convergencia, no sólo en los niveles de cánones, sino también en las formulaciones, las variables y parámetros de fijación de precios variando de país a país, representando un problema.

Los problemas encontrados respecto de los cánones se pueden definir con dos características: la diferencia en los niveles de cánones de infraestructura, y la diferencia en las variables aplicadas. Debido a que cada administrador establece sus propios cánones, la decisión de aumento de los cánones por parte de un administrador por uso de su infraestructura sin consultar a otros "vecinos" puede derivar a que una composición ferroviaria que era viable económicamente antes de dicho aumento puede ser menos viable económicamente tras él, dando lugar a una reducción de circulaciones por el corredor o incluso llegar a su cancelación. Al mismo tiempo, algunas variables entre los diferentes países son incompatibles, el uso de diferentes unidades (tren-km vs. tonelada-km) o la diferenciación en masa $u$ otras variables en un país, pero no en otro, hacen que la selección de material rodante para ese corredor sea un reto para un operador internacional lo que esta heterogeneidad en variables presenta una dificultad a las empresas ferroviarias que pretendan operar internacionalmente.

No hay transparencia en cuanto a la justificación de las tarifas así como la presencia de incentivos, algunos confusos como el caso de que trenes frecuentes y cortos pueden ser más baratos en un país que trenes más pesados y que no tienen frecuencia en el país colateral. Un mayor grado de homogeneidad sería beneficioso, y en su defecto, la implantación de tarifas internacionales especiales aprobadas por los administradores de un corredor ferroviario en particular, de forma que compartan ingresos que beneficien a los administradores implicados. 
La matriz siguiente muestra la aplicación de las variables según el administrador:

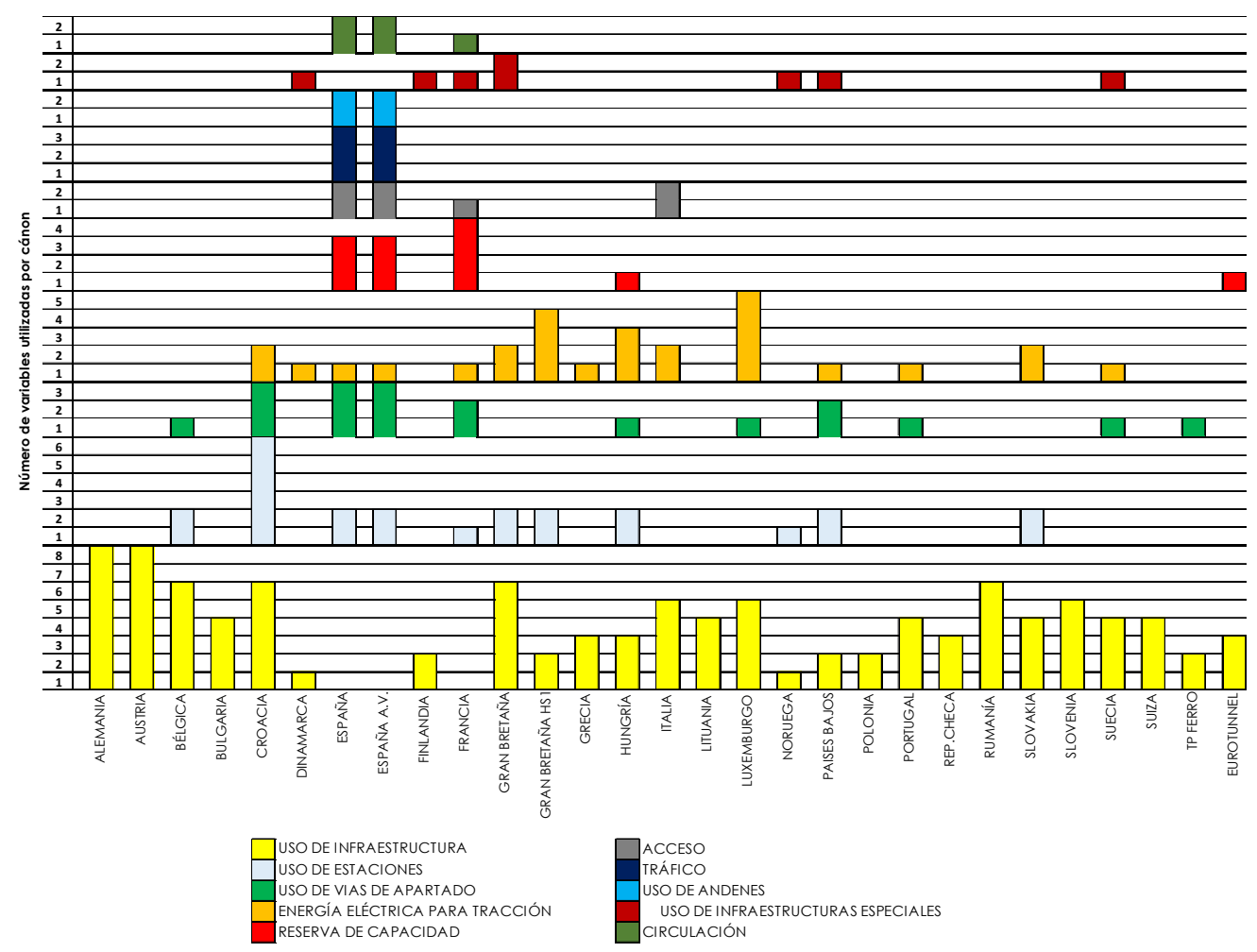

Gráfico 14. Matriz de variables aplicadas en el cálculo de los cánones por países. Elaboración propia.

La mayoría de los sistemas de tarificación comparten algunos parámetros, tales como la categoría de la línea, diferenciando el uso de líneas principales, secundarias y otras.

Algunos administradores también distinguen líneas por región, o por uso de infraestructuras especiales (por ejemplo, el paso por puentes y túneles). En cuanto al tipo de servicio y la penalización por retrasos (ya sea una parte de la cuota de uso, o esté incluido en el sistema de incentivos) son también las variables recurrentes en el cálculo del canon por uso de la infraestructura. 
Nos encontramos algunos países optan por la clasificación por categorías de peso, y otros por el número de asientos ofrecidos para el cálculo del coste por uso de la infraestructura.

Otro elemento es la existencia dentro del horario de servicio de períodos punta, donde la infraestructura está saturado de tráfico, y por lo tanto se aplica un precio con el fin de desviar el tráfico a los períodos menos ocupados y así conseguir una mejor utilización de la capacidad de la red. Algunos países refuerzan su objetivo en la reducción de este uso excesivo de la infraestructura mediante la aplicación de penalizaciones por el uso de estas líneas congestionadas, o reducciones de canon para el uso de secciones con menos tráfico. Estos son aplicados durante todo el día o sólo durante los períodos punta. Sin embargo, estas variables de períodos de uso de la infraestructura varían de país a país lo que hace difícil la planificación del transporte ferroviario en un contexto general como puede ser el uso de un corredor internacional de mercancías. Se aplica por parte de los administradores una adición a la cuota íntegra del canon de capacidad por el uso ineficiente de ésta, con el objetivo de optimizar su uso y que es calculada mediante la diferencia entre los tren-km adjudicados y los finalmente utilizados. Esta adición al canon por utilización de la infraestructura debe permitir a los administradores recuperar los gastos financieros para conseguir la sostenibilidad económica de las infraestructuras que gestionan así como un uso racional de las mismas.

Existen variables para cubrir los costes ambientales relacionados con el combustible utilizado o con el ruido generado por los vagones de los trenes de mercancías, pero no están determinadas en todos los países no se aplican. Un elemento incompatible entre países que aparece son las consideraciones con respecto al tipo de tracción, la electrificación de línea y las emisiones de combustible. Hay países que clasifican las locomotoras de tracción, algunos asignan costes superiores a la tracción diésel, mientras que otros hacen lo contrario. Pocos países penalizan la tracción con combustible de origen fósil, así como la tarificación de los costes externos debidos a las emisiones de gases de efecto invernadero, mientras que otros penalizan a los trenes diésel que circulan por las líneas electrificadas.

Debería existir un sistema generalizado para hacer frente a los gastos de mantenimiento de la infraestructura, como es la aplicación de un sistema tributario basado en la huella de carbono, como herramienta para evaluar la repercusión de los diferentes modos de transporte en el medio ambiente. El administrador sueco impone un recargo a aquellas empresas ferroviarias dependiendo el tipo de combustible utilizado en sus unidades de tracción. Suiza realiza cargos al transporte por carretera que luego son revertidos en el mantenimiento de la infraestructura ferroviaria. 
El canon por el uso de la infraestructura ferroviaria aplicado por los administradores ferroviarios ha logrado el objetivo de estructurar los mercados del transporte ferroviario y regular mediante tarifas el acceso a la misma. Si es cierto por contrapartida que las características técnicas y operativas de las redes ferroviarias o la ambigüedad en algún país ha dado lugar a una personalización del canon, produciendo una dispersión en cuanto a fijación de variables o incluso precios, no pudiendo conseguir la homogeneidad buscada como objetivo en este trabajo.

Además de las diferencias técnicas, el mercado ferroviario en Europa está fracturado por las fronteras nacionales, las diferencias en las prácticas de operación, las diferentes políticas aplicadas y como no las barreras lingüísticas hacen que sea complicado la expansión de los operadores en el mercado más allá de un país. Como resumen se han realizado proyectos europeos para reducir desafíos técnicos mediante la creación de sistemas de señalización común, normas de electrificación y otros elementos técnicos comunes, pero ha habido pocos avances para normalizar el acceso al mercado de cada país.

El acceso a la infraestructura tiene un gran peso económico en el sistema de producción del transporte ferroviario, sobre todo en la competitividad de las empresas ferroviarias representando una parte significativa del coste de un operador ferroviario. Los efectos que producen las políticas de precios, aparte de ser el principal actor en el mercado del transporte, es la asunción como instrumento para conseguir objetivos e influir en la competencia en el sector.

Existen cuestiones difíciles de resolver en el diseño de un régimen de tarificación de la infraestructura ferroviaria, un canon basado en los kilómetros recorridos por el tren no puede dar los incentivos para el uso óptimo de la infraestructura existente y menos los indicios para el desarrollo de la infraestructura en un futuro. Una solución es aplicar una tarifa constituida por dos partes, una variable y una fija, siendo el elemento variable el reflejo del coste social marginal a corto plazo por el uso de la infraestructura existente y el elemento fijo reflejo del coste evitable de proveer la capacidad disponible por un acuerdo marco.

La fórmula utilizada en Francia respecto a los cánones se constituye en torno a dos criterios: un pilar operativo, evaluando los costes marginales determinados por la explotación de la línea (cerca del $30 \%$ del valor total) y un pilar de valor económico establecido para extraer un canon de acceso tan elevado como se puedan permitir los operadores ferroviarios (cerca del $70 \%$ del valor total). 
En Alemania la política sobre cánones tiene como objetivo recuperar un alto porcentaje de costes de infraestructura de las empresas ferroviarias. En Austria, los cánones de acceso se basan en los costes operativos; en España, los cánones están dirigidos a cubrir los costes directos. En Francia, los cánones de acceso a las vías se mantienen elevados para proporcionar ingresos, y para garantizar la sostenibilidad de las operaciones en el caso de entidades con deudas importantes y así reducir la necesidad del Estado de financiar y mantener nuevas infraestructuras ferroviarias. En Italia el órgano regulador ferroviario italiano, además de garantizar el derecho de acceso a los servicios de la estación, reduce los cánones para garantizar una competencia leal, lo que mejora la situación de los viajeros, utilizando los cánones como medio para aumentar la competencia entre operadores.

Los ingresos por cánones ferroviarios se completan con otras actividades como son los alquileres, suministros de energía, servicios logísticos o los que presta en estaciones. En ADIF Alta Velocidad, los cánones suponen su principal fuente de ingresos, siendo del $52 \%$ del total, el resto corresponden a suministro de energía prestado a las empresas ferroviarias $(30 \%)$ o de alquiler y servicios de espacios (11\%).

A diferencia de ADIF, ADIF Alta Velocidad no recibe subvenciones de explotación, sufragando la totalidad de los costes operativos mediante cánones y resto de ingresos de actividades privadas. La diferenciación de las líneas (variable Tipo de Línea) hace que el canon sea más elevado en las líneas de altas prestaciones ya que sus costes son más elevados, así como la utilización de las variables Carga o Tipo de Tren permiten establecer modulaciones de tarifas, teniendo una gran influencia en el desgaste de las infraestructuras.

Cualquier aumento de los costes son a cargo de los presupuestos nacionales, a lo que se le añade el tiempo de demora en entrar en funcionamiento (emplean una media de alrededor de 16 años desde el comienzo de las obras hasta el inicio de las operaciones). En las líneas de alta velocidad los costes podrían ser muy inferiores, con una repercusión escasa o nula en las operaciones, ya que algunas líneas no son necesarias en todos los lugares en los que se han construido, pero eso es tema para futuras líneas de investigación.

En muchos casos, los trenes circulan en líneas de alta velocidad a velocidades medias muy inferiores a las que la línea fue concebida para soportar. Una nueva infraestructura ferroviaria presenta grandes diferencias entre los costes de construcción según el relieve del terreno; pero para el mismo tipo de relieve, es mucho menos importante la variación del coste al cambiar la velocidad. 
Los costes para una misma velocidad muestran una gran variabilidad según el relieve del terreno pero un cambio en la velocidad en un mismo tipo de relieve es más limitado.

Un aumento de la velocidad de diseño requiere una gran inversión y unos costes elevados de mantenimiento pero aumenta los ingresos, reduce costes operativos y capta viajeros de otros modos de transporte, mejorando la rentabilidad económico-social.

El termino tren kilómetro aplicado depende del número de trenes que circulan por una red, cuya disminución es compatible con un incremento del número de viajeros gracias a una mejora del aprovechamiento de estos, es decir, incremento de viajeros y disminución de los trenes-km, por lo que sería caso de estudio por parte de los administradores para una aplicación en trenes de viajeros más generalizada.

El canon influye en el flujo de caja y en la cuenta de resultados del operador de transporte y del gestor de infraestructura haciendo necesaria su estimación o por lo menos su estudio ya que el canon es parte implicada en la formación del precio final que pagan los viajeros y, por lo tanto, es parte implicada en la demanda. Es obvio que un elevado canon pagado por el operador obliga a éste repercutir este coste a los viajeros, y por consiguiente una pérdida de competitividad.

Reflexiones respecto al canon por utilización de las estaciones de viajeros.

Los cánones analizados muestran que existen administradores que aplican el uso de estaciones de viajeros directamente en el canon por uso de la infraestructura, siendo determinado en el momento de realizar la reserva del surco correspondiente como es el caso de Dinamarca y Luxemburgo.

La variable común es la categorización de la estación por importancia, teniendo subcategorías de clasificación tal como se muestra en la tabla mostrada más adelante.

El caso de Bélgica aplica un cargo por el tipo de parada que realiza el tren en la estación, siendo componente del canon por uso de la infraestructura, y otro cargo dependiendo de la categoría de la estación, definida por el número de viajeros. Alemania divide las estaciones por áreas geográficas, dependiendo el órgano gestor de las mismas. 


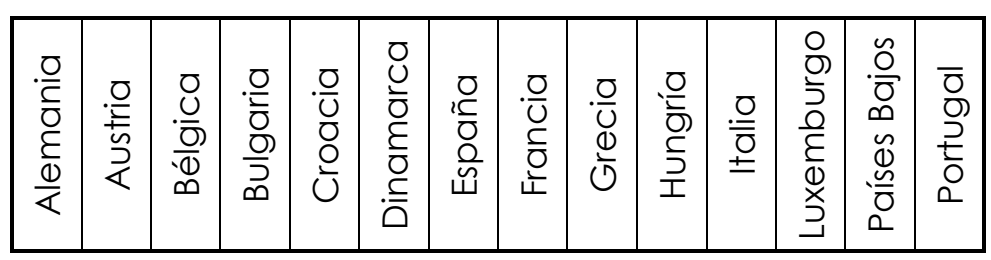

\begin{tabular}{|c|c|c|c|c|c|c|c|c|c|c|c|c|c|c|}
\hline \multirow{3}{*}{\begin{tabular}{l} 
Área geográfica \\
Categoría de la \\
\cline { 2 - 2 } Estación
\end{tabular}} & $x$ & & & & & & & & & & & & & \\
\hline & & $x$ & $x$ & $X$ & $\mathbf{X}$ & & $x$ & $x$ & $X$ & $x$ & $X$ & & $x$ & $x$ \\
\hline & & & $x$ & & $x$ & & & $X$ & & & & & & \\
\hline Tipo de Parada & & & $x$ & & & & $x$ & & $x$ & & & & $X$ & \\
\hline $\begin{array}{l}\text { Integrado en } \\
\text { otro canon }\end{array}$ & & & & & & $x$ & & & & & & $x$ & & \\
\hline $\mathrm{N}^{\circ}$ de viajeros & & & $x$ & & & & $x$ & $x$ & & $X$ & & & & \\
\hline
\end{tabular}

Tabla 33. Conceptos aplicados en el canon por uso de estaciones de viajeros. Elaboración propia.

En cuanto a la categorización de las estaciones sólo el caso de Bulgaria y de Grecia presentan una diferencia respecto al resto de países estudiados, siendo el resto similar en cuanto a número. Sólo Alemania presenta mayor número de categorías debido a la división geográfica de su red ferroviaria.

\begin{tabular}{|l|l|l|l|l|l|l|l|}
\hline \multicolumn{7}{|c|}{ Categorías estaciones } \\
\hline 1 & 2 & 3 & 4 & 5 & 6 & 7 & 8 \\
\hline
\end{tabular}

\begin{tabular}{|c|c|c|c|c|c|c|c|c|}
\hline Alemania & $x$ & $x$ & $x$ & $x$ & $x$ & $x$ & $x$ & $x$ \\
\hline Austria & $x$ & $x$ & $x$ & $x$ & $x$ & $x$ & & \\
\hline Bélgica & $x$ & $x$ & $x$ & $x$ & $x$ & & & \\
\hline Bulgaria & $x$ & $x$ & & & & & & \\
\hline España & $x$ & $x$ & $x$ & $x$ & $x$ & & & \\
\hline Francia & $x$ & $x$ & $x$ & $x$ & $x$ & & & \\
\hline Grecia & $x$ & $x$ & & & & & & \\
\hline Hungría & $x$ & $x$ & $x$ & $x$ & & & & \\
\hline Italia & $x$ & $x$ & $x$ & $x$ & $x$ & & & \\
\hline Países Bajos & $x$ & $x$ & $x$ & $x$ & $x$ & & & \\
\hline Portugal & $\mathrm{X}$ & $\mathrm{X}$ & $x$ & $x$ & & & & \\
\hline
\end{tabular}

Tabla 34. Categorías de las estaciones de viajeros. Elaboración propia. 
Las variables empleadas en la conceptualización de las categorías de las estaciones presentan variedad en las subcategorías empleadas en la clasificación anterior. En la tabla siguiente se puede observar estas variables.

\begin{tabular}{|c|c|c|c|c|c|c|c|c|c|c|c|}
\hline 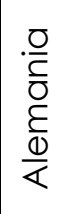 & 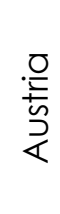 & $\begin{array}{l}\frac{0}{0} \\
\frac{0}{0} \\
\frac{D}{\infty}\end{array}$ & 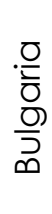 & $\begin{array}{l}\frac{O}{U} \\
\bar{O} \\
0 \\
\bar{U}\end{array}$ & 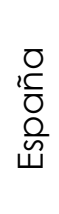 & $\begin{array}{l}\frac{\bar{O}}{U} \\
\frac{\mathrm{E}}{0} \\
\frac{\mathrm{U}}{4}\end{array}$ & $\begin{array}{l}\frac{\bar{O}}{U} \\
\frac{\mathbb{U}}{U}\end{array}$ & $\begin{array}{l}\text { 음 } \\
\text { ? } \\
\frac{1}{1}\end{array}$ & $\begin{array}{l}\frac{\overline{0}}{\overline{0}} \\
\pm\end{array}$ & 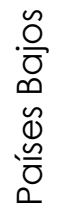 & $\begin{array}{l}\bar{\delta} \\
\text { O) } \\
\text { t. } \\
0\end{array}$ \\
\hline
\end{tabular}

\begin{tabular}{|c|c|c|c|c|c|c|c|c|c|c|c|c|}
\hline Viajeros & & & & & & & & & & & & \\
\hline Número de viajeros & & $\mathbf{X}$ & $\mathrm{X}$ & & & $\mathbf{x}$ & $\mathrm{x}$ & $\mathbf{x}$ & & $\mathbf{X}$ & $\mathbf{X}$ & $\mathrm{X}$ \\
\hline Superficies públicas & & & & & & $x$ & & & & $x$ & & \\
\hline Andenes & & & & & & & & & & & & \\
\hline$N^{\circ}$ de andenes & & $\mathbf{X}$ & & & & $x$ & & & $\mathbf{X}$ & & & \\
\hline Dimensiones & & & & & $\mathrm{x}$ & & & & & & & \\
\hline $\begin{array}{l}\text { Existencia de } \\
\text { marquesinas }\end{array}$ & & & & $\mathrm{x}$ & $x$ & & & & $\mathrm{x}$ & & & \\
\hline Tipo de acceso & & & & & & & & & $\mathbf{x}$ & & & \\
\hline Información al viajero & & & & & $x$ & & & & $x$ & & & $x$ \\
\hline Seguridad & & & & & & & & & & & & \\
\hline Servicio de vigilancia & & & & & & & & & $x$ & & & $x$ \\
\hline Vías & & & & & & & & & & & & \\
\hline Número de vías & & & & & $x$ & & & & $x$ & & & \\
\hline Vías electrificadas & & & & & & & & & $x$ & & & \\
\hline Geográficos & & & & & & & & & & & & \\
\hline Situación & $x$ & & & & $x$ & $\mathrm{X}$ & $x$ & & & & & $x$ \\
\hline Intermodalidad & & & & & & $x$ & & & & $x$ & & $x$ \\
\hline Tráfico & & & & & & & & & & & & \\
\hline Número de trenes & & & & & & $\mathrm{x}$ & $x$ & & & & & \\
\hline Tipo de trenes & & & & & & & $x$ & & & $\mathrm{x}$ & & $x$ \\
\hline
\end{tabular}

Tabla 35. Variables empleadas en la categorización de las estaciones. Elaboración propia. 
Reflexiones respecto al uso de estaciones de los administradores de la infraestructura español y francés.

En la tabla siguiente se realiza un resumen de los cargos que aplican los dos administradores:

\begin{tabular}{|c|c|c|c|}
\hline & & ADIF 12 & SNCF \\
\hline & NÚMERO DE ESTACIONES & 1.495 & 3.000 \\
\hline \multirow{5}{*}{ USO DE ESTACIONES } & VIAJEROS SUBIDOS/BAJADOS & 0 & \\
\hline & CATEGORÍA DE LA ESTACIÓN & 0 & 0 \\
\hline & TIPO DE SERVICIO & 0 & 0 \\
\hline & USO DE ANDENES & 0 & 0 \\
\hline & USO DE PUERTAS DE EMBARQUE & & 0 \\
\hline \multirow{2}{*}{$\begin{array}{l}\text { USO DE VÍAS DE } \\
\text { ESTACIONAMIENTO }\end{array}$} & CATEGORIA DE LA ESTACIÓN & 0 & \\
\hline & TIEMPO DE ESTACIONAMIENTO & 0 & \\
\hline \multirow{2}{*}{$\begin{array}{c}\text { USO DE VÍAS DE } \\
\text { ESTACIONAMIENTO PARA } \\
\text { OPERACIONES }\end{array}$} & TIPO DE OPERACIÓN & 0 & \\
\hline & CATEGORÍA DE LA ESTACIÓN & 0 & \\
\hline \multirow{5}{*}{ SERVICIOS BÁSICOS } & CATEGORÍA DE LA ESTACIÓN & 0 & 0 \\
\hline & $\begin{array}{l}\text { SOPORTES INFORMACIÓN } \\
\text { VIAJERO }\end{array}$ & 0 & 0 \\
\hline & VENTA DE TITULOS DE TRANSPORTE & 0 & 0 \\
\hline & ESPACIO MAQUINAS TICKETING & 0 & 0 \\
\hline & $\begin{array}{l}\text { LOCAL PERSONAL OPERACIONES } \\
\text { A BORDO }\end{array}$ & o & 0 \\
\hline \multirow{5}{*}{ SERVICIOS AUXILIARES } & ESPACIOS EFÍMEROS & 0 & 0 \\
\hline & PUNTO DE EMBARQUE & 0 & 0 \\
\hline & $\begin{array}{l}\text { PUNTO ATENCIÓN VIAJEROS } \\
\text { ÚLTIMA HORA }\end{array}$ & O & 0 \\
\hline & $\begin{array}{l}\text { TAQUILLAS VESTUARIO } \\
\text { COMPARTIDO }\end{array}$ & 0 & 0 \\
\hline & OBJETOS PERDIDOS & 0 & 0 \\
\hline
\end{tabular}

Tabla 36. Cánones aplicados en el ámbito de estaciones por ADIF y SNCF. Elaboración propia.

En el sistema tarifario empleado en España, el canon es abonado a la misma empresa pública ADIF, independientemente del que el canon sea por circulaciones que efectúan paradas en las estaciones o número de viajeros mientras que en el sistema francés, siendo también dos componentes como en España, por los cargos tienen destinos diferentes.

\footnotetext{
12 Incluidas las 42 estaciones de Adif Alta Velocidad.
} 
Una parte se abona a SNCF Réseau como administrador de infraestructura, por uso de las vías y andenes de las estaciones, y la otra parte denominada Base que es abonada a Mobilités Gares \& Connexions, administrador de las estaciones, por uso de las superficies e instalaciones situadas dentro de ellas. El importe total abonado es determinado por el área donde está clasificada la estación y el tipo de circulación:

\begin{tabular}{|l|c|c|c|c|}
\hline \multirow{2}{*}{\multicolumn{1}{c|}{ Área de gestión }} & \multicolumn{2}{c|}{ Otros trenes } & \multicolumn{2}{c|}{ Trenes regionales } \\
\cline { 2 - 5 } & Base & Andenes & Base & Andenes \\
\hline C BRETAGNE & 4,55 & 2,48 & 2,53 & 2,48 \\
\hline C GRAND EST & 5,82 & 2,43 & 3,23 & 2,43 \\
\hline C HAUTS DE FRANCE & 7,07 & 2,70 & 3,93 & 2,70 \\
\hline C PACA & 7,33 & 2,76 & 4,07 & 2,76 \\
\hline C NOUVELLE AQUITAINE & 6,99 & 3,18 & 3,88 & 3,18 \\
\hline C BOURGOGNE FC & 7,82 & 2,69 & 4,35 & 2,69 \\
\hline C PAYS DE LA LOIRE & 7,75 & 3,82 & 4,30 & 3,82 \\
\hline C NORMANDIE & 6,87 & 4,89 & 3,82 & 4,89 \\
\hline C ILE-DE-FRANCE & 10,32 & 1,46 & 5,73 & 1,46 \\
\hline C CENTRE VAL DE LOIRE & 9,14 & 2,93 & 5,08 & 2,93 \\
\hline C AUV-RHONE ALPES & 10,13 & 2,47 & 5,63 & 2,47 \\
\hline C OCCITANIE & 9,36 & 3,71 & 5,20 & 3,71 \\
\hline
\end{tabular}

Tabla 37. Tabla ejemplo de los porcentajes aplicados en estaciones de Francia. Elaboración propia a partir de datos de Mobilités Gares \& Connexions.

El canon en función de los viajeros que emplean el ferrocarril difiere a la hora de aplicarlo. En España se aplica tanto a viajeros subidos y a viajeros bajados en las estaciones mientras que en Francia se aplica sólo a los viajeros en origen mediante el canon por uso de puertas de embarque, es decir por viajeros sólo "subidos". En Francia el canon por uso de vías de estacionamiento es directamente imputado en el canon por uso de la infraestructura, al contrario de España que lo aplica en estaciones y diferenciando si existen operaciones adicionales como son la limpieza, abastecimiento de catering, etc. 


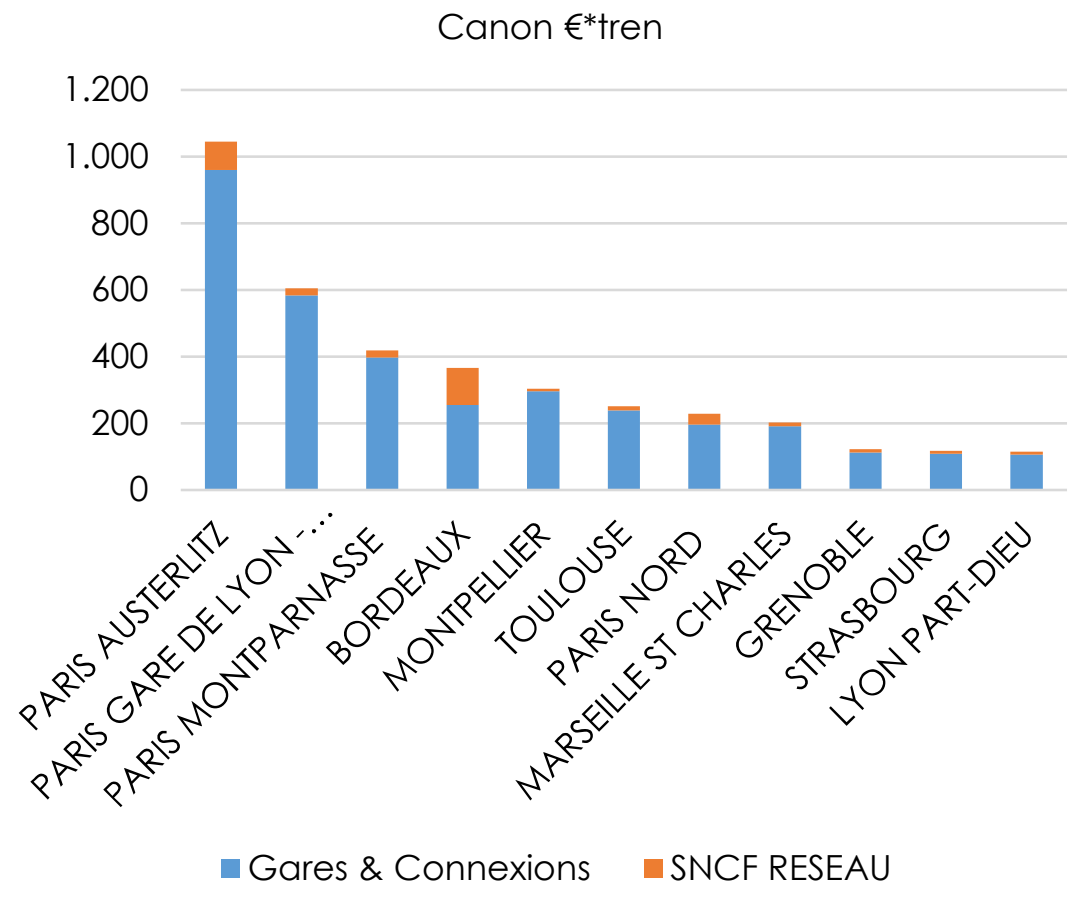

Gráfico 15. Canon por uso de estaciones en Francia. Elaboración propia.

\section{Canon $€$ *tren}

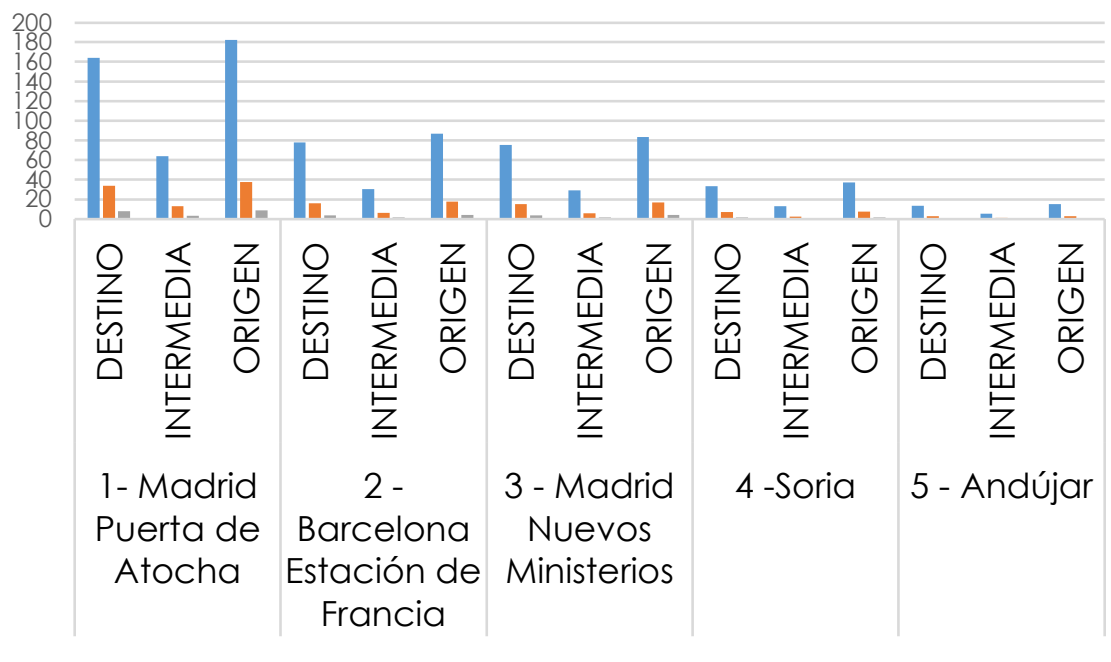

- Nacional/Internacional Interurbano Urbano

Gráfico 16. Canon por uso de estaciones en España. Elaboración propia. 
Se puede observar que las cuantías por uso de las estaciones son muy diferentes en cuanto a valor. Francia sólo emplea una tarifa por tren mientras que España aplica tres diferentes teniendo en cuenta la tipología de parada dentro del trayecto. Esta aplicación diferenciando el tipo de parada puede ocasionar que el operador no se plantee el realizar paradas durante el recorrido en estaciones intermedias si el rendimiento económico no es lo suficiente para su gestión. 
4 PROBLEMÁTICA DE LA TARIFICACIÓN POR USO DE LAS ESTACIONES DE VIAJEROS EN LÍNEAS DE ALTA VELOCIDAD: CASO DE ESTUDIO LÍNEA MADRID-LEVANTE 
4.1 Problemática de la inversiones en líneas de Alta Velocidad.

Costes de construcción.

Los datos existentes sobre los costes de construcción de infraestructuras presentan características similares pero con distintas velocidades de diseño, limitando el análisis y la elaboración de un método válido, siendo acentuado a consecuencia de las diferentes referencias disponibles debido a los distintos contextos económicos y geográficos.

Los precios asociados a la estructura de costes, por ejemplo los salarios, diferencias entre construcciones dentro del mismo país y el año en que se estudia la construcción.

Estas diferencias provocan desigualdades entre los proyectos que presentan los mismos requerimientos técnicos, lo que se traduce en diferencias en costes de inversión (Steer Davies, 2004).

\begin{tabular}{lccc} 
& $\begin{array}{c}\text { Madrid- } \\
\text { Lleida }\end{array}$ & $\begin{array}{c}\text { Lleida- } \\
\text { Barcelona }\end{array}$ & $\begin{array}{c}\text { Barcelona- } \\
\text { Frontera } \\
\text { Francesa }\end{array}$ \\
Año de puesta en servicio & 2003 & 2008 & 2013 \\
\hline km de explotación & 468 & 196 & 134 \\
\hline Velocidad diseño & 350 & 350 & 350 \\
\hline Coste total $(\mathrm{M} €)$ & 4.405 & 4.635 & 3.429 \\
\hline Coste por kilómetro $(\mathrm{M} \in / \mathrm{km})$ & 9,4 & 23,6 & 25,6 \\
\hline
\end{tabular}

Tabla 38. Coste de inversión LAV Madrid-Barcelona-Figueres. Fuente: ADIF 2009-2010.

\begin{tabular}{lccc} 
& Torrejón-Motilla & $\begin{array}{c}\text { Motilla- } \\
\text { Requena- } \\
\text { Valencia }\end{array}$ & Motilla-Albacete \\
Año de puesta en servicio & 2010 & 2010 & 2010 \\
\hline km de explotación & 224 & 144 & 70 \\
\hline Velocidad diseño & 350 & 350 & 350 \\
\hline Coste total $(\mathrm{M} €)$ & 2.785 & 2.924 & 583 \\
\hline Coste por kilómetro $(\mathrm{M} € / \mathrm{km})$ & 12,4 & 20,3 & 8,3
\end{tabular}

Tabla 39. Costes de inversión LAV Madrid-Levante. Fuente: ADIF 2009-2010.

\begin{tabular}{|c|c|c|c|}
\hline & $\begin{array}{l}\text { Madrid- } \\
\text { Sevilla }\end{array}$ & $\begin{array}{c}\text { Córdoba- } \\
\text { Málaga }\end{array}$ & Bobadilla-Granada \\
\hline Año de puesta en servicio & 1992 & 2007 & 2015 \\
\hline km de explotación & 476 & 155 & 125 \\
\hline Velocidad diseño & 270 & 350 & - \\
\hline Coste total (M€) & $2.821,4$ & $2.277,5$ & 1.410 \\
\hline Coste por kilómetro (M€/km) & 5,9 & 14,7 & 11,3 \\
\hline
\end{tabular}




\begin{tabular}{lcccc} 
Año de puesta en servicio & $\begin{array}{c}\text { Madrid- } \\
\text { Toledo } \\
2005\end{array}$ & $\begin{array}{c}\text { Madrid- } \\
\text { Valladolid } \\
2007\end{array}$ & $\begin{array}{c}\text { Variante } \\
\text { de Pajares }\end{array}$ & $\begin{array}{c}\text { Orense- } \\
\text { Santiago } \\
2011\end{array}$ \\
\hline km de explotación & 21 & 201 & 50 & 87 \\
\hline Velocidad diseño & 220 & 500 & 350 & 350 \\
\hline Coste total (M€) & 215 & 4.503 & 3.006 & 2.547 \\
\hline Coste por kilómetro (M€/km) & 10,2 & 22,4 & 60,1 & 29,3 \\
\hline Tabla 41. Costes de inversión de LAV Madrid-Centro España-Asturias-Galicia. Fuente: ADIF 2009- \\
2010.
\end{tabular}

La influencia de la velocidad en características como son el radio de curva, pendiente, etc., está ampliamente estudiada, sin embargo la relación con otras características de la infraestructura (como el porcentaje en túnel, viaducto, movimiento de tierras, características de la electrificación y señalización, etc.) no es tan evidente y tampoco lo es en su relación con el coste de inversión.

Según González Franco (2005) y previo a la identificación de las relaciones funcionales de la velocidad con el coste de inversión, elabora una clasificación del terreno tras el análisis de la orografía que se puede encontrar una infraestructura.

La construcción de una misma infraestructura ferroviaria en distintos relieves no presentará las mismas características de trazado, ni por supuesto la misma cantidad de obra construida y, por lo tanto, no supondrá el mismo coste si se trata de un relieve $u$ otro. Se entiende que construir una infraestructura que atraviese un terreno que presenta pendientes medias superiores al $20 \%$, precisará gran cantidad de túneles y de viaductos, lo que supondrá un coste muy elevado, en contraposición al trazado por grandes llanuras con bajos gradientes (entre 0 y $2,5 \%$ ).

Según González Franco las relaciones funcionales de la velocidad con el coste de inversión son:

- Longitud de la línea, a mayor velocidad se exigen mayores radios de curva, menos sinuosa será la línea y menos distancia entre origen y destino. Según García Álvarez y Fernández González (2008) las líneas de alta velocidad tienen como promedio un $13 \%$ de recorrido inferior al de la línea convencional entre los mismos puntos.

- Tipo de obra y el coste, la velocidad influye en la cantidad de túneles y viaductos a construir y cuya construcción es más costosa que la construcción sobre terreno natural. 
En los relieves suaves el porcentaje de unos y otros crece de forma relevante a velocidades altas, en el caso de las líneas en relieves muy montañosos, a partir de cierta velocidad no incide en un crecimiento importante del porcentaje del túnel o del viaducto.

- Rampas, una fuerte inclinación permite un mayor ajuste del trazado al relieve y una reducción de túneles y viaductos, lo que supone una reducción de los costes de inversión. Un aumento de la velocidad de diseño requiere a los trenes más potencia, pero a la vez les permite circular por rampas con mayor inclinación y con ello, reducir el número y longitud de túneles y viaductos necesarios.

- Sección de túnel, la sección libre de los túneles debe ser mayor cuanto mayor sea la velocidad a la que va a circular el tren por el túnel para no rebasar los límites admisibles de la presión aerodinámica. La construcción de mayores secciones de túnel significa mayor coste para el mismo tipo (monotubo o bitubo), por lo que un aumento de la velocidad conlleva desde este punto de vista un aumento del coste de inversión. dependiendo de la proporción de línea que discurra en túnel (y de la propia de longitud de los túneles), el aumento del coste al crecer la velocidad será mayor o menor.

- Anchura de plataforma, a mayor velocidad a la que circulan los trenes en una línea con vía doble, mayor es la distancia necesaria entre los ejes de las vías. Mantener dentro de valores admisibles los esfuerzos aerodinámicos que se transmiten entre los trenes en el cruce, incrementa el coste de construcción debido a la necesidad de una plataforma más ancha.

- Coste de la vía, el aumento de velocidad requiere un mayor espesor de la capa de balasto bajo traviesa, incrementándose en el coste. A mayor velocidad la tipología de desvíos también es afectada ya que implica la instalación de desvíos de punta móvil y de mayor radio, aumentando el coste de adquisición y de montaje. Por contrapartida al crecer la velocidad se necesitan menos desvíos para mantener la misma capacidad de la línea, los trenes tardan menos tiempo en los cantones existente entre estaciones, apartaderos o puestos de banalización ${ }^{13}$.

13 Puesto de banalización: Según el Reglamento de Circulación Ferroviaria, es una instalación de carácter técnico que permite la banalización de la circulación de trenes. Banalización: En trayectos con vía doble, los trenes circulan en ambos sentidos por cada vía ya que se consideran independientes en cuanto a paridad, es decir, los trenes pares o impares pueden circular por vía par o impar. 
El carril y las traviesas son elementos de la vía cuyos costes de montaje no presentan variación al variar la velocidad de diseño de la infraestructura.

- Coste de electrificación, una mayor velocidad supone un aumento de costes respecto a subestaciones, el aumento de circulaciones requiere un aumento de potencia de los transformadores, incrementando la intensidad que circula por la línea aérea de contacto siendo necesario el montaje de cables de mayor sección.

- Instalaciones de señalización y comunicaciones, el coste reside en la tipología de señales y en los sistemas de protección del tren. El incremento del coste viene determinado por las señales de tipo luminoso requeridas, la existencia de un sistema de bloqueo ${ }^{14}$ que debe ser automático, un equipamiento con un sistema de repetición de señales y frenado automático, un sistema de señalización en cabina y con sistemas de protección del tren de información continua. Para velocidades superiores a $300 \mathrm{~km} / \mathrm{h}$ se requieren además sistemas de protección de supervisión continua.

Sin embargo se produce una reducción del coste al aumentar la velocidad determinado por la menor necesidad de apartaderos o puestos de banalización y por la reducción del trazado de la línea.

- Costes de expropiación, un aumento de la velocidad reduce la longitud del trazado y menos superficie de terrenos a expropiar.

Los costes de construcción de las estaciones se han obtenido con los datos facilitados por el administrador:

\section{Coste de construcción de las estaciones en M€}

\begin{tabular}{ll} 
Cuenca Fernando Zóbel & 19,81 \\
Requena Utiel & 14,23 \\
Valencia Joaquín Sorolla & 25,31 \\
\multicolumn{1}{r}{ Total } & 59,35
\end{tabular}

Tabla 42. Costes de construcción estaciones línea. Fuente: Adif 2009-2010.

\footnotetext{
14 Bloqueo: Sistema cuyo objetivo es garantizar que los trenes que circulen por la misma vía y en el mismo sentido, lo hagan separados a una distancia que impida su alcance, y que cuando un tren circule por una vía, no circule otro en sentido contrario por la misma vía.
} 
La construcción de una nueva línea de alta velocidad siempre ha sido tema de polémica incluso se ha escrito que es más cara que la adaptación de una línea convencional para una velocidad de $200 \mathrm{~km} / \mathrm{h}$.

Según un estudio realizado por García Álvarez (2014) entre la decisión de construir simultáneamente la nueva línea de AV Madrid-Sevilla $(471$ km, 270 $\mathrm{km} / \mathrm{h}$ ) y de transformar el Corredor Mediterráneo Alicante-Barcelona (506 $\mathrm{km}, 220 \mathrm{~km} / \mathrm{h}$ ) permite visualizar las ventajas e inconvenientes de una u otra opción. La decisión de acometer ambas inversiones fue tomada en 1986 el mismo día. El plazo de construcción de la línea de Madrid a Sevilla se terminó en 1992 y desde entonces está en explotación, el Corredor Mediterráneo a fecha 2014 (28 años después) faltaba por construir el 30\% y se van a hacer obras de reconfiguración en buena parte del resto.

El coste de la infraestructura de la línea Madrid a Sevilla costó $317.000 \mathrm{M}$ de pesetas, es imposible saber el coste hasta ahora del Corredor, pero el Ministro de Fomento, en 2011 declaró en una visita que el coste, solo en el periodo 2000-2010 había sido de 1,2 billones de pesetas. En cuanto a la afectación a la explotación, para la construcción de la línea de Madrid a Sevilla no se establecieron limitaciones de velocidad relevantes ni de capacidad, en el Corredor Mediterráneo desde 1987 se incrementaron los tiempos de viaje y solo en 1996 se recuperaron los tiempos anteriores.

En la línea de Madrid a Sevilla, tras la conclusión de las obras, el tiempo de viaje de los trenes de mercancías en la línea convencional pasó de 9 a 6 horas de media y la capacidad para éstos pasó a ser ilimitada. En el Corredor Mediterráneo, el tiempo de viaje de los trenes de mercancías apenas se ha reducido y la capacidad disponible para ellos sigue siendo la misma, siendo agravado por la puesta en marcha del 3er carril.

\section{Costes de amortización.}

La amortización es el coste imputado por el uso del equipo productivo en su utilización dentro del proceso de producción. El criterio aplicado por Adif para la valoración de bienes que forman la infraestructura está establecido de manera sistemática y racional, en función de su vida útil y de su valor residual, atendiendo a la depreciación que normalmente sufren por su funcionamiento y uso. 
A continuación se muestran los años de amortización de los elementos de la infraestructura según ADIF:

\begin{tabular}{|c|c|}
\hline ELEMENTOS & AÑOS \\
\hline \multicolumn{2}{|l|}{ Plataforma } \\
\hline Movimientos de tierra & 100 \\
\hline Obras de fábrica & 100 \\
\hline Túnes y Puentes & 100 \\
\hline Drenajes & 25 \\
\hline Cerramiento & 50 \\
\hline Superestructura de vía & $30-60$ \\
\hline \multicolumn{2}{|l|}{ Instalaciones eléctricas } \\
\hline Línea áera de contacto & 20 \\
\hline Elementos soporte de catenaria & 60 \\
\hline Subestaciones eléctricas & 60 \\
\hline Instalaciones de seguridad, comunicaciones y señalización & 25 \\
\hline Edificios y otras construcciones & 50 \\
\hline Material móvil & $10-20$ \\
\hline
\end{tabular}

Tabla 43. Años amortización elementos infraestructura. Fuente: Informe de auditoría de las cuentas anuales ADIF Ejercicio 2017.

Según la tabla anterior, se amortizan todos los bienes excepto los terrenos no teniendo impacto en la cuenta de resultados la amortización de las inversiones realizadas con aportaciones de capital procedentes del Estado ni de los Fondos Europeos. En 2014 los costes de amortización de ADIF AV ascendieron a 158 millones de euros, 61.000 euros/km de línea.

\section{Costes financieros.}

Los costes financieros corresponden en su mayor parte a la financiación de los costes de inversión en la infraestructura no cubierta por la aportación del Estado o Fondos Europeos. Puede estimarse un tipo de interés medio anual del $2 \%$ y hasta la fecha de puesta en servicio están incluidos en el valor de la inversión. En 2014 los costes financieros de ADIF AV fueron de 197,6 millones de euros, 76.000 euros/km de línea ${ }^{15}$.

15 García Álvarez, A. Alta Velocidad e Intercity (2019). 
Costes corrientes.

Los costes corrientes de la infraestructura comprenden el mantenimiento de todos los elementos, costes de operación, la vigilancia, seguros, etc. Normalmente parte de estos costes son fijos, es decir, independientes del tráfico de la línea. Para la línea de alta velocidad se estima un coste fijo anual de 60.000 euros $/ \mathrm{km}$. año y un coste variable de $2 € /$ tren.km ${ }^{16}$.

Los costes de operación están compuestos por aquellos costes necesarios para la planificación y adjudicación de la capacidad así como por los generados por la gestión del tráfico. Estos costes comprenden los costes del personal encargado de estas tareas, de los equipos que emplean y del telemando de las instalaciones automatizadas que regulan el tráfico siendo de $5,96 € / \mathrm{km}$. tren. Los costes de mantenimiento incluyen los recursos humanos y material que aseguran el estado de funcionamiento de todos los sistemas que constituyen la infraestructura: plataforma, vía, electrificación, señalización, sistemas de comunicaciones, elementos de supervisión y equipos de control y mando del tráfico. Una parte de estos costes de mantenimiento es fija, depende de programas periódicos que se realizan de forma independiente del volumen de tráfico para mantener un nivel de servicio y seguridad. Otra parte de estos gastos está influenciada por la intensidad de uso debido al tráfico soportado y también por los gastos originados como consecuencia de las inclemencias meteorológicas que pudieran producirse.

De forma generalizada, no exhaustiva, se describen a continuación los trabajos de mantenimiento preventivo:

\section{En infraestructura:}

- Conservación de la plataforma.

- Prevención de incendios.

- Mantenimiento de la infraestructura de las salidas de emergencia (excepto señalización e instalaciones de protección civil de túnel).

- Mantenimiento en pleno estado operativo de los sistemas de drenaje longitudinal y transversal.

16 García Álvarez, A. Alta Velocidad e Intercity (2019). 
- Mantenimiento del cerramiento y vallado de la línea, incluyendo sus puertas de seguridad antivandálicas. Incluye el mantenimiento de las pantallas de aislamiento acústico, pantallas de prevención de impacto de aves y pantallas de protección de pasos superiores, detectores de caídas de objetos.

- Tala de árboles y arbustos que afecten a las instalaciones.

- Realización de actividades de descaste de conejos.

- Gestión de residuos generados durante los procesos de mantenimiento.

- Mantenimiento de parcelas y caminos propiedad de Adif.

- Mantenimiento de obras de fábrica y estructuras que forman parte de la infraestructura.

\section{En vía y aparatos de vía:}

- Inspecciones de vía, reparación y conservación de vía y aparatos de vía.

- Conservación de la calidad de la geometría de la vía y de los aparatos de vía.

- Vigilancia y garantía sobre el correcto funcionamiento de los elementos de la superestructura de la vía.

- Gestión de almacenes: control de los stocks de materiales que sean propiedad de Adif, destinados a su utilización como repuestos en vía y aparatos de vía.

- Acompañamientos y pilotajes al personal técnico de Adif.

- Conservación y colocación de todo tipo de carteles de señalización en vía, incluidos los derivados de cambios normativos.

- Mantenimiento de edificaciones asociadas a las bases de mantenimiento junto con todo su equipamiento.

\section{Línea Aérea de Contacto:}

Elementos por mantener:

- Cimentaciones.

- Postes.

- Dinteles de pórticos y ménsulas.

- Silletas en ménsulas y túneles.

- Soportes de equipos.

- Equipos de ménsula.

- Tirantes de anclaje. 
- Equipos de tensión mecánica.

- Cable sustentador, hilo de contacto, péndolas.

- Seccionamientos.

- Zonas neutras/Agujas aéreas.

- Seccionadores, timonería y accionamientos.

- Alimentación y control de telemando de seccionadores.

- Aisladores, uniones y conexiones.

- Feeders y cables de retorno, retorno desde carriles a subestaciones.

- Alimentación y conexiones desde pórticos de salida de subestaciones y centros de autotransformación.

- Canalizaciones, arquetas y galerías.

- Puesta a tierra de estructuras metálicas.

- Señales de aviso y protección de catenaria.

- Etiquetado de postes y cuadros, así como las de riesgo de electrificación.

- Accionamientos y transmisiones de los seccionadores de catenaria.

- Transformadores de $25 \mathrm{kv} / 230 \mathrm{~V}$, tanto aéreos como en caseta.

- Sistema de calefacción de agujas (calefactores, alimentación, cableado, armarios, control, sondas de temperatura y humedad).

- Sistema de alumbrado de túneles

- Acometidas a edificios técnicos.

- Instalaciones de catenaria en cambiadores de ancho.

- Detectores de cortocircuito en vías de estación/Detectores de tensión.

\section{Instalaciones de seguridad y señalización:}

Las instalaciones comprendidas son las siguientes:

- Enclavamientos electrónicos/Circuitos de vía, contadores de Ejes.

- CTC.

- Mando, Control y Supervisión de Desvíos y sensores de rueda

- Accionamientos de desvíos y comprobadores de posición de aguja.

- Señalización lateral.

- $\quad$ ASFA, ERTMS Nivel 1 y Nivel 2.

- Sistemas de energía, Salas Técnicas. 
- Detectores o Detectores Cajas Calientes (DCC), Detectores de Caída de Objetos (DCO), Detectores de Viento Lateral (DVL).

- Edificios Técnicos y edificio del Centro de Regulación y Control.

- Aire Acondicionado.

- Cables de alimentación y señalización, cajas de conexión.

Se considera mantenimiento correctivo a las siguientes actividades que no son programables y surgen a raíz de una incidencia o una contingencia:

- Atención a incidencias: son todas aquellas actuaciones que no son programables o previsibles y requieren la atención inmediata.

- Aplicación de los distintos planes de contingencia de Adif, tales como la aplicación de las medidas preventivas de invierno y verano, el establecimiento de vigilancia y medidas preventivas o correctivas en caso de alerta por temporal u otras causas.

- Prestación de socorro a trenes con incidencias y, en especial, asistencia a trenes de viajeros que hayan sufrida pérdida de tensión o tracción.

\begin{tabular}{lr} 
Costes Fijos Explotación & $60.000 € / \mathrm{km}$ \\
Costes Amortización Infraestructura & $61.000 € / \mathrm{km}$ \\
Costes Financieros Infraestructura & $76.000 € / \mathrm{km}$ \\
\multicolumn{1}{c}{ Tabla 44. Resumen de costes infraestructura. Fuente: García Álvarez, 2014.}
\end{tabular}

Costes ambientales.

Aun no siendo del ámbito de esta Tesis, se va a realizar un resumen del tema que está relacionado con la alta velocidad y que es interesante hacer mención así como a sus autores.

Las críticas más fuertes al ferrocarril han sido llevadas a cabo por ecologistas que llegan a recomendar el uso del ferrocarril convencional frente al de alta velocidad (Ecoloxistes-Asturies,2010) fundamentando, de forma errónea, un gran aumento del gasto energético para una escasa reducción del tiempo de viaje empleado (Greenpace,2009) y la alta dependencia de las fuentes de energía fósiles para la generación de la energía eléctrica necesaria para su movimiento. García Álvarez (2005) muestra que el consumo energético del tren de alta velocidad no es muy diferente al del tren convencional, incluso suele ser menor. 
En 2007 el mismo autor junto a Martín Cañizares comparan el consumo de energía de un mismo tren por línea convencional y alta velocidad y concluyen que el consumo de energía es inferior en la línea de alta velocidad en los casos analizados. En 2007, García Álvarez compara las emisiones del tren de alta velocidad con las de otros medios de transporte resultando que en siete de las diez rutas analizadas el tren de alta velocidad es el modo de transporte que menos emisiones emite. Por término medio, las emisiones del tren convencional son superiores en un $40 \%$ a las del tren de alta velocidad.

Beneficios económico-sociales.

García Álvarez (2008) muestra gráficamente, a partir de datos de casos reales como en tiempo de viaje invertido por el tren menor a 2 horas se obtiene cuota de mercado por encima del $85 \%$ y si el tiempo de viaje es superior a las 3 horas las cuotas están por debajo del $50 \%$.

La relación existente entre la movilidad que inducen las líneas de alta velocidad y el Producto Interior Bruto, ha sido estudiada en varias ocasiones. Citar el estudio realizado por Fernández, 2015 dentro del proyecto Optired, en el que se comprueba que la demanda crece cuando el PIB crece por encima del $1 \%$.

Posteriormente en 2015 realiza un proceso de actualización, eliminando también aquellos años con grandes variaciones en la oferta, consiguiendo un ajuste más preciso:

Var. Demanda (\%) $=0,11698^{*}(\operatorname{Var} P I B(\%)-(0,8817)) 2+1,906^{*}(\operatorname{Var} P I B(\%)-0,8817)$

La estimación de la evolución de la demanda a lo largo de la vida de una infraestructura puede abordarse analizando la evolución de la demanda en líneas de alta velocidad existentes, obteniendo de ellas el porcentaje medio de crecimiento y aplicarlo al caso estudio. Como estudios relevantes se citan:

- De Rus \& Nash en 2009 estudian línea Madrid-Sevilla en funcionamiento desde 1992 y estiman la evolución de la demanda para 30 años de vida del proyecto en un 3,125\% acumulativo anual; suponiendo un crecimiento tendencial del PIB del 2,5\% y una elasticidad de la demanda respecto a esta variable de 1,25. 
- Fröidh en 2012, sugiere un crecimiento anual de la demanda del $1,43 \%$ para los primeros 35 años de proyecto, después de los cuales la demanda se vuelve constante.

Viabilidad económica de las líneas de alta velocidad.

Algunos trabajos han establecido parámetros de aproximación a la viabilidad económica de las inversiones realizadas en este tipo de infraestructuras. Según De Rus y Nombela (2007) la estimación de las inversiones en alta velocidad es difícil de justificar cuando en el primer año de operación la demanda no excede los 8 millones de pasajeros en una línea de $500 \mathrm{~km}$ y bajo una serie de supuestos favorables. A juzgar por estos valores de referencia, y por otros procedentes de fuentes académicas e institucionales, una línea de alta velocidad debería tener nueve millones de viajeros 17 , o como mínimo seis millones, en el año de apertura para tener éxito. Según se cita en este trabajo y teniendo en cuenta el resultado financiero con ingresos y costes medios en España del año 2014, el equilibrio queda establecido alrededor de los 4.800 .000 viajeros/año, lo que demuestra que estos datos no se sostienen.

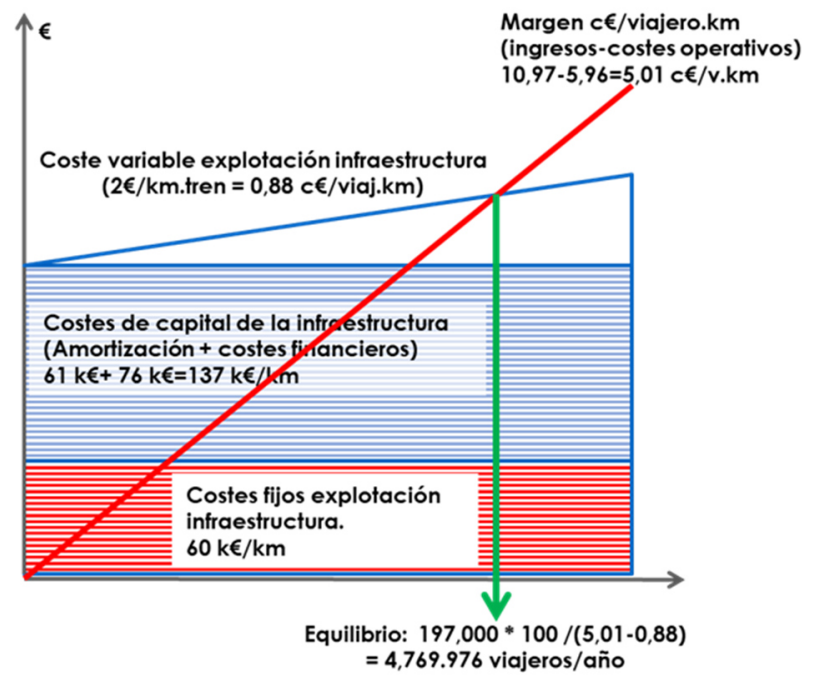

Gráfico 17. Resultado financiero línea AV en España año 2014. Fuente: García Álvarez

\footnotetext{
17 La cifra de 9 millones de pasajeros figura en: «¿En qué circunstancias está justificado invertir en líneas de alta velocidad ferroviaria?», De Rus, Gines, y Nash, C.A., Munich Personal RePEc Archive (MPRA), diciembre de 2007, así como en el documento «Guide to Cost Benefit Analysis of Investment Projects» de la Comisión Europea, 2008, p. 84 (este valor de referencia del análisis coste-beneficio de la Comisión desapareció de su última edición de 2014), probablemente por la incertidumbre del dato.
} 
Los costes de construcción dependen de varios factores, como son las características del territorio por donde va a discurrir así como del diseño de la línea. Los costes son mayores en zonas urbanas y densamente pobladas así como también lo son los trazados en zonas de orografía donde se requiera la construcción de viaductos y túneles.

Uno de los factores clave para determinar los costes de inversión es la velocidad de operación.

No son las líneas de alta velocidad más caras cuanta mayor sea la velocidad pero sí suponen una mayor inversión y mayores costes de mantenimiento que a su vez se materializan en un incremento de los ingresos, una reducción de los costes operativos permitiendo la captación (creciente con la velocidad) de viajeros de otros modos de transporte con mayores costes externos.

Por otro lado, la integración de la red de alta velocidad en la red de tráfico convencional, especialmente en el acceso a grandes ciudades, o la ubicación de estaciones en los centros o en las periferias urbanas tienen un gran "peso" en la determinación de los costes de inversión debido al elevado coste de las expropiaciones en terreno urbano.

Otro factor que afecta al coste de inversión es la funcionalidad de la red diseñada, el uso para trenes de mercancías exige unos parámetros de diseño más exigentes.

El administrador de la infraestructura está interesado en la recuperación de los fondos invertidos y los usuarios finales están interesados en un modo de transporte rápido, barato, frecuente y de calidad. Este sistema funciona dentro de un marco de fuerzas de la legislación, regulación y de mercado existentes.

Como soluciones para la reducción de los cánones sería suprimir las barreras técnicas, administrativas y de otros tipos, como la interoperabilidad ferroviaria, haciendo de esta manera que los servicios sean más frecuentes y de mayor calidad, bajando el precio de los títulos de transporte.

Puesto que las infraestructuras ferroviarias son inversiones caras, resulta fundamental analizar correctamente todos los costes y beneficios principales por adelantado antes de decidir si construir o no haciendo posible evaluar el rendimiento social de la inversión de un proyecto y su aceptación y utilidad social antes de adoptar cualquier decisión. 
La inversión en líneas de alta velocidad únicamente está justificada si pueden alcanzarse rendimientos de alta velocidad: cuanto mayor sea la base de la población (demanda futura), mayor sea la elasticidad del tiempo del trayecto ${ }^{18}$ y el rendimiento de la velocidad, mayores son los beneficios que se pueden obtener de una línea de alta velocidad.

Tampoco es cierto que la opción de mejorar las líneas convencionales existentes con el fin de aumentar las velocidades en lugar de construir una nueva línea de alta velocidad es más económica, ya que no genera un ahorro importante en los costes además de la prolongación en el tiempo la adecuación y las interferencias que ocasiona al tráfico existente. (Línea AV Madrid-Sevilla vs. Corredor Mediterráneo).

La inversión en alta velocidad puede ser beneficiosa en corredores de media distancia entre áreas metropolitanas populosas, sometidos a alta congestión, y con una demanda potencial muy elevada. Sin embargo, en la práctica se ha tendido a extender las redes mucho más allá de lo que hubiese sido razonable, con resultados económicos y sociales precarios, que están muy lejos de ser compensados por beneficios extraeconómicos de los que no existe evidencia.

El modelo de política que ha dado lugar a la red de alta velocidad más extensa del mundo en términos relativos y la segunda en términos absolutos, con los niveles de demanda más bajos entre todos los países en que se ha implantado.

\footnotetext{
18 Esto se refiere a la disposición de los posibles pasajeros a alterar su conducta en respuesta a los cambios en el tiempo de los trayectos: una gran elasticidad del tiempo del trayecto indica que los pasajeros están relativamente dispuestos a cambiar al ferrocarril cuando los tiempos de los trayectos se mejoren.
} 
4.2 Uso de las estaciones línea de Alta Velocidad Madrid-Levante e ingresos asociados en concepto de canon.

Introducción.

Dentro del canon por utilización de las instalaciones de servicio encontramos los siguientes conceptos, siendo de estudio en este capítulo el canon por utilización de las estaciones de transporte de viajeros (Modalidad A).

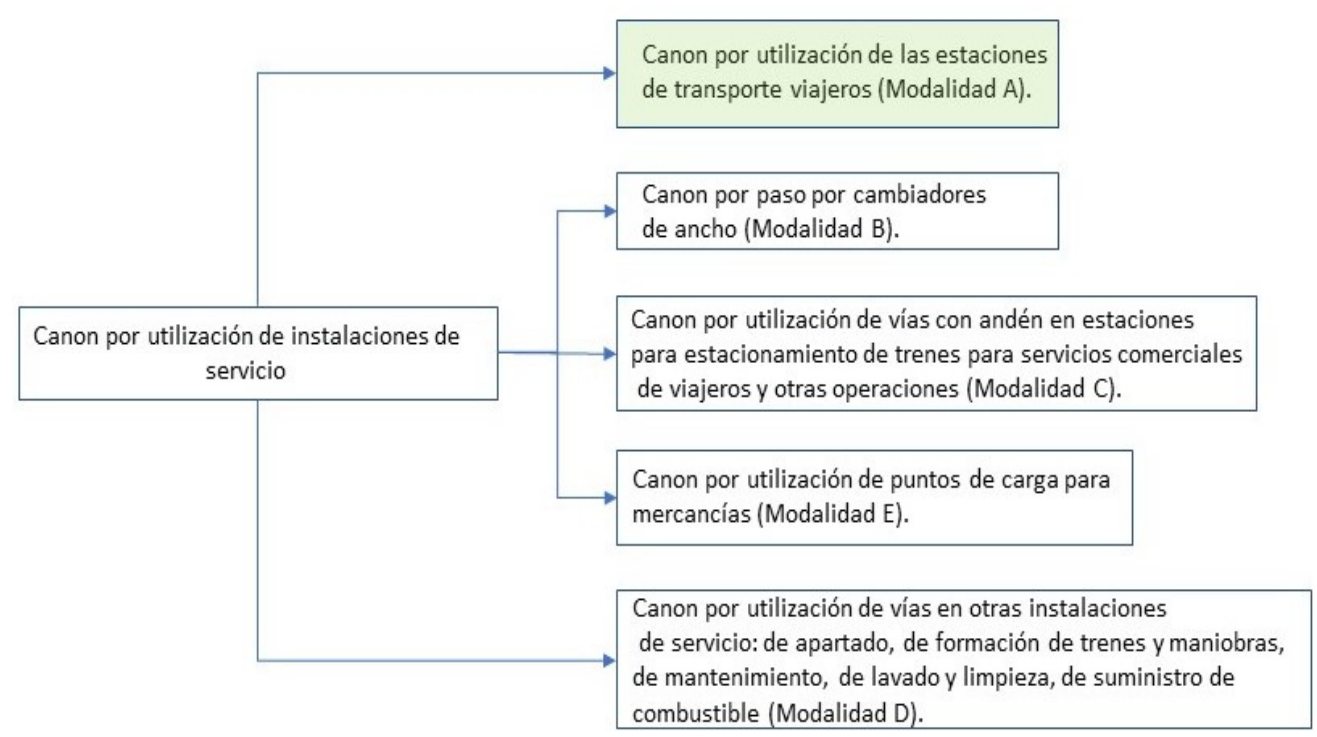

Gráfico 18. Canon por utilización de instalaciones de servicio. Elaboración propia.

El modelo contable de Adif-Adif Alta Velocidad se fundamenta en la identificación de los costes de prestación del servicio ferroviario con el fin de identificar las áreas cuya actividad está relacionada con la prestación del mencionado servicio.

Los flujos económicos se registran en unidades de gasto denominadas centros de coste que se agrupan en divisiones y estas a su vez en segmentos. Las divisiones, agregan centros de coste desde el punto de vista organizativo y desde el punto de vista de la actividad que desarrollan. Esta distribución en función de la actividad desarrollada segmenta e identifica los gastos imputados a actividades relacionadas directamente con la explotación del servicio ferroviario a través de las divisiones donde se imputan. 
El objetivo final del modelo de costes es la imputación de los costes de prestación del servicio a cada modalidad de canon, que se realiza considerando únicamente las divisiones en que se recogen los conceptos de costes recuperables de acuerdo con lo establecido en los artículos 97 y 98 de la LSF. El modelo de costes del gestor ferroviario se realiza para las dos empresas que lo forman, ADIF y ADIF AV, y el resultado es la obtención de un coste conjunto para la totalidad de la red, tanto convencional como de alta velocidad. La totalidad de los segmentos recogidos en el modelo contable, únicamente se consideran imputables tres de ellos para la obtención de los costes de los cánones correspondientes a los artículos 97 y 98 de la Ley del Sector Ferroviario.

El segmento de Administración de Red de ADIF y ADIF AV en el caso del artículo 97, y los de Gestión de Estaciones y Otros Activos de ADIF y ADIF AV y Gestión de Red y Estaciones ADIF AV en el caso del artículo 98.

Las fases del modelo de costes hasta la obtención de los costes de prestación del servicio según el canon por utilización de las líneas ferroviarias y por utilización de las instalaciones de servicio de los artículos 97 y 98 de la Ley del Sector Ferroviario, son las siguientes:

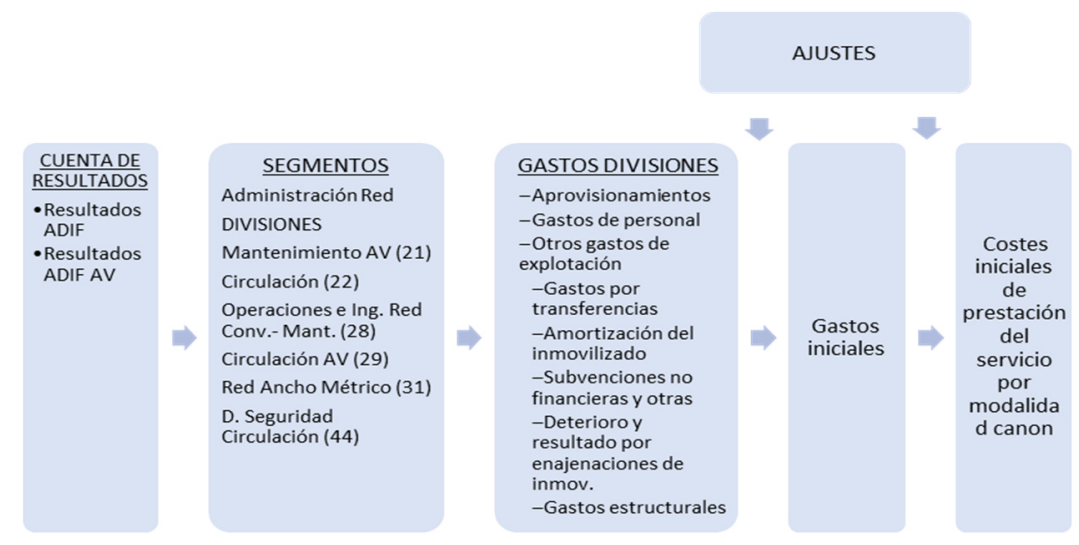

Gráfico 19. Fases del modelo de costes empleado por Adif y Adif Alta Velocidad según art.97 de la Ley del Sector Ferroviario. Elaboración propia. 


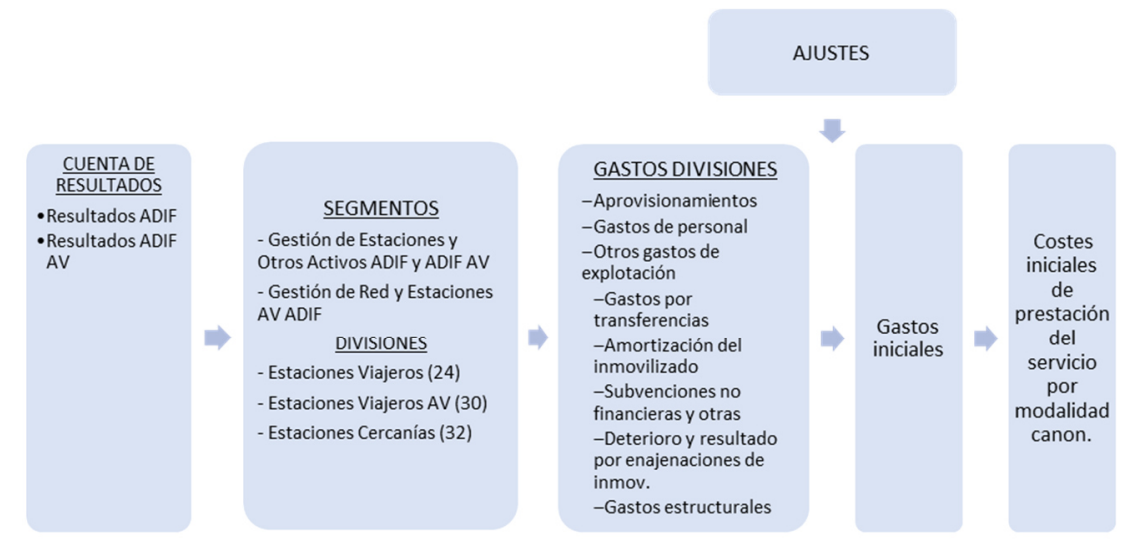

Gráfico 20. Fases del modelo de costes empleado por Adif y Adif Alta Velocidad según art.98 de la Ley del Sector Ferroviario. Elaboración propia.

Para el canon por utilización de las instalaciones de servicio (art. 98) el modelo se centra en el canon por utilización de las estaciones de transporte de viajeros (Modalidad A), ya que para el resto del artículo 98 el gestor de infraestructuras dispone de cuentas específicas $y$, por tanto, los costes se calculan directamente. A continuación se detallan las divisiones que se consideran imputables para el cálculo de los costes subyacentes relacionados con el servicio ferroviario tanto para ADIF como para ADIF AV:

\section{DIVISIONES}

\begin{tabular}{|c|c|c|}
\hline & ADIF & ADIF ALTA VELOCIDAD \\
\hline 21 & Mantenimiento AV & 21 Mantenimiento AV \\
\hline 22 & Circulación Red Convencional & 29 Circulación AV \\
\hline 24 & Estaciones de Viajeros & 30 Estaciones de Viajeros AV \\
\hline 28 & Mantenimiento Red Convencional & 44 Seguridad en la Circulación \\
\hline 29 & Circulación Alta Velocidad & 46 Planificación y Gestión de Red \\
\hline 30 & Estaciones de Viajeros Alta Velocidad & \\
\hline 31 & Red de Ancho Métrico (Mto y Circulación) & \\
\hline 44 & Seguridad en la Circulación & \\
\hline 46 & Planificación y Gestión de Red & \\
\hline
\end{tabular}

Tabla 45. Divisiones imputables para el cálculo de costes subyacentes. Fuente: ADIF y ADIF AV. 
Posteriormente, el modelo asigna las divisiones (o las partes de ellas que se consideran imputables) a cada una de las modalidades de canon a las que refiere tanto el artículo 97 como el 98 de la Ley 38/2015. Por último, de cara a la obtención de los costes iniciales del modelo, se realizan determinados ajustes, en concreto, se detraen de los costes asignados a las mismas, los costes de amortización (neta de subvenciones) registrados en la modalidad B del artículo 97 ya que la ley no contempla como coste recuperable vía canon los costes de reposición. En relación con el artículo 98 se eliminan los costes derivados de la actividad comercial de las estaciones (canal de venta, aparcamiento y consigna), al no considerarse costes relacionados con la prestación del servicio.

\section{Clasificación de las estaciones.}

Las estaciones de transporte de viajeros están concebidas como lugares de referencia de la ciudad, dotadas de espacios accesibles y funcionales donde los viajeros pueden disfrutar de servicios relacionados con el ferrocarril y el intercambio modal, oferta comercial y actividades socioculturales. Están clasificadas en 6 categorías, las 5 primeras categorías corresponden con aquellas que prestan servicios interurbanos o de larga distancia y la sexta corresponde a estaciones asignadas a servicios de cercanías.

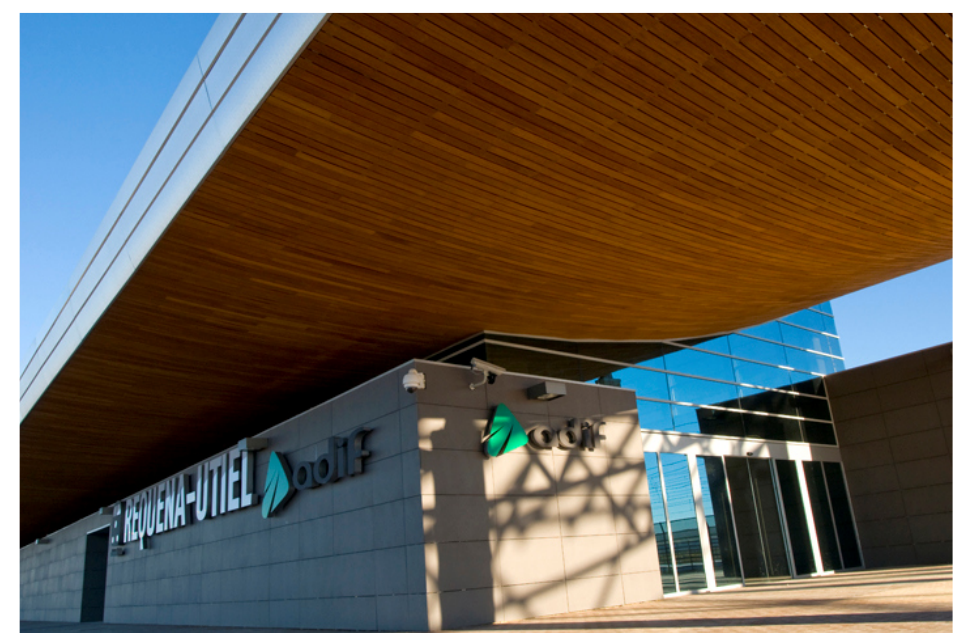

Imagen 1. Estación de Requena-Utiel. Fuente: ADIF. 
La clasificación de este grupo de estaciones es resultado de la aplicación de la siguiente fórmula:

$$
C=\sum_{i=1}^{5}(K i \cdot P i)
$$

La categoría de la estación se determina en función del valor C, perteneciendo a la categoría 1 las estaciones con valores $C>4$, a la categoría 2, las estaciones con valores $C$ entre 3 y 4 , y así sucesivamente.

Son estaciones de categoría 5 las que no pertenecen a ninguna de las anteriores (no prestan servicios de larga distancia) o bien su índice $C<1,3$. Para obtener el valor de $C$ es necesario evaluar 5 criterios que determinan el valor Ki y ponderarlos por el valor Pi.

Los criterios evaluados son:

1) Número de viajeros que entran y salen de la estación,

2) Número de trenes con parada en la estación.

3) Tamaño de la estación, medido en metros cuadrados de las áreas de utilización pública de la estación.

4) Intermodalidad de la estación, función del número de enlaces con otros medios de transporte.

5) Ubicación (según líneas) y número de andenes.

La tabla siguiente presenta los valores del índice $K$ en función de los diferentes parámetros:

\begin{tabular}{|c|c|c|c|c|c|c|}
\hline Criterio & $K=1$ & $K=2$ & $K=3$ & $K=4$ & $K=5$ & $\begin{array}{c}\text { Valor } \\
\mathrm{Pi}\end{array}$ \\
\hline \multirow{4}{*}{ Número de viajeros (V) } & $\begin{array}{c}\text { Viajeros larga distancia } \\
\text { e interurbanos }\end{array}$ & $\begin{array}{c}\text { Viajeros larga distancia } \\
\text { e interurbanos }\end{array}$ & $\begin{array}{c}\text { Viajeros larga distancia } \\
\text { e interurbanos }\end{array}$ & $\begin{array}{c}\text { Viajeros larga distancia } \\
\text { e interurbanos }\end{array}$ & $\begin{array}{c}\text { Viajeros larga distancia } \\
\text { e interurbanos }\end{array}$ & \multirow{4}{*}{0,30} \\
\hline & $V<150$ & $150<=V<750$ & $750<=V<2.000$ & $2.000<=V<10.000$ & $V>10.000$ & \\
\hline & Total viajeros & Total viajeros & Total viajeros & Total viajeros & Total viajeros & \\
\hline & $V<400$ & $400<=V<7.500$ & $7.500<=\mathrm{V}<20.000$ & $20.000<=V<100.000$ & $V>100.000$ & \\
\hline Número de trenes $(T)$ & $\mathrm{T}<25$ & $25<=\mathrm{T}<85$ & $85<=T<190$ & $190<=T<500$ & $T>500$ & 0,25 \\
\hline Tamaño de la estación (S) & $S<2.500$ & $2.500<s<5.000$ & $5.000<s<10.000$ & $10.000<s<50.000$ & $S>50.000$ & 0,25 \\
\hline Intermo-dalidad (I) & $\begin{array}{c}1<3 \\
\text { sin información } \\
\text { dedicada }\end{array}$ & $\begin{array}{c}\mid>=3 \\
\text { sin información } \\
\text { dedicada }\end{array}$ & $\begin{array}{c}I=4 \\
\text { con información } \\
\text { dedicada }\end{array}$ & $\begin{array}{c}1>4 \\
\text { con información } \\
\text { dedicada }\end{array}$ & $\begin{array}{c}1>4 \\
\text { con información } \\
\text { dedicada y tratarse } \\
\text { de un intercambiador }\end{array}$ & 0,10 \\
\hline $\begin{array}{l}\text { Ubicación y número } \\
\text { de andenes (U) }\end{array}$ & Resto situaciones & $\begin{array}{c}\text { En lineas tipo B } \\
\text { y } n .{ }^{\circ} \text { andenes }>=3\end{array}$ & $\begin{array}{c}\text { En lineas tipo } \mathrm{A} \\
\text { y } n .{ }^{\circ} \text { andenes }>=2\end{array}$ & $\begin{array}{c}\text { En capital provincia } \\
\text { o de Comunidad } \\
\text { Autónoma } \\
\text { yn. } .^{\circ} \text { andenes }>=2\end{array}$ & $\begin{array}{c}\text { En lineas tipo A } \\
\text { y capital provincia } \\
\text { o de Comunidad } \\
\text { Autónoma }\end{array}$ & 0,10 \\
\hline
\end{tabular}

Tabla 46. Valores de índice "K" para la clasificación de estaciones. Fuente: ADIF. 
Aplicada la tabla anterior, las estaciones de la línea de Alta Velocidad Madrid-Levante quedan clasificadas por las categorías siguientes:

\begin{tabular}{|c|l|}
\hline Categoría 1 & Valencia Joaquín Sorolla \\
\hline Categoría 2 & Cuenca Fernando Zóbel \\
\hline Categoría 4 & Requena-Utiel \\
\hline
\end{tabular}

Tabla 47. Categoría de las estaciones ADIF Alta Velocidad tramo Madrid-Valencia, Línea Madrid-Levante. Fuente: ADIF

Cálculo del canon por utilización de las estaciones de transporte de viajeros.

Según la Ley del Sector Ferroviario (Ley 38/2015) y de acuerdo con el apartado 4 del artículo 98, mediante este canon, se repercutirán los costes asociados al mantenimiento y conservación de las estaciones, el servicio de vigilancia de las estaciones y el control de acceso de los viajeros y sus equipajes ${ }^{19}$.

Para la determinación de los costes que sustentan el cálculo de los cánones por utilización de estaciones, se distinguen los distintos servicios que se prestan en las estaciones, utilizando el método de "Costes basados en Actividades" que permite medir el coste de las actividades necesarias para la prestación de cada servicio, y considerando únicamente los correspondientes al servicio básico. A partir de los datos correspondientes al último ejercicio cerrado se identifican los costes asociados al mantenimiento y conservación de las estaciones, a su reposición y a la prestación de los servicios básicos mínimos de las estaciones, el servicio de vigilancia de las estaciones y el control de acceso de los viajeros y sus equipajes.

La cuantía de este canon se calcula multiplicando la tarifa unitaria por el número de paradas, considerando la categoría de la estación, el tipo de parada y el tipo de tren.

19 Antes era una tasa aplicada directamente al viajero. 
Las estaciones estudiadas en el presente modelo son las estaciones que pertenecen a la línea Madrid-Levante de ADIF Alta Velocidad siendo: Cuenca-Fernando Zobel, Requena-Utiel, Valencia-Joaquín Sorolla, Castelló de la Plana, Albacete-Los Llanos, Villena AV, Alacant-Término y Murcia del Carmen. Estas estaciones son gestionadas por la Subdirección de Estaciones Este (Dirección de Estaciones de Viajeros) perteneciente a la Dirección General de Negocios y Operaciones Comerciales de ADIF, por lo que la estación de Madrid-Puerta de Atocha no está incluida en este estudio por no pertenecer a dicha Subdirección.

A fecha de terminar esta Tesis, la línea de Alta Velocidad entre AlicanteTérmino y Murcia del Carmen no se encuentra terminada por lo que los datos obtenidos para los cálculos (circulaciones y viajeros) en la estación de Murcia del Carmen son los obtenidos de los trenes de Larga Distancia.

\begin{tabular}{|c|c|r|}
\hline Estación & Tipo Parada & $\boldsymbol{\epsilon}$ /Parada Tren \\
\hline \multirow{3}{*}{ Valencia Joaquín Sorolla } & Destino & 164,0000 \\
\cline { 2 - 3 } & Intermedia & 63,7800 \\
\cline { 2 - 3 } & Origen & 182,2200 \\
\hline \multirow{3}{*}{ Cuenca Fernando Zóbel } & Destino & 78,1100 \\
\cline { 2 - 3 } & Intermedia & 30,3800 \\
\cline { 2 - 3 } & Origen & 86,7900 \\
\hline \multirow{2}{*}{ Requena-Utiel } & Destino & 33,4830 \\
\cline { 2 - 3 } & Intermedia & 13,0212 \\
\cline { 2 - 3 } & Origen & 37,2034 \\
\hline
\end{tabular}

Tabla 48. Tarifa aplicada por estaciones y tipo de parada. Fuente: ADIF.

La cuota líquida se obtiene como el resultado de aplicar sobre la cuota íntegra anterior.

En las gráficas siguientes se muestran los datos obtenidos del número de viajeros subidos-bajados en las estaciones, circulaciones de trenes en el ámbito estudiado, así como de los ingresos y gastos de las estaciones de la línea. 
VIAJEROS POR ESTACIONES 2018

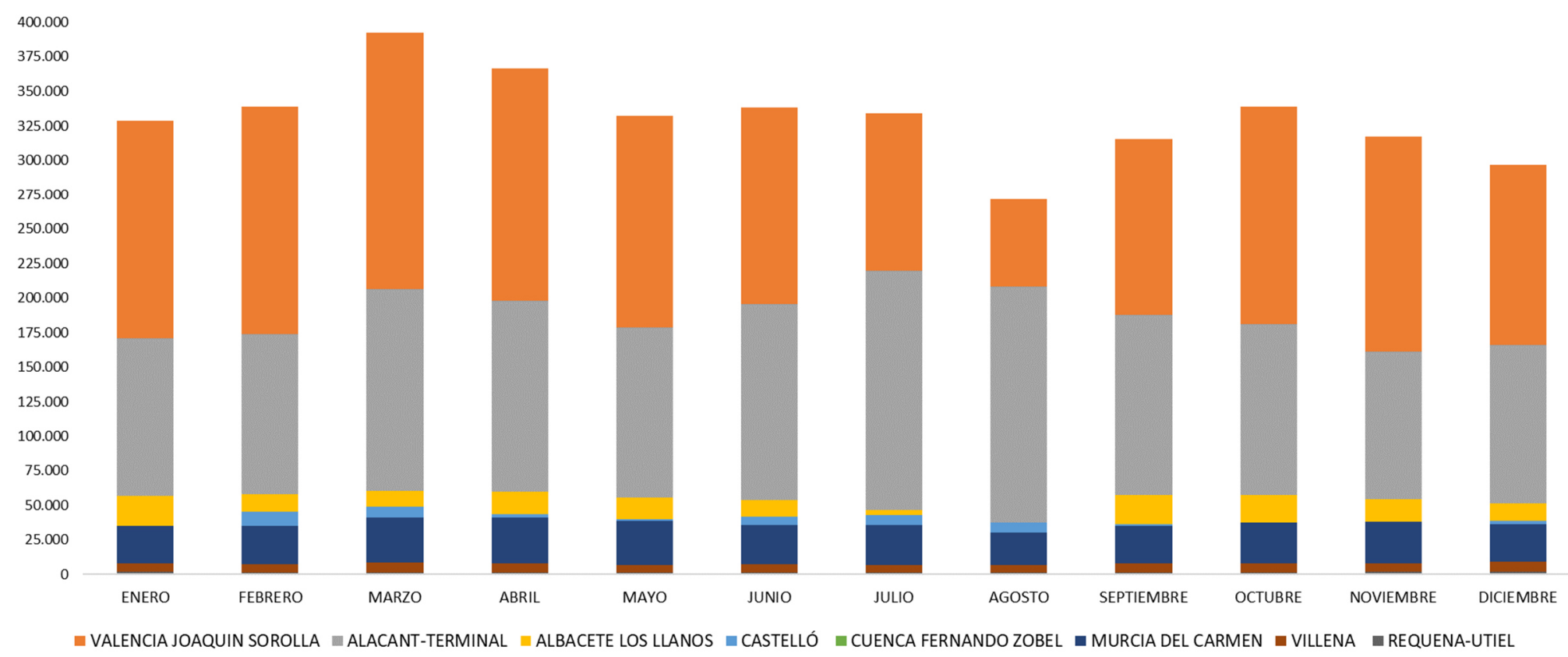

Gráfico 21. Viajeros por estaciones. Elaboración propia a partir de datos de ADIF. 
CIRCULACIONES POR ESTACIONES 2018

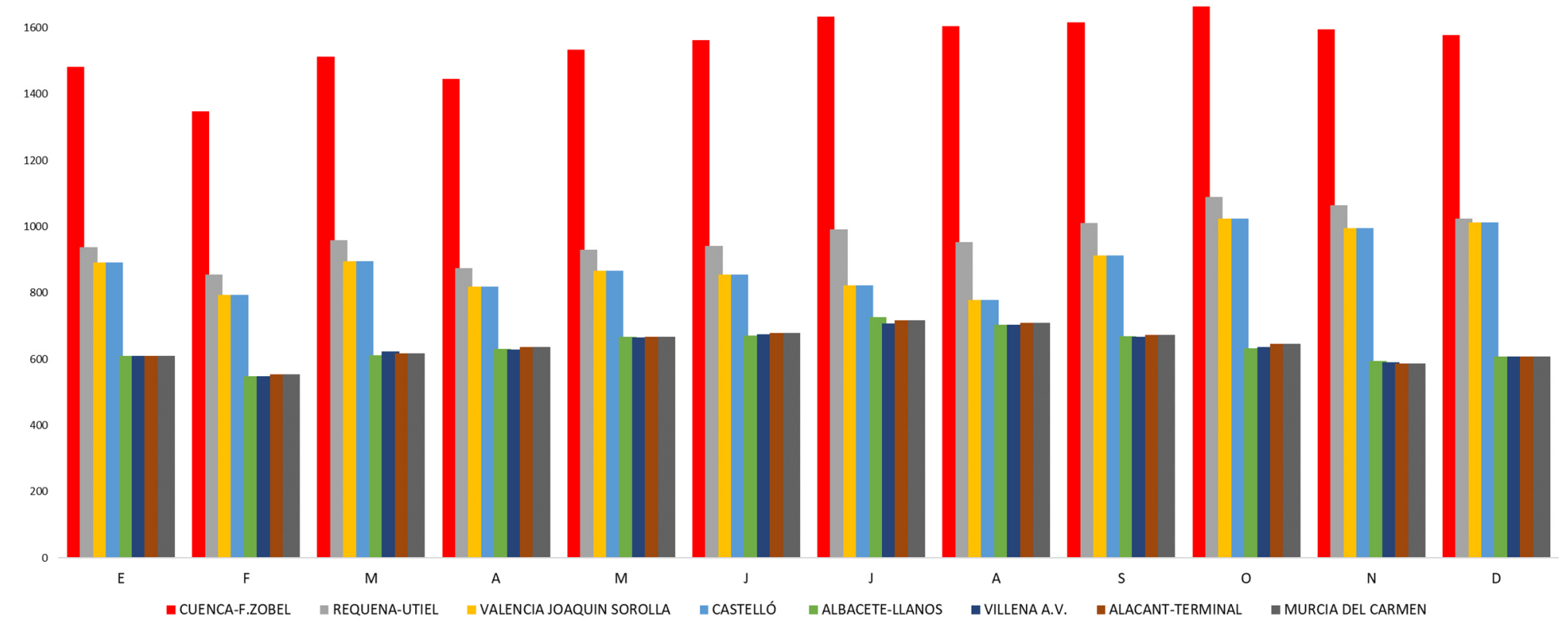

Gráfico 22. Circulaciones por estaciones. Elaboración propia a partir de datos de ADIF. 
Cánon Anual por Uso de Estaciones de Viajeros

(en miles de $€$ )

1000

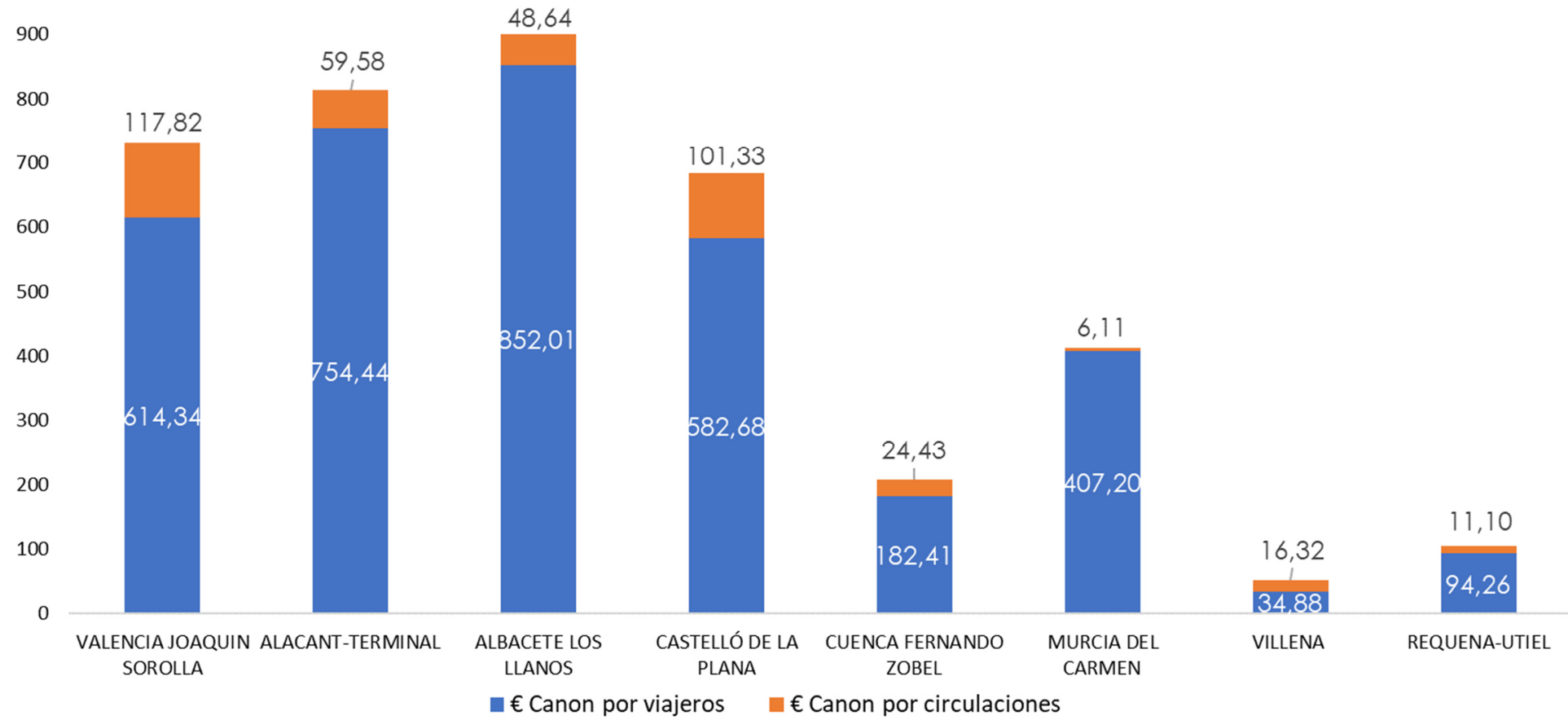

Gráfico 23. Canon anval por uso de estaciones de viajeros. Elaboración propia a partir de datos de ADIF 2018. 
En la gráfica anterior se muestra el gravamen por uso de las estaciones de viajeros. Este está compuesto por dos partes, una que es aplicada a las circulaciones, diferenciando si son estaciones origen, destino o parada intermedia y otra parte que es aplicada al número de viajeros (subidos y bajados) y llamado por uso de andenes en cada estación.

Analizados los datos obtenidos estos muestran un menor ingreso en estaciones como son Albacete Los Llanos, Cuenca Fernando Zóbel, Villena y Requena-Utiel procedente del componente de circulaciones. Esto es debido a que son estaciones clasificadas en categorías $2^{a}, 3^{a}$ y $4^{a}$ donde el canon difiere entre ellas por parada. El caso de Cuenca, Villena y RequenaUtiel presentan los valores más inferiores debido a que las circulaciones sólo efectúan paradas intermedias, lo que también supone un canon más bajo que si fueran origen o destino.

El caso de Valencia Joaquín Sorolla y Albacete-Los Llanos los valores del canon por viajeros se justifica por ser estaciones que reciben viajeros por la línea convencional y por la línea de alta velocidad ya que son estaciones comunes a ambos servicios comerciales. Valencia Joaquín Sorolla y Castellón recibe y expide trenes con destino hacia Cataluña, Alicante, Murcia y Andalucía de larga distancia y Albacete Los Llanos recibe y expide trenes hacia Madrid, Alicante y Murcia también del mismo mercado. Según los datos aportados por Adif en el ejercicio del año 2018 no se han podido segregar los viajeros que utilizaron dichas estaciones. 
4.3 Costes asociados al uso de estaciones en la línea de Alta Velocidad Madrid-Levante. Tramo Madrid-Valencia.

La recopilación de los datos reales asociados al uso de estaciones en la línea Madrid-Valencia fueron obtenidos de la Subdirección de Estaciones Este de Adif correspondientes al año 2018. Estos datos se muestran de forma resumida en la tabla siguiente:

\begin{tabular}{|l|r|r|r|}
\hline Conceptos Presupuestarios & $\begin{array}{r}\text { CUENCA } \\
\text { FERNANDO } \\
\text { ZOBEL }\end{array}$ & $\begin{array}{c}\text { REQUENA } \\
\text { UTIEL }\end{array}$ & $\begin{array}{r}\text { VALENIA } \\
\text { JOAQUIN } \\
\text { SOROLLA }\end{array}$ \\
\hline * I03016035 Alq.Arrend.Aparcam & & & $-2.750,54$ \\
** OTROS ING.EXPLOTACION & & & $-2.750,54$ \\
I1 4017015 Canon por estaciones & $-182.408,35$ & $-94.264,23$ & $-614.341,87$ \\
I1 4017020 Canon por andenes & $-24.426,84$ & $-11.097,18$ & $-117.815,74$ \\
** I.A. Otr. Ingr. Expl & $-206.835,19$ & $-105.361,41$ & $-732.157,61$ \\
*** Total Ingresos & $-206.835,19$ & $-105.361,41$ & $-734.908,15$ \\
G01011000 Sueldo / Haberes & $22.768,33$ & & $153.798,24$ \\
G01011002 Compl.pers. y pues & 241,79 & & $7.518,40$ \\
G01011014 Accid. y enfermeda & & & $5.751,08$ \\
G01011016 Remun.fijas.eje.an & 3,92 & & 20,00 \\
* G. fijos de personal & $23.014,04$ & & $167.087,47$ \\
G01021004 Primas & $9.228,50$ & & $49.309,32$ \\
G01021010 Varios de personal & $2.906,76$ & & $1.782,41$ \\
G01021011 Remun.Var.Ej.Ant. & 84,29 & & 223,60 \\
* G.Variables personal & $12.219,55$ & & $51.315,33$ \\
G01031020 Exceso de jornada & 0,00 & & $2.617,76$ \\
G01031024 Gastos de viaje & 91,82 & & 859,15 \\
G01031030 Reemplazos & $3.723,42$ & & $5.080,32$ \\
* Gastos Fluctuantes & $3.815,24$ & & $8.557,23$ \\
G01041060 Seguridad Social & $11.651,78$ & & $73.791,54$ \\
G01041061 Gastos ejerc. Ant. & 43,68 & & 422,46 \\
* Gastos Seg. Social & $11.695,46$ & & $74.214,00$ \\
** GASTOS DE PERSONAL & $50.744,29$ & & $301.174,03$
\end{tabular}




\begin{tabular}{|l|r|r|r|}
\hline G04034340 Consumo de agua & & & $6.735,19$ \\
G04034520 Alq.Maq.Inst.El.Au & & & 190,00 \\
G04034600 Rep.Cons.Electrifi & 460,62 & 637,74 & 586,50 \\
G04034625 Rep.Cons.Edificios & $6.723,21$ & $1.503,81$ & $8.747,75$ \\
G04034630 Rep.Cons.Inst.Edif & $33.504,36$ & $38.944,29$ & $57.702,99$ \\
G04034635 Limpieza edificios & $62.669,41$ & $23.110,97$ & $268.101,59$ \\
G04034665 R.C.Ot.V.Maq.Med.A & & & $3.014,00$ \\
G04034685 R.C.Inst.Eq.Varios & $1.730,00$ & $8.583,53$ & $2.589,00$ \\
G04034695 Rep.Cons.Consignas & & & $4.136,00$ \\
G04034750 Publicidad general & & & $2.268,00$ \\
G04034775 Gtos.Viaj.Personal & 238,65 & $2.504,01$ & 849,00 \\
G04034810 Gastos.Mat.Uniform & 178,82 & 216,00 & 248,00 \\
G04034835 Otros servicios ex & & & 212,00 \\
G04034840 Teléfonos & & & 215,00 \\
* Serv.Ext.Gastos.Div. & $105.505,07$ & $75.500,10$ & $355.593,81$ \\
G04064790 Tributos y tasas & $1.841,06$ & 251,79 & $5.852,67$ \\
* Tributos & $1.841,06$ & 251,79 & $5.852,67$ \\
G04074797 Actuac.Urb.Y.Cta.T & $24.426,84$ & $11.097,18$ & $117.815,74$ \\
* Actuac.Urban. y Cta. Terc. & $24.426,84$ & $11.097,18$ & $117.815,74$ \\
** Materiales, Servicios y Sumin & $131.772,97$ & $86.849,07$ & $479.262,22$ \\
G13017505 I.A. Energía UDT & $3.835,50$ & $2.936,97$ & $6.292,47$ \\
* I.A. Serv. Suministr & $3.835,50$ & $2.936,97$ & $6.292,47$ \\
** I.A. Serv. Suministr. & $3.835,50$ & $2.936,97$ & $6.292,47$ \\
*** Total Gastos & $186.352,76$ & $89.786,04$ & $786.728,72$ \\
**** Total Ingresos- Gtos & $-20.482,43$ & $-15.575,37$ & $51.820,57$
\end{tabular}

Tabla 49. Conceptos presupuestarios de las estaciones. Fuente: ADIF 2018

En el gráfico siguientes se muestran los costes correspondientes a gastos de personal, de materiales, servicios y suministros de las estaciones de la línea estudiada correspondientes al año 2018: 


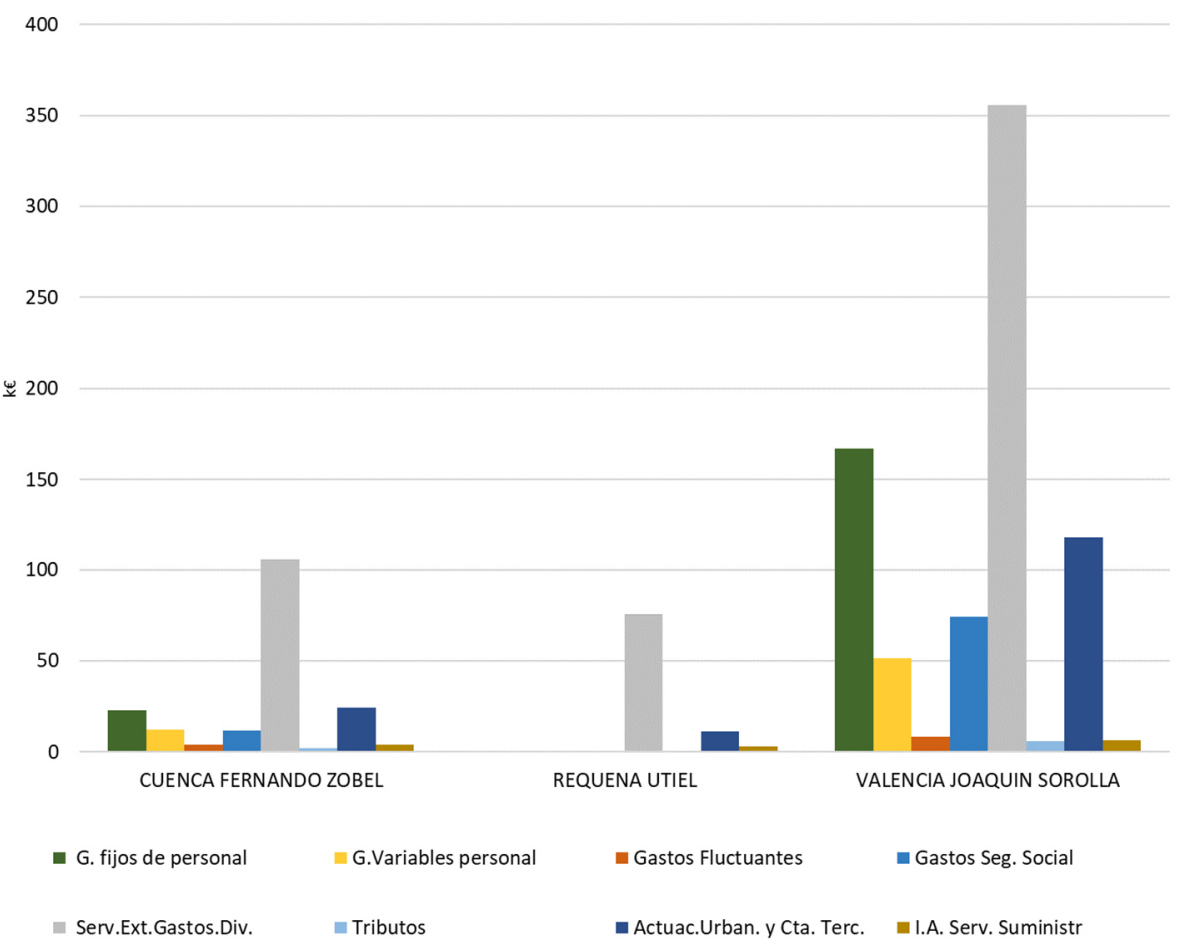

Gráfico 24. Costes de las estaciones. Elaboración propia a partir de datos de ADIF 2018.

Estos datos obtenidos permiten trazar reflexiones sobre los criterios y niveles de tarificación para poder determinar el canon mínimo a aplicar, siendo desarrollado en el apartado siguiente. 
4.4 Discusión sobre los niveles de canon por uso de estaciones en la línea Madrid-Valencia.

La determinación de los costes directos por estaciones así como el conocimiento del número de viajeros permite obtener la cuantía mínima del canon que cubra dichos costes. Los cánones aplicados por uso de estaciones, tal como se mostró en el apartado anterior está compuesto por dos componentes, uno por circulaciones, cuantía dependiente del tipo de parada (origen, intermedia o destino) y otro por uso de andenes, dependiente del número de viajeros (subidos/bajados).

En las estaciones de estudio los resultados obtenidos son los siguientes:

\begin{tabular}{cccc} 
& $\begin{array}{c}\text { Cuenca Fernando } \\
\text { Zobel }\end{array}$ & $\begin{array}{c}\text { Requena } \\
\text { Utiel }\end{array}$ & $\begin{array}{c}\text { Valencia Joaquín } \\
\text { Sorolla }\end{array}$ \\
\hline$N^{\circ}$ de Circulaciones & 17.732 & 9.828 & 9.828 \\
$N^{\circ}$ de Viajeros & 398.689 & 19.467 & 3.969 .912 \\
Tabla 50. Circulaciones y Viajeros. Elaboración propia. Fuente: ADIF 2018.
\end{tabular}

De los valores mostrados, hay que tener en cuenta que las estaciones estudiadas presentan valores muy dispares debido al número de viajeros que presenta una y otra, pero también es variable debido a la operabilidad de estas. Centrándonos en la estación de Requena Utiel, que se encuentra en el tramo entre Cuenca y Valencia, las circulaciones que realizan parada (intermedia) son pocas con respecto a las que se producen en Cuenca Fernando Zobel, que tiene también paradas intermedias de trenes origen/destino Alicante, ya que se encuentra antes de la bifurcación hacia Valencia, por lo que el ingreso por canon es más elevado, tanto por circulaciones como por viajeros. La cuantía del canon por circulación y viajero es calculada directamente de los ingresos obtenidos por estación.

\begin{tabular}{|c|c|c|c|}
\hline & $\begin{array}{c}\text { Cuenca Fernando } \\
\text { Zobel }\end{array}$ & $\begin{array}{c}\text { Requena } \\
\text { Utiel }\end{array}$ & $\begin{array}{c}\text { Valencia Joaquín } \\
\text { Sorolla }\end{array}$ \\
\hline $\begin{array}{l}\text { Canon por uso de } \\
\text { estaciones }\end{array}$ & $182.408,35$ & $94.264,23$ & $614.341,87$ \\
\hline $\begin{array}{l}\text { Canon por uso de } \\
\text { andenes }\end{array}$ & $24.426,84$ & $11.097,18$ & $117.815,74$ \\
\hline$€ /$ circulación & 10,287 & 9,591 & 62,509 \\
\hline$€ /$ viajero & 0,061 & 0,570 & 0,030 \\
\hline
\end{tabular}


El Reglamento de Ejecución de la Comisión Europea 2015/909 establece las modalidades de cálculo de los costes directamente imputables a la explotación del servicio ferroviario, a efectos de fijar los cánones de acceso mínimo y de acceso a infraestructuras. Esto significa en que en el canon aplicado se deben repercutir los costes directamente asociados al mantenimiento y conservación de las estaciones, reposición y prestación de servicios básicos mínimos ofrecidos, los servicios de vigilancia, control de acceso de viajeros y sus equipajes, por lo que se realiza una depuración de los costes presentados para poder determinar el coste imputable a la explotación de las estaciones:

\begin{tabular}{lrrr} 
& \multicolumn{1}{c}{ Cánones } & Costes directos & \multicolumn{1}{c}{ Resultado } \\
\hline Cuenca Fernando Zóbel & $206.835,19 €$ & $135.131,79 €$ & $71.703,40 €$ \\
Requena- Utiel & $105.361,41 €$ & $65.629,97 €$ & $39.731,44 €$ \\
Valencia Joaquín Sorolla & $732.157,61 €$ & $584.629 .00 €$ & $147.528,61 €$ \\
\hline$\quad$ Total & $1.044 .354,21 €$ & $785.390,76 €$ & $258.963,45 €$
\end{tabular}

Tabla 52. Costes directos en estaciones. Elaboración propia. Fuente: ADIF 2018.

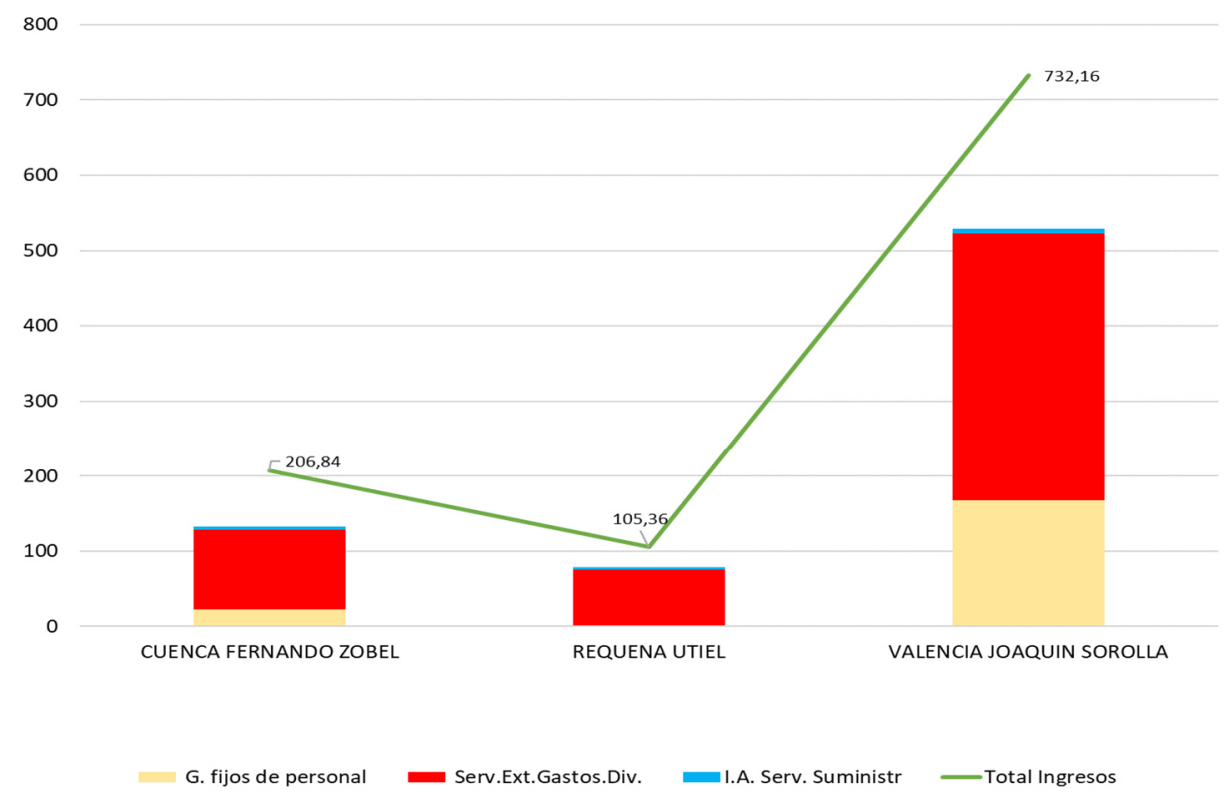

Gráfico 25. Costes directos en miles de € por estaciones. Elaboración propia. Fuente: ADIF. 
La determinación de la cuantía del canon mínimo queda plasmada a continuación en la tabla y gráficos siguientes, según la estación. Para ello se ha tomado como referencia el porcentaje de participación de cada canon aplicado en los ingresos del Administrador:

\begin{tabular}{lccc} 
& $\begin{array}{c}\text { Cuenca } \\
\text { Fernando Zobel }\end{array}$ & Requena Utiel & $\begin{array}{c}\text { Valencia } \\
\text { Joaquín Sorolla }\end{array}$ \\
\hline Costes Directos & $135.131,79 €$ & $65.629,97 €$ & $584.629,00 €$ \\
Canon por uso de estaciones & $119.172,73 €$ & $58.712,57 €$ & $490.503,73 €$ \\
Canon por uso de andenes & $15.959,06 €$ & $6.917,40 €$ & $94.125,27 €$ \\
\hline$N^{\circ}$ de Circulaciones & 17.732 & 9.828 & 9.828 \\
\hline$N^{\circ}$ de Viajeros & 398.689 & 19.467 & 3.969 .912 \\
$€ /$ circulación & $6,72 €$ & $5,97 €$ & $49,91 €$ \\
$€ /$ viajero & $0,04 €$ & $0,36 €$ & $0,02 €$
\end{tabular}

Tabla 53. Cuantía mínima por estaciones. Elaboración propia.

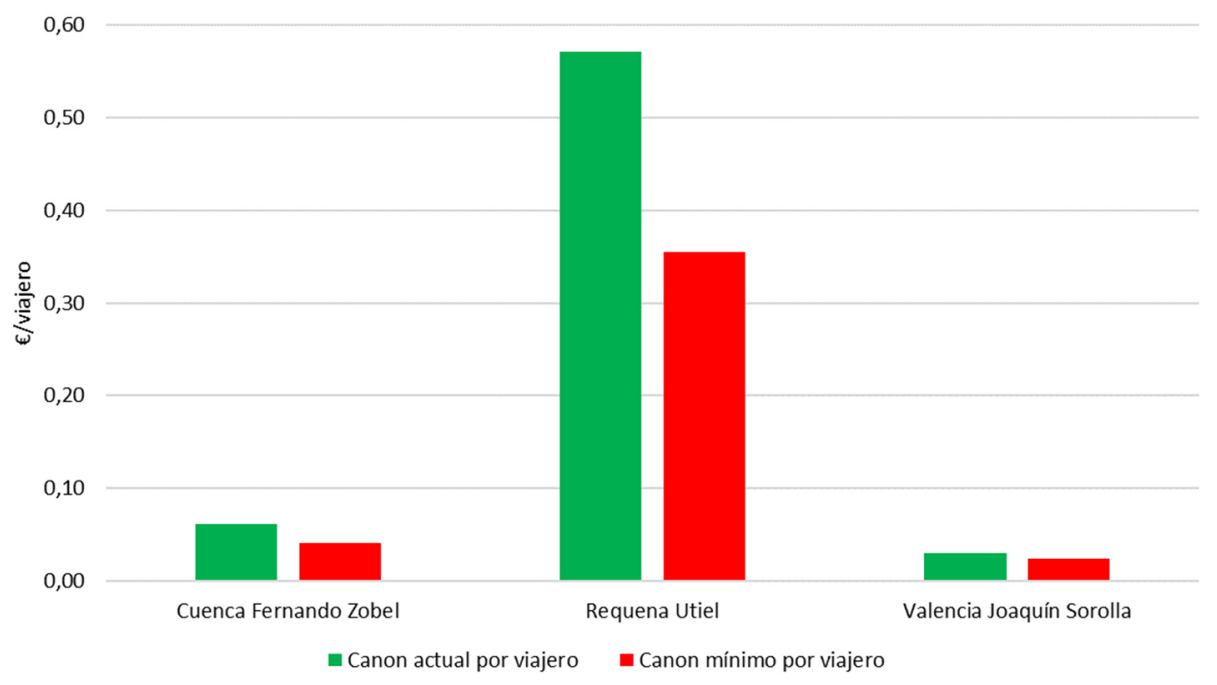

Gráfico 26. Comparativa canon estaciones. Elaboración propia.

En cuanto a la amortización de las estaciones, el criterio aplicado por Adif para la valoración de la infraestructura ferroviaria de Alta Velocidad responde a un criterio creciente en progresión geométrica del $3 \%$ anual y una vida útil de 50 años. En la tabla siguiente se muestra la cuota, amortización anual, acumulada y restante de los 50 años de vida útil de las estaciones estudiadas: 


\begin{tabular}{lllrrrr} 
Año & $\begin{array}{l}\text { Cuota por } \\
\text { Dígito }\end{array}$ & Año & \multicolumn{1}{l}{$\begin{array}{l}\text { Amortización } \\
\text { Anual }\end{array}$} & $\begin{array}{l}\text { Amortización } \\
\text { Acumulada }\end{array}$ & \multicolumn{2}{l}{$\begin{array}{l}\text { Amortización } \\
\text { Restante }\end{array}$} \\
$\mathbf{2 0 1 0}$ & $526.167,10$ & 1,000 & $526.167,10$ & $526.167,10$ & $58.823 .832,90$ \\
$\mathbf{2 0 1 1}$ & $526.167,10$ & 1,030 & $541.952,11$ & $1.068 .119,20$ & $58.281 .880,80$ \\
$\mathbf{2 0 1 2}$ & $526.167,10$ & 1,061 & $558.210,67$ & $1.626 .329,87$ & $57.723 .670,13$ \\
$\mathbf{2 0 1 3}$ & $526.167,10$ & 1,093 & $574.956,99$ & $2.201 .286,87$ & $57.148 .713,13$ \\
$\mathbf{2 0 1 4}$ & $526.167,10$ & 1,126 & $592.205,70$ & $2.793 .492,57$ & $56.556 .507,43$ \\
$\mathbf{2 0 1 5}$ & $526.167,10$ & 1,159 & $609.971,87$ & $3.403 .464,44$ & $55.946 .535,56$ \\
$\mathbf{2 0 1 6}$ & $526.167,10$ & 1,194 & $628.271,03$ & $4.031 .735,47$ & $55.318 .264,53$ \\
$\mathbf{2 0 1 7}$ & $526.167,10$ & 1,230 & $647.119,16$ & $4.678 .854,63$ & $54.671 .145,37$ \\
$\mathbf{2 0 1 8}$ & $526.167,10$ & 1,267 & $\mathbf{6 6 6 . 5 3 2 , 7 3}$ & $5.345 .387,36$ & $54.004 .612,64$ \\
$\mathbf{2 0 1 9}$ & $526.167,10$ & 1,305 & $686.528,72$ & $6.031 .916,08$ & $53.318 .083,92$ \\
$\mathbf{2 0 2 0}$ & $526.167,10$ & 1,344 & $707.124,58$ & $6.739 .040,65$ & $52.610 .959,35$ \\
$\mathbf{2 0 2 1}$ & $526.167,10$ & 1,384 & $728.338,31$ & $7.467 .378,97$ & $51.882 .621,03$ \\
$\mathbf{2 0 2 2}$ & $526.167,10$ & 1,426 & $750.188,46$ & $8.217 .567,43$ & $51.132 .432,57$ \\
$\mathbf{2 0 2 3}$ & $526.167,10$ & 1,469 & $772.694,12$ & $8.990 .261,55$ & $50.359 .738,45$ \\
$\mathbf{2 0 2 4}$ & $526.167,10$ & 1,513 & $795.874,94$ & $9.786 .136,49$ & $49.563 .863,51$ \\
$\mathbf{2 0 2 5}$ & $526.167,10$ & 1,558 & $819.751,19$ & $10.605 .887,68$ & $48.744 .112,32$ \\
$\mathbf{2 0 3 0}$ & $526.167,10$ & 1,806 & $950.316,30$ & $15.088 .623,19$ & $44.261 .376,81$ \\
$\mathbf{2 0 4 0}$ & $526.167,10$ & 2,427 & $1.277 .145,64$ & $26.309 .763,92$ & $33.040 .236,08$ \\
$\mathbf{2 0 5 0}$ & $526.167,10$ & 3,262 & $1.716 .376,95$ & $41.390 .038,75$ & $17.959 .961,25$ \\
$\mathbf{2 0 5 5}$ & $526.167,10$ & 3,782 & $1.989 .751,30$ & $50.775 .891,42$ & $8.574 .108,58$ \\
$\mathbf{2 0 5 9}$ & $526.167,10$ & 4,256 & $2.239 .482,62$ & $59.350 .000,00$ & \\
& & & & & 0,00
\end{tabular}

Tabla 54. Amortización de las estaciones de la línea. Elaboración propia.

En el caso de las estaciones de la línea la amortización anual asciende a $666.532,73 €$, esto supone un incremento en el canon aplicado a las circulaciones de 5,94€/circulación o un incremento de 0,05€/viajero en el caso de aplicarlo al canon por uso de andenes.

\begin{tabular}{|c|c|c|c|}
\hline & $\begin{array}{c}\text { Cuenca } \\
\text { Fernando } \\
\text { Zobel }\end{array}$ & $\begin{array}{c}\text { Requena } \\
\text { Utiel }\end{array}$ & $\begin{array}{c}\text { Valencia } \\
\text { Joaquín } \\
\text { Sorolla }\end{array}$ \\
\hline$€ /$ circulación (canon mínimo) & $6,72 €$ & $5,97 €$ & $49,91 €$ \\
\hline$€ /$ circulación (canon mínimo + amortización) & $12,66 €$ & $11,92 €$ & $55,85 €$ \\
\hline Incremento \% & 46,93 & 49,87 & 10,64 \\
\hline$€ /$ viajero (canon mínimo) & $0,04 €$ & $0,36 €$ & $0,02 €$ \\
\hline$€ /$ viajero (canon mínimo + amortización) & $0,09 €$ & $0,41 €$ & $0,07 €$ \\
\hline Incremento \% & 55,85 & 12,47 & 68,11 \\
\hline
\end{tabular}

Tabla 55. Cuantía en $€$ del canon mínimo con amortización. Elaboración propia. 


\begin{tabular}{|c|c|c|c|}
\hline & $\begin{array}{c}\text { Cuenca } \\
\text { Fernando Zobel }\end{array}$ & $\begin{array}{l}\text { Requena } \\
\text { Utiel }\end{array}$ & $\begin{array}{c}\text { Valencia } \\
\text { Joaquín Sorolla }\end{array}$ \\
\hline \multirow{2}{*}{$\begin{array}{l}€ / \text { circulación (canon actual) } \\
€ / \text { circulación (canon actual + } \\
\text { amortización) }\end{array}$} & $10,29 €$ & $9,59 €$ & $62,51 €$ \\
\hline & $16,23 €$ & $15,53 €$ & $68,45 €$ \\
\hline Incremento \% & 36,62 & 38,26 & 8,68 \\
\hline$€ /$ viajero (canon actual) & $0,06 €$ & $0,57 €$ & $0,03 €$ \\
\hline $\begin{array}{l}€ / \text { viajero (canon actual + } \\
\text { amortización) }\end{array}$ & $0,11 €$ & $0,62 €$ & $0,08 €$ \\
\hline Incremento \% & 45,36 & 8,16 & 62,79 \\
\hline
\end{tabular}

En ambos casos, la aplicación de los costes de amortización en el cálculo del canon, superan al canon actual aplicado así como al canon mínimo calculado, no permitiendo la recuperación de los costes de amortización de las estaciones por este método.

Para el estudio de recuperación de los costes a partir del canon aplicado por viajero se parte de la comparación entre estas estaciones con otras estaciones de Alta Velocidad y en el que se observa la relevancia del canon aplicado por viajero sólo tomando los costes directos actuales, tal como figura en el gráfico siguiente:

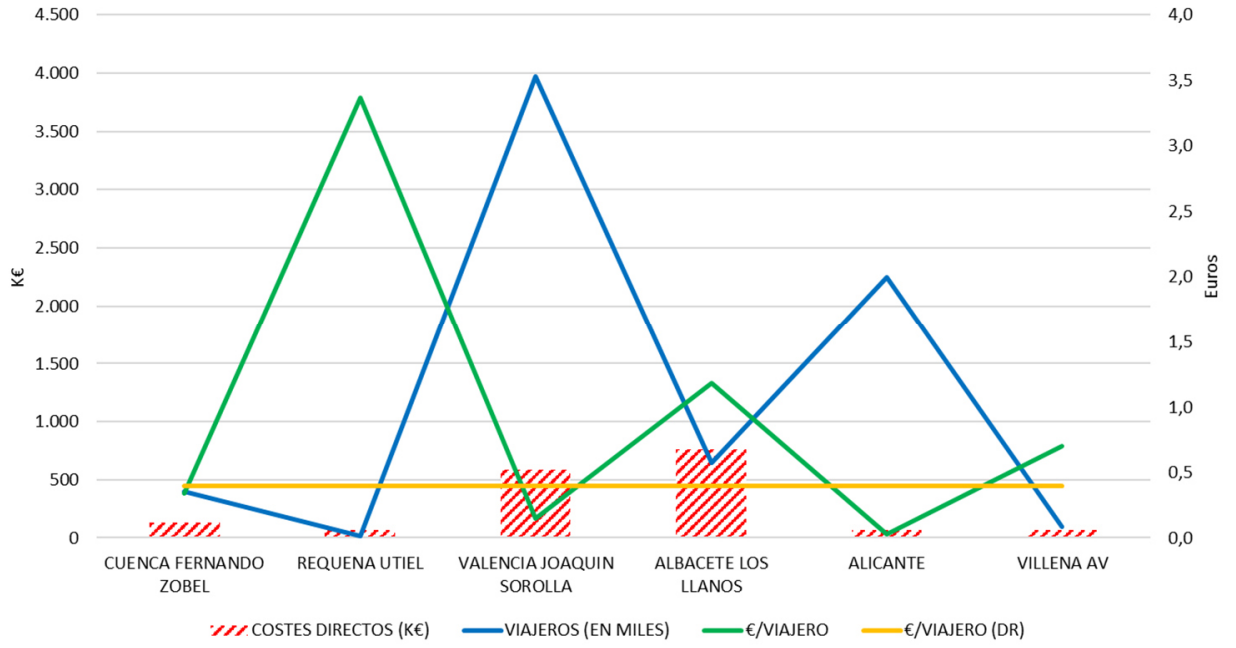

Gráfico 27. Canon mínimo aplicable por viajero. Elaboración propia. 
Las estaciones con mayor número de viajeros no presentan todas un mayor rango de gastos directos. La estación de Albacete Los Llanos tiene más gastos imputables con un menor número de viajeros en comparación con la de Valencia Joaquín Sorolla que la sextuplica, y Alicante con mayor número de viajeros que Albacete presenta menores costes. Esto produce una repercusión mayor del canon en el viajero en aquellas estaciones con menores costes y por supuesto con mayores niveles de viajeros como ocurre con las estaciones de Requena Utiel y de Villena, que por contrapartida a esto presenta un nivel de gastos y viajeros bajo.

En cuanto al canon mínimo calculado por viajero, para poder hacer frente a los costes directos encontramos que en las estaciones con canon obtenido por encima del canon de la Declaración sobre la Red, 0,40 euros por viajero subido-bajado, se podría ajustar de forma que se cubran estos costes, bien subiéndolos de forma independiente o bien calculando un canon "medio" por línea. Esto obligaría a recalcular de forma independiente su aplicación en las diferentes líneas de alta velocidad de ADIF y así compensar los costes de las estaciones con baja afluencia de viajeros.

En cuanto a las relaciones entre los costes y el canon por circulación es bastante dispar, al igual que lo expuesto anteriormente. Hay que señalar que el canon por circulación es aplicado al tipo de parada (existen tres tipos, origen, intermedia y destino) que efectúa la composición así como a la categoría de la estación (4 categorías en este caso) y con una cuantía aplicada de canon distinta. La estación de Cuenca Fernando Zóbel, con más circulaciones de todas, no presenta los mayores costes directos, y con un elevado número de circulaciones. En cambio la estación con mayores costes, Albacete Los Llanos, no tiene el mayor número de circulaciones y la mayoría de ellas son paradas tipo intermedia por lo que la cuantía obtenida por circulaciones es menor.

Antes de determinar la variable más adecuada para la tarificación de estos servicios y que cubra el objetivo de recuperar los costes directos imputados a las estaciones se plantean varias cuestiones al respecto. El hecho de aplicar solamente el canon por circulaciones a los trenes por el tipo de parada y categoría de la estación da lugar a poner en circulación trenes de mayor capacidad, pudiendo transportar el doble de viajeros que otros existentes en la actualidad y abonando el mismo canon. En cambio la aplicación del canon por viajero (subido/bajado) generaría un aumento de los ingresos ante la situación de trenes de mayor capacidad y evitaría que las empresas ferroviarias "renunciaran" a no efectuar paradas en estaciones para evitar el abono del canon de esa parada intermedia. 
El canon por uso de estaciones debería ser aplicado con la variable de "viajeros", ya que son los usuarios reales de las instalaciones y servicios prestados. Además al ser aplicado no tiene en cuenta el tipo de tren que efectúa la parada ya que circulan otros tipos de tren por esta línea con velocidades inferiores (trenes Alvia con $250 \mathrm{~km} / \mathrm{h}$ de velocidad máxima).

El canon por circulaciones debería estar incluido dentro del canon por uso de la infraestructura como está el canon que grava el tráfico producido y que establece un importe unitario para cada combinación según periodo horario, tipo de línea, tipo de servicio teniendo en cuenta las plazas del tren. Este canon por tráfico es el único canon que segmenta los trenes que no son de alta velocidad y que circulan por estas líneas.

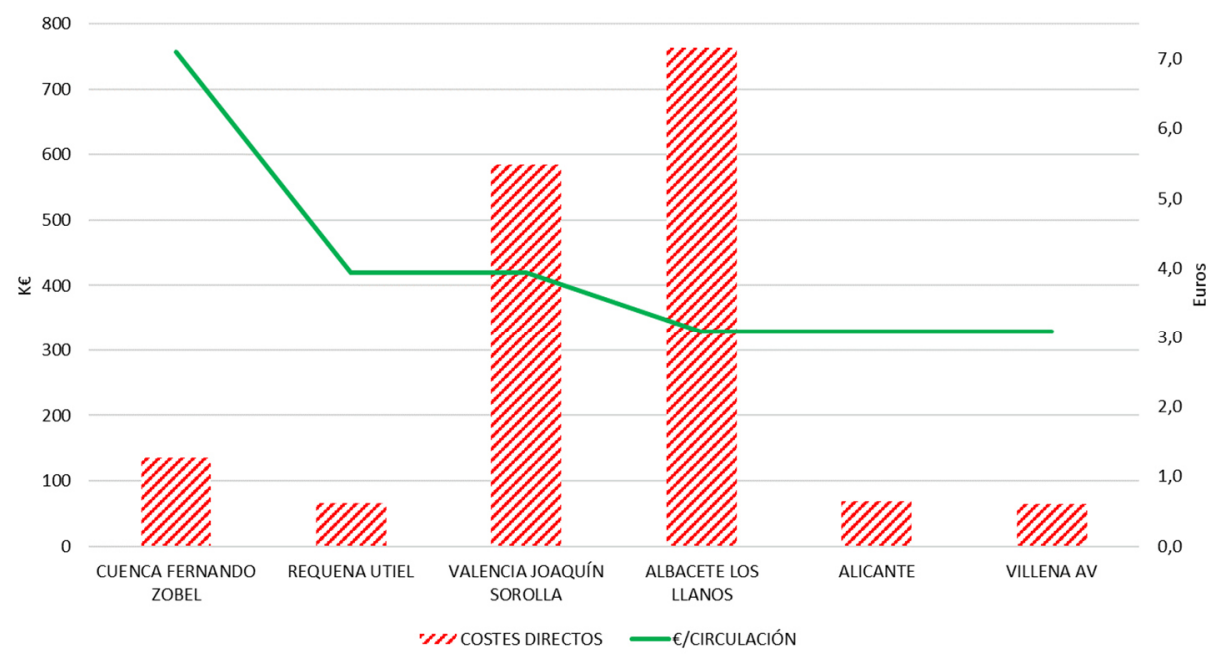

Gráfico 28. Canon mínimo aplicable por circulación. Elaboración propia. 
4.5 Nuevo escenario con la entrada de nuevos operadores ferroviarios en la línea de Alta Velocidad Madrid-Levante (Tramo Madrid-Valencia).

Introducción.

La apertura a la competencia privada del transporte de viajeros en la Unión Europea se producirá a partir del 14 de diciembre de 2020 de forma definitiva, dando paso a la operación de nuevas empresas ferroviarias en los servicios de alta velocidad y larga distancia.

A fecha de la elaboración de este trabajo las dos empresas que empezarán a operar en España son:

- ILSA (INTERMODALIDAD DEL LEVANTE, S.A.), compañía formada por los socios de la aerolínea Air Nostrum y Trenitalia.

- RIELSFERA, cuyo accionista a 100\% es el operador SNCF.

Un ejemplo del impacto de la apertura a la competencia es el producido en las líneas de alta velocidad de Italia. En el año 2012 empezó a operar NTV (Nuovo Trasporto Viaggiatori) estableciéndose una guerra de precios entre el nuevo operador y Trenitalia (Grupo Ferrovie dello Stato).

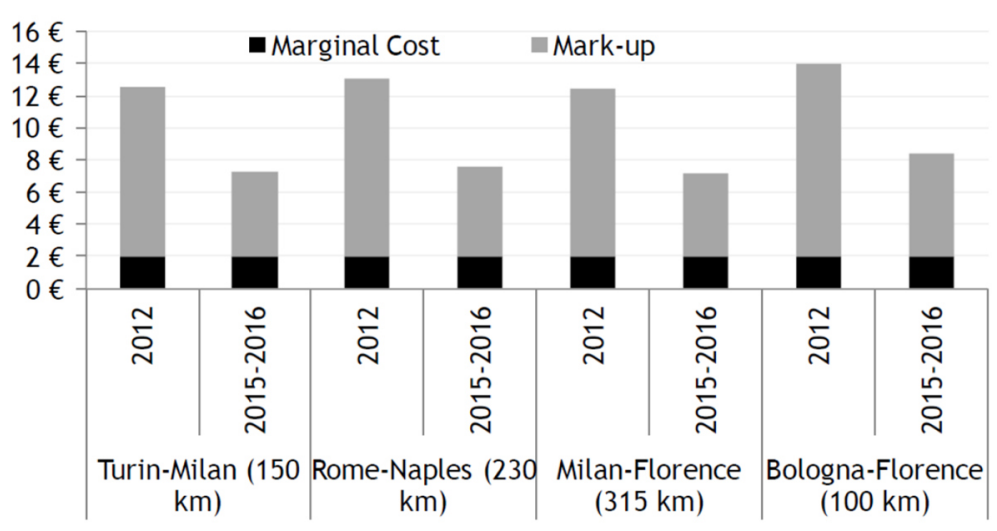

Gráfico 29. Reducción del canon realizado por RFI. Fuente: Texeira 201920.

20 Teixeira (2019). "La asignación de la capacidad de las líneas: el canon por uso de infraestructura". Material del aula de Asignación de Capacidad. Máster en Sistemas Ferroviarios y Tracción Eléctrica, Universidad Politècnica de Catalunya (UPC). Junio 2019. 
Entre 2015 y 2016 el administrador de la infraestructura ferroviaria italiana (Rete Ferroviaria Italiana) decidió realizar una reducción de hasta el $40 \%$ en los cánones por uso de su infraestructura.

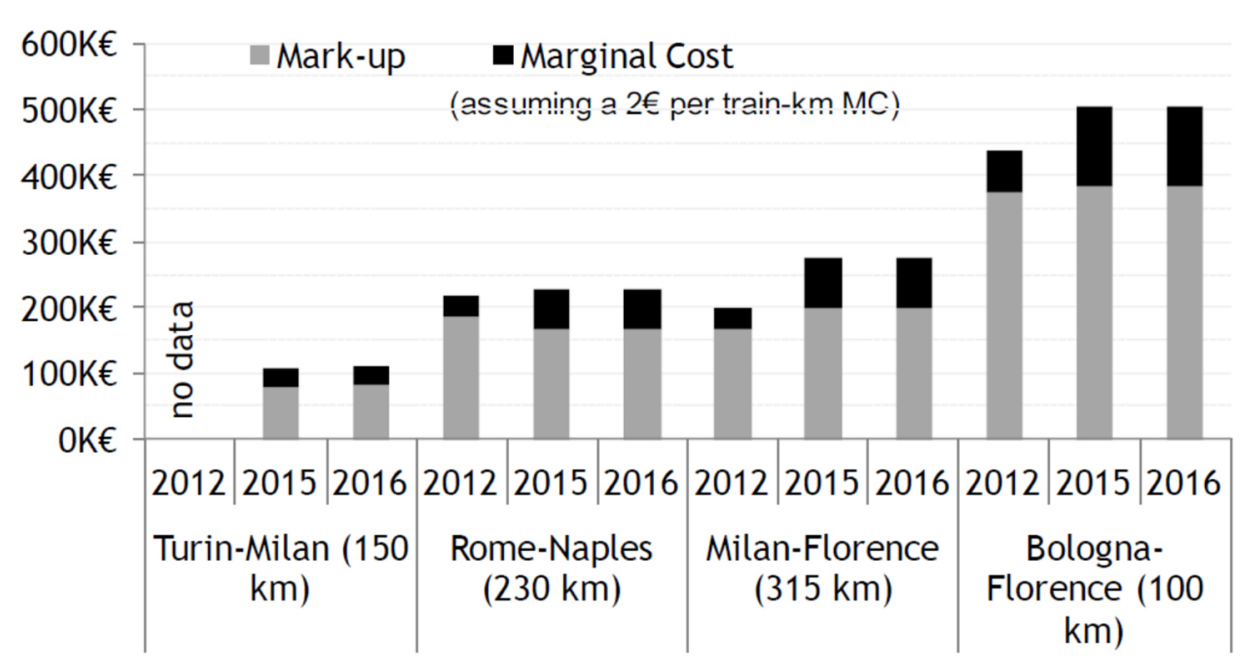

Gráfico 30. Ingresos de RFI por cánones. Fuente: Texeira 2019.

Esto quedó materializado en un incremento del tráfico, y no supuso pérdidas al administrador así como unos resultados financieros positivos para el nuevo operador que fueron invertidos en la compra de nuevo material rodante.

Estudio del nuevo escenario.

Ante la liberalización efectiva de los servicios comerciales, de acuerdo con las directrices de la Unión Europea y la Comisión Nacional de los Mercados y la Competencia, el administrador de infraestructuras español debe asegurar una gestión eficiente del tráfico ferroviario y garantizar un acceso no discriminatorio a las mismas. Esta obligación se extiende no sólo a las vías, sino también a los espacios en las estaciones dedicados a las actividades de los operadores de transporte. 
Para ello ADIF AV, elaboró una oferta de capacidad marco21 (junto a otros dos) para el corredor Madrid - Levante (Valencia y Alacant), vinculando la capacidad de la línea con el estacionamiento en las estaciones de viajeros. Esta capacidad marco queda agrupada en 3 paquetes con las características siguientes:

\begin{tabular}{cl}
\hline Paquete A & 1 tren/hora Madrid- Valencia \\
& 1 tren/hora Madrid- Alicante \\
\hline Paquete B & 1 tren/2 horas Madrid- Valencia \\
\hline Paquete C & 4 tren/2 horas Madrid- Alicante \\
\hline
\end{tabular}

Tabla 57. Capacidad marco. Fuente Adif AV.

Los paquetes son asignados a la empresa ferroviaria $u$ otro candidato que se comprometa a una mayor utilización en un periodo de 10 años.

En el tramo estudiado la variación de capacidad queda ofertada según la siguiente tabla:

\begin{tabular}{c|c|c|c|c}
\hline $\begin{array}{c}\text { Surcos/día } \\
\text { (ambos sentidos) }\end{array}$ & Capacidad líneas & $\begin{array}{c}\text { Servicios } \\
\text { actuales }\end{array}$ & $\begin{array}{c}\text { Capacidad } \\
\text { marco }\end{array}$ & Incremento \\
\hline Madrid-Valencia & 184 & 36 & 52 & $+44 \%$ \\
\hline
\end{tabular}

Tabla 58. Variación en la capacidad actual y ofertada. Fuente Adif AV.

\begin{tabular}{|c|c|c|c|c|c|c|c|}
\hline \multirow{2}{*}{$\begin{array}{c}\text { Surcos/día } \\
\text { (ambos }\end{array}$} & \multirow{2}{*}{$\begin{array}{c}\text { Servicios } \\
\text { sentidos) }\end{array}$} & \multicolumn{6}{|c|}{ Paquetes propuestos } \\
\cline { 3 - 9 } & actuales & \multicolumn{2}{|c|}{ A } & \multicolumn{2}{|c|}{ B } & \multicolumn{2}{c|}{ C } \\
\cline { 3 - 9 } & & Surcos & $\%$ & Surcos & $\%$ & Surcos & $\%$ \\
\hline Madrid-Valencia & 36 & 32 & $62 \%$ & 16 & $31 \%$ & 4 & $8 \%$ \\
\hline
\end{tabular}

Tabla 59. Configuración de la capacidad marco propuesta. Fuente Adif AV.

\footnotetext{
21 De acuerdo con el artículo 3 del RE-2016/545, los administradores de infraestructuras deben elaborar una Declaración de capacidad marco en la que se indique la capacidad marco ya adjudicada, aquella todavía disponible para acuerdos marco, así como la capacidad máxima que se asignará mediante este mecanismo. Además, el Considerando $2^{\circ}$ de este Reglamento señala que los administradores de infraestructuras deben reservar capacidad para el procedimiento anual de confección de horarios, considerando estas limitaciones antes de adjudicar parte de la capacidad mediante acuerdos marco.
} 
Así mismo, la previsión estimada para la futura demanda ${ }^{22}$ de viajeros para los próximos años para la estación de Valencia Joaquín Sorolla es la siguiente:

\begin{tabular}{c|cccc} 
AÑO & 2019 & 2020 & 2025 & 2026 \\
\hline VIAJEROS & $4.000 .000^{23}$ & 5.600 .000 & 8.749 .000 & 10.097 .000 \\
\hline
\end{tabular}

Tabla 60. Estimación de demanda de viajeros. Fuente: Adif.

Para este nuevo escenario se utilizará como modelo un tren que cubre un servicio directo entre Madrid-Puerta de Atocha y Valencia Joaquín Sorolla (O-D), con una demanda regular y simétrica, es decir con un número de viajeros y circulaciones diarias por igual. La composición ferroviaria utilizada es el automotor S-112 fabricado por Talgo-Bombardier con 365 plazas ofertadas y una ocupación efectiva de un $80 \%$ (292 plazas), estimando la duración del viaje en 1 hora y 40 minutos y una velocidad media comercial de $235 \mathrm{~km} / \mathrm{h}$, siendo un tiempo de viaje de 2 horas por dirección. Se considera que existe un embarque y tiempo de preparación del tren antes de cada servicio de 15 minutos (0,25 horas) y que los trenes operarán 18 horas al día (de 06:00 a 24:00 horas).

Usando los valores anteriores y partiendo de la estimación de la demanda diaria por sentido, el número de circulaciones se obtiene de la relación siguiente:

$$
\text { Frecuencia }=\frac{\frac{\text { Demanda }_{\text {diaria }}}{\text { Ocupación } n_{\text {efectiva }}}}{\text { Horas de operación }}
$$

\begin{tabular}{|c|c|c|c|c|c|}
\hline Año & $\begin{array}{l}\text { Viajeros } \\
\text { anuales }\end{array}$ & $\begin{array}{c}\text { Demanda } \\
\text { diaria }\end{array}$ & $\begin{array}{l}\text { Ocupación } \\
\text { efectiva }\end{array}$ & $\begin{array}{c}\text { Servicios } \\
\text { necesarios }\end{array}$ & $\begin{array}{c}\text { Frecuencia } \\
\text { (circulaciones } \\
\text { hora) }\end{array}$ \\
\hline 2020 & 5.600 .000 & 7.672 & \multirow{3}{*}{292 plazas } & 26 & 1,45 \\
\hline 2025 & 8.749 .000 & 11.985 & & 41 & 2,28 \\
\hline 2026 & 10.097 .000 & 13.832 & & 48 & 2,63 \\
\hline
\end{tabular}

Tabla 61. Frecuencia de circulaciones por sentido ante el nuevo escenario. Elaboración propia.

\footnotetext{
22 Según la Subdirección de Estudios de Demanda y Planificación de Inversiones de ADIF.

23 Estimación de ADIF basada en los 2.611 .357 viajeros acumulados hasta agosto.
} 


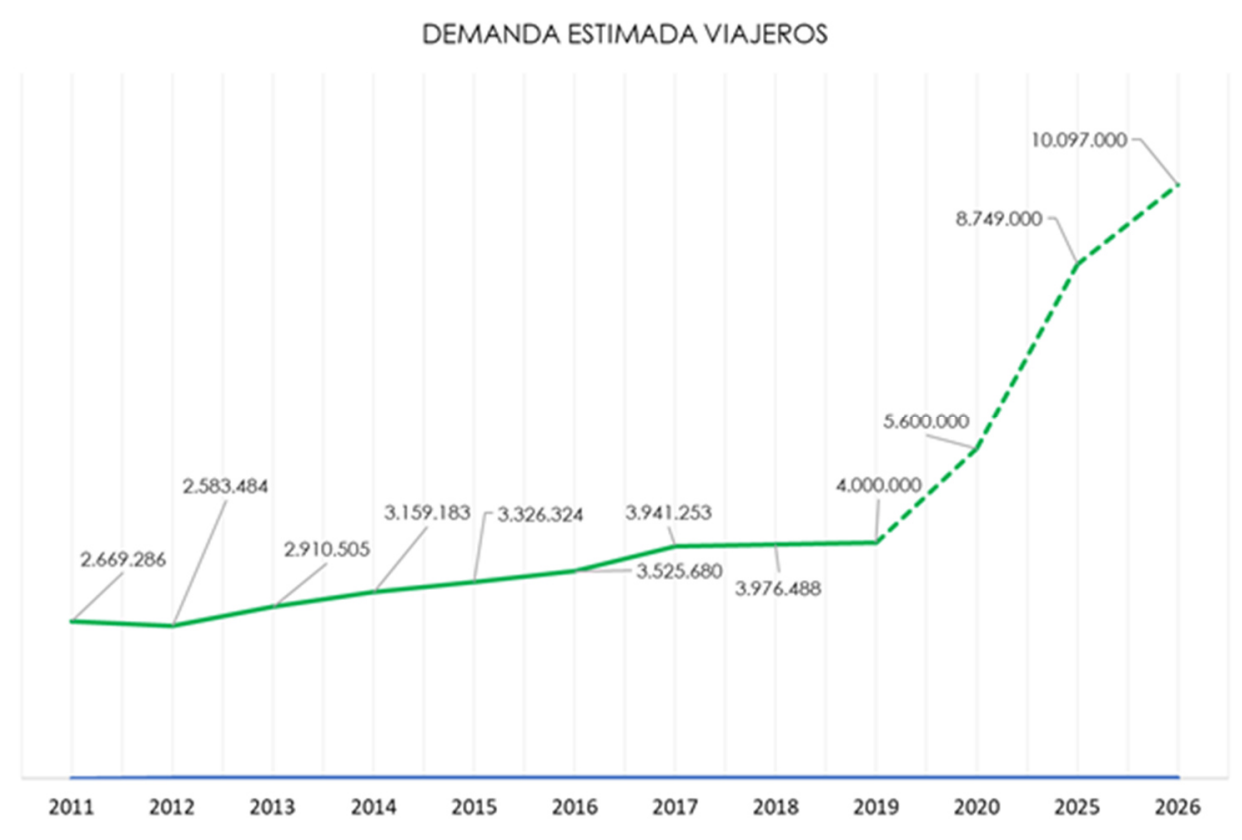

Gráfico 31. Estimación de la demanda de viajeros a partir de 2011. Fuente: ADIF

Previsión de circulaciones y frecuencia

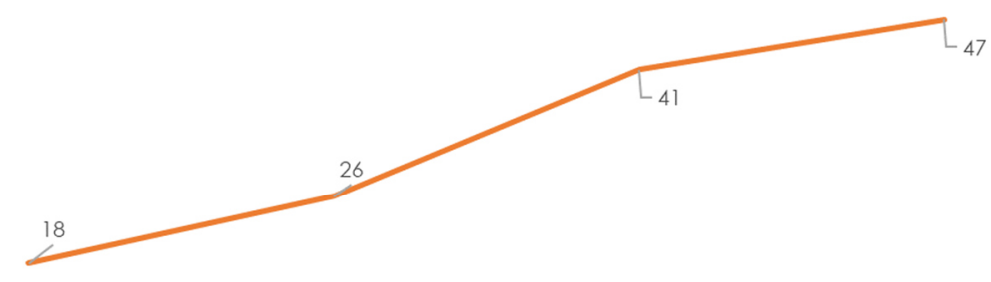

\begin{tabular}{|c|c|c|c|}
\hline - 1,04 & {$[1,45$} & 2,28 & 2,63 \\
\hline 2019 & $\begin{array}{l}2020 \\
\text { esarios }\end{array}$ & $\begin{array}{l}2025 \\
\text { circulaciones hora) }\end{array}$ & 2026 \\
\hline
\end{tabular}

Gráfico 32. Previsión de circulaciones y frecuencias a partir de 2019. Elaboración propia. 
Consideraciones ante la situación actual de la línea de alta velocidad Madrid-Levante.

Los ingresos por uso de las estaciones de transporte de viajeros, proviene con mayor porcentaje del canon por uso de las estaciones, canon basado en el número de viajeros subidos/bajados en cada una de ellas. En cuanto al canon por uso de andenes es dispar entre las estaciones de la línea, siendo más bajo en las estaciones que no son origen-destino, es decir intermedias.

Este canon, basado en los trenes que circulan por la línea, no repercute en ellas los trenes que no tienen parada comercial (trenes directos) o a las pocas composiciones que tienen parada comercial en ellas (caso de Cuenca Fernando Zóbel, Requena-Utiel y Villena AV en la actualidad).

El número correcto de estaciones resulta vital para el éxito y la sostenibilidad operativa de la línea. Si la línea tiene pocas o ninguna parada intermedia, la velocidad global entre origen y destino es alta, y la competitividad con otros modos de transporte es óptima; sin embargo, esto perjudica la sostenibilidad, puesto que son menos los posibles viajeros residentes a lo largo de la línea que pueden utilizarla. En cambio, si la línea tiene más paradas, su velocidad media es inferior, y está en juego la competitividad con otros modos de transporte, pero pueden subir a bordo más viajeros, aumentando los ingresos de la venta de billetes y el aumento de ingresos procedentes del canon.

A fin de evaluar el posible número de usuarios de la línea se deberían examinar las zonas de influencia de esta. Algunas estaciones no tienen suficiente número de viajeros en sus zonas de influencia inmediatas, o están demasiado próximas como el caso de Requena-Utiel y Valencia Joaquín Sorolla reduciendo la eficacia general de los servicios de alta velocidad.

Para tener éxito y ser competitivas, las estaciones deben estar bien situadas, accesibles para los viajeros mediante otros modos de transporte y ofrecer unas instalaciones de transporte público adecuadas y espacios para el aparcamiento a precios asequibles. Excepto las estaciones de Valencia, Albacete, Alicante, Murcia y Castelló el resto son poco accesibles, encontrándose en una ubicación aislada, donde los únicos medios para llegar a ellas son alguna línea de autobuses local servidos por los propios ayuntamientos o servicio de taxis.

Contar con el número correcto de estaciones resulta vital para el éxito y la sostenibilidad operativa de una línea, siendo su situación y conexiones fundamentales. 
Así mismo el disponer de un número suficiente de trenes a lo largo del día con parada comercial produciría un efecto de reurbanización como consecuencia de la contribución a la actividad económica de la zona donde están ubicadas y un aumento de los usuarios, así como el efecto llamada para la explotación de terceros de los servicios que ahora no existen y que el administrador de infraestructuras posee los locales sin arrendar y sin los correspondientes ingresos complementarios.

La presencia de nuevos operadores incrementa según la previsión de ADIF, un $40 \%$ de viajeros y un aumento del tráfico ferroviario. Este aumento de tráfico, en referencia a las estaciones de viajeros, y teniendo en cuenta la previsión, incrementa no sólo el ingreso del canon por uso de la infraestructura, sino que el aumento de viajeros aumenta el ingreso del canon por número de viajeros. Se puede dar el caso que el operador ponga menos trenes en la línea circulando pero aumentando el número de plazas, con lo que el ingreso por circulaciones es menor pero mayor la cuantía del canon por viajero (subido/bajado) a abonar al administrador.

El modelo ferroviario español es un modelo dual en el que está separada completamente la administración de las infraestructuras de la prestación de los servicios de transporte, atribuyendo estas actuaciones a dos entidades públicas diferentes, una de las cuales abona a la otra los cánones establecidos legalmente con la finalidad de repercutir a los usuarios de las infraestructuras los costes de su construcción y explotación. Esta separación de los centros de gastos que recaen sobre la red ferroviaria dificulta la evaluación, en términos globales, de la viabilidad económica de las infraestructuras y del equilibrio en la prestación de los servicios ferroviarios; es por ello por lo que, para lograr una mayor transparencia, deberían adoptarse medidas que permitan evaluar de un modo global la gestión de la explotación de la red ferroviaria. Dados los costes de inversión tan elevados, la alta velocidad debe aportar un importante retorno económico y social que justifique el uso ingente de recursos de la economía orientados a estos proyectos de infraestructura, que no se produce en el caso estudiado.

En el nuevo escenario de la liberalización, el paquete de capacidad marco propuesto a los candidatos ofrece la posibilidad de competir con la variable "frecuencias" para atraer a clientes a este proceso pero producen importantes incertidumbres además de incrementar el tráfico ferroviario. 
Este aumento de frecuencias requiere por parte de las empresas candidatas además de realizar las correspondientes solicitudes de capacidad desarrollar un proyecto empresarial. Esto supone una gran inversión en material rodante y otros elementos como son las bases de mantenimiento, cuyos costes y periodo efectivo de disponibilidad es elevado debido a autorizaciones de entrada en servicio del material o la expedición de certificados de seguridad y homologación de estos.

El coste de explotación está vinculado a la capacidad de los trenes, es decir el número de trenes puesto por el operador para dar servicio. El operador ante el objetivo de reducir al máximo su coste de explotación deberá de comprar trenes cuya capacidad está optimizada a la demanda de la ruta. Cuanto mayor capacidad del tren, generalmente, mayor coste de inversión en material rodante por lo que, el posible ahorro en costes de explotación puede no compensar el incremento en el coste de adquisición, proponiendo el tema para tratar en nuevos trabajos de investigación y que está bajo la influencia del denominado "valor de la infraestructura". Esto beneficia a las empresas que puedan realizar grandes inversiones, aunque con el criterio de asignación basado en el compromiso de uso en 10 años permitirá a las empresas que no dispongan de material rodante y no puedan solicitar capacidad desde el principio estar en el mismo nivel que aquellas que ya dispongan de él. Las inversiones en material rodante que deben realizar los nuevos operadores requieren la garantía de tener la disponibilidad de capacidad a largo plazo. Los acverdos marco entre el administrador y el operador constituyen la herramienta idónea para reducir la incertidumbre en la toma de decisiones de inversión por parte del candidato, incentivando su entrada en el mercado. Sin embargo, estos acuerdos conllevan riesgos, vincular parte de la capacidad a un candidato a largo plazo, reduce la capacidad disponible para nuevos operadores durante la duración del acuerdo.

El aumento de la velocidad en la línea y desde el punto de vista de los operadores, produciría un mayor número de viajeros, lo que no significa que existan mayores beneficios. Si se fija el aumento de viajeros como ingresos como consecuencia de una reducción del tiempo de viaje lleva también asociado un aumento de ingresos pero, a falta de analizar con detalle, el aumento de demanda lleva inducido un incremento en la oferta, es decir, un aumento de material rodante por parte del operador y un aumento de los costes, por lo que un aumento de ingresos no significa que exista un incremento igual de beneficios. El importe del canon que tiene que pagar el operador es una cuantía muy considerable dentro de la estructura de costes y que afecta a su competitividad. 
En referencia a las estaciones de viajeros existe un tema crítico, las vías de estacionamiento, ya que existen estaciones coordinadas 24 en las que se exigirá una programación en detalle de la capacidad de estacionamiento y mayor detalle en las de circulación.

A fecha de terminación de esta Tesis no se ha podido conocer la existencia de incentivos por el uso de las vías de estacionamientos con un periodo de ocupación menor que favorezcan incrementar la capacidad de la estación. La congestión de las principales estaciones podría incentivar un mayor uso de estaciones secundarias por parte de los operadores ferroviarios, como muestran las experiencias previas en el sector aéreo y del operador ferroviario francés 25 .

Otro tema, no desarrollado en esta Tesis y que no se debe obviar, es que la apertura efectiva del transporte de viajeros en estas líneas no concreta como acceder a las instalaciones de mantenimiento en condiciones transparentes y no discriminatorias como está estipulado en la normativa vigente. Se ha estudiado el problema en las estaciones de Madrid-Puerta de Atocha y en Valencia-Joaquín Sorolla debido a los accesos a Cerro Negro a la falta de, tanto de vías de apartado como a la longitud de los andenes en las vías de estacionamiento, respectivamente.

En cuanto a los cánones, definidos como tasas. Según la legislación se trata de tributos cuyo hecho imponible es la utilización privativa del dominio público ferroviario, los elementos esenciales de los cánones se establecen por ley, en la Ley de Presupuestos Generales del Estado.

La consideración de los cánones como tributos impide que ADIF pueda optimizar la utilización de la infraestructura ferroviaria mediante el sistema de tarifación, puesto que la determinación de los cánones se limita a calcular el importe del canon en cada caso concreto, aplicando una fórmula previamente determinada, por lo que el sistema impide que esta tenga la flexibilidad que requiere una gestión óptima de la infraestructura. De esta forma la revisión de los cánones ferroviarios es incluida en la Ley de Presupuestos Generales del Estado, sometiendo a las empresas ferroviarias y candidatos a una incertidumbre sobre el nivel de cánones e influyendo en la tarifa a aplicar y aceptando de forma predeterminada su establecimiento.

24 Estación de viajeros con altas exigencias de calidad de servicio en la que se prevé una elevada demanda de ocupación y estacionamientos en sus vías (por ejemplo Valencia Joaquín Sorolla).

25 Chiambaretto y Fernández (2014). 
Las variaciones de la tarifa acentúan una fuerte sensibilidad en el resultado económico-social, valores bajos de la tarifa conducen a resultados muy buenos desde el punto económico-social, mientras que los valores altos llevan a valores bajos del resultado.

La potencialidad en términos de valor que ofrece la infraestructura puede ser aprovechada o no por el operador de servicios en función de su estrategia y su diseño operativo (por ejemplo, puede no estar interesado en aumentar la capacidad de cada tren para así ofrecer más frecuencia en una relación origen destino en la que la demanda sea muy sensible a este factor) y siempre que lo permita los parámetros de la línea. Esta limitación de capacidad es lo que priva al operador de la posibilidad de explotar este tipo de trenes $y$, por ello, limitando potencialmente su competitividad frente a otros modos de transporte.

Además de por la capacidad (número de plazas) del tren, el valor del surco se ve afectado por la posibilidad de generar ingresos y reducir costes en la operación, debe mencionarse el aumento de la velocidad media del tren como un factor que incide tanto en el aumento de los ingresos por plaza (los viajeros están dispuestos a pagar más cuando mayor sea la velocidad) como en la reducción de costes (es preciso emplear menos recursos como trenes o personal para un mismo servicio si éste se completa en menos tiempo). 
Consideraciones ante la liberación de las líneas de alta velocidad Madrid-Levante.

A continuación se hace una serie de reflexiones a las conclusiones obtenidas ante los desafíos a los que se van a enfrentar los operadores frente la liberalización del actual sistema ferroviario:

Reflexiones respecto a la explotación en la actual infraestructura. Valor de la infraestructura.

La diferente caracterización y funcionalidad de la red plantea un problema ante la capacidad de absorber el aumento de circulaciones adjudicadas y futuras, es el valor de la infraestructura, valor que aumentará cuanto mayor sea la posibilidad de transporte que ofrezca y cuanto más atractivas y menos costosas sean las condiciones de acceso a este transporte.

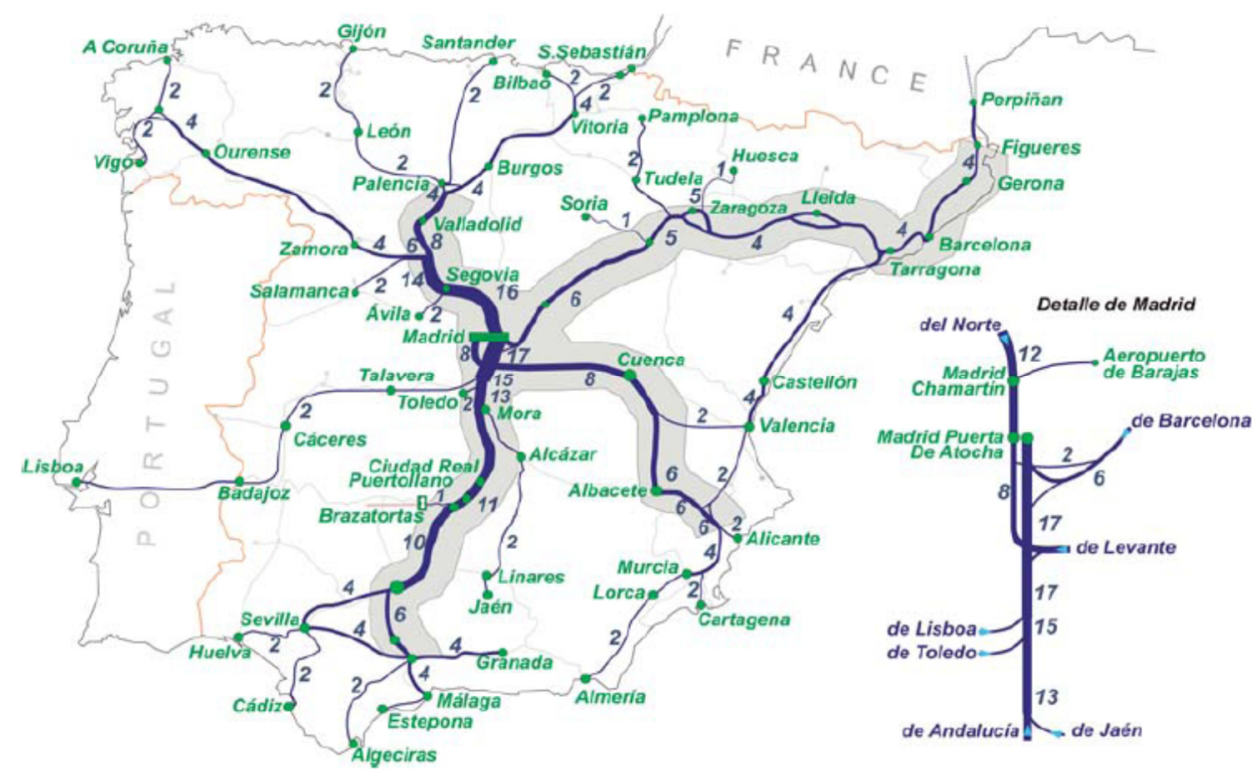

Gráfico 33. Troncalidad de la red de alta velocidad. Fuente: García Álvarez (2011). 
Para los operadores el valor potencial generado por la operación está compuesto por el producto de dos factores:

El valor de cada surco, valor dependiente del número de viajeros que puede transportar un tren que utiliza el surco y del margen económico que esos viajeros pueden aportar al operador del servicio.

Cuando estos viajeros estén dispuestos a pagar una cantidad mayor por su billete y cuanto el transporte resulte menos costoso para el operador del servicio, más valor tendrá el surco, y por ello más valor potencial tiene la infraestructura.

El número surcos en un periodo de tiempo, queda definido como la capacidad de circulación de la línea.

La maximización del valor de la infraestructura puede venir por la combinación más adecuada de los factores anteriores pudiéndose obtener con un menor número de surcos con mayor valor unitario, o con un mayor número de surcos pero de menor valor cada uno.

Valor de la infraestructura $=N^{\circ}$ de viajeros por surco $x$ (Ingreso por viajero-Gasto por viajero) x Número de surcos por periodo

El aumento del valor de la infraestructura puede venir, tanto del aumento de la capacidad (número de surcos por periodo), como de la capacidad de cada tren, apoyándose en parámetros y condiciones de la infraestructura, o mejorando las condiciones económicas para el operador.

El valor del surco depende del número de plazas por cada tren, del ingreso que potencialmente puede aportar cada viajero y del coste que supone. El número de plazas por tren y los ingresos o costes unitarios deben referirse a los aspectos en que vienen condicionados por la infraestructura, por sus parámetros y por su explotación.

El valor de un surco se inscribe en el ámbito de la operación del servicio, donde existen puntos sobre los que actuar para que cambie el valor del tren, pero la propia infraestructura condiciona el valor del tren. Así, y por lo que se refiere al número de plazas ofertadas por tren, si se aceptan trenes más anchos, más altos o largos por así permitirlo ADIF, con un mismo tren podrán transportarse muchos más viajeros. ADIF, al fijar estas condiciones de admisión de los trenes, aumenta el valor de cada surco permitiendo al operador que aumente la capacidad del tren que lo utiliza. 
La potencialidad en términos de valor que ofrece la infraestructura puede ser aprovechada o no por el operador de servicios en función de su estrategia y su diseño operativo (por ejemplo, puede no estar interesado en aumentar la capacidad de cada tren para así ofrecer más frecuencia en una relación origen-destino en la que la demanda sea muy sensible a este factor), pero si el administrador no hace posible el aumento de la capacidad de cada tren (por no permitirlo los parámetros de la línea) se está privando al operador de la posibilidad de explotar este tipo de trenes $y$, por ello, limitando potencialmente su competitividad frente a otros modos de transporte.

Además de la capacidad (número de plazas) del tren, el valor del surco se ve afectado por la posibilidad de generar ingresos y reducir costes en la operación.

Mención tiene en el valor del surco el aumento de la velocidad media del tren como un factor que incide tanto en el aumento de los ingresos por plaza (los viajeros están dispuestos a pagar más cuando mayor sea la velocidad) como en la reducción de costes (es preciso emplear menos recursos, es decir, menos trenes y personal para un mismo servicio si éste se completa en menos tiempo) ${ }^{26}$

Pero la capacidad no sólo se limita a las composiciones que pueden circular por una línea o tramo, la capacidad está también relacionada con el resto de las infraestructuras como son las estaciones, vías de apartado, centros de mantenimiento, etc.

En el caso de los centros de mantenimiento, en la actualidad existen centros de mantenimiento que corresponden a Renfe Operadora, que en ellos se realizan las tareas correspondientes a la puesta a punto de trenes y a reparaciones necesarias para el cumplimiento de la normativa correspondiente, con el fin de realizar el transporte de viajeros de forma segura.

\footnotetext{
${ }^{26}$ Como una referencia de la incidencia de velocidad del tren en los precios que el operador del servicio puede cargar a los clientes finales, puede citarse el dato de que en el sistema de precios que emplea la Unidad de Negocio de Grandes Líneas de Renfe (según la exposición de su Director de Marketing, José Luis Parra, en el XIV Curso General de Transportes Terrestres de la FFE, 2000), el precio base para una ruta, que se calcula con una fórmula $\mathrm{P}=\mathrm{A}+\mathrm{Bk}-\mathrm{Ck} 2$ (donde $\mathrm{k}$ es la distancia), está afectado por un coeficiente $\mathrm{Ci}$ que depende la velocidad. Este cociente, para un mismo tipo de tren, oscila entre 0,81 si la velocidad media es menor de $100 \mathrm{~km} / \mathrm{h}, 0,87$ si está entre 100 y $120 \mathrm{~km} / \mathrm{h}$ y 0,92 si es mayor de $120 \mathrm{~km} / \mathrm{h}$. Sobre la incidencia de la velocidad según Andersson et al. (2001), los costes presentan una elasticidad de $-0,2$ respecto a la velocidad media del tren.
} 
Resaltar que estos centros de mantenimiento deben estar homologados así como su personal debe estar en posesión de la correspondiente habilitación que le permita realizar estos trabajos y que las nuevas empresas ferroviarias, en caso de utilizar centros propios para este mantenimiento, deberán poseerlos.

En el caso de las estaciones de transporte de viajeros, ejemplo Valencia Joaquín Sorolla y Madrid Puerta de Atocha, se ha realizado un estudio sobre dos problemáticas de naturaleza distinta y que ocurren en la actualidad sin darse todavía el esperado incremento de las circulaciones debido a la liberalización y que a continuación se exponen:

\section{Madrid-Puerta de Atocha.}

La estación es el origen de las líneas de alta velocidad con destino a Barcelona - frontera francesa, Levante y Andalucía. Las vías de circulación de entrada y salida (2 vías) de la estación desde Andalucía y Levante, a fecha de hoy, son las mismas desde la bifurcación de Torrejón de Velasco que está situada en el P.K. 28,8, siendo su origen la estación de MadridPuerta de Atocha. En la tabla siguiente ${ }^{27}$ la existencia de limitaciones permanentes de velocidad a la salida de la estación tiene mucha influencia en la capacidad de la línea, sin tener en cuenta las incidencias que puedan producirse a consecuencia de situaciones degradadas.

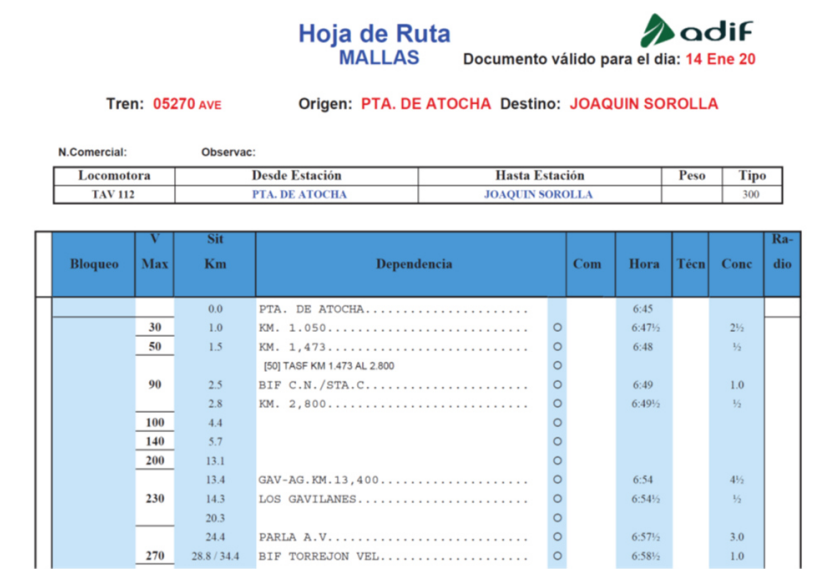

Tabla 62. Fragmento de Hoja de Ruta Madrid-Puerta de Atocha-Bif. Torrejón de Velasco. Fuente: ADIF.

27 Es la hoja de ruta empleada por los maquinistas de cada tren donde se recoge toda la información específica referente a la línea y al tren con el que se circula. 
Otro punto para tener en cuenta es la disposición de las vías en la estación. Según el esquema siguiente encontramos una diagonal que "cizalla" las 4 vías de entrada y salida y que da acceso a la base de mantenimiento y vías de apartado de Cerro Negro produciéndose paradas técnicas que repercuten en retrasos, tanto a las circulaciones de entrada como a las de salida. En el gráfico siguiente se observa la disposición de las vías así como el ejemplo del recorrido que realiza una composición desde una vía de estacionamiento (vía 6 A) hasta la aguja de entrada de la citada base. La distancia existente entre la vía de estacionamiento y las agujas de entrada a la base es de 2,441 kilómetros y la limitación de velocidad máxima permitida en el trayecto oscila entre los 30 y $50 \mathrm{~km} / \mathrm{h}$.

- El tiempo invertido por las composiciones, teniendo en cuenta la actuación del diferímetro28 es el siguiente:

- Establecimiento del itinerario: 3 minutos.

- Recorrido de la composición: 2 minutos.

- Liberación del itinerario : 3 minutos.

Esto penaliza la duración del viaje con un tiempo de espera de 8 minutos debido a esta maniobra, que se debe realizar en espacios de tiempo donde la afección a la circulación sea mínima.

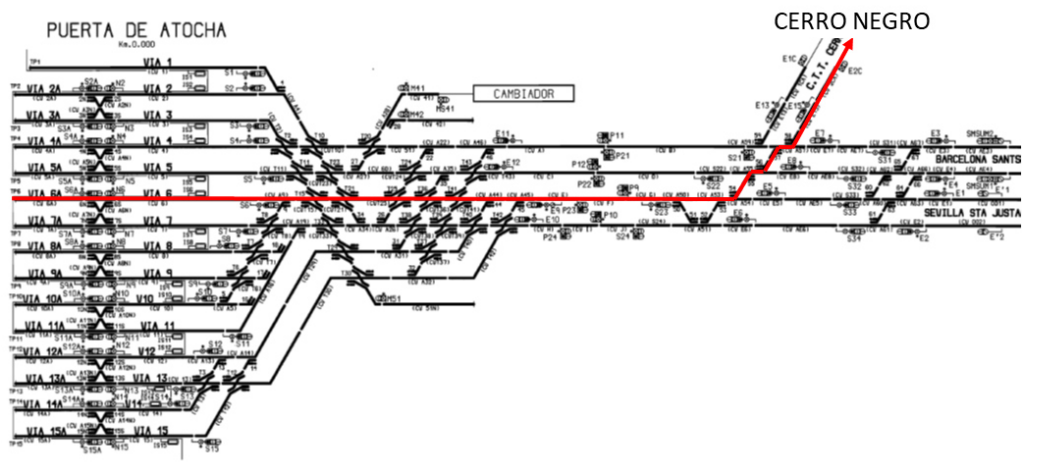

Gráfico 34. Interferencia en las circulaciones en Madrid-Puerta de Atocha. Fuente: ADIF.

\begin{abstract}
28 Diferímetro: aparato temporizador relacionado con procesos de señalización o control de circulación en los que se considera necesario que la instalación deje pasar un tiempo determinado entre una acción y la siguiente, por motivos de seguridad.
\end{abstract}




\section{Valencia Joaquín Sorolla}

En el caso de esta estación (estación provisional) se plantea el problema de estacionamiento tanto para circulaciones en doble composición como para el estacionamiento de una circulación en composición simple en vía ocupada. La estación cuenta a fecha de elaboración de este trabajo con 9 vías de estacionamiento, 6 vías de ancho estándar ( $1.435 \mathrm{~mm}$.) y 3 vías de ancho ibérico ( $1.668 \mathrm{~mm}$ ). En la tabla siguiente se muestra la longitud de los andenes de la estación:

\begin{tabular}{|c|c|c|}
\hline Ancho vía & Vía & Longitud andenes \\
\hline \multirow{4}{*}{ Estándar } & $\begin{array}{l}1 \\
2\end{array}$ & $227 \mathrm{~m}$. \\
\hline & $\frac{2}{3}$ & \\
\hline & 4 & $409 \mathrm{~m}$. \\
\hline & $\begin{array}{l}5 \\
6\end{array}$ & $227 \mathrm{~m}$. \\
\hline \multirow{3}{*}{ Ibérico } & 7 & $185 \mathrm{~m}$. \\
\hline & 8 & $374 \mathrm{~m}$. \\
\hline & 9 & $400 \mathrm{~m}$. \\
\hline
\end{tabular}

Tabla 63. Longitud de andenes de la estación Joaquín Sorolla. Fuente: ADIF.

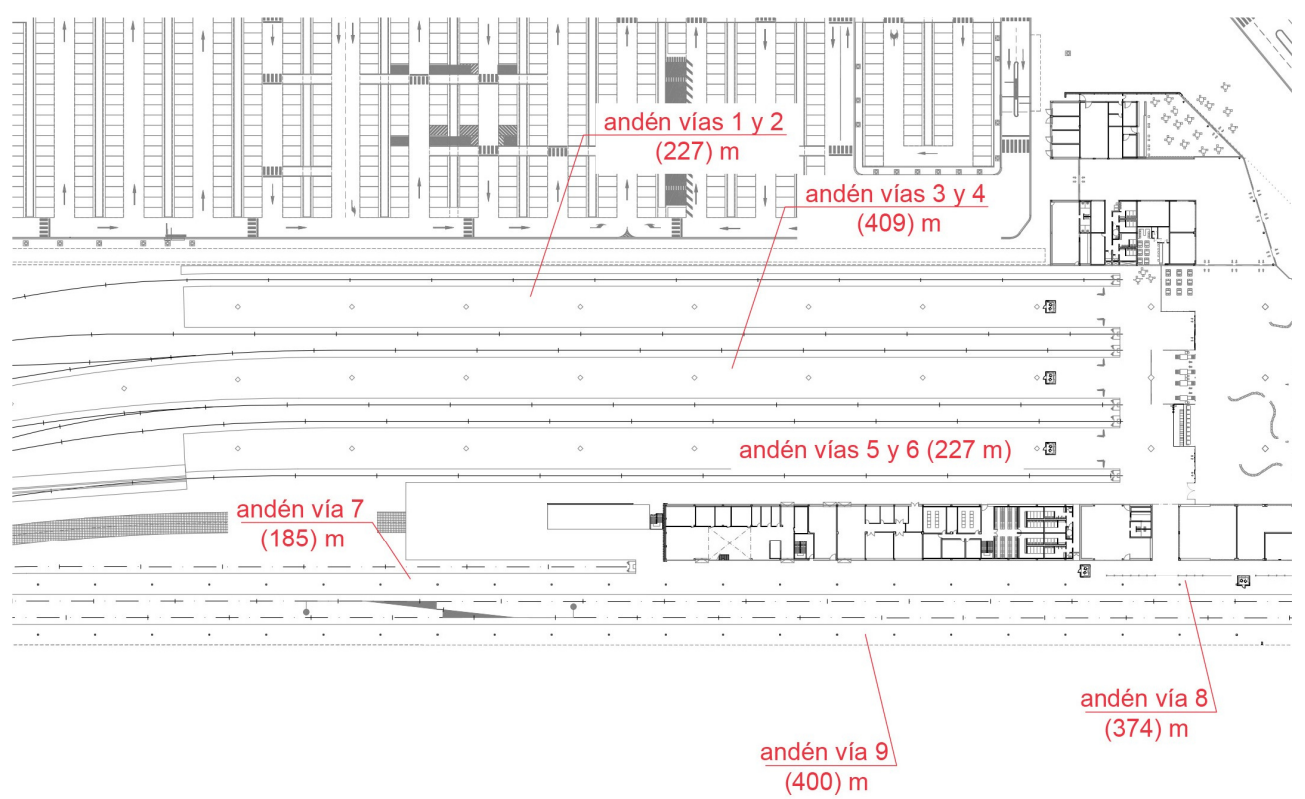

Gráfico 35. Disposición de vías de estacionamiento en la estación de Joaquín Sorolla. Fuente: ADIF. 
Según las dimensiones de los andenes, sólo se pueden estacionar trenes que circulen en doble composición en las vías 3 y 4 y no pudiendo estacionar ningún tren sobre vía ocupada por otro.

En la actualidad la estación utiliza las vías de estacionamiento como vías de apartado par material rodante fuera de servicio, lo que reduce la capacidad de las vías.

Reflexiones de los efectos de la tarifa en los costes de la infraestructura durante la explotación.

La tarifa aplicada a los viajeros tiene una influencia muy importante en el resultado económico-social y en el financiero de la línea ferroviaria, siendo la variable con mayor incidencia en el resultado después de la cuantía de la propia inversión. Jaro (2011) presenta las variables críticas con más influencia en los resultados en el caso de los análisis realizados en España para las líneas de alta velocidad, y resultan ser el importe de la inversión y la tarifa aplicada, por encima incluso de la variación del PIB y del valor del tiempo.

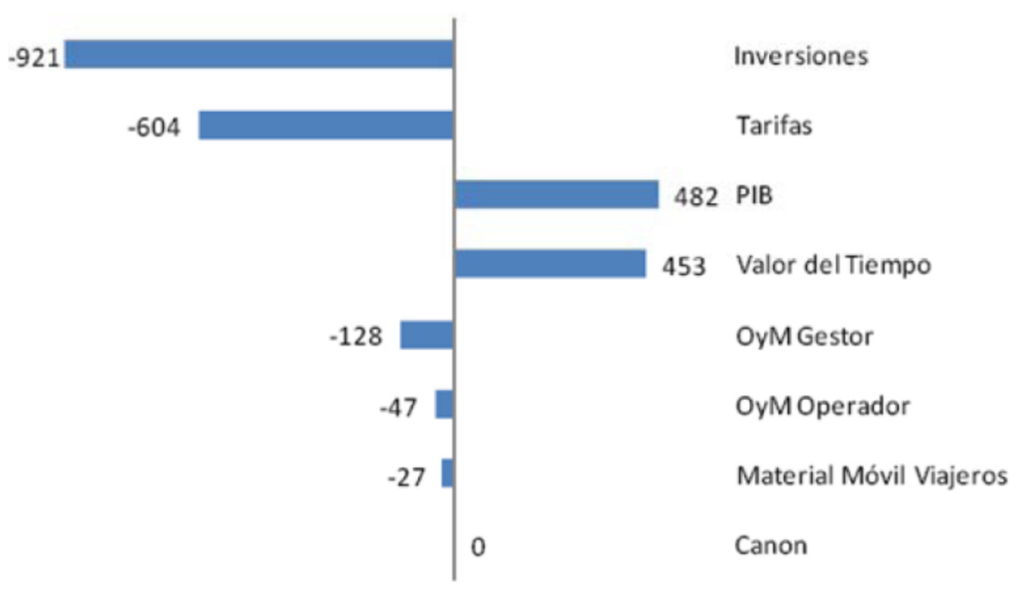

Gráfico 36. Importancia relativa de las variables críticas en el VAN. Fuente: Álvarez García, González Franco, Rubio García (2015), Jaro (2011).

La decisión de construir o no construir una línea de alta velocidad suele apoyarse en el análisis coste-beneficio. Se compara la situación con proyecto con la situación sin proyecto y se analiza la diferencia entre ambos. 
Se calcula la rentabilidad financiera basada en flujos económicos actualizados con una tasa de descuento y también la rentabilidad económico social en la que se tiene en cuenta los beneficios sociales como son la reducción de tiempo, accidentes, emisiones, consumo energético, etc., pero el análisis se realiza sin distinguir entre los resultados del constructor de la infraestructura, de su administrador y de los operadores de transporte que operaran.

Con frecuencia la rentabilidad financiera resulta negativa, y sin embargo la infraestructura se construye porque tiene una rentabilidad económico-social positiva. Y ello ocurre no solo en el caso de las líneas de alta velocidad, sino también en otro tipo de infraestructuras de transporte en las que la rentabilidad financiera es negativa, como en el caso de las autovías, libres de peaje y por ello no generan ningún ingreso para compensar los costes de su construcción y de mantenimiento. Pese a ello, las administraciones deciden soportar el coste de construcción y de mantenimiento de estas vías porque se les supone una rentabilidad económico-social positiva. Los costes de mantenimiento y explotación aumentan al bajar las tarifas y aumentar el número de viajeros, haciéndolo en proporción al número de trenes (cuyo crecimiento, por efecto del aumento del aprovechamiento, es menor que el del número de viajeros). Los costes fijos de explotación, así como amortizaciones y costes financieros de la infraestructura no sufren variación.

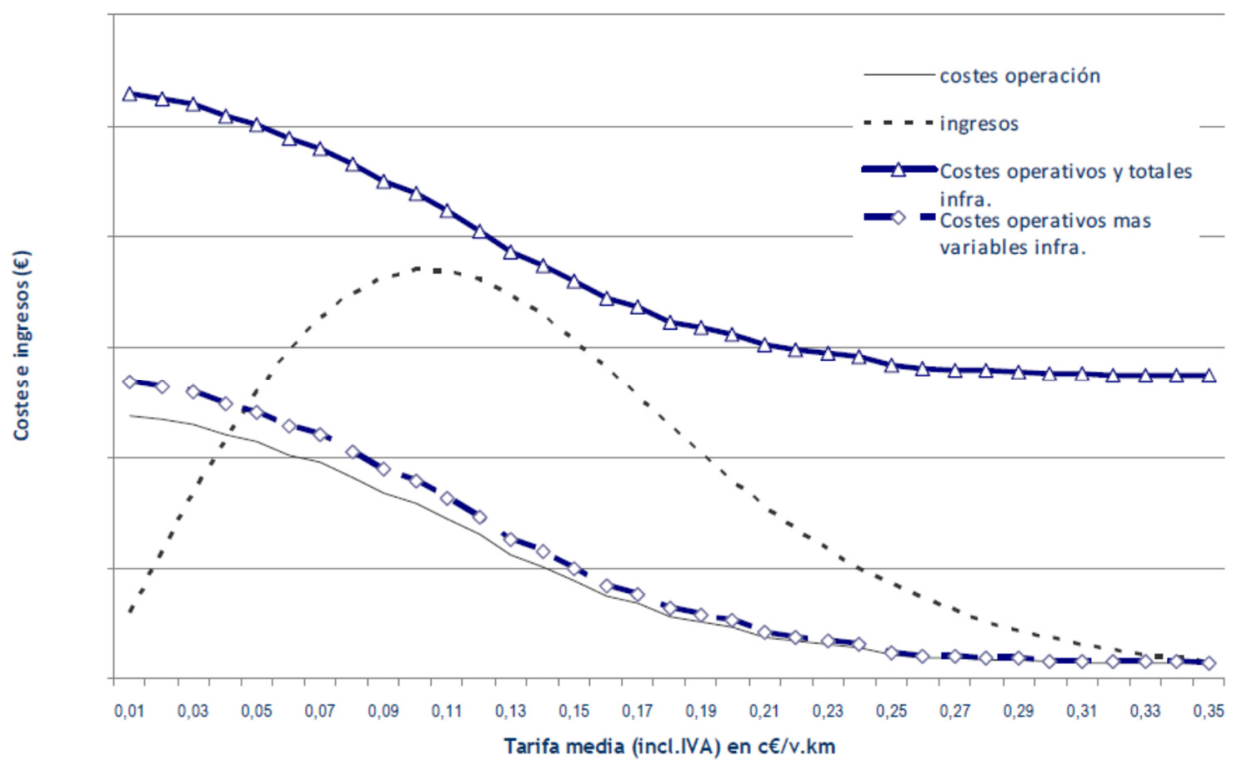

Gráfico 37. Cambios en los costes operativos y totales de la infraestructura al cambiar las tarifas. Fuente: Álvarez García, González Franco, Rubio García (2015). 
En el gráfico anterior se observa la variación de los costes, manteniéndose como referencia la variación de los ingresos y de los costes operativos. Las conclusiones son que con valores de la tarifa por debajo de la que conduce al ingreso máximo, el margen empeora; por encima de esa tarifa mejora; y con precios ya muy altos, empeora de nuevo. Como consecuencia de las variaciones que los cambios de tarifas inducen en los ingresos, en los costes de la operación y de la infraestructura, así como en los ahorros externos producen variaciones en el margen financiero y en el margen económico social.

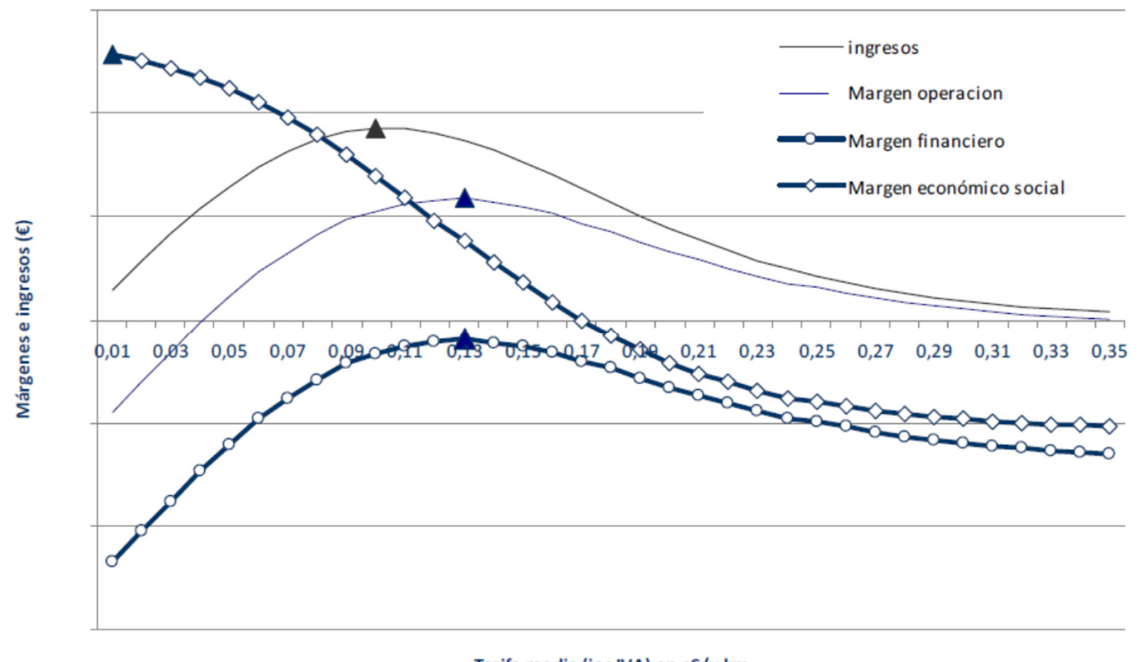

Tarifa media (inc.IVA) en $c \in / v . k m$

Gráfico 38. Cambios en el margen financiero y en el margen económico social. Fuente: Álvarez García, González Franco, Rubio García (2015).

Reflexiones ante la interoperabilidad del material rodante.

El material rodante de las nuevas empresas ferroviarias debe ser compatible con el sistema de explotación de la línea por donde va a circular, es decir, debe estar dotado de equipos embarcados compatibles con el mismo sistema de protección instalado en la infraestructura. Pero el problema se plantea en el caso de querer operar en otras líneas de alta velocidad del país, en el caso de ser adjudicatarias en un futuro en esas líneas. En la actualidad las líneas están operadas por la empresa Renfe Operadora con una flota de trenes que presentan ciertas restricciones de circulación debido a la incompatibilidad de los sistemas de seguridad embarcados y la líneas de ADIF. 
Según la tabla adjunta, se muestra esta incompatibilidad entre las series y el trazado:

\begin{tabular}{|c|c|c|c|c|c|c|}
\hline \multirow{2}{*}{ Series } & \multicolumn{7}{|c|}{ Línea ferroviaria } \\
\cline { 2 - 7 } & CONVENC. & FRANCIA & $\begin{array}{c}\text { MADRID- } \\
\text { BARCELONA }\end{array}$ & $\begin{array}{c}\text { MADRID- } \\
\text { SEVILLA }\end{array}$ & $\begin{array}{c}\text { MADRID- } \\
\text { VALENCIA }\end{array}$ & $\begin{array}{c}\text { MADRID- } \\
\text { VALLADOLID }\end{array}$ \\
\hline 100 & $\mathrm{X}$ & $\mathrm{X}$ & 0 & 0 & 0 & $\mathrm{X}$ \\
\hline $100 \mathrm{~F}$ & $\mathrm{X}$ & 0 & 0 & 0 & $\mathrm{X}$ & $\mathrm{X}$ \\
\hline 103 & $\mathrm{X}$ & $\mathrm{X}$ & 0 & 0 & $\mathrm{X}$ & 0 \\
\hline $102 / 12$ & $\mathrm{X}$ & 0 & 0 & 0 & 0 & 0 \\
\hline 120 & 0 & $\mathrm{X}$ & 0 & $\mathrm{X}$ & 0 & $\mathrm{X}$ \\
\hline $120 / 5$ & 0 & $\mathrm{X}$ & 0 & 0 & 0 & 0 \\
\hline 130 & 0 & $\mathrm{X}$ & 0 & 0 & 0 & 0 \\
\hline 730 & 0 & $\mathrm{X}$ & 0 & 0 & 0 & 0 \\
\hline 104 & 0 & $\mathrm{X}$ & 0 & 0 & 0 & $\mathrm{X}$ \\
\hline 114 & 0 & $\mathrm{X}$ & 0 & 0 & $\mathrm{X}$ & 0 \\
\hline
\end{tabular}

Tabla 64. Incompatibilidad de las series de Renfe Operadora y las líneas de AV. Elaboración propia. Fuente: García Álvarez (2019).

En la necesidad de tener que utilizar trenes de ancho variable, pasar de la red de alta velocidad a la red convencional o viceversa supone una pérdida de 5 minutos en los cambiadores de ancho y 5 minutos en el cambio del sistema de protección del tren al ETCS además de un coste añadido por tener que utilizar dicha instalación y material con ancho variable.

\begin{tabular}{|c|c|c|c|c|}
\hline & $\begin{array}{c}\text { Ancho } \\
\text { de vía }\end{array}$ & Electrificación & $\begin{array}{c}\text { Sistemas de } \\
\text { Protección }\end{array}$ & Comunicaciones \\
\hline $\begin{array}{c}\text { Red } \\
\text { Convencional }\end{array}$ & $1.668 \mathrm{~mm}$ & CC $3 \mathrm{kV}$ & $\begin{array}{c}\text { ASFA } \\
\text { EBICAB }\end{array}$ & Tren Tierra \\
\hline $\begin{array}{c}\text { Red Alta } \\
\text { Velocidad }\end{array}$ & $1.435 \mathrm{~mm}$ & CA $50 \mathrm{~Hz} 25 \mathrm{kV}$ & $\begin{array}{c}\text { ETCS Nivel } 1 \\
\text { y Nivel } 2 \\
\text { LZB } 32\end{array}$ & GSM-R 33 \\
\hline
\end{tabular}

Tabla 65. Características técnicas líneas ferroviarias gestionadas por ADIF. Elaboración propia.

29 ASFA: Anuncio de Señales y Frenado Automático, es un sistema de repetición de señales en cabina con ciertas funciones de control sobre el tren.

30 EBICAB: Sistema de protección automática de trenes con supervisión continua.

31 ETCS: European Train Control System.

32 LZB: Linienzubbeeinflussung, sistema de control de tráfico ferroviario con supervisión continua.

33 GSM-R: Global System for Mobile-Railway, sistema de comunicación digital específico para ferrocarril, que provee a los trenes de radiotelefonía y línea de datos. 
Reflexiones ante la financiación de servicios comerciales en líneas convencionales.

Otro tema que tratar es la financiación de los servicios comerciales operados por Renfe Operadora en las líneas convencionales, el resultado positivo de los servicios prestados por la empresa en Alta Velocidad, después de la liquidación de los correspondientes cánones compensa los resultados negativos de todos los demás negocios de viajeros y de mercancías.

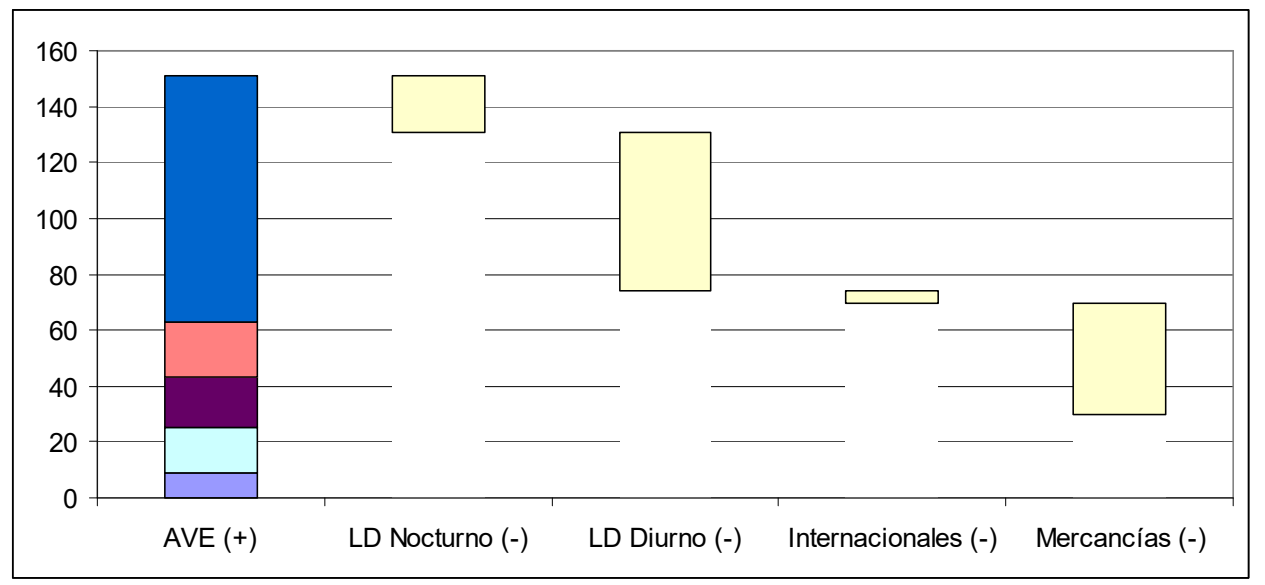

Gráfico 39. Contribución del AVE a la financiación de servicios comerciales de Renfe. Fuente: García, 2019.

En el caso que nos ocupa, la posible demanda de viajeros, bien inducida o nueva ante los nuevos operadores, puede ocasionar un descenso de clientes en el actual operador, lo que obliga a realizar una política económica de búsqueda de captación de clientes, como puede ser lanzamientos de ofertas, bajadas de precios, etc. Frente a este escenario un descenso de los ingresos por el operador actual haría insostenible el sistema de mantenimiento de los servicios en las líneas convencionales y que no están soportadas por Obligaciones de Servicio Público. Habría que estudiar muy bien un aumento de los cánones a aplicar a las nuevas empresas que entren en el mercado español en función de la cuota de mercado abarcado y así poder ayudar al sostenimiento económico de los citados servicios. En el caso de las estaciones, y vista la capacidad de los trenes que pretenden poner en circulación, el canon por viajero podría representar una parte importante de esa aportación, siendo compensados los costes directos y parte del mantenimiento de los servicios en las líneas convencionales. 
5 CONCLUSIONES 
La presente tesis trata de abordar la problemática actual sobre la tarificación por uso de la infraestructura en Europa y se realiza un enfoque particular al sistema tarifario por uso de estaciones, haciendo un estudio pormenorizado en España, en la línea de alta velocidad Madrid-Valencia ante el nuevo escenario de la liberalización del transporte de viajeros en la Unión Europea.

Respecto a los cánones relacionados con el concepto de uso de la infraestructura se confirma que se utiliza una gran diversidad de variables, siendo la más utilizada la variable tipo de línea, tipo de tren y horario de circulación, pero no hay ningún administrador que aplique más del $35 \%$ de los conceptos existentes para tarificar sus servicios. La mayoría de los sistemas de tarificación comparten algunos parámetros, tales como la categoría de la línea, diferenciando el uso de líneas principales, secundarias y otras. Estas variables aplicadas recuperan los costes marginales y los costes variables correspondientes a la operación, mantenimiento y renovación. Tras examinar cada estructura de tarificación en profundidad existen administradores que no realizan una clara distinción entre los costes marginales y los márgenes de beneficio.

En los corredores ferroviarios internacionales, a pesar de la legislación existente que obliga a una convergencia de enfoque para un sistema basado en costes directos, sigue existiendo esa falta de convergencia, no sólo en los niveles de cánones, sino también en las formulaciones, las variables y parámetros de fijación de precios variando de país a país, representando un problema. La diferencia en los niveles de cánones de infraestructura, y la diferencia en las variables aplicadas hace que, además de que cada administrador establece sus propios cánones, la decisión de aumento de los cánones por parte de un administrador por uso de su infraestructura sin consultar a otros "vecinos" puede derivar a que una composición ferroviaria que era viable económicamente antes de dicho aumento puede ser menos dando lugar a una reducción de circulaciones por el corredor o incluso llegar a su cancelación. No hay transparencia en cuanto a la justificación de las tarifas así como la presencia de incentivos, algunos confusos como el caso de que trenes frecuentes y cortos pueden ser más baratos en un país que trenes más pesados y que no tienen frecuencia en el país colateral. Un mayor grado de homogeneidad sería beneficioso, y en su defecto, la implantación de tarifas internacionales especiales aprobadas por los administradores de un corredor ferroviario en particular, de forma que compartan ingresos que beneficien a los administradores implicados. 
Los cánones analizados en la tarificación por uso de las estaciones de viajeros muestran que existen administradores que aplican directamente el canon dentro del de uso de la infraestructura, siendo determinado en el momento de realizar la reserva del surco.

La subvariable común entre los administradores es la categorización de la estación por importancia, teniendo subcategorías de clasificación con gran variedad de parámetros empleados en esta clasificación.

Ante esto no es posible simplificar la formulación empleada para el cálculo de los cánones por los países estudiados en busca de una expresión común aplicable para conseguir eliminar una de las barreras en la red ferroviaria europea.

En vista de los expuesto y ante el futuro escenario del ferrocarril en España con la entrada al mercado nacional de los nuevos operadores ferroviarios sería de interés reformar la Ley del Sector Ferroviario con el objetivo de modificar el sistema mediante el que se fijan los cánones. Este cambio supondría separar esta tasa de los Presupuestos Generales del Estado y permitir que los administradores de infraestructuras puedan establecer con total libertad bonificaciones en los cánones para, expresamente, incentivar el transporte. Esta flexibilización permitiría reducir el importe que cada operadora paga por usar la infraestructura e instalaciones, traduciéndose en un incremento de las circulaciones, aumento de los ingresos del administrador y en una reducción de las tarifas de transporte de viajeros y mercancías. Por contrapartida, se deberá prestar particular atención en la desarrollo de mecanismos de financiación de servicios comerciales en las líneas convencionales no rentables, sustituyendo la eventual financiación cruzada implícita del operador actual y teniendo en cuenta la apertura a la competencia.

Respecto a la problemática de la tarificación por uso de las estaciones de viajeros en líneas de alta velocidad - línea Madrid-Levante-, se verificó, para el caso de estudio, que los ingresos por uso de las estaciones de transporte de viajeros, proviene con mayor porcentaje del canon, canon basado en el número de circulaciones que tienen origen/destino o parada comercial y en el número de viajeros subidos/bajados en cada una de ellas. En cuanto al canon aplicado a las circulaciones es dispar entre las estaciones de la línea, siendo más bajo en las estaciones que no son origen-destino, es decir intermedias. 
Como conclusión en el ámbito de las estaciones estudiadas, los cánones aplicados por usos de estaciones a pesar de ser elevados cubren por encima los costes directos, es decir, están fuera de las directrices comunitarias. Estos ingresos por cánones tal como legisla la Unión Europea, no deben producir beneficios sólo deben recuperar los costes directos, es decir son cánones máximos aplicables. En cambio estos ingresos son insuficientes para equilibrar el balance económico de estas, sobre todo en estaciones que a pesar de no tener un número elevado de viajeros presentan gastos altos no cubriéndose tampoco los gastos de amortización. Para cumplir con la Directiva europea, la primera propuesta sería separar los gastos directos del resto. Los gastos directos serían imputados al canon correspondiente al aplicado por número de viajeros, actores principales en el ferrocarril, ya que hacen uso de las estaciones e instalaciones anexas como puede ser el sistema de información al viajero, servicio de radioscopias y seguridad en los accesos, etc. Este modo de tarificación permite al Administrador obtener mayores ingresos por viajero, sobre todo en el caso de la circulación de trenes con alta capacidad (500 plazas) como tiene estudiado los nuevos operadores. El resto de los gastos será imputado al número de circulaciones que tengan origen, destino o parada comercial intermedia. Este canon sería aplicado como parte de uso de la infraestructura pero con repercusión en las estaciones compensando el desequilibrio existente entre estaciones, sobre todo estaciones intermedias, donde no realizan parada comercial todos los trenes, con menor número de viajeros y sin elevados costes directos, ya que carecen por ejemplo de personal. Esto permite cubrir total o parcialmente mediante compensación los gastos directos de las estaciones. 
6 FUTURAS LÍNEAS DE INVESTIGACIÓN 
En la presente Tesis se han formulado expresiones mediante las variables aplicadas en el cálculo de los cánones, pero existen una serie de áreas con relevancia para una mayor expansión y mejora de esta. A continuación se hace una relación de futuras líneas a desarrollar en futuras investigaciones:

- Análisis de los costes totales de producción incluyendo los gastos de los cánones de los servicios de transporte por ferrocarril como elementos de la competitividad entre empresas ferroviarias.

- Definición de las influencias al unificar o eliminar variables y su impacto en la economía del administrador de infraestructuras así como sus interdependencias.

- La ampliación de los estudios para la validación conceptual propuesta completándose con casos documentados de transferencia entre administraciones ferroviarias.

- Repercusión de la velocidad de diseño en las líneas de Alta Velocidad y su impacto de los cánones en los operadores ferroviarios.

- El análisis de la relación entre canon, precio de billete y demanda de viajeros.

- Influencia de los nuevos operadores en la sostenibilidad económica del tráfico ferroviario sujeto a Obligaciones de Servicio Público.

- El valor de la infraestructura y el coste de operación para las empresas ferroviarias.

- Nuevo canon por uso de estaciones de viajeros bajo el cumplimiento de los objetivos de las Directivas europeas. Implantación de comparaciones objetivas y cuantitativas con el canon actual aplicado. 
REFERENCIAS BIBLIOGRÁFICAS 
1-ADIF, Declaración sobre la red 2016. Madrid, 2015.

2-ADIF Alta Velocidad, Declaración sobre la red 2016. Madrid, 2015.

3-ADIF-Subdirección Internacional, Pilar Técnico 40 Paquete Ferroviario, Noviembre. Madrid.

4-Bahnen D., "Railway statistics 2017 synopsis," Int. Union Railw., vol. 4, no. 14, pp. 564-567, 2018.

5-Banedanmark, Network Statement 2015. København, 2015.

6-Calvo F. and J. De Oña, "Are rail charges connected to costs?," J. Transp. Geogr., vol. 22, pp. 28-33, 2012.

7-CFR Compagnie Nationale des Chemins de Fer Roumains, Network Statement 2017. Bucaresti, 2015.

8-Comisión Unión Europea "REGLAMENTO DE EJECUCIÓN (UE) 2015/909 de 12 de junio de 2015, vol. 2015, no. 9. 2015.

9-Comisión Unión Europea, "DIRECTIVA (UE) 2016/2370 DEL PARLAMENTO EUROPEO Y DEL CONSEJO de 14 de diciembre de 2016," vol. 2014, pp. 1-17, 2016.

10-Comisión Unión Europea, "REGLAMENTO DE EJECUCIÓN (UE) 2017/2177 DE LA COMISIÓN de 22 de noviembre de 2017 relativo al acceso a las instalaciones de servicio y a los servicios ferroviarios conexos," pp. 1-13, 2017.

11-Comisión Unión Europea, "DIRECTIVA (UE) 2016/798 DEL PARLAMENTO EUROPEO Y DEL CONSEJO de 11 de mayo de 2016 sobre la seguridad ferroviaria," pp. 102-149, 2016.

12-Comisión Unión Europea, "DIRECTIVA (UE) 2016/797 DEL PARLAMENTO EUROPEO Y DEL CONSEJO de 11 de mayo de 2016 sobre la interoperabilidad del sistema ferroviario dentro de la Unión Europea (versión refundida)," vol. 2014, pp. 44-101, 2016.

13-Comisión Unión Europea, "REGLAMENTO (UE) 2016/2338 DEL PARLAMENTO EUROPEO Y DEL CONSEJO de 14 de diciembre de 2016," vol. 2014, no. 5, pp. 22-31, 2016.

14-Comisión Unión Europea, D. E. L. Parlamento, and E. Y. Del, "REGLAMENTO (UE) 2016/796 DEL PARLAMENTO EUROPEO Y DEL CONSEJO de 11 de mayo de 2016 relativo a la Agencia Ferroviaria de la Unión Europea," 2016.

15-Comision Nacional de la Competencia, "Informe sobre la competencia en el transporte de mercancías por ferrocarril en España," Madrid, 2008.

16-DB NETZ, Network Statement 2016, vol. 2016, no. April 2016. Frankfurt an Main, 2016. 
17-R. Development and C. S. Office, Declaración de la Red 2018 Linea Figueras Perpignan Perthus, vol. 1. 2016.

18-Diego Fernández Belmonte, "Transferability Assessment of Rail Infrastructure Charges: Contribution," Universitat Politècnica de Catalunya, 2008.

19-T. C. Endangered and S. C. Council, "Annual Report Annual Report," COSEWIC Annu. Rep., no. June, pp. 2007-2008, 2007.

20-Código de Legis/ación Ferroviaria. Madrid, 2018.

21-European Comision, Statistical Pocketbook 2017. Luxembourg: : Publications Office of the European Union, 2017.

22-P. Europeo et al., "L 220/16," pp. 16-39, 2004.

23-Eurotunnel, Network Statement 2014. 2014.

24-Finnish Transport Agency, Network Statement 2017. Helsinki, 2015.

25-García Álvarez, A. "Magnitudes, unidades, indicadores y estadísticas del transporte de viajeros".

26-García Álvarez, A. "Explotación económica y regulación del transporte de viajeros por ferrocarril", ISBN: 84-96349-17-9, Mayo 2006.

27-García Álvarez, A. "Efectos en el diseño y en la explotación del carácter troncal de la red de alta velocidad", Revista de Alta Velocidad, número 3, pp-19-22.

28-García Álvarez,A., González Franco,I.,Rubio García, A. "El efecto perverso de la predeterminación de la tarifa en el análisis coste beneficio de las nuevas infraestructuras de alta velocidad". Revista de Alta Velocidad, número 3, pp-3-18.

29-González Franco, I. "Efecto de la velocidad de diseño en el coste de construcción de la infraestructura". Revista de Alta Velocidad, número 1, pp33-53.

30-J. B. Font Torres, "Interferencias por la aplicación de los cánones por uso de la infraestructura ferroviaria en la interoperabilidad en el Corredor Mediterráneo," I Congr. del Corredor Mediterráneo, pp. 1-9, 2016.

31-J. B. Font Torres, "INTERFERENCES BY THE APPLICATION FOR THE CHARGES BY USE OF RAIL INFRASTRUCTURE IN EUROPE," ISEC9 Int. Congr. Resilient Struct. Sustain. Constr., pp. 1-5, 2017.

32-J. B. Font Torres, "Cánones por uso de la Infraestructura Ferroviaria Española," XII Congr. Ing. del Transp., 2016. 
33-F. Franklin, F. Nemtanu, and P. F. Teixeira, "Rail infrastructure, ITS and access charges," Res. Transp. Econ., vol. 41, no. 1, pp. 31-42, 2013.

34-L. geležinkeliai, Network Statement 2017, no. January 2016. Vilnius, 2016.

35-Greek Railways Organization, Network Statement 2016. Athens, 2015.

36-High Speed 1, Network Statement 2017, vol. 1, no. March 2016. London, 2016.

37-HŽ Infrastruktura, Network Statement 2017. Zagreb, 2016.

38-Independent Regulators' Group - Rail, "Updated Review of Charging Practices for the Minimum Access Package in Europe," no. November, pp. $1-49,2015$.

39-Infrabel, Document de Référence du Réseau 2016. 2015.

40-Infrabel, "Network Statement," no. March 2015, pp. 1-55, 2016.

41-Infraestruturas de Portugal, Network Statement 2016, no. March 2015. Lisboa, 2016.

42-Jernbaneverket, Network Statement 2017, no. December 2016. Oslo.

43-Lang M., M. Laperrouza, and M. Finger, "Competition Effects in a Liberalized Railway Market," J. Ind. Compet. Trade, vol. 13, no. 3, pp. 375-398, 2013.

44-Laurino A., F. Ramella, and P. Beria, "The economic regulation of railway networks: A worldwide survey," Transp. Res. Part A Policy Pract., vol. 77, pp. 202-212, 2015.

45-Lietuvos geležinkeliai, Network Statement 2017, no. January.

46-R. F. Luxembourgeois, Network Statement 2017. Luxembourg, 2015.

47-Martín Cañizares, MP. "Determinación de la velocidad óptima de los trenes de muy alta velocidad para minimizar las emisiones de dióxido de carbono en un corredor", Revista de Alta Velocidad, número 1, pp-53-62.

48-Matthews, C. Evangelinos, D. Johnson, and D. Meunier, "Impacts and incentives of differentiated rail infrastructure charges in Europe - focus on freight," Eur. Transp., vol. 43, pp. 83-112, 2009.

49-MÁV ZRT AND GYSEV ZRT, Network Statement 2016, no. 18. Hungary, 2015.

50-L. E. Mesa Santos, I. Palacio Vijande, S. Martín Cabo, G. Manzano Cortijo, and J. R. Domínguez Galán, "ATLAS - Alta Velocidad Ferroviaria en España.," p. 68. 
51-Ministerio de Economía y Hacienda. Orden EHA/733/2010, de 25 de marzo, por la que se aprueban aspectos contables de empresas públicas que operan en determinadas circunstancias.

52-M. Muñoz Rubio, Renfe, 75 años de historia (1941-2016). 2016.

53-C. L. Navarro, "La liberación del sector ferroviario en Europa: Efectos sobre la eficiencia productiva y sobre los mercados del transporte.," 2015.

54-Network Rail, Network Statement 2017, no. December 2016. London, 2016.

55-NRIC, Network Statement 2017. Sofia, 2016.

56-ÖBB-Infrastruktur, Network Statement 2017. Vienna, 2016.

57-Parlamento y Consejo de Europa, "L 343/32," Dir. 2012/34/UE del Parlam. Eur. y del Cons., vol. 2012, no. 8, pp. 32-77, 2012.

58-Parlamento y Consejo de Europa, "Directiva 2001/14/CE," no. 7, pp. 2937.

59-Pérez and B. L. R. Binders, Table of of contents, vol. 3, no. 2. 2003.

60-PKP Polskie Linie Kolejowe, Network Statement 2015. Warszawa, 2015.

61-Prodan, A and Teixeira P. F. "EU Railway Infrastructure Tariff Systems: 20052012 Analysis and Trends," World Conf. Transp. Res., p. 12, 2013.

62-Prodan, A.,Infrastructure Access Charges in Vertically-Separated Railway Systems. UNIVERSIDADE DE LISBOA, INSTITUTO SUPERIOR TÉCNICO

63-ProRail, Network Statement 2017, vol. 2017, no. March 2015. Utrecht, 2016. 64-Rete Ferroviaria Italiana, Network Statement 2017. Roma, 2016.

65-Sánchez-Borrás M. "Impact of Rail Infrastructure Charging Systems implemented in Europe on the Competitiveness of High Speed Services. Universitat Politècnica de Catalunya, 2009.

66-Sánchez-Borràs M. , Nash C., Abrantes P., and López-Pita A., "Rail access charges and the competitiveness of high speed trains," Transp. Policy, vol. 17, no. 2, pp. 102-109, 2010.

67-Santos R., Teixeira Fonseca P., and Pais Antunes A., "Planning and scheduling efficient heavy rail track maintenance through a Decision Rules Model," Res. Transp. Econ., vol. 54, pp. 20-32, 2015.

68-Scordamaglia D. and I. Katsarova, The fourth railway package: Another step towards a Single European Railway Area, no. March. 2016.

69-SNCF Réseau, Document De Reference Du Reseau Ferre National 2017. Paris, 2015. 
70-Swiss Train Paths Ltd, Network Statement 2017, no. December 2016. Bern, 2017.

71-Sž Slovenske železnice - Infrastruktura, Network Statement 2016, no. March 2015. Ljubljana, 2016.

72-SžDC, Správa železniční dopravní cesty, státní organizace on nationwide and regional rail networks, no. 266. Praha, 2017.

73-teixeira, P.F., Prodan, A. \& López-Pita, A., 2013. UIC STUDY ON RAILWAY STATION AND AUXILIARY CHARGES IN EUROPE, Final Report, Lisbon, Portugal. Dsiponible en : http://www.vic.org/.

74-Teixeira, P.F., A. Prodan, J. Cunha, R. Maciel (2017). "CHARGE4RAIL Railway Infrastructure Charges for Passenger Services". Final Report. UIC, International Union of Railways. 116 pp.

75-Teixeira (2019). "La asignación de la capacidad de las líneas: el canon por uso de infraestructura". Material del aula de Asignación de Capacidad. Máster en Sistemas Ferroviarios y Tracción Eléctrica, Universidad Politècnica de Catalunya (UPC). Junio 2019.

76-Trafikverket and S. T. Administration, Network Statement 2017. Borlänge, 2015.

77-D. Ue, D. E. L. Parlamento, and E. Y. Del, "L 343/32," vol. 2012, no. 8, pp. 32-77, 2012.

78-M. Urdánoz and C. Vibes, "Regulation and cost efficiency in the European railways industry," J. Product. Anal., vol. 39, no. 3, pp. 217-230, 2013.

79-Železnice slovenskej republiky, Network Statement 2017, no. 20440. Bratislava, 2017. 
ANEJOS 
Alemania.

DB Netze AG, administrador de la infraestructura alemana es responsable de la prestación, el desarrollo y el funcionamiento de la mayor parte de la infraestructura ferroviaria alemana, también cubre la infraestructura operada por RNI ${ }^{34}$. Tras los tratados de Estado de 1.852 entre el Gran Ducado de Baden y la Confederación Suiza, DB Netz AG opera instalaciones de servicio en el territorio suizo. La infraestructura ferroviaria de DB Netz AG constituye un componente de los corredores ferroviarios de mercancías: Rhine-Alpine (Corredor 1), Scandinavian-Mediterranean (Corredor 3), Atlantic (Corredor 4), North Sea-Baltic (Corredor 8), establecidos en virtud del Reglamento UE 913/2010 y completado por el Anexo II del Reglamento UE $n^{\circ}$ 1316/2013 y la Decisión de Ejecución UE 2015/111.

El canon por uso de la infraestructura está definido por el tipo de servicio y por la categoría de la línea férrea. La clasificación de las líneas ferroviarias alemanas es la siguiente:

- FPLUS: Líneas con tráfico de alta velocidad, con su mayor parte con velocidades admisibles mayores de $280 \mathrm{~km} / \mathrm{h}$.

- Fl: Líneas con servicio de alta velocidad y tráfico mixto con velocidades entre $200 \mathrm{~km} / \mathrm{h}$ y $280 \mathrm{~km} / \mathrm{h}$.

- F2: Líneas con velocidades entre $160 \mathrm{~km} / \mathrm{h}$ y $200 \mathrm{~km} / \mathrm{h}$. Destinadas principalmente a servicios de alta velocidad o para operaciones mixtas.

- F3: Líneas de operaciones mixtas con rangos de velocidad entre 100 $\mathrm{km} / \mathrm{h}$ y $160 \mathrm{~km} / \mathrm{h}$.

- F4: Líneas con velocidades entre $101 \mathrm{~km} / \mathrm{h}$ y $160 \mathrm{~km} / \mathrm{h}$ y que están destinadas principalmente para servicios rápidos interurbanos.

- F5: Líneas destinadas principalmente para uso de servicios interurbanos con velocidad máxima de $120 \mathrm{~km} / \mathrm{h}$.

- F6: Líneas con velocidades comprendidas entre 101 y $160 \mathrm{~km} / \mathrm{h}$. Destinadas - principalmente para el tráfico ferroviario de pasajeros local.

- Z1: Líneas con velocidades máximas comprendidas entre $50 \mathrm{~km} / \mathrm{h}$ y 100 $\mathrm{km} / \mathrm{h}$. Destinadas principalmente a los servicios ferroviarios de pasajeros de cercanías.

34 RegioNetz Infrastruktur $\mathrm{GmbH}$ 
- Z2: Líneas con velocidad máxima de $50 \mathrm{~km} / \mathrm{h}$. Están equipadas con sistema de control básico o carece de él.

- S1: Líneas con velocidad máxima de $120 \mathrm{~km} / \mathrm{h}$. Están destinadas principal - exclusivamente para los servicios urbanos de transporte público rápido.

- S2: Líneas con velocidad máxima de $120 \mathrm{~km} / \mathrm{h}$. Líneas de tráfico rápido urbano alimentados con CC en la ciudad de Hamburgo.

- S3: Líneas con velocidad máxima de $120 \mathrm{~km} / \mathrm{h}$. Líneas de tránsito rápido urbanos alimentados con CC en Berlín.

\begin{tabular}{|c|c|}
\hline Tipo de Línea & $\boldsymbol{\epsilon} \mathbf{k m} /$ tren \\
\hline Fplus & 9,97 \\
\hline F1 & 5,09 \\
\hline F2 & 3,53 \\
\hline F3 & 3,17 \\
\hline F4 & 3,06 \\
\hline F5 & 2,25 \\
\hline F6 & 3,01 \\
\hline Z1 & 3,11 \\
\hline Z2 & 3,21 \\
\hline S1 & 2,02 \\
\hline S2 & 2,70 \\
\hline S3 & 3,21 \\
\hline
\end{tabular}

Tabla 66. Canon por tipo de línea DB Netze AG. Elaboración propia

Los tipos de servicio definidos por DB Netze AG son los siguientes:

a) Viajeros.

- Servicio Express: Proporciona un enlace más rápido y directo entre los núcleos urbanos. Tienen prioridad sobre todos los trenes, excepto trenes de rescate y emergencia.

- Servicio Regular de Larga Distancia y Cercanías: Se caracteriza por un servicio de al menos cuatro pares de trenes al día, cuyo itinerario coincide la mayor parte de la ruta (más del 50\%) y/o están vinculados entre sí por medio de programas de operación para formar un sistema regular de circulaciones. Los trayectos regulares también se dividen en larga distancia y servicios de cercanías.

Los servicios de cercanías abarcan todas las rutas de tráfico locales, incluyendo rutas de tránsito rápido urbanas, vinculados entre sí por medio de servicios regulares y de conexión. Los de larga distancia abarcan como su denominación indica todos los de larga distancia e incluye surcos para tráfico de alta velocidad.

- Servicio Económico: Se trata de un servicio de viajeros no cubierto por un sistema regular de circulaciones. 
b) Mercancías.

- Servicio Express: Enlaces de servicio de carga rápida y directa entre los centros principales de Alemania. En la gestión de las operaciones que se ejecutan, la ruta de tren tiene la máxima prioridad sobre todos los trenes, excepto trenes de rescate y emergencia.

- Servicio Standard: La ruta de tren está vinculada entre sí por medio de servicios de conexión o están sujetos a restricciones especiales, como son tiempos fijos de llegada al destino.

- LZ: Locomotoras aisladas y trenes formados por vagones circulando en vacío.

- Servicio de Conexión: Trenes para conexión entre ramales y líneas principales. Presenta la restricción de que la longitud del ramal hasta la conexión no debe ser mayor de 75 kilómetros.

\begin{tabular}{|c|c|}
\hline Trenes de viajeros & Factor \\
\hline Servicio Express & 1,80 \\
\hline Servicio Regular Larga Distancia & 1,65 \\
\hline Servicio Regular cercanías & 1,65 \\
\hline Servicio Económico & 1,00 \\
\hline Trenes de mercancías & Factor \\
\hline Servicio Express & 1,65 \\
\hline Servicio Estándar & 1,00 \\
\hline LZ & 0,65 \\
\hline Servicio Conexión & 0,50 \\
\hline
\end{tabular}

Tabla 67. Factores aplicados por tipo de tren DB Netze AG. Elaboración propia

Las variables aplicadas son:

a) Incumplimiento de la velocidad mínima

\begin{tabular}{|c|c|}
\hline Velocidad mínima & Factor \\
\hline$<50 \mathrm{~km} / \mathrm{h}$ & 1,5 \\
\hline
\end{tabular}

Tabla 68. Factor aplicable por incumplimiento de la velocidad mínima DB Netze AG.

a) NDTAC: El suplemento es de 3,0 puntos porcentuales del canon del surco reservado. El suplemento se aplica a todos los trenes de mercancías. Los vagones deben cumplir al menos el $90 \%$ con los requisitos de la TSI35 de ruido.

b) Suplemento por carga: Aplicable a los trenes de mercancías con peso superior a 3.000 toneladas brutas.

1,02 euros por tren/kilómetro

Tabla 69. Suplemento por carga DB Netze AG.

35 Technical Specification for Interoperability 
Austria.

El administrador de la infraestructura ferroviaria austriaca es ÖBBInfrastruktur AG. En virtud del artículo 31 de la BBG (Bundesbahngesetz) ${ }^{36}$ sus actividades son los de una empresa que prevé una infraestructura ferroviaria segura y orientada hacia el mercado, además de las funciones de construcción, mantenimiento y puesta a disposición de las infraestructuras a los operadores ferroviarios.

Por la red de ÖBB-Infrastruktur AG discurren 3 corredores ferroviarios: el corredor 3, Estocolmo-Malmö-Copenhague-Hamburgo-Innsbruck-VeronaPalermo, el corredor 5 Gdynia-Katowice-Ostrava/Žilina-Bratislava/Viena/ Klagenfurt-Udine-Venecia/Trieste/Bolonia/Ravenna/Graz-Maribor-LiublianaKoper/Trieste y el corredor 7, Praga-Viena/Bratislava-Budapest/BucarestConstanza/Vidin-Sofía-Tesalónica-Atenas.

En la tabla siguiente se muestran los cánones aplicados a los trenes que circulan por la red austriaca y que están formados por el canon base por uso de la infraestructura, canon por suplementos y deducciones y otros componentes aplicables a la tarificación que se relacionan en las tablas siguientes.

\begin{tabular}{|c|c|c|c|}
\hline Producto/Servicio & Unidad & Factor & Precio $€$ \\
\hline \multicolumn{4}{|c|}{ Canon Base } \\
\hline \multicolumn{4}{|c|}{ Por categoría de línea (trenes de viajeros) } \\
\hline $\begin{array}{c}\text { PT line Brenner (Kufstein-Innsbruck- } \\
\text { Brenner) }\end{array}$ & tren-km & $\mathrm{zpB}$ & 3,7988 \\
\hline PT líneas secundarias & tren-km & $\mathrm{zpE}$ & 1,1294 \\
\hline PT otras líneas internacionales & tren-km & zpSiA & 2,1065 \\
\hline PT otras líneas principales & tren-km & zpSK & 1,5374 \\
\hline PT línea oeste & tren-km & zpW & 3,1131 \\
\hline \multicolumn{4}{|c|}{ Por categoría de línea (trenes de mercancías) } \\
\hline $\begin{array}{c}\text { FT line Brenner (Kufstein-Innsbruck- } \\
\text { Brenner) }\end{array}$ & tren-km & $\mathrm{zgB}$ & 2,5017 \\
\hline FT líneas secundarias & tren-km & $\mathrm{zgE}$ & 0,7436 \\
\hline FT otras líneas internacionales & tren-km & zgSiA & 1,3873 \\
\hline FT otras líneas principales & tren-km & ZgSK & 1,0124 \\
\hline
\end{tabular}

36 Ley Federal de Ferrocarriles de Austria 


\begin{tabular}{|c|c|c|c|}
\hline FT línea oeste & tren-km & $\mathrm{zgW}$ & 2,0502 \\
\hline \multicolumn{4}{|c|}{ Por categoría de línea (vagones como parte del tráfico de mercancías) } \\
\hline $\begin{array}{l}\text { LDIWT line Brenner (Kufstein- } \\
\text { Innsbruck-Brenner) }\end{array}$ & tren-km & zewfvB & 2,1890 \\
\hline LDIWT líneas secundarias & tren-km & zewfvE & 0,6507 \\
\hline LDIWT otras líneas internacionales & tren-km & zewfvSiA & 1,2139 \\
\hline LDIWT otras líneas principales & tren-km & zewfvSK & 0,8859 \\
\hline LDIWT línea oeste & tren-km & zewfvW & 1,7939 \\
\hline \multicolumn{4}{|c|}{ Por categoría de línea (locomotoras aisladas) } \\
\hline $\begin{array}{l}\text { LT line Brenner line (Kufstein- } \\
\text { Innsbruck-Brenner) }\end{array}$ & tren-km & $\mathrm{zdB}$ & 2,5017 \\
\hline LT líneas secundarias & tren-km & $\mathrm{zdE}$ & 0,7436 \\
\hline LT otras líneas internacionales & tren-km & zdSiA & 1,3873 \\
\hline LT otras líneas principales & tren-km & zdSK & 1,0124 \\
\hline LT línea oeste & tren-km & $z d W$ & 2,0502 \\
\hline \multicolumn{4}{|l|}{ Por carga toneladas-kilometro } \\
\hline toneladas-kilometro & gtkm & btk & 0,001293 \\
\hline \multicolumn{4}{|c|}{ Suplementos y deducciones } \\
\hline \multicolumn{4}{|l|}{ Cualitativos } \\
\hline $\begin{array}{l}\text { Factor de unidad de tracción } \\
\text { categoría A }\end{array}$ & tren-km & tfzA & $-0,0280$ \\
\hline $\begin{array}{l}\text { Factor de unidad de tracción } \\
\text { categoría B }\end{array}$ & tren-km & $t f z B$ & 0,0000 \\
\hline $\begin{array}{l}\text { Factor de unidad de tracción } \\
\text { categoría C }\end{array}$ & tren-km & $\mathrm{tfzC}$ & 0,0251 \\
\hline \multicolumn{4}{|l|}{ Especificos de línea } \\
\hline $\begin{array}{l}\text { Suplemento por congestión de la } \\
\text { línea }\end{array}$ & tren-km & eng & 1,2980 \\
\hline $\begin{array}{l}\text { Incentivo por uso del corredor } \\
\text { específico para mercancías de } \\
\text { Semmering }\end{array}$ & tren-km & kvas & $-1,1359$ \\
\hline $\begin{array}{l}\text { Incentivo por uso del corredor } \\
\text { específico para mercancías de } \\
\text { Wechsel }\end{array}$ & tren-km & kvaW & $-0,5727$ \\
\hline
\end{tabular}

Tabla 70. Cánones aplicables por ÖBB-Infrastruktur AG.

La categoría del factor de unidad de tracción se obtiene mediante las tablas siguientes, teniendo en cuenta el tipo de locomotora: 
- $\quad d<1=>$ Tracción de categoría A.

- $\quad d>=1<=1,03=>$ Tracción de categoría B.

- $\quad d>1,03=>$ Tracción de categoría C.

\begin{tabular}{|c|c|c|}
\hline Clasificación Unidad de Tracción & $d$ & Categoría \\
\hline \multicolumn{3}{|c|}{ Locomotoras eléctricas } \\
\hline TUC 101 & 1,051 & C \\
\hline TUC 110 & 1,080 & C \\
\hline TUC 111 & 1,069 & C \\
\hline TUC 112 & 1,077 & C \\
\hline TUC 113 & 1,091 & C \\
\hline TUC 139 & 1,080 & C \\
\hline TUC 140 & 1,069 & C \\
\hline TUC 151 & 1,123 & C \\
\hline TUC 152 & 1,115 & C \\
\hline TUC 182 & 1,036 & C \\
\hline TUC 183 & 1,047 & C \\
\hline TUC 185 & 1,019 & B \\
\hline TUC 186 & 1,019 & B \\
\hline TUC 189 & 1,051 & C \\
\hline TUC 193 & 1,121 & C \\
\hline TUC 380 & 1,039 & C \\
\hline TUC 0470 & 1,036 & C \\
\hline TUC 1010 & 1,097 & C \\
\hline TUC 1012 & 1,016 & B \\
\hline TUC 1014 & 0,896 & A \\
\hline TUC 1016 & 1,042 & C \\
\hline TUC 1116 & 1,036 & C \\
\hline TUC 1216 & 1,047 & C \\
\hline TUC 1041 & 1,037 & C \\
\hline TUC1042 & 1,075 & C \\
\hline TUC 1142 & 1,071 & C \\
\hline TUC 1144.0 & 1,082 & C \\
\hline TUC 1144.200 & 1,027 & $B$ \\
\hline TUC 1063 & 1,004 & $B$ \\
\hline TUC 1163 & 0,991 & A \\
\hline TUC 1193 & 1,121 & $\mathrm{C}$ \\
\hline TUC 1064 & 1,073 & $\mathrm{C}$ \\
\hline TUC 1822 & 0,961 & A \\
\hline
\end{tabular}

Tabla 71. Clasificación de locomotoras eléctricas ÖBB-Infrastruktur AG.

\begin{tabular}{|c|c|c|}
\hline Clasificación Unidad de Tracción & d & Categoría \\
\hline \multicolumn{3}{|c|}{ Locomotoras de vapor } \\
\hline Locomotora de vapor & 1,200 & C \\
\hline
\end{tabular}

Tabla 72. Clasificación de locomotoras de vapor ÖBB-Infrastruktur AG. 


\begin{tabular}{|c|c|c|}
\hline \begin{tabular}{|l|}
\hline Clasificación Unidad de Tracción \\
Locomotoras diésel
\end{tabular} & C & Categoría \\
\hline \multicolumn{2}{|l|}{} \\
\hline TUC 2016 & 0,931 & $\mathrm{~A}$ \\
\hline TUC 2043 & 0,954 & $\mathrm{~A}$ \\
\hline TUC 2143 & 0,925 & $\mathrm{~A}$ \\
\hline TUC 2048 & 0,750 & $\mathrm{~A}$ \\
\hline TUC 2060 & 0,750 & $\mathrm{~A}$ \\
\hline TUC 2062 & 0,750 & $\mathrm{~A}$ \\
\hline TUC 2067 & 1,025 & $\mathrm{~B}$ \\
\hline TUC 2068 & 0,804 & $\mathrm{~A}$ \\
\hline TUC 2070 & 0,805 & $\mathrm{~A}$ \\
\hline TUC 2150 & 1,028 & $\mathrm{~B}$ \\
\hline TUC 2170 & 0,977 & $\mathrm{~A}$ \\
\hline TUC V 100 & 0,806 & $\mathrm{~A}$ \\
\hline
\end{tabular}

Tabla 73. Clasificación de locomotoras diésel ÖBB-Infrastruktur AG.

\begin{tabular}{|c|c|c|}
\hline Clasificación Unidad de Tracción & D & Categoría \\
\hline Unidades autopropulsadas eléctricas & \\
\hline TUC 4010 ÖBB & 1,042 & $\mathrm{C}$ \\
\hline TUC 4010 WEST & 0,978 & $\mathrm{~A}$ \\
\hline TUC 4011 & 0,822 & $\mathrm{~A}$ \\
\hline TUC 4020 & 1,019 & $\mathrm{~B}$ \\
\hline TUC 4023 & 0,986 & $\mathrm{~A}$ \\
\hline TUC 4024 & 0,975 & $\mathrm{~A}$ \\
\hline TUC 4124 & 0,975 & $\mathrm{~A}$ \\
\hline TUC 4062 & 0,893 & $\mathrm{~A}$ \\
\hline TUC 401 & 0,896 & $\mathrm{~A}$ \\
\hline TUC 411 & 0,822 & $\mathrm{~A}$ \\
\hline TUC 425 & 0,750 & $\mathrm{~A}$ \\
\hline TUC 426 & 0,750 & $\mathrm{~A}$ \\
\hline TUC 680 & 0,796 & $\mathrm{~A}$ \\
\hline
\end{tabular}

Tabla 74. Clasificación unidades autopropulsadas eléctricas ÖBB-Infrastruktur AG.

\begin{tabular}{|c|c|c|}
\hline Clasificación Unidad de Tracción & $d$ & Categoría \\
\hline \multicolumn{3}{|c|}{ Unidades autopropulsadas diésel } \\
\hline TUC 5022 & 0,750 & A \\
\hline TUC 5047 & 0,750 & A \\
\hline TUC 5062 & 0,892 & A \\
\hline TUC 5063 & 0,892 & A \\
\hline TUC 5147 & 0,750 & A \\
\hline
\end{tabular}

Tabla 75. Clasificación unidades autopropulsadas diésel ÖBB-Infrastruktur AG. 
Bélgica.

Infrabel como administrador de la infraestructura de Bélgica es una sociedad anónima de derecho público. Su misión está definida en un contrato de gestión con el estado federal. Además de la gestión diaria, mantenimiento y desarrollo de la infraestructura, Infrabel también es responsable de la regulación y la seguridad de todo el tráfico ferroviario. A continuación, se muestra un mapa con la red gestionada por Infrabel, así como los corredores que discurren por su infraestructura.

- $\quad$ El corredor 1 Rhine-Alpine (Zeebrugge/Antwerpen/Amsterdam/ Vlissingen/Rotterdam/Duisburg/Basel/Milano/Genova.

- $\quad$ El corredor 2, North Sea - Mediterranean (Glasgow/Edinburgh/

Southampton/Felixstowe/London/Duinkerke/Rijsel/Luik/Parijs/

Amsterdam/Rotterdam/Zeebrugge/Antwerpen/Luxemburg/Metz/

Dijon/Lyon/Bazel-Marseille.

- El corredor 8 North Sea - Baltic (Wilhelmshaven/Bremerhaven/ Hamburg/Amsterdam/Rotterdam/Antwerpen/Aken/BerlijnWarschau/Terespol (Pools-Wit-Russische grens)/Kaunas/Riga/Tallinn.

El canon de acceso y uso de la infraestructura es el resultante del sumatorio de los cánones de cada sección o tramo recorrido. Se obtiene mediante el producto del precio unitario del kilómetro por unos coeficientes como son por prioridad de circulación, equipamiento técnico de la sección, peso del tren, etc. y que se describen en las tablas adjuntas. Para el cálculo se aplica la ecuación siguiente:

$$
T R-L j=P^{*} P t C j^{*}{ }^{2} i L i^{*} C 1 i^{*} C 2 i^{*} C e^{*} C i j^{*} H i j^{*} T i j
$$

Siendo:

TR-L: Canon por uso de la infraestructura.

i: Sección de la línea.

j: Tren $j$.

P: Precio unitario kilómetro $=0,354122 €$ para todo tipo de tren.

Ptj: Coeficiente por tipo de circulación según tabla siguiente:

\begin{tabular}{|c|c|c|}
\hline Categoría & Tipo de Tren & Valor Ptj \\
\hline 1 & HST & 1,50 \\
\hline 2 & Trenes viajeros internacional & 1,50 \\
\hline 3 & IC, IR, ICT y CR & 1,40 \\
\hline 4 & Trenes P y L, trenes de mercancías rápidos & 1,20 \\
\hline 5 & Trenes de mercancías lentos, & 1,00 \\
\hline 6 & Trenes "en vacío" & 1,00 \\
\hline
\end{tabular}

Tabla 76. Obtención del coeficiente por tipo de circulación (Ptj) Infrabel. 
Li: Longitud de la sección en kilómetros.

Cli: Coeficiente relativo a la importancia operacional de la sección según tabla siguiente:

\begin{tabular}{|c|c|}
\hline Categoría & Valor de Cli \\
\hline 1 & 2 \\
\hline 2 & 1,75 \\
\hline 3 & 1,25 \\
\hline 4 & 1 \\
\hline
\end{tabular}

Tabla 77. Obtención del coeficiente Cli Infrabel

C2i: Coeficiente relativo al equipamiento técnico de la sección.

\begin{tabular}{|c|c|c|}
\hline Categoría & Valor de C2i & Velocidad de referencia de la línea \\
\hline 1 & 3,5 & $\mathrm{~V}>220 \mathrm{~km} / \mathrm{h}$ \\
\hline 2 & 2,5 & Línea Nord-Midi \\
$220 \mathrm{~km} / \mathrm{h} \geq \mathrm{V}>160 \mathrm{~km} / \mathrm{h}$
\end{tabular}

Tabla 78. Obtención del coeficiente C2i Infrabel.

Ce: Coeficiente de impacto ambiental $=1$.

Cij: Coeficiente de masa, que representa la masa total del tren sobre la sección.

\begin{tabular}{|c|c|c|}
\hline Categoría & Intervalo peso (en toneladas) & Valor de Cij \\
\hline 1 & De 0 a 400 & 1,20 \\
\hline 2 & De 401 a 800 & 1,55 \\
\hline 3 & De 801 a 1.200 & 1,90 \\
\hline 4 & De 1.201 a 1.600 & 2,25 \\
\hline 5 & De 1.601 a 2.200 & 2,60 \\
\hline \multicolumn{2}{|c|}{ Por aumento de peso en 400 t. se incrementará 0,35 } \\
\hline
\end{tabular}

Tabla 79. Obtención del coeficiente Cij Infrabel.

Hij: Coeficiente por franja horaria, día y sentido de la circulación en la sección según tabla siguiente:

\begin{tabular}{|c|c|c|}
\hline Categoría & Densidad de tráfico & Valor de Hij \\
\hline 1 & Alta & 4 \\
\hline 2 & Media & 3 \\
\hline 3 & Normal & 1 \\
\hline
\end{tabular}

Tabla 80. Obtención del coeficiente Hij Infrabel. 
Tij: Coeficiente de desviación en función de la diferencia entre los tiempos de viaje en el surco y el tiempo empleado estándar del mismo. Su obtención se detalla en la tabla siguiente:

\begin{tabular}{|c|c|}
\hline \multicolumn{2}{|c|}{ Trenes de mercancías } \\
\hline $\begin{array}{l}\text { Desviación comparada con estándar del } \\
\text { surco. }\end{array}$ & Valor Tij \\
\hline Desviación de 0 a $99 \%$ & 1,00 \\
\hline Desviación de 100 a $199 \%$ & 1,20 \\
\hline Desviación de 200 a $299 \%$ & 1,40 \\
\hline 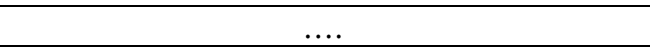 & $+0,2$ \\
\hline Máxima desviación & 2,2 \\
\hline \multicolumn{2}{|c|}{ Trenes de viajeros } \\
\hline $\begin{array}{l}\text { Desviación comparada con estándar del } \\
\text { surco. }\end{array}$ & Valor \\
\hline Desviación de 0 a $4 \%$ & 1,00 \\
\hline Desviación de 5 a $9 \%$ & 1,15 \\
\hline Desviación de 10 a $14 \%$ & 1,30 \\
\hline$\ldots$ & $+0,15$ \\
\hline Máxima desviación & 16,75 \\
\hline
\end{tabular}

Tabla 81. Obtención del coeficiente Tij Infrabel.

Bulgaria.

La Sociedad Nacional de Infraestructuras Ferroviarias (NRIC) es una empresa de propiedad estatal de conformidad con el art. 62, párr. 3 de la Ley de Comercio de Bulgaria y establecida conforme a la Ley de Transporte Ferroviario (LRT). La red ferroviaria búlgara tiene $6.474 \mathrm{~km}$ de longitud, de los cuales $2.906 \mathrm{~km}$ son en vía única (44,9\% del total) y $1.976 \mathrm{~km}$ en vía doble $(30,5 \%$ del total). La longitud total de las líneas ferroviarias electrificada es de $5.102 \mathrm{~km}$, lo que representa un $70 \%$ de la red total.

La metodología empleada para el cálculo del canon está basada en los servicios que conforman el paquete mínimo y el acceso a la infraestructura.

El canon de acceso está formado por dos variables, medidas en kilómetros-tren y en toneladas kilómetro. El canon de acceso y la determinación del importe están aplicados teniendo en cuenta los costes directos prestados y los costes de los trabajos realizados en la infraestructura durante el año anterior. Este canon es igual para todo tipo de circulación independiente del tipo de tren e igual para la línea por donde se circula. 
Se obtiene mediante las siguientes expresiones:

$$
T_{\text {cap }}=L^{*} C_{\text {cap }}
$$

Siendo:

- Tcap: Canon por capacidad.

- L: Longitud de la línea en km.

- Ccap: Canon por kilómetro-tren.

$$
T_{\text {pass }}=T g / t / k m+T t / k m
$$

Siendo:

- Tpass: Canon por uso de la infraestructura.

- Tg/t/km: Canon por carga transportada.

- Tt/km: Canon por distancia recorrida.

Para el cálculo para obtener el Tg/t/km (Canon por carga transportada) se aplica la siguiente fórmula:

$$
\mathrm{Tg} / \mathrm{t} / \mathrm{km}=\Sigma \mathrm{Lij}^{*} \mathrm{Qij}{ }^{*} \mathrm{Cg} / \mathrm{t} / \mathrm{km}
$$

Siendo:

- Tg/t/km: Canon por carga transportada.

- Lij: Longitud en kilómetros del tramo.

- Qij: Peso en toneladas.

- Cg/t/km: Canon por uso de la infraestructura en BGN37.

Para el cálculo para obtener el Tt/km (Canon por distancia) se aplica la siguiente expresión:

$$
\mathrm{Tt} / \mathrm{km}=\mathrm{L}^{*} \mathrm{C} t / \mathrm{km}
$$

37 BGN: Formato ISO de la moneda búlgara LEV. 
Siendo:

- Tt/km: Canon por distancia recorrida.

- L: Longitud en kilómetros del tramo.

- Qij: Peso en toneladas.

Croacia.

Ct/km: Canon del kilómetro en BGN.

La administración de la infraestructura está a cargo de HZ Infrastruktur gestionando una longitud de líneas férreas de $2.605 \mathrm{~km}$. El canon por uso de la infraestructura ferroviaria croata es determinado por la velocidad de la infraestructura, declividad, carga por eje, electrificación, tipo de tren, masa del tren, tipo de línea, número de vías de la línea.

Se obtiene por medio de la siguiente ecuación:

$$
C=\left(\left((T+d m+d n) \Sigma\left(L^{*} I\right) * C V l k m\right)+\left(l e{ }^{*} C e l\right)\right) * K
$$

Siendo:

C: Canon mínimo de acceso.

T: $\quad$ Tipo de tren.

dm: Canon adicional por carga.

dn: Canon por uso de la tecnología basculante.

L: $\quad$ Coeficiente por línea.

l: $\quad$ Longitud del surco $(\mathrm{km})$.

Cel: Canon adicional para composiciones con tracción eléctrica.

K: $\quad$ Coeficiente corrector del precio.

Cvlkm: Precio básico (HRK/km-tren).

lel: Longitud del surco con catenaria $(\mathrm{km})$.

Los valores de "T" a aplicar en los trenes de viajeros y mercancías se muestran en la tabla siguiente:

\begin{tabular}{|c|c|c|}
\hline Tipo de Tren & Tipo de "T" & Valor de "T" \\
\hline Eurocity, Intercity, Express & $\mathrm{T}_{11}$ & 2,02 \\
\hline Rápidos, Semi-rápidos & $\mathrm{T}_{12}$ & 1,79 \\
\hline Viajeros, transfronterizos & $\mathrm{T}_{13}$ & 0,94 \\
\hline Suburbanos & $\mathrm{T}_{14}$ & 1,46 \\
\hline Trenes vacíos & $\mathrm{T}_{15}$ & 0,82 \\
\hline
\end{tabular}

Tabla 82. Valores de "T" para trenes de viajeros $\mathrm{HZ}$ Infrastruktur.

\begin{tabular}{|c|c|c|}
\hline Tipo de Tren & Tipo de "T" & Valor de "T" \\
\hline $\begin{array}{c}\text { Trenes con cargas no combinadas, } \\
\text { intermodales, exprés, directos, rápidos. }\end{array}$ & $\mathrm{T}_{21}$ & 1,07 \\
\hline Ramas de trenes & $\mathrm{T}_{22}$ & 0,87 \\
\hline Trenes de trabajos, ramas industriales & $\mathrm{T}_{23}$ & 0,58 \\
\hline Trenes vacíos & $\mathrm{T}_{24}$ & 0,54 \\
\hline
\end{tabular}

Tabla 83. Valores de "T" para trenes de mercancías HZ Infrastruktur. 
El canon por carga adicional "dm" es aplicable sólo a trenes de mercancías que sobrepasen las 1.500 T, incrementándose en 0,30.

El canon adicional por uso de la tecnología basculante "dn" es aplicable sólo a trenes de viajeros equipados con dicha tecnología incrementándose en 0,20 .

El coeficiente por línea "L" está definido por la integración de los siguientes elementos:

- Parámetros técnicos de la línea.

- Operación en la línea.

- Coste de la línea.

\begin{tabular}{|c|c|c|}
\hline $\begin{array}{l}\text { Categoría } \\
\text { línea }\end{array}$ & Líneas & Coeficiente " $L$ " \\
\hline Ll & $\begin{array}{l}\text { M101, M102, M103, M104, M401, } \\
\text { M402, M403, M405, M406, M407, } \\
\text { M408, M409, M410, M502, R102. }\end{array}$ & 2,00 \\
\hline L2 & $\begin{array}{c}\text { M201, M202, M203, M404, M602, } \\
\text { M603, L212. }\end{array}$ & 1,60 \\
\hline L3 & M301, M302, M303, M304, L208. & 0.80 \\
\hline L4 & M604, M605, M606, M607, L211. & 0,50 \\
\hline L5 & R202, M501. & 0,70 \\
\hline L6 & $\begin{array}{l}\text { M601, R101, R103, R104, R105, R106, } \\
\text { R201, L101, L102, L103, L201, L202, } \\
\text { L203, L204, L205, L206, L207, L209, L210, } \\
\text { L213. }\end{array}$ & 0,30 \\
\hline
\end{tabular}

Tabla 84. Valores del coeficiente "L" HZ Infrastruktur.

El precio básico por kilómetro-tren "Cvikm" por utilización depende del tipo de tren:

- Para trenes de viajeros: 6,26 HRK/km-tren.

- Para trenes de mercancías: 13,34 HRK/km-tren.

Existe un cargo adicional "Cel" por km-tren para trenes con tracción eléctrica de 1,86 HRK/km-tren.

Dinamarca. 
La infraestructura ferroviaria danesa está gestionada por Banedanmark. Su red forma parte del corredor 3, Estocolmo-Malmö-Copenhague-HamburgoInnsbruck-Verona-Palermo, corredor creado en 2015. Además del canon por operar en la red ferroviaria estatal, existen una serie de subvenciones para potenciar el transporte intermodal. El esquema del canon se basa en dos componentes:

- Un componente fijo dependiendo del tipo de servicio y distancia recorrida.

- Un componente adicional aplicado sólo a trenes que circulan por el paso de Storebaelt y Öresund destinado a recuperar la inversión.

España.

La entidad pública empresarial Administrador de Infraestructuras Ferroviarias ADIF tiene como objetivo el desarrollo y administración del sistema de infraestructuras ferroviarias de servicio público en España.

Es un organismo público adscrito al Ministerio de Fomento que goza de personalidad jurídica propia, plena capacidad de obrar para el cumplimiento de sus fines y patrimonio propio. En el ejercicio de sus funciones actúa con autonomía de gestión, dentro de los límites establecidos por su Estatuto y teniendo en cuenta, en todo caso, la garantía del interés público, la satisfacción de las necesidades sociales, la seguridad de los usuarios y la eficacia global del sistema ferroviario, así como los principios de transparencia, no discriminación, imparcialidad e independencia de cualquier operador ferroviario.

Los corredores ferroviarios europeos de mercancías que transitan por España son:

- El corredor 4 o Atlántico, con más de 4.500 kilómetros de vías a lo largo del eje Sines/Setúbal/Lisboa/Aveiro/Leixöes-Algeciras/Madrid/BillbaoBourdeaux/Paris/Le Havre/Metz/Mannheim cruzando las fronteras internacionales de Vilar Formoso/Fuentes de Oñoro, Elvas/Badajoz e Irún/Hendaya.

- El corredor 6 o Mediterráneo que conecta Madrid y los principales puertos de la costa este española con Europa a través de Francia, suma más de $6.000 \mathrm{Km}$. de vías a lo largo del eje Almería-Valencia/MadridZaragoza/Barcelona-Marseille-Lyon-Turin-Milan-Verona-Padua/VeniceTrieste/ oper-Ljubljana-Budapest-Záhony.

Los cánones se fijan de acuerdo con los principios de viabilidad económica de las infraestructuras, explotación de estas, situación del 
mercado y equilibrio financiero en la prestación de servicios con criterios de igualdad, transparencia y no discriminación entre prestadores de servicios de transporte. La Ley 38/2015, de 29 de septiembre, del Sector Ferroviario, en su Título Vl, Artículos 96 a 100 establece que los Cánones Ferroviarios son las tasas que el administrador de infraestructuras ferroviarias recibe de las $\mathrm{EE}$. FF que utilicen las líneas de la Red Ferroviaria de Interés General, así como las estaciones de transporte de viajeros, terminales de transporte de mercancías y otras instalaciones de servicio.

El canon de acceso regula el derecho de utilización con carácter general de la RFIG. Se determina en función del tipo de tramos de red en los que se pretende prestar los servicios y la declaración de actividad realizada por el sujeto pasivo de acuerdo con el nivel de tráfico previsto en cada uno de ellos. Para cada uno de los niveles de tráfico, se establecen dos cuantías: una para los servicios que se lleven a cabo en líneas de categoría A, y otra para aquellos que se produzcan en el resto de las líneas según tablas adjuntas:

\begin{tabular}{|c|c|c|}
\hline \multicolumn{2}{|c|}{ Tipo de Línea } & Velocidad Máxima de la Línea \\
\hline \multirow[t]{2}{*}{ A } & A. 1 & $\begin{array}{c}\text { Línea Madrid-Barcelona-Frontera Francesa (Límite con la } \\
\text { Sección Internacional entre Figueras-Perpignan administrada } \\
\text { por TP Ferro). }\end{array}$ \\
\hline & A.2 & $\begin{array}{l}\text { Resto de líneas con } \vee \text { máx. }>250 \mathrm{~km} / \mathrm{h} \text { en al menos } 2 / 3 \text { de su } \\
\text { recorrido. }\end{array}$ \\
\hline B & B. 1 & $\begin{array}{c}250 \mathrm{Km} / \mathrm{h} \geq \mathrm{V} \text { máx. Línea }>200 \mathrm{~km} / \mathrm{h} \text { en al menos } 2 / 3 \text { de su } \\
\text { recorrido. }\end{array}$ \\
\hline \multirow{2}{*}{ C } & C.1 & Núcleos de Cercanías. \\
\hline & C.2 & Resto de líneas. \\
\hline
\end{tabular}

Tabla 85. Clasificación de las líneas ferroviarias ADIF.

\begin{tabular}{|c|l|r|}
\hline \multicolumn{3}{|c|}{ Canon de Acceso Líneas Tipo A } \\
\hline Nivel & \multicolumn{1}{|c|}{ Volumen de Tráfico } & $\boldsymbol{\epsilon} /$ Año \\
\hline N1. A & $\leq 0,2$ millones km/Tren-año & $60.600,00$ \\
\hline N1.B & $>0,2 y \leq 0,5$ millones de km/Tren-año & $151.500,00$ \\
\hline N1.C & $>0,5 y \leq 1$ millones de km/Tren-año & $303.000,00$ \\
\hline N2. A & $>1 y \leq 2,5$ millones de km/Tren-año & $757.500,00$ \\
\hline N2. B & $>2,5 y \leq 5$ millones de km/Tren-año & $1.515 .000,00$ \\
\hline N2.C & $>5 y \leq 10$ millones de km/Tren-año & $3.030 .000,00$ \\
\hline N3. A & $>10 y \leq 15$ millones de km/Tren-año & $4.545 .000,00$ \\
\hline N3. B & $>15 y \leq 20$ millones de km/Tren-año & $6.060 .000,00$ \\
\hline N3.C & $>20 y \leq 30$ millones de km/Tren-año & $7.575 .000,00$ \\
\hline N3. D & $>30 y \leq 40$ millones de km/Tren-año & $9.090 .000,00$ \\
\hline N3. E & $>40 y \leq 50$ millones de km/Tren-año & $12.120 .000,00$ \\
\hline N3. F & $>50$ millones de km/Tren-año & $15.150 .000,00$ \\
\hline
\end{tabular}

Tabla 86. Canon de acceso a líneas ferroviarias tipo A ADIF. 


\begin{tabular}{|c|l|r|}
\hline \multicolumn{3}{|c|}{ Canon de Acceso Resto de Líneas } \\
\hline Nivel & \multicolumn{1}{|c|}{ Volumen de Tráfico } & $\boldsymbol{\epsilon} /$ Año \\
\hline N1.A & $\leq 0,2$ millones km/Tren-año & $13.251,56$ \\
\hline N1.B & $>0,2 y \leq 0,5$ millones de km/Tren-año & $33.128,92$ \\
\hline N1.C & $>0,5 y \leq 1$ millones de km/Tren-año & $66.257,83$ \\
\hline N2. A & $>1 y \leq 2,5$ millones de km/Tren-año & $116.178,60$ \\
\hline N2. B & $>2,5 y \leq 5$ millones de km/Tren-año & $165.644,60$ \\
\hline N2.C & $>5 y \leq 10$ millones de $\mathrm{km} /$ Tren-año & $364.418,11$ \\
\hline N3. A & $>10 y \leq 15$ millones de $\mathrm{km} /$ Tren-año & $761.965,14$ \\
\hline N3. B & $>15 y \leq 20$ millones de $\mathrm{km} /$ Tren-año & $1.557 .059,19$ \\
\hline N3.C & $>20 y \leq 30$ millones de $\mathrm{km} /$ Tren-año & $1.557 .059,19$ \\
\hline N3. D & $>30 y \leq 40$ millones de km/Tren-año & $1.557 .059,19$ \\
\hline N3. D & $>40 y \leq 50$ millones de km/Tren-año & $1.557 .059,19$ \\
\hline N3. F & $>50$ millones de km/Tren-año & $1.557 .059,19$ \\
\hline
\end{tabular}

Tabla 87. Canon de acceso al resto de líneas ferroviarias ADIF.

El canon por reserva de capacidad grava la disponibilidad del trayecto reservado. La cuantía del canon se obtiene en función de los kilómetros-tren reservados, según el tipo de línea, el tipo de servicio y el periodo horario según tablas siguientes:

\begin{tabular}{|c|c|l|}
\hline Clase & Tipo & \multicolumn{1}{c|}{ Características } \\
\hline Viajeros & VL1 & $\begin{array}{l}\text { Servicios de larga distancia excepto las designados } \\
\text { como VL2, VL3 Y VOT }\end{array}$ \\
\hline Viajeros & VL2 & $\begin{array}{l}\text { Servicios de larga distancia en relaciones de } \\
\text { ancho variable siempre que al menos un 10\% de su } \\
\text { recorrido total discurra por líneas de ancho ibérico. }\end{array}$ \\
\hline Viajeros & VL3 & $\begin{array}{l}\text { Servicios de larga distancia en relaciones } \\
\text { transversales largas: recorridos superiores a } 700 \mathrm{~km} . \\
\text { que no tengan origen, destino o paradas } \\
\text { intermedias en Madrid y sus ramas. }\end{array}$ \\
\hline Viajeros & $\begin{array}{l}\text { Servicios urbanos o suburbanos: los que discurren } \\
\text { íntegramente dentro de un núcleo de cercanías. } \\
\text { Servicios interurbanos: los que no siendo urbano ni } \\
\text { suburbanos tienen recorridos inferiros a 300 km. Se } \\
\text { excluyen los trenes internacionales y las ramas de } \\
\text { trenes de larga distancia. } \\
\text { Servicios declarados como obligaciones de } \\
\text { servicio público. }\end{array}$ \\
\hline Viajeros & VOT & $\begin{array}{l}\text { Trenes y material de viajeros sin pasajeros, incluidas } \\
\text { máquinas aisladas, movimiento de trenes en vacío, } \\
\text { formación y pruebas. }\end{array}$ \\
\hline Mercancías & M & $\begin{array}{l}\text { Todos los servicios de mercancías, incluidos los } \\
\text { cargados, los vacíos, las máquinas aisladas y } \\
\text { pruebas. }\end{array}$ \\
\hline
\end{tabular}

Tabla 88. Características de los tipos de servicio y tipos de tren ADIF. 


\begin{tabular}{|c|c|c|}
\hline Periodo $^{38}$ & Inicio & Fin \\
\hline Valle & $0: 00$ & $5: 59$ \\
\hline Punta & $6: 00$ & $9: 29$ \\
\hline Llano & $9: 30$ & $17: 59$ \\
\hline Punta & $18: 00$ & $20: 29$ \\
\hline Llano & $20: 30$ & $23: 59$ \\
\hline
\end{tabular}

Tabla 89. Periodos horarios. ADIF.

\begin{tabular}{|c|c|c|c|c|c|c|c|}
\hline Periodo horario & $\begin{array}{l}\text { Tipo } \\
\text { de }\end{array}$ & \multicolumn{6}{|c|}{ Tipo de Servicio/Tren } \\
\hline & & VL1 & VL2 & VL3 & VCM & VOT & $M$ \\
\hline & & \multicolumn{6}{|c|}{$€ /$ Tren-km reservado } \\
\hline \multirow{5}{*}{ Punta } & Al & 2,8371 & 1,5089 & 2,8371 & 1,5089 & 1,5089 & 0,5757 \\
\hline & A2 & 2,7169 & 1,4241 & 2,7169 & 1,4241 & 1,4241 & 0,5757 \\
\hline & $\mathrm{Bl}$ & 1,4241 & 1,4241 & 1,4241 & 1,4241 & 0,404 & 0,5757 \\
\hline & $\mathrm{Cl}$ & 0,404 & 0,404 & 0,404 & 0,404 & 0,404 & 0,3333 \\
\hline & $\mathrm{C} 2$ & 0,404 & 0,404 & 0,404 & 0,404 & 0,404 & 0,3333 \\
\hline
\end{tabular}

\begin{tabular}{|c|c|c|c|c|c|c|c|}
\hline \multirow{4}{*}{ Llano } & $\mathrm{A} 1$ & 2,8371 & 1,5089 & 2,8371 & 1,5089 & 1,5089 & 0,5757 \\
\cline { 2 - 8 } & $\mathrm{A} 2$ & 2,7169 & 1,4241 & 2,7169 & 1,4241 & 1,4241 & 0,5757 \\
\cline { 2 - 8 } & $\mathrm{B} 1$ & 1,4241 & 1,4241 & 1,4241 & 1,4241 & 0,404 & 0,5757 \\
\cline { 2 - 8 } & $\mathrm{C} 1$ & 0,404 & 0,404 & 0,404 & 0,404 & 0,404 & 0,0505 \\
\cline { 2 - 8 } & $\mathrm{C} 2$ & 0,404 & 0,404 & 0,404 & 0,404 & 0,404 & 0,0505 \\
\hline
\end{tabular}

\begin{tabular}{|c|c|c|c|c|c|c|c|}
\hline \multirow{4}{*}{ Valle } & $\mathrm{A} 1$ & 2,8371 & 1,5089 & 2,8371 & 1,5089 & 1,5089 & 0,5757 \\
\cline { 2 - 8 } & $\mathrm{A} 2$ & 2,7169 & 1,4241 & 2,7169 & 1,4241 & 1,4241 & 0,5757 \\
\cline { 2 - 8 } & $\mathrm{B} 1$ & 1,4241 & 1,4241 & 1,4241 & 1,4241 & 0,404 & 0,5757 \\
\cline { 2 - 8 } & $\mathrm{C} 1$ & 0,202 & 0,202 & 0,202 & 0,202 & 0,202 & 0,0505 \\
\cline { 2 - 8 } & $\mathrm{C} 2$ & 0,202 & 0,202 & 0,202 & 0,202 & 0,202 & 0,0505 \\
\hline
\end{tabular}

Tabla 90. Canon por reserva de capacidad ADIF.

38 El periodo punta no se aplica a sábados, domingos, ni a los doce días festivos de carácter nacional o autonómico. Los tramos horarios de dicho período en estos días se consideran período normal. 
El canon por circulación, que regula la utilización efectiva de la circulación se establece en función de los kilómetros-tren utilizados, teniendo en cuenta el tipo de línea y el tipo de servicio prestado según las tablas siguientes:

\begin{tabular}{|c|c|l|}
\hline \multicolumn{2}{|c|}{ Tipo de Línea } & \multicolumn{1}{c|}{ Velocidad Máxima de la Línea } \\
\hline \multirow{2}{*}{ A } & A.1 & $\begin{array}{l}\text { Línea Madrid-Barcelona-Frontera Francesa (Límite con } \\
\text { la Sección Internacional entre Figueras-Perpignan } \\
\text { administrada por TP Ferro). }\end{array}$ \\
\cline { 2 - 3 } & A.2 & $\begin{array}{l}\text { Resto de líneas con V máx. }>250 \mathrm{~km} / \mathrm{h} \text { en al menos } 2 / 3 \\
\text { de su recorrido. }\end{array}$ \\
\hline \multirow{2}{*}{ B } & B.1 & $\begin{array}{l}250 \mathrm{~km} / \mathrm{h} \geq \vee \text { máx. Línea }>200 \mathrm{Km} / \mathrm{h} \text { en al menos } 2 / 3 \text { de } \\
\text { su recorrido. }\end{array}$ \\
\hline \multirow{2}{*}{ C } & C.1 & Núcleos de Cercanías. \\
\cline { 2 - 3 } & C.2 & Resto de líneas. \\
\hline
\end{tabular}

Tabla 91. Clasificación de las líneas ferroviarias ADIF.

\begin{tabular}{|c|c|l|}
\hline Clase & Tipo & \multicolumn{1}{|c|}{ Características } \\
\hline Viajeros & VL1 & $\begin{array}{l}\text { Servicios de larga distancia excepto los designados } \\
\text { como VL2, VL3 Y VOT. }\end{array}$ \\
\hline Viajeros & VL2 & $\begin{array}{l}\text { Servicios de larga distancia en relaciones de ancho } \\
\text { variable siempre que al menos un 10\% de sU } \\
\text { recorrido total discurra por líneas de ancho ibérico. }\end{array}$ \\
\hline Viajeros & $\begin{array}{l}\text { Servicios de larga distancia en relaciones } \\
\text { transversales largas: recorridos superiores a } 700 \mathrm{~km} . \\
\text { que no tengan origen, destino o paradas } \\
\text { intermedias en Madrid y sus ramas. }\end{array}$ \\
\hline VCM & $\begin{array}{l}\text { Servicios urbanos o suburbanos: los que discurren } \\
\text { integramente dentro de un núcleo de cercanías. } \\
\text { Servicios interurbanos: los que no siendo urbano ni } \\
\text { suburbanos tienen recorridos inferiros a 300 km. Se } \\
\text { excluyen los trenes internacionales y las ramas de } \\
\text { trenes de larga distancia. } \\
\text { Servicios declarados como obligaciones de servicio } \\
\text { público. }\end{array}$ \\
\hline Viajeros & VOT & $\begin{array}{l}\text { Trenes y material de viajeros sin pasajeros, incluidas } \\
\text { máquinas aisladas, movimiento de trenes en vacío, } \\
\text { formación y pruebas. }\end{array}$ \\
\hline Mercancías & $\begin{array}{l}\text { Todos los servicios de mercancías, incluidos los } \\
\text { cargados, los vacíos, las máquinas aisladas y } \\
\text { pruebas. }\end{array}$ \\
\hline
\end{tabular}

Tabla 92. Características de los servicios y tipos de tren ADIF. 


\begin{tabular}{|c|c|c|c|c|c|c|}
\hline \multirow{3}{*}{ Tipo de Línea } & \multicolumn{7}{|c|}{ Tipo de servicio/tren } \\
\cline { 2 - 8 } & VL1 & VL2 & VL3 & VCM & VOT & $M$ \\
\cline { 2 - 7 } & \multicolumn{7}{|c|}{$\epsilon /$ Tren-km Circulado } \\
\hline A1 & 2,2018 & 0,8484 & 2,2018 & 0,8484 & 0,8484 & 0,5050 \\
\hline A2 & 2,1008 & 0,7676 & 2,1008 & 0,7676 & 0,7676 & 0,5050 \\
\hline B1 & 0,7676 & 0,7676 & 0,7676 & 0,7676 & 0,1313 & 0,5050 \\
\hline C1 & 0,1212 & 0,1212 & 0,1212 & 0,1212 & 0,1207 & 0,0606 \\
\hline C2 & 0,1212 & 0,1212 & 0,1212 & 0,1212 & 0,1207 & 0,0606 \\
\hline
\end{tabular}

Tabla 93. Canon por circulación ADIF.

El canon por tráfico grava el tráfico producido sobre la infraestructura ferroviaria. Se establece un importe unitario para cada combinación de tipo de línea, tipo de servicio y periodo horario. La cuantía del canon por tráfico es el resultante de multiplicar los importes unitarios antes citados por cada 100 plaza-kilómetro ofertadas, o fracción. La capacidad ofertada en plazaskilómetro es el resultado de multiplicar el número total de plazas que tiene la composición de un tren por los kilómetros totales recorridos.

\begin{tabular}{|c|c|c|c|c|c|c|}
\hline \multirow{3}{*}{\multicolumn{2}{|c|}{$\begin{array}{l}\text { Periodo Horario --.-- Tipo } \\
\text { Línea }\end{array}$}} & \multicolumn{5}{|c|}{ Tipo de Servicio / Tren } \\
\hline & & VLI & VL2 & VL3 & VCM & VOT \\
\hline & & \multicolumn{5}{|c|}{$€ / 100$ Plazas $-\mathrm{km}$} \\
\hline \multirow{5}{*}{ Punta } & $\mathrm{A} 1$ & 2,4019 & 0,7878 & 1,0204 & 1,1358 & 0,0000 \\
\hline & $\mathrm{A} 2$ & 1,8617 & 0,7272 & 0,9839 & 0,9055 & 0,0000 \\
\hline & $\mathrm{B} 1$ & 0,4833 & 0,4833 & 0,4833 & 0,4833 & 0,0000 \\
\hline & $\mathrm{Cl}$ & 0,0000 & 0,0000 & 0,0000 & 0,0000 & 0,0000 \\
\hline & $\mathrm{C} 2$ & 0,0000 & 0,0000 & 0,0000 & 0,0000 & 0,0000 \\
\hline \multirow{5}{*}{ Normal } & $\mathrm{Al}$ & 1,6369 & 0,5454 & 0,6955 & 0,7864 & 0,0000 \\
\hline & $\mathrm{A} 2$ & 1,2412 & 0,4848 & 0,6560 & 0,6037 & 0,0000 \\
\hline & $\mathrm{B} 1$ & 0,4833 & 0,4833 & 0,4833 & 0,4833 & 0,0000 \\
\hline & $\mathrm{Cl}$ & 0,0000 & 0,0000 & 0,0000 & 0,0000 & 0,0000 \\
\hline & $\mathrm{C} 2$ & 0,0000 & 0,0000 & 0,0000 & 0,0000 & 0,0000 \\
\hline \multirow{5}{*}{ Valle } & $\mathrm{Al}$ & 1,3922 & 0,4646 & 0,5915 & 0,6698 & 0,0000 \\
\hline & $\mathrm{A} 2$ & 1,0085 & 0,3939 & 0,5330 & 0,4905 & 0,0000 \\
\hline & B1 & 0,4833 & 0,3939 & 0,4833 & 0,4833 & 0,0000 \\
\hline & $\mathrm{Cl}$ & 0,0000 & 0,0000 & 0,0000 & 0,0000 & 0,0000 \\
\hline & $\mathrm{C} 2$ & 0,0000 & 0,0000 & 0,0000 & 0,0000 & 0,0000 \\
\hline
\end{tabular}

Tabla 94. Canon por tráfico ADIF. 
España- Alta Velocidad.

El Administrador de Infraestructuras Ferroviarias percibe por parte de la empresa ferroviaria que utilice la infraestructura de la Red Ferroviaria de Interés General, así como las estaciones y otras instalaciones ferroviarias el abono de las tasas siguientes en concepto de cánones ferroviarios.

El canon de acceso es función de los tramos de red en los que se pretenda prestar los servicios y de la declaración de actividad realizada por la empresa, que se pagará de una sola vez, al inicio de cada periodo por el que se haya producido la adjudicación de capacidad.

\begin{tabular}{|c|l|r|}
\hline \multicolumn{3}{|c|}{ Canon de Acceso Líneas Tipo $\boldsymbol{A}$} \\
\hline Nivel & \multicolumn{1}{|c|}{ Volumen de Tráfico } & \multicolumn{1}{|c|}{ Año } \\
\hline N1. A & $\leq 0,2$ millones km/Tren-año & $60.600,00$ \\
\hline N1. B & $>0,2 y \leq 0,5$ millones de km/Tren-año & $151.500,00$ \\
\hline N1.C & $>0,5 y \leq 1$ millones de km/Tren-año & $303.000,00$ \\
\hline N2. A & $>1 y \leq 2,5$ millones de km/Tren-año & $757.500,00$ \\
\hline N2. B & $>2,5 y \leq 5$ millones de km/Tren-año & $1.515 .000,00$ \\
\hline N2.C & $>5 y \leq 10$ millones de km/Tren-año & $3.030 .000,00$ \\
\hline N3. A & $>10 y \leq 15$ millones de km/Tren-año & $4.545 .000,00$ \\
\hline N3. B & $>15 y \leq 20$ millones de km/Tren-año & $6.060 .000,00$ \\
\hline N3.C & $>20 y \leq 30$ millones de km/Tren-año & $7.575 .000,00$ \\
\hline N3. D & $>30 y \leq 40$ millones de km/Tren-año & $9.090 .000,00$ \\
\hline N3. E & $>40 y \leq 50$ millones de km/Tren-año & $12.120 .000,00$ \\
\hline N3. F & $>50$ millones de km/Tren-año & $15.150 .000,00$ \\
\hline
\end{tabular}

Tabla 95. Canon de acceso a la línea de Alta Velocidad ADIF.

El canon por reserva de capacidad es calculado en función de los kilómetros de longitud del tramo de red reservado, distinguiendo por tipo de línea y hora del día en que se reserva, y por tipo de servicio de transporte ferroviario y tipo de tren que lo presta.

\begin{tabular}{|c|c|c|}
\hline Periodo & Inicio & Fin \\
\hline Valle & $0: 00$ & $5: 59$ \\
\hline Punta & $6: 00$ & $9: 29$ \\
\hline Normal & $9: 30$ & $17: 59$ \\
\hline Punta & $18: 00$ & $20: 29$ \\
\hline Normal & $20: 30$ & $23: 59$ \\
\hline
\end{tabular}

Tabla 96. Periodos horarios línea Alta Velocidad ADIF. 


\begin{tabular}{|c|c|l|}
\hline Clase & Tipo & \multicolumn{1}{|c|}{ Características } \\
\hline Viajeros & VL1 & $\begin{array}{l}\text { Servicios de larga distancia excepto los } \\
\text { designados como VL2, VL3 Y VOT. }\end{array}$ \\
\hline Viajeros & VL2 & $\begin{array}{l}\text { Servicios de larga distancia en relaciones de } \\
\text { ancho variable siempre que al menos un 10\% } \\
\text { de su recorrido total discurra por líneas de } \\
\text { ancho ibérico. }\end{array}$ \\
\hline VL3 & $\begin{array}{l}\text { Servicios de larga distancia en relaciones } \\
\text { transversales largas: recorridos superiores a } \\
700 \text { km. que no tengan origen, destino o } \\
\text { paradas intermedias en Madrid y sus ramas. }\end{array}$ \\
\hline Viajeros & $\begin{array}{l}\text { Servicios urbanos o suburbanos: los que } \\
\text { discurren íntegramente dentro de un núcleo } \\
\text { de cercanías. } \\
\text { Servicios interurbanos: los que no siendo } \\
\text { urbano ni suburbanos tienen recorridos } \\
\text { inferiros a 300 km. Se excluyen los trenes } \\
\text { internacionales y las ramas de trenes de larga } \\
\text { distancia. } \\
\text { Servicios declarados como obligaciones de } \\
\text { servicio público. }\end{array}$ \\
\hline Mercancías & VOT & $\begin{array}{l}\text { Trenes y material de viajeros sin pasajeros, } \\
\text { incluidas máquinas aisladas, movimiento de } \\
\text { trenes en vacío, formación y pruebas. }\end{array}$ \\
\hline M & $\begin{array}{l}\text { Todos los servicios de mercancías, incluidos } \\
\text { los cargados, los vacíos, las máquinas } \\
\text { aisladas y pruebas. }\end{array}$ \\
\hline
\end{tabular}

Tabla 97. Características de los servicios y tipos de tren ADIF.

\begin{tabular}{|c|c|l|}
\hline \multicolumn{2}{|c|}{ Tipo de Línea } & \multicolumn{1}{c|}{ Líneas } \\
\hline \multirow{4}{*}{ A.1 } & $\begin{array}{l}\text { Línea Madrid-Barcelona-Frontera Francesa (Límite con } \\
\text { la Sección Internacional entre Figueras-Perpignan } \\
\text { administrada por TP Ferro). }\end{array}$ \\
\cline { 2 - 3 } & A.2 & $\begin{array}{l}\text { Resto de líneas con V máx. > 250 km/h en al menos 2/3 } \\
\text { de su recorrido que comprenden: } \\
\text { Madrid-Sevilla. } \\
\text { Córdoba-Málaga. } \\
\text { Madrid-Valladolid-Palencia-León. } \\
\text { Madrid-Albacete-Alicante. } \\
\text { Madrid-Valencia. } \\
\text { Badrid-Zamora. }\end{array}$ \\
\hline \multirow{2}{*}{ B } & B.1 & $\begin{array}{l}\text { 250 km/h } \geq \text { V máx. Línea >200 km/h en al menos 2/3 de } \\
\text { su recorrido. La Sagra-Toledo. }\end{array}$ \\
\hline & C.1 & $\begin{array}{l}\text { Núcleo de Cercanías de Valencia. } \\
\text { Tramo 600 desde Valencia Estació del Nord hasta } \\
\text { Castelló de la Plana. }\end{array}$ \\
\cline { 2 - 3 } & C.2 & Resto de líneas. \\
\hline
\end{tabular}

Tabla 98. Clasificación de las líneas de Alta Velocidad ADIF. 


\begin{tabular}{|c|c|c|c|c|c|c|c|}
\hline Periodo horario & $\begin{array}{c}\text { Tipo } \\
\text { de }\end{array}$ & \multicolumn{6}{|c|}{ Tipo de Servicio/Tren } \\
\hline & & VL1 & VL2 & VL3 & VCM & VOT & $M$ \\
\hline & & \multicolumn{6}{|c|}{$€ /$ Tren-km reservado } \\
\hline \multirow{5}{*}{ Punta } & $\mathrm{Al}$ & 2,8371 & 1,5089 & 2,8371 & 1,5089 & 1,5089 & 0,5757 \\
\hline & A2 & 2,7169 & 1,4241 & 2,7169 & 1,4241 & 1,4241 & 0,5757 \\
\hline & $\mathrm{Bl}$ & 1,4241 & 1,4241 & 1,4241 & 1,4241 & 0,404 & 0,5757 \\
\hline & $\mathrm{Cl}$ & 0,404 & 0,404 & 0,404 & 0,404 & 0,404 & 0,3333 \\
\hline & $\mathrm{C} 2$ & 0,404 & 0,404 & 0,404 & 0,404 & 0,404 & 0,3333 \\
\hline \multirow{6}{*}{ Normal } & & & & & & & \\
\hline & Al & 2,8371 & 1,5089 & 2,8371 & 1,5089 & 1,5089 & 0,5757 \\
\hline & A2 & 2,7169 & 1,4241 & 2,7169 & 1,4241 & 1,4241 & 0,5757 \\
\hline & $\mathrm{Bl}$ & 1,4241 & 1,4241 & 1,4241 & 1,4241 & 0,404 & 0,5757 \\
\hline & $\mathrm{Cl}$ & 0,404 & 0,404 & 0,404 & 0,404 & 0,404 & 0,0505 \\
\hline & $\mathrm{C2}$ & 0,404 & 0,404 & 0,404 & 0,404 & 0,404 & 0,0505 \\
\hline \multirow{5}{*}{ Valle } & $\mathrm{Al}$ & 2,8371 & 1,5089 & 2,8371 & 1,5089 & 1,5089 & 0,5757 \\
\hline & $\mathrm{A} 2$ & 2,7169 & 1,4241 & 2,7169 & 1,4241 & 1,4241 & 0,5757 \\
\hline & $\mathrm{B} 1$ & 1,4241 & 1,4241 & 1,4241 & 1,4241 & 0,404 & 0,5757 \\
\hline & $\mathrm{Cl}$ & 0,202 & 0,202 & 0,202 & 0,202 & 0,202 & 0,0505 \\
\hline & $\mathrm{C2}$ & 0,202 & 0,202 & 0,202 & 0,202 & 0,202 & 0,0505 \\
\hline
\end{tabular}

Tabla 99. Canon por reserva de capacidad líneas de Alta Velocidad ADIF.

El canon por circulación regula la utilización efectiva de la circulación. Se establece en función de los kilómetros-tren efectivamente utilizados, teniendo en cuenta el tipo de línea, y el tipo de servicio prestado según las tablas 75 y 76 .

\begin{tabular}{|c|c|c|c|c|c|c|}
\hline \multirow{2}{*}{ Tipo de Línea } & \multicolumn{7}{|c|}{ Tipo de servicio/tren } \\
\cline { 2 - 7 } & VL1 & VL2 & VL3 & VCM & VOT & M \\
\cline { 2 - 7 } & \multicolumn{7}{|c|}{ / Tren-km Circulado } \\
\hline A1 & 2,2018 & 0,8484 & 2,2018 & 0,8484 & 0,8484 & 0,5050 \\
\hline A2 & 2,1008 & 0,7676 & 2,1008 & 0,7676 & 0,7676 & 0,5050 \\
\hline B1 & 0,7676 & 0,7676 & 0,7676 & 0,7676 & 0,1313 & 0,5050 \\
\hline C1 & 0,1212 & 0,1212 & 0,1212 & 0,1212 & 0,1207 & 0,0606 \\
\hline C2 & 0,1212 & 0,1212 & 0,1212 & 0,1212 & 0,1207 & 0,0606 \\
\hline
\end{tabular}

Tabla 100. Canon por circulación en líneas de Alta Velocidad ADIF. 
El canon por tráfico grava el tráfico producido sobre la infraestructura ferroviaria. Se establece un importe unitario para cada combinación según periodo horario, tipo de línea y tipo de servicio según las tablas 74,75 y 76 respectivamente.

La cuantía del canon por tráfico será la que resulte de multiplicar los importes unitarios antes citados por cada 100 plaza-kilómetro ofertadas, o fracción. La capacidad ofertada en plazas-kilómetro será el resultado de multiplicar el número total de plazas que tiene la composición de un tren por los kilómetros totales recorridos.

A efectos de la determinación del periodo horario de aplicación, se toma en consideración las paradas que realice el tren en estaciones para la subida y bajada de viajeros (parada comercial).

\begin{tabular}{|c|c|c|c|c|c|c|}
\hline \multirow{3}{*}{ Periodo Horario } & \multirow{3}{*}{ Tipo Línea } & \multicolumn{5}{|c|}{ Tipo de Servicio / Tren } \\
\hline & & VLI & VL2 & VL3 & VCM & VOT \\
\hline & & \multicolumn{5}{|c|}{$€ / 100$ Plazas -km } \\
\hline \multirow{5}{*}{ Punta } & $\mathrm{Al}$ & 2,4019 & 0,7878 & 1,0204 & 1,1358 & 0,0000 \\
\hline & $\mathrm{A} 2$ & 1,8617 & 0,7272 & 0,9839 & 0,9055 & 0,0000 \\
\hline & $\mathrm{Bl}$ & 0,4833 & 0,4833 & 0,4833 & 0,4833 & 0,0000 \\
\hline & $\mathrm{Cl}$ & 0,0000 & 0,0000 & 0,0000 & 0,0000 & 0,0000 \\
\hline & $\mathrm{C} 2$ & 0,0000 & 0,0000 & 0,0000 & 0,0000 & 0,0000 \\
\hline \multirow{5}{*}{ Normal } & $\mathrm{Al}$ & 1,6369 & 0,5454 & 0,6955 & 0,7864 & 0,0000 \\
\hline & A2 & 1,2412 & 0,4848 & 0,6560 & 0,6037 & 0,0000 \\
\hline & $\mathrm{B} 1$ & 0,4833 & 0,4833 & 0,4833 & 0,4833 & 0,0000 \\
\hline & $\mathrm{Cl}$ & 0,0000 & 0,0000 & 0,0000 & 0,0000 & 0,0000 \\
\hline & $\mathrm{C} 2$ & 0,0000 & 0,0000 & 0,0000 & 0,0000 & 0,0000 \\
\hline \multirow{5}{*}{ Valle } & $\mathrm{Al}$ & 1,3922 & 0,4646 & 0,5915 & 0,6698 & 0,0000 \\
\hline & A2 & 1,0085 & 0,3939 & 0,5330 & 0,4905 & 0,0000 \\
\hline & $\mathrm{Bl}$ & 0,4833 & 0,3939 & 0,4833 & 0,4833 & 0,0000 \\
\hline & $\mathrm{Cl}$ & 0,0000 & 0,0000 & 0,0000 & 0,0000 & 0,0000 \\
\hline & $\mathrm{C} 2$ & 0,0000 & 0,0000 & 0,0000 & 0,0000 & 0,0000 \\
\hline
\end{tabular}

Tabla 101. Canon por tráfico en líneas de Alta Velocidad ADIF. 
Eurotunnel.

Eurotúnel es el administrador de la infraestructura bajo el Canal de la Mancha, en régimen de concesión, facilitando las operaciones ferroviarias entre Reino Unido y Europa de acuerdo con la Decisión del Consejo del Parlamento de Europa del 7 de julio de $2010^{39}$.

El túnel está formado por dos túneles para tráfico ferroviario de 50 kilómetros de longitud y un diámetro interno de 7,6 metros y una declividad máxima de 11 por mil. Los raíles se asientan sobre placa de hormigón armado siendo la alimentación de la catenaria de $25 \mathrm{kV}$ a $50 \mathrm{~Hz}$. Existe un túnel de servicio entre ambos túneles con comunicación cada 375 metros entre ellos.

Existe la limitación de longitud máxima permitida de composiciones de 750 metros, así como de carga máxima por eje de 22,5 toneladas.

El sistema de cánones de acceso se estableció originalmente en 1987 teniendo en cuenta los costes de construcción y operación del túnel, la situación del mercado, así como el uso óptimo de su capacidad, basada en las previsiones de tráfico proporcionadas por los gobiernos y empresas ferroviarias estatales (16,5 Mpax 40 y 7,3 Mton 41 , aumentando a 20 Mpax y 10 Mton.). Para trenes de viajeros el canon por viajero ofrece una reducción en costes de acceso con el fin de desarrollar nuevos servicios o facilitar la entrada de nuevos operadores. Para trenes de mercancías ofrece reducciones de hasta el $50 \%$ en el canon de acceso en función del tipo de tren.

En cuanto a trenes de mercancías hay establecidas 5 categorías para este tipo de trenes:

- Categoría 1 Tren semanal reservado: Un tren por semana laborable durante un año.

- Categoría 2 Tren diario: Cinco o más trenes por semana durante un año.

- Categoría 3 Tren individual reservado: Único tren que circula al año.

- Categoría 4 Tren adicional sin reserva: Un tren sin reserva y solicitadas 24 horas antes de su expedición.

- Categoría 5 Locomotoras aisladas: Locomotoras circulando en días laborables y con solicitud de reserva con al menos 1 semana de antelación a su expedición.

\footnotetext{
39 Decisión 661/2010/UE para el desarrollo de una red europea de transporte.

40 Mpax: Millones de viajeros.

${ }^{41}$ Mton: Millones de toneladas.
} 
Además del tipo de tren, se aplica una variable dependiendo del horario en el cual se realiza la circulación, según la tabla adjunta:

\begin{tabular}{|c|c|c|}
\hline Periodo & Hora Inicio 42 & Hora Fin 15 \\
\hline Off- Peak ${ }^{43}$ & $22: 00$ & $07: 00$ \\
\hline Peak (Mañana) & 07:00 & $11: 00$ \\
\hline Intermedio & $11: 00$ & $17: 00$ \\
\hline Peak (Tarde) & $17: 00$ & $22: 00$ \\
\hline Mantenimiento 44 & $23: 00$ & $07: 00$ \\
\hline
\end{tabular}

Tabla 102. Periodo horario para trenes de mercancías Eurotunnel.

\begin{tabular}{|c|c|c|c|c|}
\hline $\begin{array}{c}\text { Tipo de } \\
\text { tren }(\mathrm{km} / \mathrm{h})\end{array}$ & Periodo & $\begin{array}{c}\text { Velocidad } \\
\text { máxima } \mathrm{km} / \mathrm{h}\end{array}$ & $\begin{array}{c}\text { Canon } \\
\text { Reserva } \epsilon\end{array}$ & $\begin{array}{c}\text { Canon } \\
\text { Acceso } \epsilon\end{array}$ \\
\hline \multirow{3}{*}{120 a 140} & Off-Peak & \multirow{3}{*}{$120-140$} & 191,25 & $1.721,25$ \\
\hline & Intermedio & & 247,50 & $2.227,50$ \\
\hline & Peak & & 270,00 & $2.430,00$ \\
\hline 100 & Off-Peak & 100 & 225,00 & $2.025,00$ \\
\hline Todos & Mantenimiento & 100 & 337,50 & $3.037,50$ \\
\hline
\end{tabular}

Tabla 103. Cánones aplicados a trenes de mercancías Categoría 1 Eurotunnel.

\begin{tabular}{|c|c|c|c|c|}
\hline $\begin{array}{c}\text { Tipo de } \\
\text { tren }(\mathbf{k m} / \mathbf{h})\end{array}$ & Periodo & $\begin{array}{c}\text { Velocidad } \\
\text { máxima } \mathbf{~ k m} / \mathbf{h}\end{array}$ & $\begin{array}{c}\text { Canon } \\
\text { Reserva } \boldsymbol{\epsilon}\end{array}$ & $\begin{array}{c}\text { Canon } \\
\text { Acceso } \boldsymbol{\epsilon}\end{array}$ \\
\hline \multirow{2}{*}{120 a 140} & Off-Peak & \multirow{2}{*}{$120-140$} & 191,25 & $1.721,25$ \\
\cline { 2 - 3 } & Intermedio & 247,50 & $2.227,50$ \\
\cline { 2 - 2 } & Peak & & 270,00 & $2.430,00$ \\
\hline 100 & Off-Peak & 100 & 225,00 & $2.025,00$ \\
\hline Todos & Mantenimiento & 100 & 225,00 & $2.025,00$ \\
\hline \multicolumn{4}{|r|}{ Costes administrativos no aplicables. } \\
\hline
\end{tabular}

Tabla 104. Cánones aplicados a trenes de mercancías Categoría 2 Eurotunnel.

\begin{tabular}{|c|c|c|c|c|}
\hline $\begin{array}{c}\text { Tipo de } \\
\text { tren }(\mathrm{km} / \mathrm{h})\end{array}$ & Periodo & $\begin{array}{c}\text { Velocidad } \\
\text { máxima } \mathrm{km} / \mathrm{h}\end{array}$ & $\begin{array}{c}\text { Canon } \\
\text { Reserva } €\end{array}$ & $\begin{array}{c}\text { Canon } \\
\text { Acceso } €\end{array}$ \\
\hline \multirow{3}{*}{120 a 140} & Off-Peak & \multirow{3}{*}{$120-140$} & 210,38 & $1.893,38$ \\
\hline & Intermedio & & 272,25 & $2.450,25$ \\
\hline & Peak & & 297,00 & $2.673,00$ \\
\hline 100 & Off-Peak & 100 & 247,50 & $2.227,50$ \\
\hline Todos & Mantenimiento & 100 & 371,25 & $3.341,25$ \\
\hline
\end{tabular}

Tabla 105. Cánones aplicados a trenes de mercancías Categoría 3 Eurotunnel.

\footnotetext{
42 Horario central europeo.

43 Excepto periodos de mantenimiento.

44 Viernes, sábado y domingo noche.
} 


\begin{tabular}{|c|c|c|c|}
\hline $\begin{array}{c}\text { Tipo de } \\
\text { tren }(\mathrm{km} / \mathrm{h})\end{array}$ & Periodo & $\begin{array}{c}\text { Velocidad } \\
\text { máxima } \mathrm{km} / \mathrm{h}\end{array}$ & $\begin{array}{c}\text { Canon } \\
\text { Acceso } €\end{array}$ \\
\hline \multirow{3}{*}{120 a 140} & Off-Peak & \multirow{3}{*}{$120-140$} & $2.295,00$ \\
\hline & Intermedio & & $2.970,00$ \\
\hline & Peak & & $3.240,00$ \\
\hline \multirow{3}{*}{100} & Off-Peak & \multirow{3}{*}{100} & $2.700,00$ \\
\hline & & & $4.050,00$ \\
\hline & & & $5.400,00$ \\
\hline Todos & Mantenimiento & 100 & $4.050,00$ \\
\hline
\end{tabular}

Tabla 106. Cánones aplicados a trenes de mercancías Categoría 4 Eurotunnel.

\begin{tabular}{|c|c|c|c|}
\hline $\begin{array}{c}\text { Tipo de } \\
\text { tren }(\mathbf{k m} / \mathbf{h})\end{array}$ & Periodo & $\begin{array}{c}\text { Velocidad } \\
\text { máxima } \mathbf{~ k m} / \mathbf{h}\end{array}$ & $\begin{array}{c}\text { Canon } \\
\text { Acceso } \boldsymbol{\epsilon}\end{array}$ \\
\hline 120 a 140 & $\begin{array}{c}\text { Fuera de } \\
\text { periodos de } \\
\text { mantenimiento }\end{array}$ & $120-140$ & $1.125,00$ \\
\hline 100 & $\begin{array}{c}\text { Periodos } \\
\text { de } \\
\text { mantenimiento }\end{array}$ & 100 & $2.250,00$ \\
\hline \multicolumn{3}{|c|}{ Costes administrativos: 7.500 euros por contrato. } \\
\hline
\end{tabular}

Tabla 107. Cánones aplicados a trenes de mercancías Categoría 5 Eurotunnel.

Para los trenes de viajeros se establecen las siguientes categorías:

- Tren semanal reservado: Un tren por semana laborable durante un año.

- Tren diario: Cinco o más trenes por semana durante un año.

- Tren individual reservado: Único tren que circula al año.

- Tren fuera de servicio: Trenes sin servicio comercial para traslado de material rodante y con solicitud de reserva con al menos una semana de antelación a su expedición.

La variable de horario aplicada es el siguiente:

\begin{tabular}{|c|c|c|}
\hline Periodo & Hora Inicio 45 & Hora Fin \\
\hline Off- Peak 46 & $22: 00$ & 07:00 \\
\hline Peak (Mañana) ${ }^{47}$ & 07:00 & $11: 00$ \\
\hline Intermedio & $11: 00$ & $17: 00$ \\
\hline Peak (Tarde) ${ }^{20}$ & $17: 00$ & $22: 00$ \\
\hline Mantenimiento 48 & 23:00 & 07:00 \\
\hline
\end{tabular}

Tabla 108. Periodo horario para trenes de viajeros Eurotunnel.

\footnotetext{
45 Horario central europeo.

${ }^{46}$ Excepto periodos de mantenimiento.

47 Excepto sábados y domingos, incluidos en Intermedio.

48 Viernes, sábado y domingo noche.
} 


\begin{tabular}{|c|c|c|c|}
\hline Periodo & $\begin{array}{c}\text { Velocidad } \\
\text { máxima } \mathbf{k m} / \mathbf{h}\end{array}$ & $\begin{array}{c}\text { Canon } \\
\text { Reserva } \boldsymbol{\epsilon}\end{array}$ & $\begin{array}{c}\text { Canon } \\
\text { Acceso } \\
\boldsymbol{\epsilon} / \text { viajero }\end{array}$ \\
\hline Intermedio & $140-160$ & 2.400 & \multirow{2}{*}{8,45} \\
\cline { 1 - 2 } Peak & 120 & 2.640 & \multirow{2}{*}{2.160} \\
\hline Off-Peak & 100 & 3.600 & \\
\hline Mantenimiento & \multicolumn{2}{|c|}{ Costes administrativos: 7.500 euros por contrato. } \\
\hline
\end{tabular}

Tabla 109. Cánones aplicados a trenes de viajeros Categoría 1 Eurotunnel.

\begin{tabular}{|c|c|c|c|}
\hline Periodo & $\begin{array}{c}\text { Velocidad } \\
\text { máxima km/h }\end{array}$ & $\begin{array}{c}\text { Canon } \\
\text { Reserva } \epsilon\end{array}$ & $\begin{array}{c}\text { Canon } \\
\text { Acceso } \\
\epsilon / \text { viajero }\end{array}$ \\
\hline Intermedio & \multirow{2}{*}{$140-160$} & 2.640 & \multirow{4}{*}{8,45} \\
\hline Peak & & 2.940 & \\
\hline Off-Peak & 120 & 2.376 & \\
\hline Mantenimiento & 100 & 3.960 & \\
\hline
\end{tabular}

Tabla 110. Cánones aplicados a trenes de viajeros Categoría 2 Eurotunnel.

\begin{tabular}{|c|c|c|c|}
\hline Periodo & $\begin{array}{c}\text { Velocidad } \\
\text { máxima } \mathbf{k m} / \mathbf{h}\end{array}$ & $\begin{array}{c}\text { Canon } \\
\text { Reserva } \boldsymbol{\epsilon}\end{array}$ & $\begin{array}{c}\text { Canon } \\
\text { Acceso } \\
\boldsymbol{\epsilon} / \text { viajero }\end{array}$ \\
\hline Intermedio & $140-160$ & 2.760 & \multirow{2}{*}{8,45} \\
\cline { 1 - 2 } Peak & 120 & 3.036 & \multirow{2}{*}{8.484} \\
\hline Off-Peak & 100 & 4.140 & \\
\hline Mantenimiento & \multicolumn{2}{|r|}{ Costes administrativos: 7.500 euros por contrato. } \\
\hline
\end{tabular}

Tabla 111. Cánones aplicados a trenes de viajeros Categoría 3 Eurotunnel.

\begin{tabular}{|c|c|c|}
\hline Periodo & $\begin{array}{c}\text { Velocidad } \\
\text { máxima } \mathbf{~ k m} / \mathbf{h}\end{array}$ & Canon Reserva $\boldsymbol{\epsilon}$ \\
\cline { 1 - 1 } & \multirow{2}{*}{140} & 2.400 \\
\cline { 1 - 1 } & 120 & 2.640 \\
\hline Peak & 100 & 2.160 \\
\hline Off-Peak & 100 & 3.600 \\
\hline Mantenimiento & Costes administrativos: 7.500 euros por contrato. \\
\hline
\end{tabular}

Tabla 112. Cánones aplicados a trenes de viajeros Categoría 4 Eurotunnel. 
Finlandia.

La infraestructura ferroviaria de Finlandia tiene una longitud de $5.944 \mathrm{~km}$, siendo 5.342 líneas de vía única. Tienen un ancho de vía de $1.524 \mathrm{~mm}$, de los cuales $3.256 \mathrm{~km}$ son líneas electrificadas Los ferrocarriles están explotados por la empresa estatal VR Group y desde el año 2010 el mantenimiento y la construcción de la red ferroviaria es responsabilidad de la Agencia de Transporte de Finlandia.

El canon por uso de la infraestructura cubre el paquete de acceso mínimo incluyendo el acceso a la red ferroviaria y a las instalaciones de servicios.

Los cánones se muestran en la siguiente tabla:

\begin{tabular}{|c|c|c|c|}
\hline \multirow{2}{*}{ Canon básico } & \multicolumn{2}{|c|}{ Trenes de mercancías } & $0,1350 € /$ tonelada-km. \\
\hline & \multicolumn{2}{|c|}{ Trenes de viajeros } & $0,1308 € /$ tonelada-km. \\
\hline \multirow{3}{*}{$\begin{array}{c}\text { Canon por uso } \\
\text { de } \\
\text { infraestructura }\end{array}$} & \multirow{2}{*}{$\begin{array}{l}\text { Trenes de } \\
\text { mercancías: }\end{array}$} & $\begin{array}{l}\text { Tracción } \\
\text { eléctrica }\end{array}$ & $0,05 € /$ tonelada-km. \\
\hline & & Tracción diésel & $0,1 € /$ tonelada-km \\
\hline & \multicolumn{2}{|c|}{ Trenes de viajeros } & $0,01 € /$ tonelada-km. \\
\hline \multirow{2}{*}{$\begin{array}{c}\text { Tasa por } \\
\text { inversión } \\
\text { (aplicado al } \\
\text { tramo Kerava- } \\
\text { Lahti) }\end{array}$} & \multicolumn{2}{|c|}{ Trenes de mercancías } & \\
\hline & \multicolumn{2}{|c|}{ Trenes de viajeros } & $0,5 € /$ tonelada-km. \\
\hline
\end{tabular}

Tabla 113. Cánones aplicados por VR Group.

Francia.

SNCF Reseau es una empresa pública con carácter industrial y comercial, de servicio público con el fin de promover y desarrollar el transporte ferroviario en Francia ${ }^{49}$.

El canon se establece según la demanda en la línea, teniendo en cuenta el tipo de línea, definido por la densidad de tráfico, así como el periodo de uso del surco reservado.

49 De acuerdo con el artículo L.2111-9 del Code des Transports. 


\begin{tabular}{|c|c|c|c|}
\hline $\begin{array}{c}\text { Categoría de } \\
\text { las líneas }\end{array}$ & \multicolumn{2}{|c|}{ Subcategorías } & Denominación \\
\hline \multirow{2}{*}{$\begin{array}{l}\text { Líneas } \\
\text { suburbanas }\end{array}$} & \multicolumn{2}{|l|}{ Tráfico alto } & $\mathrm{A}$ \\
\hline & \multicolumn{2}{|l|}{ Tráfico medio } & $\mathrm{B}$ \\
\hline \multirow{7}{*}{$\begin{array}{l}\text { Grandes } \\
\text { Líneas } \\
\text { Interurbanas }\end{array}$} & \multicolumn{2}{|c|}{ Tráfico alto } & $\mathrm{C}$ \\
\hline & \multicolumn{2}{|c|}{ Tráfico alto a $220 \mathrm{~km} / \mathrm{h}$} & C-GV \\
\hline & \multicolumn{2}{|c|}{ Paralela a LGV SEA } & C-SEA \\
\hline & \multicolumn{2}{|c|}{ Paralela a LGV BPL } & C-BPL \\
\hline & \multicolumn{2}{|c|}{ Tráfico medio } & $\mathrm{D}$ \\
\hline & \multicolumn{2}{|c|}{$\begin{array}{l}\text { Tráfico medio } \\
\text { à } 220 \text { km/h y línea du Haut-Bugey }\end{array}$} & D-GV \\
\hline & \multicolumn{2}{|c|}{ Tráfico medio incluidas en Plan Rail } & D-pr \\
\hline \multirow{12}{*}{$\begin{array}{l}\text { Línea de alta } \\
\text { velocidad }\end{array}$} & \multirow{2}{*}{ Eje Sud-Est } & Tráfico alto & SE-1 \\
\hline & & Tráfico medio & SE-2 \\
\hline & \multirow{4}{*}{ Eje Atlantique } & \multirow{3}{*}{ LGV Atlantique } & ATL-0 \\
\hline & & & ATL-1 \\
\hline & & & ATL-2 \\
\hline & & LGV BPL & $\mathrm{BPL}$ \\
\hline & \multirow{2}{*}{ Eje Nord } & Tráfico alto & NOR-1 \\
\hline & & Tráfico medio & NOR-2 \\
\hline & \multirow{2}{*}{ Eje Est } & Tráfico alto & EST-1 \\
\hline & & Tráfico medio & EST-2 \\
\hline & \multicolumn{2}{|l|}{ Interconexión } & ICO-1 \\
\hline & \multicolumn{2}{|c|}{ LGV Rhin-Rhône } & $\mathrm{RH}-\mathrm{l}$ \\
\hline & \multicolumn{2}{|c|}{ Otras líneas de alta velocidad } & $E$ \\
\hline Otras líneas & \multicolumn{2}{|c|}{$\begin{array}{l}\text { Otras líneas de alta velocidad, incluidas en } \\
\text { Plan Rail }\end{array}$} & E-pr \\
\hline
\end{tabular}

Tabla 114. Clasificación de las líneas ferroviarias SNCF.

Los coeficientes por aplicar según el periodo horario se muestran en la tabla siguiente:

\begin{tabular}{|c|c|c|c|}
\hline Hora valle & Hora normal & Hora intermedia & Hora punta \\
\hline 0,5 & 1 & 1,25 & 1,5 \\
\hline
\end{tabular}

Tabla 115. Coeficientes horarios SNCF. 
Como objetivo de mejorar el intercambio económico entre SNCF y las empresas ferroviarias hay establecidos una serie de incentivos con el objeto de fomentar el tráfico ferroviario en aquellos tramos menos rentables y descongestionar las estaciones parisinas.

Los coeficientes aplicados a los trenes de mercancías están calculados en base a la longitud del surco reservado y la velocidad media del tren.

\begin{tabular}{|c|c|c|c|c|c|c|c|c|c|c|}
\hline \multicolumn{11}{|c|}{ Canon por Reserva para trenes de viajeros } \\
\hline \multicolumn{11}{|c|}{ Canon por reserva $=\mathrm{PKR} * \mathrm{C} 1 * \mathrm{C} 2 * \mathrm{C} 3 * \mathrm{C} 6 * \mathrm{~km}$ reservado. } \\
\hline \multicolumn{11}{|c|}{ Líneas convencionales } \\
\hline 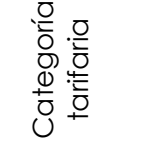 & A & B & C & C G V & $\mathrm{D}$ & $D-G V$ & $D \cdot p r$ & \multicolumn{2}{|c|}{ E } & E-pr \\
\hline $\begin{array}{c}\text { PKR (€ HT } \\
\text { por } \\
\text { surco- } \\
\text { km) }\end{array}$ & 5,65 & 2,64 & 1,27 & 1,272 & $\begin{array}{c}0,50 \\
6\end{array}$ & 0,506 & 0,010 & \multicolumn{2}{|c|}{0,074} & 0,01 \\
\hline \multicolumn{11}{|c|}{ Línea de Alta Velocidad (LGV) } \\
\hline $\begin{array}{l}\text { Categorí } \\
\text { a tarifaria }\end{array}$ & SE-1 & SE-2 & ATL-1 & ATL-2 & $\begin{array}{c}\text { NOR- } \\
1\end{array}$ & $\begin{array}{l}\mathrm{NO} \\
\mathrm{R}-2\end{array}$ & ICO-1 & $\begin{array}{c}\text { EST- } \\
1\end{array}$ & $\begin{array}{l}\text { EST- } \\
2\end{array}$ & $\mathrm{RH} 1$ \\
\hline $\begin{array}{l}\text { PKR (€ HT } \\
\text { por } \\
\text { surco-km) }\end{array}$ & 16,12 & 5,49 & 18,82 & 5,941 & 14,78 & 6,37 & 3,57 & $\begin{array}{l}6,85 \\
7\end{array}$ & 3,42 & 5,03 \\
\hline \multicolumn{11}{|c|}{ Coeficientes par trenes de viajeros } \\
\hline \multirow{2}{*}{$\mathrm{XCl}$} & \multirow{2}{*}{\multicolumn{5}{|c|}{ Para todas las líneas }} & $\mathrm{HC}$ & $H N$ & & 11 & HP \\
\hline & & & & & & 0,50 & 1,00 & & 25 & 1,50 \\
\hline \multirow{2}{*}{$x \mathrm{C} 2$} & \multirow{2}{*}{\multicolumn{5}{|c|}{ TAGV no convencionales sobre LGV }} & Rac & & \multicolumn{3}{|c|}{ Intersección } \\
\hline & & & & & & 1, & & & 1,68 & \\
\hline$x C 3$ & \multicolumn{5}{|c|}{ Trenes regionales sobre LGV } & \multicolumn{5}{|c|}{0,46} \\
\hline XC6 & \multicolumn{5}{|c|}{$\begin{array}{c}\text { TAGV origen-destino Ginebra sobre } \\
\text { LGV }\end{array}$} & \multicolumn{5}{|c|}{0,95} \\
\hline
\end{tabular}

Tabla 116. Coeficientes para el cálculo del canon por reserva en trenes de viajeros SNCF. 


\begin{tabular}{|c|c|c|c|}
\hline \multicolumn{4}{|c|}{ Canon por Circulación para trenes de viajeros } \\
\hline \multicolumn{4}{|c|}{ Canon por circulación = PKC $\times$ C4 $\times$ km circulado } \\
\hline \multirow{3}{*}{$\begin{array}{c}\text { PKC (€ HT por tren- } \\
\text { km) }\end{array}$} & \multicolumn{2}{|c|}{$\begin{array}{l}\text { Trenes Regionales de viajeros no aptos para } \\
\text { gran velocidad ( } 220 \mathrm{~km} / \mathrm{h} \text { o más). }\end{array}$} & 2,371 \\
\hline & \multicolumn{2}{|c|}{ Trenes de viajeros fuera de servicio. } & 1,282 \\
\hline & $\times C 4$ & $\begin{array}{l}\text { Coeficiente sobre E y } \\
\text { E-pr únicamente. }\end{array}$ & 0,60 \\
\hline \multirow{5}{*}{$\begin{array}{c}\text { PKC (€ HT por tren- } \\
\text { km) }\end{array}$} & \multicolumn{2}{|c|}{$\begin{array}{c}\text { Trenes de viajeros aptos para gran } \\
\text { velocidad (220 km/h o más) circulando } \\
\text { sobre LGV }\end{array}$} & 4,453 \\
\hline & \multicolumn{2}{|c|}{$\begin{array}{c}\text { Trenes de viajeros aptos para gran } \\
\text { velocidad ( } 220 \mathrm{~km} / \mathrm{h} \text { o más) circulando } \\
\text { sobre líneas convencionales. }\end{array}$} & 3,613 \\
\hline & \multicolumn{2}{|c|}{ Otros trenes no aptos para gran velocidad } & 3,197 \\
\hline & \multicolumn{2}{|c|}{$\begin{array}{l}\text { Trenes Regionales de viajeros no aptos para } \\
\text { gran velocidad }\end{array}$} & 4,402 \\
\hline & \multicolumn{2}{|c|}{$\begin{array}{c}\text { Trenes de viajeros aptos para gran } \\
\text { velocidad (220 km/h o más) circulando } \\
\text { sobre LGV }\end{array}$} & 4,453 \\
\hline
\end{tabular}

Tabla 117. Coeficientes para el cálculo del canon por circulación trenes de viajeros SNCF

Canon por suministro de energía eléctrica para tracción trenes de viajeros Canon por suministro de energía eléctrica para tracción $=$ PU x $\mathbf{~ m m ~ c i r c u l a d o ~}$

\begin{tabular}{l|l|l} 
Precio unitario ( $€$ HT por tren-km) & Trenes con tracción eléctrica & 0,226
\end{tabular}

Tabla 118. Canon por suministro de energía eléctrica para tracción trenes de viajeros SNCF.

\begin{tabular}{|l|c|l|c|}
\hline \multicolumn{4}{|c|}{ Canon de Acceso } \\
\hline \multicolumn{4}{|c|}{ Sólo aplicable para trenes regionales de viajeros (TER y Transilien) y trenes TET en $€$ HT } \\
\hline Alsace & 53.018 .872 & Limousin & 47.622 .936 \\
\hline Aquitaine & 75.318 .375 & Lorraine & 79.798 .662 \\
\hline Auvergne & 80.294 .902 & Midi-Pyrénées & 88.860 .102 \\
\hline Basse-Normandie & 35.279 .814 & Nord-Pas-de-Calais & 83.140 .231 \\
\hline Bourgogne & 76.297 .398 & Pays de la Loire & 72.077 .283 \\
\hline Bretagne & 63.246 .213 & Picardie & 76.127 .891 \\
\hline Centre & 89.829 .330 & Poitou-Charentes & 42.541 .526 \\
\hline Champagne-Ardenne & 55.487 .948 & $\begin{array}{l}\text { Provence - Alpes - } \\
\text { Côte d'Azur }\end{array}$ & 68.649 .539 \\
\hline Franche-Comté & 42096086 & Rhône-Alpes & 164.418 .921 \\
\hline Haute-Normandie & 39.897 .315 & STIF (Transilien) & 151.923 .825 \\
\hline Languedoc-Roussillon & 48.065 .534 & Etat (TET) & 440.488 .076 \\
\hline
\end{tabular}

Tabla 119. Canon de Acceso SNCF. 


\begin{tabular}{|c|c|c|c|c|c|}
\hline \multicolumn{6}{|c|}{ Canon por Reserva para trenes de mercancías } \\
\hline \multicolumn{6}{|c|}{ 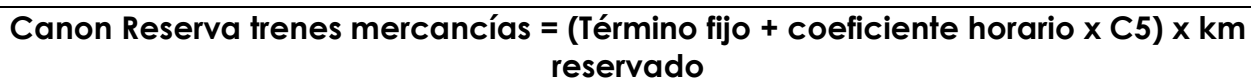 } \\
\hline \multicolumn{6}{|c|}{ Precio del kilómetro reservado en $€$ por surco-kilómetro } \\
\hline \multirow{2}{*}{ Tipo de línea } & \multirow{2}{*}{$\begin{array}{l}\text { Clase } \\
\text { tarifa }\end{array}$} & \multirow{2}{*}{$\begin{array}{l}\text { Término } \\
\text { fijo }\end{array}$} & \multicolumn{3}{|c|}{ Coeficiente horario } \\
\hline & & & HC & $\mathrm{HN}$ & HP \\
\hline \multirow{9}{*}{$\begin{array}{c}\text { Líneas } \\
\text { convencionales } \\
\text { (LC) }\end{array}$} & A & 0,019 & 2,475 & 6,735 & 19,478 \\
\hline & $\mathrm{B}$ & 0,019 & 1,004 & 1,939 & 4,388 \\
\hline & $\mathrm{C}$ & 0,019 & 1,004 & 1,004 & 2,074 \\
\hline & C-GV & 0,019 & 1,004 & 1,004 & 2,074 \\
\hline & D & 0,000 & 0,013 & 0,068 & 0,068 \\
\hline & D-GV & 0,000 & 0,013 & 0,068 & 0,068 \\
\hline & D-pr & 0,000 & 0,013 & 0,068 & 0,068 \\
\hline & E & 0,000 & 0,000 & 0,006 & 0,006 \\
\hline & E-pr & 0,000 & 0,000 & 0,006 & 0,006 \\
\hline \multirow{10}{*}{$\begin{array}{l}\text { Líneas de alta } \\
\text { velocidad (LGV) }\end{array}$} & SE-1 & 1,378 & 7,998 & 16,283 & 19,852 \\
\hline & SE-2 & 1,378 & 1,871 & 7,284 & 10,427 \\
\hline & ATL-1 & 1,378 & 7,998 & 16,283 & 19,852 \\
\hline & ATL-2 & 1,378 & 1,871 & 7,284 & 10,427 \\
\hline & NOR-1 & 1,378 & 7,998 & 16,283 & 19,852 \\
\hline & NOR-2 & 1,378 & 1,871 & 7,284 & 10,427 \\
\hline & $\mathrm{ICO}-1$ & 1,378 & 1,342 & 3,727 & 6,285 \\
\hline & EST-1 & 1,378 & 1,191 & 3,331 & 5,740 \\
\hline & EST-2 & 1,378 & 0,595 & 1,666 & 2,870 \\
\hline & $\mathrm{RH}-\mathrm{l}$ & 1,378 & 1,758 & 3,516 & 5,275 \\
\hline
\end{tabular}

Tabla 120. Coeficientes para el cálculo del canon por reserva en trenes de mercancías SNCF.

Coeficiente C5

L=Longitud del surco, $V=$ velocidad.

\begin{tabular}{|c|c|}
\hline$L \leq 300 \mathrm{~km} \circ \mathrm{V}<70 \mathrm{~km} / \mathrm{h}$ & 0,60 \\
\hline $\mathrm{L}>300 \mathrm{~km}, 70 \mathrm{~km} / \mathrm{h} \leq \mathrm{V}<85 \mathrm{~km} / \mathrm{h}$ & 1,00 \\
\hline $\mathrm{L}>300 \mathrm{~km}, 85 \mathrm{~km} / \mathrm{h} \leq \mathrm{V}<105 \mathrm{~km} / \mathrm{h}$ & 1,15 \\
\hline $\mathrm{L}>300 \mathrm{~km}, 105 \mathrm{~km} / \mathrm{h} \leq \mathrm{V}$ & 1,30 \\
\hline
\end{tabular}

Tabla 121. Coeficiente C5 a aplicar a trenes de mercancías por líneas convencionales SNCF.

\begin{tabular}{|c|c|c|}
\hline \multicolumn{3}{|c|}{ Canon por Circulación para trenes de mercancías } \\
\hline \multicolumn{3}{|c|}{ Canon por circulación = PKC $\mathbf{x ~ k m}$ circulado } \\
\hline PKC (€ HT por tren-km) & Trenes de mercancías y trenes sin carga & 0,601 \\
\hline
\end{tabular}

Tabla 122. Coeficientes para el cálculo del canon por circulación trenes de mercancías SNCF.

Canon por suministro de energía eléctrica para tracción trenes de mercancías Canon por suministro de energía eléctrica para tracción = PU x km circulado \begin{tabular}{|l|l|l}
\hline Precio unitario (€ HT por tren-km) & Trenes con tracción eléctrica & 0,226
\end{tabular} Tabla 123. Canon por suministro de energía eléctrica tracción trenes de mercancías SNCF. 
Grecia.

La red ferroviaria griega gestionada por OSE tiene una longitud de 2.265 kilómetros, de los cuales el $80 \%$ corresponden al ancho de $1.435 \mathrm{~mm}$ discurriendo por ella el corredor de mercancías 7.

El cálculo del canon se realiza diferenciando la línea por la que se circula mediante el coeficiente $\mathbf{k}_{\mathbf{q}}$, coeficiente de calidad que se obtiene según la siguiente tabla:

\begin{tabular}{|c|l|c|}
\hline \multicolumn{2}{|c|}{ Línea/Tramo } & $\boldsymbol{k}_{\mathbf{q}}$ \\
\hline A & Piraeus -Thessaloniki & 0,57 \\
\hline A1 & Piraeus-Athens (Larissa RS) & 0,73 \\
\hline A2 & Athens (Larissa R.S.) - Inoi & 0,90 \\
\hline A3 & Inoi - Tithorea & 0,75 \\
\hline A4 & Tithorea - Domokos & 0,88 \\
\hline A5 & Domokos - Thessaloniki & \\
\hline B & Thessaloniki - Alexandroupoli - Or- menio & 0,76 \\
\hline B1 & Thessaloniki - Alexandroupoli & 0,65 \\
\hline B2 & Alexandroupoli - Ormenio & 0,67 \\
\hline B3 & Thessaloniki - Idomeni & 0,59 \\
\hline B4 & Strymonas - Promahonas & $\mathbf{0 , 7 3}$ \\
\hline C & Thessaloniki - Kozani - Florina & $\mathbf{0 , 7 6}$ \\
\hline D & Paleofarsalos - Kalambaka & $\mathbf{0 , 7 4}$ \\
\hline E & Larissa - Volos & $\mathbf{0 , 6 8}$ \\
\hline F & Inoi - Halkida & $\mathbf{0 , 8 8}$ \\
\hline G & Corinth-SKA - Airport & $\mathbf{0 , 5 3}$ \\
\hline H & Metrical network & \\
\hline I & Diakopto - Kalavryta & \\
\hline
\end{tabular}

Tabla 124. Coeficiente $k_{q}$ según línea/tramo OSE. 
Así mismo se categoriza el tráfico según el periodo horario en el que se realiza la circulación, en función de la hora de salida de las composiciones, obteniéndose el valor del coeficiente $\mathbf{L}_{\mathbf{2}}$ y según estaciones según las tablas adjuntas:

\begin{tabular}{|c|c|c|c|c|}
\hline & Punta & Normal & Valle & $\begin{array}{c}\text { Circulación } \\
\text { fuera de } \\
\text { horario punta }\end{array}$ \\
\cline { 2 - 5 } & 1 & $\|$ & 111 & VV \\
\hline L2 & 1,2 & 1,1 & 0,9 & 0,7 \\
\hline
\end{tabular}

Tabla 125. Coeficiente $L_{2}$ según periodo horario.

\begin{tabular}{|c|c|c|c|}
\hline Estación & Punta & Normal & Valle \\
\hline ATHENS & $\begin{array}{l}06.00-10.00 \\
14.00-18.00 \\
20.00-23.00\end{array}$ & $\begin{array}{l}05.00-06.00 \\
10.00-14.00 \\
18.00-20.00 \\
23.00-00.00\end{array}$ & $00.00-05.00$ \\
\hline CHALKIS & $\begin{array}{l}06.00-08.00 \\
21.00-23.00\end{array}$ & $\begin{array}{l}08.00-10.00 \\
14.00-21.00\end{array}$ & $\begin{array}{l}00.00-06.00 \\
10.00-14.00 \\
23.00-24.00\end{array}$ \\
\hline LIANOKLADI & & $\begin{array}{l}01.00-04.00 \\
08.00-14.00 \\
17.00-22.00\end{array}$ & $\begin{array}{l}00.00-01.00 \\
04.00-08.00 \\
14.00-17.00 \\
22.00-24.00\end{array}$ \\
\hline PALAIOFARSALOS & & $\begin{array}{l}04.00-08.00 \\
10.00-15.00 \\
17.00-22.00\end{array}$ & $\begin{array}{l}00.00-04.00 \\
08.00-10.00 \\
15.00-17.00 \\
22.00-24.00\end{array}$ \\
\hline KALAMPAKA & & $\begin{array}{l}07.00-09.00 \\
16.00-18.00\end{array}$ & $\begin{array}{l}00.00-07.00 \\
09.00-16.00 \\
18.00-24.00\end{array}$ \\
\hline LARISSA & $\begin{array}{l}07.00-10.00 \\
13.30-17.30\end{array}$ & $\begin{array}{l}06.00-07.00 \\
10.00-13.30 \\
17.30-18.30\end{array}$ & $\begin{array}{l}00.00-06.00 \\
18.30-24.00\end{array}$ \\
\hline VOLOS & & $\begin{array}{l}06.00-09.00 \\
15.00-20.00\end{array}$ & $\begin{array}{l}00.00-06.00 \\
09.00-15.00 \\
20.00-24.00\end{array}$ \\
\hline
\end{tabular}




\begin{tabular}{|c|c|c|c|}
\hline THESSALONIKI & $\begin{array}{l}06.00-09.00 \\
11.00-13.00 \\
15.00-19.00\end{array}$ & $\begin{array}{l}05.00-06.00 \\
09.00-11.00 \\
13.00-15.00 \\
19.00-20.00\end{array}$ & $\begin{array}{l}00.00-05.00 \\
20.00-24.00\end{array}$ \\
\hline SERRES & & & $00.00-24.00$ \\
\hline DRAMA & & & $00.00-24.00$ \\
\hline ALEXANDROUPOLIS & $\begin{array}{l}08.30-13.30 \\
15.30-20.30\end{array}$ & $\begin{array}{l}07.00-08.30 \\
13.30-15.30 \\
20.30-21.30\end{array}$ & $\begin{array}{l}00.00-07.00 \\
21.30-24.00\end{array}$ \\
\hline DIKAIA & & & $00.00-24.00$ \\
\hline EDESSA & $17.00-22.00$ & $\begin{array}{l}16.00-17.00 \\
22.00-23.00\end{array}$ & $\begin{array}{l}00.00-16.00 \\
23.00-24.00\end{array}$ \\
\hline
\end{tabular}

Tabla 126. Periodos horarios en estaciones OSE.

\begin{tabular}{|c|c|c|c|}
\hline Estación & Punta & Normal & Valle \\
\hline PATRA & $\begin{array}{l}09.00-13.00 \\
15.00-19.30\end{array}$ & $\begin{array}{l}08.00-09.00 \\
13.00-15.00 \\
19.30-20.30\end{array}$ & $\begin{array}{l}00.00-08.00 \\
20.30-24.00\end{array}$ \\
\hline PYRGOS & & $\begin{array}{l}06.00-08.30 \\
13.00-16.00\end{array}$ & $\begin{array}{l}00.00-06.00 \\
08.30-13.00 \\
16.00-24.00\end{array}$ \\
\hline OLYMPIA & & & $00.00-24.00$ \\
\hline KYPARISSIA & & $\begin{array}{l}06.00-07.00 \\
13.00-17.00\end{array}$ & $\begin{array}{l}00.00-06.00 \\
07.00-13.00 \\
17.00-24.00\end{array}$ \\
\hline KALAMATA & $\begin{array}{l}08.00-12.00 \\
18.30-22.30\end{array}$ & $\begin{array}{l}07.00-08.00 \\
12.00-18.30 \\
22.30-23.30\end{array}$ & $\begin{array}{l}00.00-07.00 \\
23.30-24.00\end{array}$ \\
\hline
\end{tabular}

Tabla 127. Periodos horarios en estaciones de ancho métrico OSE. 
Para el cálculo del canon se utiliza una variable $\mathbf{L}_{\mathbf{1}}$, definida por el cociente entre el tiempo real empleado en un trayecto y el tiempo ideal para dicho trayecto. Este tiempo ideal está referenciado en la tabla adjunta en función del tramo utilizado por la circulación:

\begin{tabular}{|c|l|c|}
\hline Categoría & \multicolumn{1}{|c|}{ Tramo } & $\begin{array}{c}\text { Tiempo ideal } \\
\text { (hh:mm) }\end{array}$ \\
\hline A & Piraeus - Thessaloniki & $0: 15$ \\
\hline A 1 & Piraeus - Athens (Larissa R.S.) & $0: 42$ \\
\hline A2 & Athens (Larissa R.S.) - Inoi & $0: 37$ \\
\hline A3 & Inoi - Tithorea & $1: 34$ \\
\hline A4 & Tithorea - Domokos & $1: 34$ \\
\hline A5 & Domokos - Thessaloniki \\
\hline B & Thessaloniki - Alexandroupoli - Ormenio \\
\hline B1 & Thessaloniki - Alexandroupoli & $4: 31$ \\
\hline B2 & Alexandroupoli - Ormenio & $2: 28$ \\
\hline B3 & Thessaloniki - Idomeni & $0: 56$ \\
\hline B4 & Strymonas - Promahonas & $0: 12$ \\
\hline C & Thessaloniki - Kozani / Florina & $2: 15$ \\
\hline D & Paleofarsalos - Kalambaka & $0: 45$ \\
\hline E & Larissa - Volos & $0: 55$ \\
\hline F & Inoi - Halkida & $0: 23$ \\
\hline G & SKA - Airport SKA & $0: 28$ \\
\hline Corinth & $0: 57$ \\
\hline H1 & Metrical network & \\
\hline H3 & Corinth - Patra & $1: 40$ \\
\hline H4 & Patra - Pyrgos & $1: 52$ \\
\hline H5 & Pyrgos - Kyparissia & $1: 32$ \\
\hline H6 & Kyparissia - Kalamata & $1: 10$ \\
\hline I & Diakopto - Kalavryta & $1: 30$ \\
\hline & \multicolumn{2}{|c|}{ Taba 1:10 Iempo } \\
\hline
\end{tabular}

Tabla 128. Tiempo ideal por tramos OSE.

$$
L_{1}=\frac{\text { Tiempo real empleado en la circulación }}{\text { Tiempo ideal }} \geq 1
$$

Para determinar el coste por uso de la infraestructura se tienen en cuenta criterios como la velocidad, la composición del tren (número de ejes) así 
como la carga por eje, obteniéndose el coeficiente ktrain. Las tablas siguientes muestran los valores de dichas variables para la obtención del ktrain.

\begin{tabular}{|c|c|c|}
\hline Categoría del tren & Velocidad $(\mathrm{km} / \mathrm{h})$ & Carga por eje (T) \\
\hline$\Sigma 1$ & \multirow{5}{*}{$<=120$} & $<14,3$ \\
\hline$\Sigma 2$ & & $14,4-16,3$ \\
\hline$\Sigma 3$ & & $16,4-18,4$ \\
\hline$\Sigma 4$ & & $18,5-20,4$ \\
\hline$\Sigma 5$ & & $20,5-22,9$ \\
\hline$\Sigma 6$ & \multirow{5}{*}{$121-140$} & $<14,3$ \\
\hline$\Sigma 7$ & & $14,4-16,3$ \\
\hline$\Sigma 8$ & & $16,4-18,4$ \\
\hline$\Sigma 9$ & & $18,5-20,4$ \\
\hline$\Sigma 10$ & & $20,5-22,9$ \\
\hline$\Sigma 11$ & \multirow{5}{*}{$141-160$} & $<14,3$ \\
\hline$\Sigma 12$ & & $14,4-16,3$ \\
\hline$\Sigma 13$ & & $16,4-18,4$ \\
\hline$\Sigma 14$ & & $18,5-20,4$ \\
\hline$\Sigma 15$ & & $20,5-22,9$ \\
\hline$\Sigma 16$ & \multirow{5}{*}{$161-200$} & $<14,3$ \\
\hline$\Sigma 17$ & & $14,4-16,3$ \\
\hline$\Sigma 18$ & & $16,4-18,4$ \\
\hline$\Sigma 19$ & & $18,5-20,4$ \\
\hline$\Sigma 20$ & & $20,5-22,9$ \\
\hline
\end{tabular}

Tabla 129. Categoría del tren OSE. 


\begin{tabular}{|c|c|c|}
\hline Categoría del tren & Velocidad $(\mathbf{k m} / \mathbf{h})$ & Carga por eje $(\mathbf{T})$ \\
\hline$\Sigma M 1$ & $<120$ & $<12,2$ \\
\hline$\Sigma M 2$ & $120-140$ & $12,3-16,3$ \\
\hline
\end{tabular}

Tabla 130. Categoría del tren ancho métrico OSE.

El canon básico se deduce de la suma del canon PTM que corresponde a la gestión del tráfico y el canon PLM que corresponde al mantenimiento de la línea mediante las siguientes expresiones:

$$
P=P T M+P L M
$$

El canon PTM se obtiene mediante la siguiente expresión:

$$
P T M=B V_{T M} * L_{1} * L_{2}
$$

Siendo:

PTM: Canon por gestión de tráfico.

$B V_{T M}$ : Coste marginal base por gestión de tráfico $(0,65 € / \mathrm{km})$.

$L_{1}:$ Coeficiente de ocupación del surco.

L2: Coeficiente de periodo horario "punta".

El canon PLM se obtiene mediante la siguiente expresión:

$$
P L M=B V_{L M} * k_{q} * k_{\text {train }}
$$

Siendo:

PLM: Canon por mantenimiento.

$B V_{L M}$ : Coste marginal base por mantenimiento $(0,40 € / \mathrm{km})$.

$k_{q}$ : Coeficiente de calidad de la línea.

ktrain: Coeficiente por tipo de tren.

Hungría.

Según el párrafo 2 del punto 4.12 de la Ley de Ferrocarriles, los administradores de infraestructuras son: MÁV Magyar Államvasutak Zártkörüen Működő Részvénytársaság (en lo sucesivo, MÁV Zrt) y GyörSopron-Ebenfurti Vasút Zártkörűen Működő Részvénytársaság (en lo sucesivo, GySEV Zrt). En 2004 se estableció la Oficina de Asignación de Capacidad 
(VPE) ${ }^{50}$. VPE es independiente de las empresas ferroviarias y los administradores de infraestructuras, y tiene competencia a nivel nacional en la asignación de capacidad de la red ferroviaria y en la determinación de las tarifas de acceso a la red. VPE es propiedad exclusiva de la República de Hungría.

El canon de acceso a la infraestructura varía dependiendo del administrador, siendo sus cuantías las siguientes:

\begin{tabular}{|c|c|}
\hline Administrador ferroviario & Canon (HUF51/tren reservado) \\
\hline MÁV Zr† & 586 \\
\hline GYSEV Zrt & 437 \\
\hline \multicolumn{2}{|c|}{ Tabla 131. Canon por reserva de capacidad MÁV Zrt- GYSEV Zrt }
\end{tabular}

El canon por uso de la infraestructura también varía dependiendo del administrador, tipo de tren, categoría de la línea y carga transportada según las tablas siguientes:

\begin{tabular}{|l|c|c|c|}
\hline \multirow{2}{*}{\multicolumn{2}{|c|}{ MÁV Zrt }} & \multicolumn{3}{|c|}{ Categoría de la línea } \\
\cline { 2 - 4 } & \multicolumn{3}{|c|}{ Canon (HUF/tren km) } \\
\cline { 2 - 4 } & Categoría I & Categoría II & Categoría III \\
\hline Trenes de viajeros & 386 & 338 & 127 \\
\hline Trenes de mercancías & 397 & 374 & 202 \\
\hline Locomotoras & 369 & 366 & 362 \\
\hline
\end{tabular}

Tabla 132. Canon por categoría de la línea y tipo de tren MÁV Zrt.

\begin{tabular}{|c|c|}
\hline Tipo de tren & Canon por tonelada kilómetro (HUF) \\
\hline Trenes de viajeros & 0,24 \\
\hline Trenes de mercancías & \\
\hline Locomotoras & \\
\hline
\end{tabular}

Tabla 133. Canon por tonelada kilómetro y tipo de tren MÁV Zrt.

La red administrada por GYSEV Zrt aplica por tren kilómetro según la tabla adjunta los siguientes importes:

\begin{tabular}{|c|c|c|c|}
\hline \multirow{2}{*}{ GYSEV Zrt } & \multicolumn{3}{|c|}{ Categoría de la línea } \\
\cline { 2 - 4 } & \multicolumn{3}{|c|}{ Canon (HUF/tren km) } \\
\cline { 2 - 4 } & Categoría I & Categoría II & Categoría III \\
\hline Trenes de viajeros & 277 & 264 & 100 \\
\hline Trenes de mercancías & 270 & 262 & 100 \\
\hline Locomotoras & 316 & 264 & 100 \\
\hline
\end{tabular}

Tabla 134. Canon por categoría de la línea y tipo de tren GYSEV Zrt.

${ }^{50}$ En virtud de la Ley de 1993 de Ferrocarriles.

${ }^{51}$ Florines húngaros. 
La red administrada por GYSEV Zrt aplica por tonelada kilómetro transportada según la tabla adjunta los siguientes valores:

\begin{tabular}{|l|c|}
\hline \multicolumn{1}{|c|}{ Tipo de tren } & Canon por tonelada kilómetro (HUF) \\
\cline { 1 - 1 } Trenes de viajeros & \\
\cline { 1 - 1 } Trenes de mercancías & 0,23 \\
\hline Locomotoras & \\
\hline
\end{tabular}

Tabla 135. Canon por tonelada kilómetro y tipo de tren GYSEV Zrt.

Italia.

La Rete Ferroviaria Italiana SpA (RFI) quedó establecida mediante el programa de reorganización del Grupo FS el 1 de julio 2001. Está autorizada por el Gobierno para operar como servicio nacional de transporte por ferrocarril público, así como administrador de la infraestructura nacional, bajo una única licencia emitida por el Ministerio de Infraestructura y Transporte.

El canon por uso de la infraestructura se obtiene según las tablas siguientes:

\begin{tabular}{|c|c|c|c|}
\hline \multicolumn{2}{|c|}{ Categoría de la línea } & Canon de acceso $(\epsilon)$ & Canon por uso $(\epsilon)$ \\
\hline \multirow{3}{*}{$\begin{array}{l}\text { Línea } \\
\text { compleme } \\
\text { ntaria }\end{array}$} & Secundaria & 47,9319 (€/línea) & \multirow{3}{*}{$1,0312(€ / \mathrm{km}) * \mathrm{~km}$} \\
\hline & Tráfico medio & 23,9660 ( $€$ /línea) & \\
\hline & Tráfico bajo & 0,00 & \\
\hline \multicolumn{2}{|c|}{ Línea principal } & $50,5925 / 66,5767$ (€/línea) & $\begin{array}{c}1,0312(€ / \mathrm{km}){ }^{*} \mathrm{~km}^{*} \\
\left(M_{\text {velocidad }} M_{\text {densidad }+M u s o}\right. \\
/ 3\end{array}$ \\
\hline \multicolumn{2}{|l|}{ Nudo } & 53,2634 & $1,0312(€ / \min ){ }^{*} \min ^{*} \psi^{*}$ \\
\hline
\end{tabular}

Tabla 136. Cánones de acceso y de uso RFI.

Según la tabla anterior el canon por uso se calcula mediante el producto de un precio unitario, de los kilómetros y de los coeficientes " $M$ " que se obtienen dependiendo de la velocidad, de la densidad de la línea y del uso.

En la tabla siguiente se muestran los valores de dichos coeficientes: 


\begin{tabular}{|c|c|c|c|c|c|}
\hline \multicolumn{2}{|c|}{$\begin{array}{l}\text { Velocidad } \\
\begin{array}{l}\text { Pvelocità }=\mid \text { Vel. comm. }- \text { Vel. omot. } \mid / \text { Velocità } \\
\text { mot. }\end{array} \\
\text { Vel. Omot. } \rightarrow \text { vedi Appendice D Tab. } 6\end{array}$} & \multicolumn{2}{|c|}{$\begin{array}{c}\text { Densidad } \\
\text { Mdensità } \rightarrow \text { vedi Appendice D Tab. } 7 \\
\text { Pdensità } \rightarrow \text { All. Tec. } 10 \text { DM 43/T/2000 }\end{array}$} & \multicolumn{2}{|c|}{$\begin{array}{c}\text { Uso } \\
\text { Pusura }=\left[0,85 \cdot(\text { VEL2 } \cdot \text { PESO })+0,15 \cdot\left(\text { VEL } \cdot n^{\circ} \text { pant. }\right)\right] \\
2.720 .012\end{array}$} \\
\hline IPvelocità & Mvelocità & Pdensità & Mdensità & Pusura & Musura \\
\hline $0 \div 0,2$ & 1,0 & $<50 \%$ & 0,3 & $0 \div 0,8$ & 0,7 \\
\hline $0,2 \div 0,5$ & 1,3 & $50 \% \div 75 \%$ & 1,0 & $0,8 \div 1,2$ & 1,0 \\
\hline $0,5 \div 1$ & 3,0 & $>75 \%$ & 1,5 & $1,2 \div 2$ & 1,8 \\
\hline$>1$ & 5,0 & & & $>2$ & 3,5 \\
\hline
\end{tabular}

Tabla 137. Cálculo de coeficientes "M" para obtener el canon por uso RFI.

Las estaciones principales del nudo a fin del cálculo de " $\psi$ " son las siguientes:

\begin{tabular}{|c|c|}
\hline Nudo & Estación \\
\hline TORINO & TO PORTA NUOVA \\
\hline MILANO & MI CENTRALE \\
\hline VENEZIA & VE S. LUCIA, solo nel caso di fermata con sosta \\
\hline GENOVA & nessuna \\
\hline BOLOGNA & nessuna \\
\hline FIRENZE & FI S. M. NOVELLA \\
\hline ROMA & RM TERMINI \\
\hline NAPOLI & NA CENTRALE \\
\hline
\end{tabular}

Tabla 138. Estaciones de nudo para el cálculo de " $\psi$ " RFI. 
El coeficiente horario " $\varphi$ " se obtiene a través de la siguiente tabla:

\begin{tabular}{|c|c|}
\hline Periodo horario & Coeficiente $\boldsymbol{\varphi}$ \\
\hline $22: 00-6: 00$ & 0,8 \\
\hline $6: 00-9: 00$ & 1,3 \\
\hline $9: 00-22: 00$ & 1,0 \\
\hline
\end{tabular}

Tabla 139. Coeficiente horario " $\varphi$ " RFI.

Lituania.

Lietuvos geležinkeliai $A B$ es la empresa pública que administra la red ferroviaria de Lituania. Está formada por $1.745,8 \mathrm{~km}$ con ancho de $1.520 \mathrm{~mm}$. y $122 \mathrm{~km}$. con ancho de $1.435 \mathrm{~mm}$.

Las tarifas de los cánones se muestran en la tabla siguiente:

\begin{tabular}{|c|c|c|}
\hline \multicolumn{2}{|c|}{ Cánones que forman el paquete mínimo de acceso } & Tarifas \\
\hline \multicolumn{2}{|c|}{ Canon Reserva de capacidad } & $1,4886 € /$ tren-km. \\
\hline \multicolumn{2}{|l|}{ Canon por circulación. } & $0,0018 € /$ GTK \\
\hline \multicolumn{2}{|l|}{ Canon por viajeros. } & $0,0052 € /$ GTK \\
\hline \multicolumn{2}{|l|}{ Canon por mercancías. } & $0,0090 € /$ NTK \\
\hline \multirow{4}{*}{$\begin{array}{l}\text { Canon por manipulación de } \\
\text { mercancías. }\end{array}$} & TEU's & $0 € /$ NTK \\
\hline & $\begin{array}{l}\text { Mercancías } \\
\text { peligrosas }\end{array}$ & $0,0194 € /$ NTK \\
\hline & $\begin{array}{l}\text { Mercancía de } \\
\text { bajo valor }\end{array}$ & $0 € /$ NTK \\
\hline & Otras & $0,0036 € /$ NTK \\
\hline \multicolumn{2}{|c|}{ Canon por uso de la línea aérea de contacto. } & $0,5725 € /$ tren-km \\
\hline
\end{tabular}

Tabla 140. Cánones que forman el paquete mínimo de acceso Lietuvos geležinkeliai AB.

Como se puede observar en la declaración de la red de Lietuvos geležinkeliai $A B$ son precios fijados sin detallar las variables que forman los componentes del canon. 
Luxemburgo.

La infraestructura ferroviaria de Luxemburgo es administrada por el estado de Luxemburgo por la Société Nationale des Chemins de Fer Luxembourgeois (CFL), de conformidad con la Ley modificada de 10 de mayo de 1995 relativa a la infraestructura ferroviaria y los contratos de gestión de infraestructura firmado el 7 de mayo de 2009 (Reglamento del Gran Ducado de 6 de noviembre de 2009).

El canon por los servicios mínimos de acceso es igual al coste directo por la operación del servicio ferroviario y una tarifa relacionada con las capacidades. Incluye los siguientes elementos:

- Un elemento asociado a la tramitación administrativa de la solicitud de capacidad:

Para los surcos regulares, esta cuota cubre el tratamiento administrativo asociado a la solicitud para un surco reservado para un período determinado de tiempo. En el caso de solicitud de surcos extraordinarios o modificados, el canon cubre el tratamiento administrativo asociado a la solicitud del surco calculado para cada tren por separado.

- Un elemento relacionado con el uso de la vía.

- Un elemento asociado a las capacidades en las secciones que se declaren congestionadas y son atravesadas por la circulación durante los períodos de saturación.

Para su cálculo se aplica la siguiente expresión:

$$
U=A+C+S
$$

Siendo:

U: Canon de utilización de la vía del tren (€ /surco).

A: Canon por tratamiento administrativo de reserva de capacidad (€ / surco).

C: canon de utilización del surco (€ / surco).

S: Canon por utilización de tramos congestionados (€/surco). 
El coste de reserva de capacidad (A) realiza una distinción entre tres tipos de surcos solicitados según la tabla siguiente:

\begin{tabular}{|c|c|}
\hline Tipo de surco & $\boldsymbol{\epsilon} /$ tren surco \\
\hline Regulares & 110,14 \\
\hline Modificados & 9,15 \\
\hline Extraordinarios & 18,31 \\
\hline
\end{tabular}

Tabla 141.Canon por tratamiento administrativo de la reserva de capacidad ACF.

En cuanto al canon asociado directamente con el coste de operación (C), llamado "huella de desgaste", se calcula sobre la base del producto de un precio por unidad, el recorrido del tren, un factor asociado con el peso del tren y un factor asociado con el tipo de tren en cuestión, según la expresión siguiente:

$$
C=C^{*} L^{*} \varphi i^{*} \beta j
$$

Siendo:

c: Coste por unidad asociada con el uso del surco $(€ / \mathrm{km})$ siendo de 1,756 $€ / \mathrm{km}$-tren.

L: Longitud total del surco ( $\mathrm{km})$.

पi: Factor de modulación relacionado con el peso total (tren + carga remolcada) en trenes de mercancías y locomotoras aisladas y el número de coches para trenes de viajeros. En las tablas siguientes se muestran los factores a aplicar.

\begin{tabular}{|c|c|}
\hline \multicolumn{2}{|c|}{ Trenes de Mercancías } \\
\hline Rango de peso (T) & $\boldsymbol{\varphi i}$ \\
\hline $0-400$ & 0,8528 \\
\hline $400-800$ & 1,1858 \\
\hline $800-1.200$ & 1,3822 \\
\hline $1.200-1.600$ & 1,5290 \\
\hline $1.600-2.000$ & 1,6487 \\
\hline $2.000-2.400$ & 1,7510 \\
\hline $2.400-2.800$ & 1,8410 \\
\hline $2.800-3.200$ & 2,0510 \\
\hline $3.200-3.600$ & 2,2276 \\
\hline $3.600-4.000$ & 2,4503 \\
\hline$>4.000$ & 2,6954 \\
\hline
\end{tabular}

Tabla 142. Factor pi para trenes de mercancías para el cálculo del coste de operación ACF. 


\begin{tabular}{|c|c|}
\hline & \multicolumn{2}{|c|}{ Locomotoras aisladas } \\
\hline Media de peso (T) & $\boldsymbol{\varphi i}$ \\
\hline 1.000 & 0,6927 \\
\hline
\end{tabular}

Tabla 143. Factor pi para locomotoras aisladas para el cálculo del coste de operación ACF.

\begin{tabular}{|c|c|}
\hline \multicolumn{2}{|c|}{ Trenes de Viajeros remolcados } \\
\hline Número de coches & $\boldsymbol{\varphi} \mathbf{i}$ \\
\hline $1-2$ & 0,7823 \\
\hline $3-4$ & 0,8894 \\
\hline $5-6$ & 1,000 \\
\hline $7-8$ & 1,0877 \\
\hline$>8$ & 1,1615 \\
\hline
\end{tabular}

Tabla 144. Factor pi para trenes de viajeros remolcados para el cálculo del coste de operación ACF.

\begin{tabular}{|c|c|}
\hline \multicolumn{2}{|c|}{ Trenes de Viajeros Autopropulsados } \\
\hline Número de coches & $\boldsymbol{\varphi} \mathbf{i}$ \\
\hline $1-2$ & 0,6927 \\
\hline $3-4$ & 0,8894 \\
\hline $5-6$ & 1,0173 \\
\hline $7-8$ & 1,1159 \\
\hline$>8$ & 1,1975 \\
\hline
\end{tabular}

Tabla 145. Factor pi para trenes de viajeros autopropulsados para el cálculo del coste de operación ACF.

Bj: Factor de modulación relacionado con la categoría de tren. Las categorías de tren y el valor correspondiente del factor se definen en función de las cargas por eje, la velocidad media y el nivel de servicio requerido por las diferentes categorías. Se hace una distinción entre las siguientes categorías:

\begin{tabular}{|c|c|}
\hline Tipo de Tren & $\boldsymbol{\beta j}$ \\
\hline Transporte combinado & 0,3501 \\
\hline Otros trenes de mercancías & 0,3747 \\
\hline Autopropulsados de viajeros & 1,0801 \\
\hline Trenes de viajeros con locomotora & 1,0355 \\
\hline Locomotoras aisladas & 0,4488 \\
\hline
\end{tabular}

Tabla 146.Factor ßj para el cálculo del coste de operación ACF. 
El coste por uso de surcos o tramos congestionados se calcula sobre la base de un producto de factor de congestión, la longitud de la sección declarada congestionada, unos coeficientes de rigidez y un coeficiente de tiempo de reserva.

El coeficiente de rigidez depende de la diferencia entre el funcionamiento y de la marcha del tren según se estimó sobre la base del horario de servicio.

El coeficiente de momento de la reserva depende del tiempo comprendido entre la solicitud inicial del surco realizado por la empresa ferroviaria y la fecha prevista para la primera circulación del tren en cuestión.

La expresión siguiente permite obtener el canon por uso de surcos congestionados:

$$
S=\Sigma(s i \cdot L i) \cdot Y j \cdot \delta k
$$

Siendo:

si: Factor de forma de la congestión i, para la sección declarada congestionada y utilizado por el tren durante el período de saturación (€ / km). Para secciones saturadas es de $17,46 € / \mathrm{km}$.

Li: Longitud de la sección ( $\mathrm{km})$.

yj: Coeficiente de rigidez en función del margen horario del tren propuesto por el organismo adjudicador y aceptado por la empresa ferroviaria (adimensional).

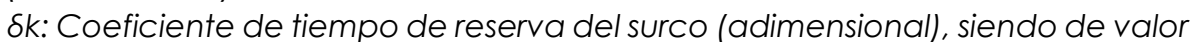
1 .

En la tabla siguiente se obtienen los coeficientes:

\begin{tabular}{|c|c|}
\hline Tiempo en minutos & Factor $\boldsymbol{Y}_{\boldsymbol{j}}$ \\
\hline$<3$ & $100 \%$ \\
\hline Entre 3 y 5 & $37,50 \%$ \\
\hline Entre 5 and 10 & $20,00 \%$ \\
\hline Entre 10 and 15 & $12,00 \%$ \\
\hline Entre 15 and 20 & $8,60 \%$ \\
\hline Entre 20 and 30 & $6,00 \%$ \\
\hline Entre 30 and 40 & $4,30 \%$ \\
\hline Entre 40 and 50 & $3,30 \%$ \\
\hline Entre 50 and 60 & $2,70 \%$ \\
\hline$>60$ & $2,50 \%$ \\
\hline
\end{tabular}

Tabla 147. Coeficiente de rigidez $\mathrm{Y}_{\mathrm{j}} \mathrm{ACF}$. 
Norvega.

Jernbaneverket (The Norwegian National Rail Administration) es el administrador de la infraestructura ferroviaria norvega. El paquete básico contiene los siguientes servicios:

- La gestión de las aplicaciones de la capacidad de infraestructura.

- Derecho a utilizar la capacidad asignada.

- El uso de vías y las conexiones entre ellas necesarias para utilizar el surco solicitado.

- El control del tráfico, incluyendo la señalización, la aplicación de procedimientos de control, mantenimiento de trenes, así como la transmisión y la recopilación de información sobre el tráfico de trenes.

- otros datos 52 necesarios para explotar el servicio.

El canon para todos los trenes que circulan por la línea Gardermoen (entre Etterstad y Gardermoen) es de 21,80 NOK/tren km. El canon de estación en la línea de Gardermoen (por tren) es el siguiente:

- Terminal aeropuerto de Oslo: 144 NOK/tren.

- Lillestrøm: 24,50 NOK/tren.

- Gardermoen: 96,80 NOK/tren.

En trenes de mercancías y trenes de transporte combinado de hasta $25 \mathrm{~T} / \mathrm{eje}$ el canon de acceso es de 0,0 NOK/tren $\mathrm{km}$. ${ }^{33}$, en los de más de $25 \mathrm{~T} / \mathrm{eje}$ el canon es de 0,045 NOK/tren km. Los trenes de viajeros están exentos del canon.

Países Bajos.

ProRail BV es una empresa privada ${ }^{44}$ sometida a las leyes holandesas que se encarga de la gestión de la infraestructura de los ferrocarriles holandeses bajo régimen de concesión.

\footnotetext{
52 Incluye todos los gráficos, rutas, documentación ruta y las normas de tráfico los cuales son emitidos por la Administración Nacional Noruega de ferrocarriles de las rutas que la empresa ferroviaria tiene permiso para operar.

${ }^{53}$ Corona noruega/tren $\mathrm{km}$.

54 ProRail BV, empresa registrada en la Cámara de Comercio de Utrecht, número 30124359
} 
En la tabla siguiente se muestran los principales corredores:

\begin{tabular}{|c|c|c|c|}
\hline \multicolumn{2}{|c|}{ Corredor } & \multirow{2}{*}{ Corredor Principal } & \multirow{2}{*}{$\begin{array}{c}\text { Parte del corredor que } \\
\text { discurre por los Países } \\
\text { Bajos }\end{array}$} \\
\hline Nombre & Número & & \\
\hline Rhine - Alpine & RFC 1 & $\begin{array}{l}\text { Zeebrugge - Antwerp / } \\
\text { Amsterdam / Vlissingen* / } \\
\text { Rotterdam - Duisburg - } \\
\text { [Basel] - Milan - Genoa }\end{array}$ & $\begin{array}{l}\text { Maasvlakte - Kijfhoek / } \\
\text { Amsterdam Westhaven / } \\
\text { Amsterdam } \\
\text { Houtrakpolder > } \\
\text { Meteren - Zevenaar } \\
\text { (border) }\end{array}$ \\
\hline $\begin{array}{l}\text { North Sea - } \\
\text { Mediterranean } \\
\text { Corridor }\end{array}$ & RFC 2 & $\begin{array}{l}\text { London* / Dunkirk* / Rijsel* / } \\
\text { Liege* / Paris* / } \\
\text { Amsterdam* - Rotterdam - } \\
\text { Zeebrugge* / Antwerp - } \\
\text { Luxembourg - Metz - Dijon } \\
\text { - Lyon / Basel - } \\
\text { Marseille }\end{array}$ & $\begin{array}{l}\text { Maasvlakte - Kijfhoek - } \\
\text { Roosendaal (border) }\end{array}$ \\
\hline $\begin{array}{l}\text { North Sea - } \\
\text { Baltic }\end{array}$ & RFC 8 & $\begin{array}{l}\text { Wilhelmshaven / } \\
\text { Bremerhaven / Hamburg / } \\
\text { Amsterdam / Rotterdam / } \\
\text { Antwerp - Aachen / Berlin } \\
\text { - Warsaw - Terespol (Polish } \\
\text { - Belarusian border) / } \\
\text { Kaunas - Riga* - Tallinn* }\end{array}$ & $\begin{array}{l}\text { Maasvlakte - } \\
\text { Kijfhoek/Amsterdam } \\
\text { Westhaven/Amsterdam } \\
\text { Houtrakpolder > Meteren } \\
- \\
\text { Zevenaar (border) }\end{array}$ \\
\hline
\end{tabular}

Tabla 148. Corredores europeos que discurren por los Países Bajos ProRail BV.

El canon por uso de infraestructura se obtiene teniendo en cuenta la carga por kilómetro tren, incluyendo el manejo de las solicitudes de reserva de capacidad, así como la información relativa a la circulación del tren. Las siguientes tablas relacionan la carga del tren con el canon a aplicar:

\begin{tabular}{|c|c|}
\hline Peso & Canon por tren-km. $(\boldsymbol{\epsilon})$ \\
\hline Hasta 120 t. & 2,4764 \\
\hline De 121 hasta 160 t. & 2,4764 \\
\hline De 161 hasta 320 t. & 2,7909 \\
\hline De 321 hasta 600 t. & 2,9346 \\
\hline De 601 hasta 1.600 t. & 2,9346 \\
\hline De 1.601 hasta 3.000 t. & 2,9346 \\
\hline Más de 3.001 t. & 3,9158 \\
\hline
\end{tabular}

Tabla 149. Canon por circulación para trenes de mercancías ProRail.

\begin{tabular}{|c|c|}
\hline Peso & Canon por tren-km. $(\boldsymbol{\epsilon})$ \\
\hline Hasta 120 t. & 0,8466 \\
\hline De 121 hasta 160 t. & 1,0595 \\
\hline De 161 hasta 320 t. & 1,3420 \\
\hline De 321 hasta 600 t. & 1,8751 \\
\hline De 601 hasta 1.600 t. & 3,0028 \\
\hline De 1.601 hasta 3.000 t. & 3,6156 \\
\hline
\end{tabular}


\begin{tabular}{l|r} 
Más de 3.001 †. & 3,9220
\end{tabular}

Tabla 150. Canon por circulación para otros trenes ProRail.

\begin{tabular}{|c|c|c|}
\hline \multirow{2}{*}{ Peso del tren y locomotoras eléctricas } & \multicolumn{2}{|c|}{ Canon básico por tren kilómetro } \\
\cline { 2 - 3 } & $\begin{array}{c}\text { Línea } \\
\text { Havenspoor }\end{array}$ & Tramo A15 \\
\hline Locomotora eléctrica & 1,38 & 2,76 \\
\hline Hasta 3.000 t. & 2,76 & 2,76 \\
\hline Más de 3.000 t. & 2,98 & 2,98 \\
\hline
\end{tabular}

Tabla 151. Canon por circulación para trenes que circulan por la línea Betuwe ProRail.

Polonia.

PKP Polskie Linie Kolejowe es el administrador del ferrocarril polaco, estando inscrito en el Registro de Empresas con el número KRS 0000037568 de 22 de agosto de 2001 por decisión legal del tribunal regional de la ciudad de Varsovia, de 21 de agosto de 2001.

Cuenta con una red ferroviaria de $18.516 \mathrm{~km}$ con un ancho de vía de 1.520 $\mathrm{mm}$.

Los corredores de transporte internacional que discurren por Polonia son:

- Corredor 5 (Báltico - Adriático): Świnoujście / Gdynia - Katowice Ostrava / Žilina -Bratislava / Vienna - / Klagenfurt - Udine - (Venice - Bologna / Ravenna) / Trieste / - Graz - Maribor - Ljubljana - Koper / Trieste.

- Corredor 8 Mar del Norte - Báltico: Wilhelmshaven / Bremerhaven / Hamburg / Amsterdam / Rotterdam / Antwerp - Aachen Hannover / Berlin - Warsaw - Terespol (Poland-Belarus border) / Kaunas - Riga - Talinn / Falkenberg - Praha / Wroclaw - Katowice Medyka (ampliación prevista en 2020).

El canon de acceso se calcula según las siguientes variables:

Categoría de la línea, teniendo en cuenta la intensidad media diaria y la velocidad permitida incluyendo las restricciones permanentes que puedan existir.

El peso bruto total de la composición, incluyendo el peso de locomotoras. 
La categoría de línea está definida por los parámetros siguientes y según el tipo de tren:

Los parámetros siguientes son aplicados para los trenes de viajeros:

\begin{tabular}{|c|c|c|c|c|c|}
\hline \multirow{2}{*}{ Parámetro } & \multicolumn{5}{|c|}{ Valor de los parámetros } \\
\cline { 2 - 6 } & $\mathbf{1}$ & $\mathbf{2}$ & $\mathbf{3}$ & $\mathbf{4}$ & $\mathbf{5}$ \\
\hline $\begin{array}{c}\text { Velocidad } \\
\text { media }\end{array}$ & $\begin{array}{c}0<\mathrm{Vmax} \\
\leq 40\end{array}$ & $\begin{array}{c}40<\mathrm{Vmax} \leq 8 \\
0\end{array}$ & $\begin{array}{c}80<\mathrm{Vmax} \leq 10 \\
0\end{array}$ & $\begin{array}{c}100<\mathrm{Vmax} \leq 1 \\
20\end{array}$ & Vmax $>120$ \\
\hline $\begin{array}{c}\text { Tráfico } \\
\text { medio de } \\
\text { trenes de } \\
\text { viajeros y } \\
\begin{array}{c}\text { mercancías } \\
\text { por km de } \\
\text { vía. }\end{array}\end{array}$ & $0<\mathrm{N} \leq 6$ & $6<\mathrm{N} \leq 10$ & $10<\mathrm{N} \leq 20$ & $20<\mathrm{N} \leq 40$ & $\mathrm{~N}>40$ \\
\hline
\end{tabular}

Tabla 152. Parámetros definitorios de la categoría de la línea para trenes de viajeros PKP.

Los parámetros para los trenes de mercancías son:

\begin{tabular}{|c|c|c|c|c|c|}
\hline \multirow{2}{*}{ Parámetro } & \multicolumn{5}{|c|}{ Valor de los parámetros } \\
\hline & 1 & 2 & 3 & 4 & 5 \\
\hline $\begin{array}{c}\text { Velocidad } \\
\text { media }\end{array}$ & $\begin{array}{c}0<V_{\max } \leq 4 \\
0\end{array}$ & $\begin{array}{c}40<V_{\text {max }} \leq 6 \\
0\end{array}$ & $\begin{array}{c}60<V_{\text {max }} \leq 8 \\
0\end{array}$ & $\begin{array}{c}80<V_{\max } \leq 10 \\
0\end{array}$ & $V \max >100$ \\
\hline $\begin{array}{c}\text { Tráfico } \\
\text { medio de } \\
\text { trenes de } \\
\text { viajeros y } \\
\text { mercancías } \\
\text { por km de } \\
\text { vía. }\end{array}$ & $0<\mathrm{N} \leq 6$ & $6<N \leq 10$ & $10<\mathrm{N} \leq 20$ & $20<N \leq 40$ & $N>40$ \\
\hline
\end{tabular}

Tabla 153. Parámetros definitorios de la categoría de la línea para trenes de mercancías PKP. 
Portugal.

Infraestructuras de Portugal (IP) es responsable de gestionar la infraestructura ferroviaria, en los campos de la construcción, mantenimiento, patrimonio, gestión de la capacidad, la gestión del tráfico y la seguridad.

El Grupo de Infraestructuras de Portugal, integra las siguientes compañías:

- IP Ingeniería.

- $\quad$ IP Telecom.

- IP Patrimonio.

Infraestructuras de Portugal participa en el Corredor Atlántico, formado por las secciones de infraestructuras ferroviarias existentes y previstas entre Sines / Setúbal / Lisboa / Aveiro / Leixões - Algeciras / Madrid / Bilbao - Burdeos / París / Le Havre / Metz, tras cruzar las fronteras de Vilar Formoso / Fuentes de Oñoro, Elvas / Badajoz e Irún / Hendaya.

El canon de acceso se calcula mediante la siguiente expresión:

$$
\mathrm{TSE}=\sum_{\mathrm{i}=1}^{\mathrm{n}} \mathrm{Ti} * \mathrm{CKi}
$$

Siendo:

TSE: Canon correspondiente al acceso mínimo a un surco.

i: Surco en cuestión.

Ti: Precio del surco o tramo según el tipo de servicio y tipo de tracción utilizado $(€)$.

CKi: Distancia en km. del surco utilizado.

El cobro del canon se realiza teniendo en cuenta toda la capacidad realmente utilizada por cada operador.

La cantidad que cada operador tiene que pagar depende del tipo de servicio y la tracción utilizado y la distancia recorrida entre el origen y destino del servicio. La cantidad total es la suma de todas las secciones cubiertas por el producto de la longitud de cada sección por la carga aplicable. 


\section{Reino Unido.}

Network Rail es una empresa que realiza operaciones de tráfico, mantenimiento y desarrollo de la red principal ferroviaria en Gran Bretaña. Además de incluir la infraestructura ferroviaria también realiza la explotación de las siguientes estaciones: Birmingham New Street - Bristol Temple Meads Edinburgh Waverley - Glasgow Central - Leeds - Liverpool Lime Street London Bridge - London Cannon Street - London Charing Cross - London Euston - London King's Cross - London Liverpool Street - London Paddington London St. Pancras International (Midland Road) - London Victoria - London Waterloo (excepto Waterloo East and Waterloo International (andenes 23 y 24) - Manchester Piccadilly - Reading.

Las estaciones restantes (aproximadamente 2.550) son gestionadas por empresas operadoras. Network Rail gestiona ocho líneas ferroviarias que son: Anglia, London North Eastern (LNE) \& East Midland, London North Western (LNW), South East, Scotland, Wales, Wessex y Western. Cada línea funciona como una unidad de negocio separada.

Los cánones y tarifas que se aplican por parte de Network Rail a las empresas ferroviarias candidatas al uso de la red son aprobados por ORR ${ }^{55}$. El ORR actúa como el regulador económico y de seguridad de la industria de ferrocarril y es independiente de gobierno, aunque bajo la supervisión del parlamento. Se encarga de aprobar el acceso de las empresas ferroviarias que quieran operar en la red.

El canon de acceso por parte de las empresas ferroviarias está determinado de forma anual, dependiendo de la línea y el día de la semana que circula la composición ferroviaria, así como si el tren está condicionado a wash-up 56 teniendo cada operador ferroviario asignada la cuantía por tren-millas recorrida (ver anexo 2).

55 OFF (Office of Rail and Road): Es la Autoridad Nacional de Seguridad (NSA) para el ferrocarril. En Gran Bretaña tiene la responsabilidad entre otras de expedir los certificados de seguridad y las autorizaciones al material rodante.

56Wash up: Durante el año, las empresas ferroviarias de pasajeros pagan un cargo equivalente a la capacidad según la carga de tráfico existente, teniendo un descuento del 25 $\%$ aplicado a la circulación en sábados y domingos. Al final del año, un reajuste (wash -up) hace que las empresas ferroviarias de pasajeros paguen una tarifa más alta por lo general, se denomina wash up, en el tráfico por encima de la línea de base. Un descuento del 33 por ciento se aplica para el tráfico en sábados y domingos. 


\begin{tabular}{|c|c|c|c|c|c|c|}
\hline \multirow[t]{2}{*}{$\begin{array}{l}\text { Operador } \\
\text { Ferroviario }\end{array}$} & \multirow[t]{2}{*}{ Servicio } & \multirow[t]{2}{*}{ Código } & $\begin{array}{c}\text { Diario } \\
\text { (Pgtwdi) }\end{array}$ & $\begin{array}{c}\text { Fin de } \\
\text { semana } \\
\text { (Pgtwei) }\end{array}$ & $\begin{array}{l}\text { Wash- } \\
\text { Up } \\
\text { (diario) }\end{array}$ & $\begin{array}{l}\text { Wash-Up } \\
\text { (fin de } \\
\text { semana) }\end{array}$ \\
\hline & & & $\begin{array}{c}\text { E/tren } \\
\text { milla }\end{array}$ & $\begin{array}{c}\text { f/tren } \\
\text { milla }\end{array}$ & $\begin{array}{l}\text { E/tren } \\
\text { milla }\end{array}$ & $\begin{array}{c}\text { E/tren } \\
\text { milla }\end{array}$ \\
\hline $\begin{array}{l}\text { Eurostar } \\
\text { International } \\
\text { Limited }\end{array}$ & GA01 & 24638004 & 0,3467 & 0,2600 & 0,7982 & 0,5348 \\
\hline $\begin{array}{l}\text { Eurostar } \\
\text { International } \\
\text { Limited }\end{array}$ & GA01 & 81001009 & 0,3467 & 0,2600 & 0,7982 & 0,5348 \\
\hline $\begin{array}{l}\text { Eurostar } \\
\text { International } \\
\text { Limited }\end{array}$ & GA01 & 81002009 & 0,3467 & 0,2600 & 0,7982 & 0,5348 \\
\hline $\begin{array}{l}\text { Eurostar } \\
\text { International } \\
\text { Limited }\end{array}$ & GA01 & 81003109 & 0,3467 & 0,2600 & 0,7982 & 0,5348 \\
\hline $\begin{array}{l}\text { Grand Central } \\
\text { (Sunderland) }\end{array}$ & ECO1 & 21755001 & 0,5410 & 0,4057 & 3,2678 & 2,1894 \\
\hline $\begin{array}{l}\text { Grand Central } \\
\text { (West Riding) }\end{array}$ & EC02 & 21756006 & 0,5401 & 0,4051 & 3,2623 & 2,1857 \\
\hline $\begin{array}{l}\text { Grand Central } \\
\text { (West Riding) }\end{array}$ & EC99 & 21755005 & 0,3105 & 0,2329 & 1,8759 & 1,2569 \\
\hline $\begin{array}{l}\text { Heathrow Express } \\
\text { Operating } \\
\text { Company } \\
\text { Limited }\end{array}$ & EEO2 & 25503003 & 1,1350 & 0,8513 & 3,5872 & 2,4035 \\
\hline $\begin{array}{l}\text { Hull Trains } \\
\text { Company } \\
\text { Limited }\end{array}$ & PFO1 & 21750001 & 0,5207 & 0,3905 & 3,1451 & 2,1072 \\
\hline
\end{tabular}

Tabla 154. Canon de acceso para trenes de viajeros condicionado a WASH UP Network Rail.

\begin{tabular}{|c|c|c|c|c|}
\hline \multirow{2}{*}{ Mercancías } & $\begin{array}{c}\text { Diario } \\
\text { (FCRmf) }\end{array}$ & $\begin{array}{c}\text { Fin de } \\
\text { semana } \\
\text { (FCRw) }\end{array}$ & $\begin{array}{c}\text { Wash-Up } \\
\text { (diario) }\end{array}$ & $\begin{array}{c}\text { Wash-Up } \\
\text { (fin de } \\
\text { semana) }\end{array}$ \\
\cline { 2 - 5 } & $\begin{array}{c}\mathbf{f} / \text { tren } \\
\text { milla }\end{array}$ & $\begin{array}{c}\mathbf{f} / \text { tren } \\
\text { milla }\end{array}$ & $\mathbf{f} /$ tren milla & $\mathbf{f} /$ tren milla \\
\hline Aplicado a todos los operadores & 0,1428 & 0,1071 & 0,8034 & 0,5383 \\
\hline
\end{tabular}

Tabla 155. Canon de acceso para trenes de mercancías Network Rail.

El canon por circulación se aplica en función del tipo de material rodante utilizado por el operador ferroviario, especificando el tipo de coche o vagón utilizado para el transporte y en la mercancía transportada. Son aplicados a nivel nacional, sin existir variaciones por área o región. 
En los anexos 3 y 4 se indica el canon por el coche o vagón utilizado en el transporte, así como el canon por mercancía transportada respectivamente.

Según el tipo de tren, viajeros o mercancías, así como para los trenes no programados, los cánones aplicados se muestran en las tablas siguientes:

\begin{tabular}{|l|c|}
\hline \multicolumn{1}{|c|}{ Tipo de vehículo } & Pence por vehículo/milla \\
\hline Locomotora & 68,21 \\
\hline Autopropulsado (motor) & 30,37 \\
\hline Autopropulsado (remolque) & 14,28 \\
\hline Coche & 12,56 \\
\hline
\end{tabular}

Tabla 156. Canon fijo para trenes de viajeros por tipo de vehículo Network Rail.

\begin{tabular}{|l|c|}
\hline \multicolumn{1}{|c|}{ Tipo de vehículo } & $\mathbf{f} / \mathbf{k g t m}$ \\
\hline Locomotoras & 5,9848 \\
\hline Vagón (carga) & 4,1759 \\
\hline Vagón (tara) & 2,1472 \\
\hline
\end{tabular}

Tabla 157. Canon fijo para trenes de mercancías por tipo de vehículo Network Rail.

\begin{tabular}{|c|c|c|}
\hline Tipo de composición & £/día ( $\leq 250$ millas). & £/día (> 250 millas). \\
\hline Con tracción diésel o eléctrica & 335,8539 & 335,8539 \\
\hline Con tracción vapor & 599,9721 & 840,1782 \\
\hline
\end{tabular}

Tabla 158. Canon para trenes no programados Network Rail.

Es de mencionar la existencia de cánones especiales aplicados a los trenes de transporte de carbón o el aplicado a los trenes que circulan por líneas exclusivas para trenes de mercancías. El canon por transporte de carbón se trata de un canon que grava este tipo de transporte.

Con la aplicación este canon se sufraga el mantenimiento de la infraestructura debido al impacto que produce el derrame del carbón sobre la misma, desde la limpieza hasta los trabajos de mantenimiento preventivo que hay que realizar en aparatos de vía. 
En la tabla siguiente se indica el canon a aplicar:

\begin{tabular}{|c|c|}
\hline Tipo de Carbón & $\mathbf{f} / \mathbf{k g t m}$ \\
\hline Carbón ESI ${ }^{57}$ & 0,4340 \\
\hline Otros carbones & 0,4340 \\
\hline
\end{tabular}

Tabla 159. Canon por transporte de carbón Network Rail.

El canon por uso exclusivo de líneas por trenes de mercancías tiene como objetivo contribuir a la recuperación de los gastos fijos asociados con las líneas solamente de mercancías (líneas usadas por empresas de ferrocarril de mercancías solamente). Sólo se aplica al tráfico ferroviario de carbón, transporte de residuos procedente de centrales nucleares y al transporte de mineral de hierro.

En el caso de carbón el canon se aplica en función del uso de este según tabla adjunta:

\begin{tabular}{|c|c|}
\hline Materia Prima & $\mathbf{f} / \mathbf{k g t m}$ \\
\hline Carbón ESI & 0,5670 \\
\hline Mineral de hierro & 0,1837 \\
\hline
\end{tabular}

Tabla 160. Canon para aplicar al transporte de carbón Network Rail.

En el caso del transporte de residuos procedentes de las centrales nucleares este canon es aplicado según el vagón utilizado en la composición del tren:

\begin{tabular}{|c|c|}
\hline Tipo de vagón (T=tara, $\mathbf{L}=$ carga) & $\boldsymbol{\mathbf { f }} \mathbf{\text { kgtm }}$ \\
\hline PFAC (T) & 0,6580 \\
\hline PFAC (L) & 0,6580 \\
\hline FNAB (T) & 0,6580 \\
\hline FNAB (L) & 0,6580 \\
\hline FNAC (T) & 0,6580 \\
\hline FNAC (L) & 0,6580 \\
\hline
\end{tabular}

Tabla 161. Canon por transporte de residuos de centrales nucleares Network Rail.

57 Carbón ESI: Carbón empleado para generación de electricidad en centrales térmicas. 
El servicio de alta velocidad es administrado por HS1 Ltd. en concesión hasta diciembre de 2040. En el año 2009 comenzaron los servicios comerciales de viajeros y a partir de 2012 servicios comerciales de mercancías. Tiene la red de alta velocidad una longitud de $109 \mathrm{~km}$ de longitud entre Londres y el Túnel del Canal de la Mancha y cuenta con cuatro estaciones, dos en Londres, St. Pancras International (estación término) y Stratford International y dos en Kent, Ebbsfleet International y Ashford International con conexiones con la red ferroviaria convencional.

El canon por uso de la infraestructura está formado por los siguientes componentes:

IRC- Recuperación parcial de la inversión.

\begin{tabular}{|l|c|c|c|c|}
\hline & $\begin{array}{c}\text { Servicios } \\
\text { Internacional } \\
\text { es desde St. } \\
\text { Pancras }\end{array}$ & $\begin{array}{c}\text { Servicios } \\
\text { convencionale } \\
\text { s desde St. } \\
\text { Pancras a } \\
\text { Ashford }\end{array}$ & $\begin{array}{c}\text { Servicios } \\
\text { convencionale } \\
\text { s desde St. } \\
\text { Pancras a } \\
\text { Springhead Jn }\end{array}$ & $\begin{array}{c}\text { Servicios } \\
\text { convencionales } \\
\text { desde St. } \\
\text { Pancras a } \\
\text { Ebbsfleet }\end{array}$ \\
\hline Unidad & 31 minutos & 31 minutos & 16.5 minutos & 14 minutos \\
\hline $\begin{array}{l}\text { IRC por } \\
\text { tren }\end{array}$ & $2.479,07$ & $2.479,07$ & $1.319,51$ & $1.119,58$ \\
\hline
\end{tabular}

Tabla 162. Canon IRC para trenes de viajeros HSI.

OMRC - Gastos de operación, mantenimiento y renovación. Este está formado por dos conceptos:

Un concepto es determinado por la ORR, por período (5 años) y la carga es calculada anualmente en base al IRP58 $+1,1 \%$. Su pago se realiza trimestralmente por adelantado en base del número de surcos planificados realizándose un ajuste al final del año con los servicios reales realizados.

El otro concepto OMRC se compone de las operaciones, los costes de mantenimiento y de renovación de infraestructura. Se pagan trimestralmente por adelantado sobre la base del número de surcos programados de forma estimada siendo al final de año ajustado por si existe cualquier diferencia entre los costes estimados y de ejecución, según tabla siguiente:

58 Items Retail Prices: Índice de precios al consumo elaborado por la Oficina Nacional de Estadística de Reino Unido. 


\begin{tabular}{|c|c|c|c|c|}
\hline & $\begin{array}{c}\text { Servicio } \\
\text { Internacional } \\
\text { desde St. } \\
\text { Pancras }\end{array}$ & $\begin{array}{c}\text { Servicio } \\
\text { convencional } \\
\text { desde St. } \\
\text { Pancras a } \\
\text { Ashford }\end{array}$ & $\begin{array}{c}\text { Servicio } \\
\text { convencional } \\
\text { desde St. Pancras } \\
\text { a Springhead Jn }\end{array}$ & $\begin{array}{c}\text { Servicio } \\
\text { convencional } \\
\text { desde St. } \\
\text { Pancras a } \\
\text { Ebbsfleet }\end{array}$ \\
\hline Unidad & 31 minutos & 31 minutos & 16.5 minutos & 14 minutos \\
\hline $\begin{array}{c}\text { OMRC por } \\
\text { tren por } \\
\text { minuto }\end{array}$ & 56,38 & 43,58 & 43,58 & 43,8 \\
\hline $\begin{array}{c}\text { OMRC por } \\
\text { tren circulado }\end{array}$ & $1.747,78$ & $1.350,98$ & 719,07 & 610,12 \\
\hline
\end{tabular}

Tabla 163. Canon OMRC para trenes de viajeros HSI.

República Checa.

Správa Železniční cesty dopravní, (SŽDC) se estableció según la Ley 77/2002 como uno de los sucesores legales de los ferrocarriles checos. Es una organización inscrita en el Registro de Empresas del Tribunal Municipal de Praga. SŽDC es miembro de los siguientes corredores ferroviarios de mercancías:

• RFC 5 "Báltico - Adriático".

- RFC 7 "Oriente / Este-Medio".

- RFC 8 "Mar del Norte - Báltico".

- RFC 9 "Rin-Danubio".

La longitud de la red ferroviaria es de $9.459 \mathrm{~km}$ de ancho $1.435 \mathrm{~mm}$ siendo de vía única un total de $7.534 \mathrm{~km}$ y $3.216 \mathrm{~km}$ de vías electrificadas.

Las vías electrificadas están divididas por el voltaje de la línea siendo:

- $\quad 1.382 \mathrm{~km}$ de $25 \mathrm{kV} \mathrm{AC/50Hz}$.

- $\quad 1.819 \mathrm{~km}$ de $3 \mathrm{kV}$ DC.

- $\quad 14 \mathrm{~km}$ de AC $15000 \mathrm{~V} / 162 / 3 \mathrm{~Hz}$

SŽDC prevé en su canon los costes justificados y directamente empleados en el funcionamiento el transporte ferroviario. El canon está formado por dos 
componentes, la reserva de capacidad de infraestructura y el uso de la infraestructura.

El precio para la reserva de capacidad de infraestructura se determina dependiendo de:

- Duración del período entre la presentación de la solicitud de la infraestructura, la asignación de capacidad y la fecha requerida de su uso.

- Relación entre la solicitud presentada para la adjudicación de capacidad de infraestructura y la fecha límite para la planificación del calendario anual o sus cambios planificados,

- $\quad$ La complejidad de manejo de la solicitud.

El canon para la reserva de capacidad de infraestructura incluye:

- $\quad$ Cargo por adjudicación de capacidad de infraestructura.

- $\quad$ El pago de la planificación de los horarios del tren (excepto costes de impresión y distribución) asignado a la solicitud dada del solicitante.

- $\quad$ La carga suplementaria para la negociación a corto plazo.

El cargo por reserva de capacidad se obtiene mediante la siguiente fórmula:

$$
\text { Canon }\left(C Z K^{59}\right)=K 1+K 2 \times L+K 3 \times D
$$

Siendo:

K1: Precio por preparación de gráfico de marcha del surco (CZK/km).

K2: Precio por elaboración del surco (CZK/km).

L: Longitud del surco en $\mathrm{km}$.

K3: Precio por reserva del surco (CZK/día)

D: Días de uso del surco.

59 CSK: Corona checa. 
Los valores de $K 1, K 2$ y $K 3$ se muestran en la tabla siguiente:

\begin{tabular}{|l|c|c|c|}
\hline \multicolumn{1}{|c|}{ Producto } & $\mathbf{K 1}$ & $\mathbf{K 2}$ & $\mathbf{K 3}$ \\
\hline $\begin{array}{l}\text { Solicitud de capacidad dentro de los plazos } \\
\text { determinados en la Declaración de la Red }\end{array}$ & 1.700 & 8 & 10 \\
\hline $\begin{array}{l}\text { Solicitud de capacidad antes de 3 días de la } \\
\text { expedición }\end{array}$ & 100 & 0 & 70 \\
\hline $\begin{array}{l}\text { Solicitud de capacidad dentro de los 3 días antes de } \\
\text { la expedición }\end{array}$ & 100 & 0 & 160 \\
\hline $\begin{array}{l}\text { Solicitud de capacidad para realización de pruebas } \\
\text { con material rodante }\end{array}$ & 480 & 0 & 70 \\
\hline Solicitud de capacidad para trenes de trabajos & 0 & 0 & 0 \\
\hline
\end{tabular}

Tabla 164. Valores de K1, K2 y K3 para el canon de adjudicación de capacidad SžDC.

Rumania.

La infraestructura ferroviaria rumana pertenece al Estado y está asignada en concesión a la Compañía Nacional de Ferrocarriles (CFR) en su calidad de administrador de la infraestructura.

La red ferroviaria tiene una longitud de $20.077 \mathrm{~km}$ de $1.435 \mathrm{~mm}$ de ancho divididos de la forma siguiente:

- $\quad 4.474 \mathrm{~km}$ equipados con carril tipo 65.

- $\quad 2.292 \mathrm{~km}$ con carril tipo 54,

- $\quad 8.030 \mathrm{~km}$ con carril tipo 49.

- $\quad 4.785 \mathrm{~km}$ con carril inferior al tipo 49.

El canon de acceso se obtiene con las siguientes variables:

a) Distancia recorrida por el tren.

b) Tonelaje del tren.

c) El tipo de tren.

d) El tipo de línea.

e) La categoría de la sección de tráfico y sus sistemas de electrificación para el suministro de potencia de tracción.

Las líneas o tramos se dividen por categorías teniendo en cuenta las características técnicas de cada sección (velocidad máxima admitida por la línea), según la tabla siguiente: 


\begin{tabular}{|c|c|c|}
\hline & \multicolumn{2}{|c|}{ Velocidad $(\mathbf{k m} / \mathbf{h})$} \\
\hline Categoría & Desde & Hasta \\
\hline A & 121 & 160 \\
\hline B & 91 & 120 \\
\hline C & 51 & 90 \\
\hline D & 0 & 50 \\
\hline $\begin{array}{c}\text { E (sólo trenes de } \\
\text { mercancías) }\end{array}$ & 0 & - \\
\hline $\begin{array}{c}\text { D (Líneas con tráfico } \\
\text { menor a 5 trenes/día) }\end{array}$ & - & - \\
\hline $\begin{array}{c}\text { E (para líneas de vía } \\
\text { estrecha) }\end{array}$ & - & 50 \\
\hline
\end{tabular}

Tabla 165. Clasificación de las líneas CFR.

Las variables de carga aplicables para la obtención del canon de acceso se incluyen en la tabla siguiente:

\begin{tabular}{|c|c|c|c|c|c|c|c|}
\hline $\begin{array}{c}\text { Elementos del } \\
\text { canon }\end{array}$ & \multicolumn{7}{|c|}{ Canon } \\
\hline $\begin{array}{c}\text { Elementos del } \\
\text { canon } \\
\text { dependiendo de la }\end{array}$ & \multicolumn{7}{|c|}{ Canon por tren-km dependiente del tonelaje (LEI/tren-km) } \\
\hline $\begin{array}{l}\text { Categoría de del } \\
\text { tramo }\end{array}$ & A & B & C & $\mathrm{D}$ & $\mathrm{E}$ & $\mathrm{R}$ & I \\
\hline $\begin{array}{l}\text { Tramos } \\
\text { electrificados }\end{array}$ & Ttse & Ttse & Ttse & Ttse & Ttse & Ttse & Ttse \\
\hline $\begin{array}{l}\text { Tramos no } \\
\text { electrificados }\end{array}$ & Ttsn & Ttsn & Ttsn & Ttsn & Ttsn & Ttsn & Ttsn \\
\hline Tonelaje mínimo & Tmin & Tmin & Tmin & Tmin & Tmin & Tmin & Tmin \\
\hline Factor toneladas & $\mathrm{Ft}$ & $\mathrm{F \dagger}$ & $\mathrm{Ft}$ & $\mathrm{F \dagger}$ & $\mathrm{Ft}$ & $\mathrm{Ft}$ & $\mathrm{Ft}$ \\
\hline $\begin{array}{c}\text { Elementos del } \\
\text { canon } \\
\text { dependiendo de la } \\
\text { distancia }\end{array}$ & \multicolumn{7}{|c|}{$\begin{array}{l}\text { Canon por tren-km dependiente de la distancia (LEI/tren- } \\
\text { km) }\end{array}$} \\
\hline $\begin{array}{l}\text { Categoría del } \\
\text { tramo }\end{array}$ & $A$ & B & C & $\mathrm{F}$ & $E$ & $\mathrm{R}$ & I \\
\hline Tráfico & Tc & Tc & TC & Tc & Tc & TC & TC \\
\hline
\end{tabular}


Siendo:

TTSE: Cargo por el uso de las instalaciones de electrificación para cada categoría de tramos electrificados; no incluye el suministro de energía de tracción.

Ttsn: Canon en función del tonelaje para cada categoría de tramos no electrificados.

Tmín: Tonelaje bruto de tren a partir del cual se aplica el factor de tonelaje.

Ft: Factor de tonelaje que representa un coeficiente de corrección que se aplica al tonelaje total del tren.

Tc: Carga de tráfico en función de la distancia para cada categoría de tramo.

El valor del canon para un tren que circula en un tramo se calcula mediante la suma de los cánones para la distancia que se ejecuta en dicho tramo, en función de su categoría y con la siguiente fórmula:

$$
I A C=\sum \text { Sección IAC }
$$

Siendo:

Sección IAC: Tonelaje IAC + Tráfico IAC.

Tonelaje IAC: Cargo de acceso a la infraestructura ferroviaria para una categoría de tramo en función de la distancia recorrida y la existencia del sistema de electrificación, así como en el tonelaje ponderado del tren, que se calcula con la siguiente fórmula:

$$
\text { Tonelaje IAC }=\mathrm{Km} \times \text { Ttsn }[1+(\text { Tonelaje bruto }- \text { Tmin }) \times \mathrm{Ft}]
$$

Siendo:

Km: Kilómetros del tramo.

Ft: O para trenes con tonelaje bruto inferior a Tmin.

Tonelaje bruto: Tonelaje total del tren.

Tráfico IAC: Cargo por el tráfico dependiendo de la distancia calculado según la fórmula siguiente:

$$
\text { Tráfico } I A C=K m \times(T c+T t s e)
$$




\section{Siendo:}

Km: Número de kilómetros realizados en el tramo.

Ttse: Aplicable en líneas electrificadas y trenes de tracción eléctrica.

Serbia.

A la fecha de finalizar esta Tesis Doctoral no se ha podido conseguir documentación del administrador de infraestructuras ferroviarias serbio.

Slovaquia.

Železnice Slovenskej Republiky (Zsr) fue establecida el 1 de enero de 1993 por decisión del Gobierno de la República Eslovaca en el establecimiento de una empresa pública estatal tras la separación de los Ferrocarriles del estado checoeslovaco en dos entidades independientes.

Los corredores ferroviarios de mercancías situadas en las líneas ferroviarias de Zsr son el corredor 5 (Báltico - Adriático), el corredor 7 (Oriente / Medio Mediterráneo) y el corredor 9 (Checoeslovaco).

El canon de uso de la infraestructura depende de la línea por donde circula la composición ferroviaria. Estas líneas están clasificadas según la relación adjunta y la lista nominal de cada una de ellas se puede consultar en el anexo 5.8:

- Líneas principales:

Categoría 1 - Principales líneas con mayor importancia

Categoría 2 - Principales líneas con menor importancia.

- $\quad$ Líneas secundarias:

Categoría 3 - líneas secundarias

Categoría 4 - líneas secundarias con el control del tráfico simplificado

Categoría 5 - líneas de vía estrecha TEZ y OZ.

Categoría 6 - Otras líneas de vía estrecha. 
Siendo sus cánones según tabla adjunta:

\begin{tabular}{|c|c|}
\hline Categoría de la línea & $U_{1 i}$ en $€$ por tren-kilómetro \\
\hline 1 & 0,0207 \\
\hline 2 & 0,0190 \\
\hline 3 & 0,0188 \\
\hline 4 & 0,0160 \\
\hline 5 & 0,0141 \\
\hline 6 & 0,0096 \\
\hline
\end{tabular}

Tabla 167. Canon Uli por asignación de capacidad ZSR.

\begin{tabular}{|c|c|}
\hline Categoría de la línea & $\boldsymbol{U}_{\mathbf{2}}$ en $\boldsymbol{\epsilon}$ por tren-kilómetro \\
\hline 1 & 0,958 \\
\hline 2 & 0,881 \\
\hline 3 & 0,871 \\
\hline 4 & 0,742 \\
\hline 5 & 0,651 \\
\hline 6 & 0,445 \\
\hline
\end{tabular}

Tabla 168. Canon U2i por ordenación y gestión tráfico ZSR.

\begin{tabular}{|c|c|}
\hline Categoría de la línea & $\boldsymbol{U}_{3 \mathbf{i}}$ en $\boldsymbol{€}$ por cada $\mathbf{1 . 0 0 0}$ toneladas-km \\
\hline 1 & 1,311 \\
\hline 2 & 1,261 \\
\hline 3 & 1,243 \\
\hline 4 & 1,064 \\
\hline 5 & 0,934 \\
\hline 6 & 0,649 \\
\hline
\end{tabular}

Tabla 169. Canon U3i por uso de la infraestructura ZSR.

Una vez obtenidos las variables obtenidas según la categoría de la línea férrea se puede obtener el canon de acceso mediante la expresión siguiente:

$$
U_{m p}=U_{1}+U_{2}+U_{3}
$$


Donde:

$$
\begin{gathered}
U_{1}=\sum_{i=1}^{6} U_{1 i} * L_{i} \\
U_{2}=\sum_{i=1}^{6} U_{2 i} * L_{i} \\
U_{3}=\frac{1}{1000} * \sum U_{3 i} * L_{i} * k_{e}
\end{gathered}
$$

Siendo:

- $\quad$ i: Categoría de línea.

- $\quad$ U1i: Canon por asignación de capacidad en euros por tren-km.

- U2i: Canon por gestión del tráfico y de la organización en euros por tren-km.

- U3i: Canon por uso de la infraestructura en euros por cada 1.000 toneladas-km.

- UMP: Canon total en euros.

- $\quad$ Li: Longitud total entre los respectivos puntos de transporte de la línea de la categoría en particular en kilómetros.

- Qi: Masa total del tren bruto en toneladas en la línea de categoría determinada en toneladas.

ke: Coeficiente tracción independiente en las líneas electrificadas y en una categoría particular de línea, siendo 1,2 y 1,00 para la tracción eléctrica.

Slovenia.

En la República de Eslovenia, el administrador de infraestructuras ferroviarias es la empresa Slovenske železnice Infrastruktura d.o.o. que, de acuerdo con lo dispuesto en la legislación estatal, es responsable del control de tráfico ferroviario y de la administración de la infraestructura.

El canon de uso de la infraestructura queda expresado con la ecuación siguiente:

$$
U_{t p 3}=\sum_{i=1}^{I} * \sum_{w=1}^{W} Q_{v l k m j(w, i)} * F_{w} * P_{i} * C_{v l k m} * C_{v p}
$$


Siendo:

U: Canon.

Qvlkm (VV, i): Kilómetros de la línea en cuestión y el mismo material de

tracción.

Cvlkm: Coste por tren kilómetro.

Pi: Coeficiente de carga por tipo de línea.

FVV: Coeficiente de potencia por unidad de tracción.

Cvp: Suplemento por tipo de tren.

En las tablas siguientes se muestran los valores de las variables anteriores y que se aplican para la obtención del canon de circulación.

\begin{tabular}{|l|c|}
\hline \multicolumn{1}{|c|}{ Tipo de tren } & CVP \\
\hline Trenes de mercancías hasta 1.000 t. & 0,72 \\
\hline Trenes de mercancías de 1.001 a 1.500 t. & 1,00 \\
\hline Trenes de mercancías de 1.501 a 1.750 t. & 1,24 \\
\hline Trenes de mercancías de 1.751 a 2.000 t. & 1,55 \\
\hline Trenes de mercancías más de 2.000 t. & 1,86 \\
\hline Trenes de mercancías "vacíos" (menos de 100 t) & 0,30 \\
\hline Locomotoras aisladas & 0,30 \\
\hline Trenes con tecnología basculante & 0,83 \\
\hline Trenes de viajeros & 0,61 \\
\hline Automotores a través del túnel de Bohinj & 0,30 \\
\hline Otros automotores & 0,42 \\
\hline Trenes de viajeros "vacíos" & 0,30 \\
\hline Trenes históricos & 0,42 \\
\hline
\end{tabular}

Tabla 170. Valores de $C_{v p}$ para el cálculo del canon de circulación SZI.

\begin{tabular}{|c|c|c|c|}
\hline Categoría de línea & $P_{i}$ & & Número y denominación línea \\
\hline \multirow{5}{*}{ R1 } & \multirow{5}{*}{0,411} & 42 & Liutomer - Gornia Radaona \\
\hline & & 43 & d.m. - Lendava \\
\hline & & 71 & Branching Šempeter pri Gorici-Vrtojba-d.m. \\
\hline & & 73 & branchina Kreplie - Repentabor - d.m. \\
\hline & & 82 & Grosuplie - Kočevie \\
\hline \multirow{3}{*}{ R2 } & \multirow{3}{*}{0,587} & 70 & Jesenice - Sežana \\
\hline & & 81 & Sevnica - Trebnie \\
\hline & & 80 & section Trebnie - Liubliana \\
\hline \multirow{3}{*}{ R3 } & & 21 & Ljubljana Šiška - Kamnik Graben \\
\hline & & 31 & Celie - Velenie \\
\hline & & 80 & section d.m. - Metlika - Trebnie \\
\hline
\end{tabular}




\begin{tabular}{|c|c|c|c|}
\hline & 0,542 & 34 & section Maribor - Ruše \\
\hline \multirow{6}{*}{ R4 } & \multirow{6}{*}{0,531} & 13 & Liubliana Zaloa - Liubliana (P5) \\
\hline & & 32 & d.m. - Roaatec - Grobelno \\
\hline & & 33 & d.m. - Imeno - Stranie \\
\hline & & 34 & section Ruše - Prevalie - d.m. \\
\hline & & $6]$ & Branchina Prešnica-Podaorie - d.m. \\
\hline & & 72 & Prvačina - Aidovščina \\
\hline \multirow{4}{*}{ G1 } & \multirow{4}{*}{0,788} & 40 & Pradersko - Ormož \\
\hline & & 41 & Ormož - Hodoš - d.m. \\
\hline & & 44 & Ormož-Središče - d.m. \\
\hline & & 64 & Pivka - lirska Bistrica - d.m. \\
\hline \multirow[b]{3}{*}{ G2 } & \multirow[b]{3}{*}{1,104} & 20 & Liubliana - Jesenice - d.m. \\
\hline & & 60 & Divača - branchina Prešnica \\
\hline & & 62 & branchina Prešnica - Koper \\
\hline \multirow{5}{*}{ G3 } & \multirow{5}{*}{1,000} & 10 & d.m. - Dobova - Liubliana \\
\hline & & 11 & Liubliana Zaloa - branchina Kaiuhova (P3) \\
\hline & & 12 & Liubliana Zaloa - Liubliana (P4) \\
\hline & & 30 & Zidani Most - Šentilj - d.m. \\
\hline & & 50 & Liubliana - Sežana - d.m. \\
\hline
\end{tabular}

Tabla 171. Valores de Pi para el cálculo del canon de circulación SZI.

\begin{tabular}{|c|c|c|c|}
\hline Categoría & Fvv & Serie & Descripción \\
\hline \multirow{15}{*}{ A } & \multirow{15}{*}{0,95} & 3120 & SŽ electric multiple unit Siemens (two-carriage) \\
\hline & & 3121 & SŽ electric multiple unit Siemens (three-carriage) \\
\hline & & 6420 & \multirow{3}{*}{ Sž Diesel locomotive } \\
\hline & & 6421 & \\
\hline & & 6422 & \\
\hline & & 7110 & \multirow{4}{*}{ Sž Diesel multiple unit } \\
\hline & & 7130 & \\
\hline & & 7131 & \\
\hline & & 7145 & \\
\hline & & 7320 & \multirow{2}{*}{ SŽ Diesel } \\
\hline & & 7321 & \\
\hline & & 8130 & \multirow{2}{*}{ Sž Diesel multiple unit } \\
\hline & & 8131 & \\
\hline & & 30 & \multirow{2}{*}{ SŽ steam locomotive } \\
\hline & & 60 & \\
\hline
\end{tabular}




\begin{tabular}{|c|c|c|c|}
\hline & & 170 & \\
\hline & & 250 & \\
\hline & & 330 & \\
\hline \multirow{10}{*}{ B } & \multirow{10}{*}{1,00} & 1216 & ÖBB electric locomotive \\
\hline & & 2016 & ÖBB Diesel locomotive \\
\hline & & 3100 & SŽ electric multiple unit ICS (tilting train) \\
\hline & & 3420 & \multirow{6}{*}{ Sž electric locomotive } \\
\hline & & 5410 & \\
\hline & & 5411 & \\
\hline & & 5412 & \\
\hline & & 5415 & \\
\hline & & 5416 & \\
\hline & & 6440 & Sž Diesel locomotive \\
\hline \multirow{6}{*}{ c } & \multirow{6}{*}{1,00} & 3110 & \multirow{2}{*}{ SŽ electric multiple unit } \\
\hline & & 3112 & \\
\hline & & 6610 & \multirow{4}{*}{ Sž Diesel locomotive } \\
\hline & & 6611 & \\
\hline & & 6640 & \\
\hline & & 6641 & \\
\hline
\end{tabular}

Tabla 172. Valores de Fuv para el cálculo del canon de circulación SZI.

\section{Suecia.}

La Administración de Transporte de Suecia (Trafikverket) es la autoridad responsable en cuanto a transportes ante el Gobierno de Suecia. El ministerio responsable de los ferrocarriles es el Departamento de Empresa, Energía y Comunicaciones. La Administración de Transporte de Suecia gestiona las operaciones administrativas con la responsabilidad de planificar infraestructuras a largo plazo y la construcción, operación y mantenimiento de las carreteras estatales y ferrocarriles.

De conformidad con el Decreto $913 / 2010$ de la UE sobre la red ferroviaria europea para el transporte de mercancías, existe un corredor ferroviario internacional establecido a partir de Estocolmo/Oslo a través de Malmö, Hamburgo, Innsbruck hasta Palermo (Corredor-escandinavo Mediterráneo). Este corredor está operativo desde 10 de octubre de 2015.

El paquete de acceso mínimo es tarificado en base a TKBR y pasajeros, dependiendo del tipo de tren y del tipo de línea donde se reserva el surco, 
así como las emisiones, basadas en los costes socioeconómicos en términos de efectos ambientales y de salud generados por la operación del tren.

\begin{tabular}{|l|l|l|}
\hline \multicolumn{1}{|c|}{ Canon por acceso } & Carga por eje & \multicolumn{1}{c|}{$\begin{array}{c}\text { Canon } \\
\left.\text { (SEK }{ }^{60} / T K B T\right)\end{array}$} \\
\hline \multirow{4}{*}{ Trenes de mercancías } & $\leq 20 \mathrm{~T}$. & 0,0056 SEK/TKBT \\
\cline { 2 - 3 } & $>20 \mathrm{~T} . \leq 22,5 \mathrm{~T}$. & 0,0070 SEK/TKBT \\
\cline { 2 - 3 } & $>22,5 \mathrm{~T} . \leq 25 \mathrm{~T}$. & 0,0077 SEK/TKBT \\
\cline { 2 - 3 } & $>25 \mathrm{~T}$. & 0,0084 SEK/TKBT \\
\hline \multirow{2}{*}{ Trenes de viajeros } & $\leq 20 \mathrm{~T}$. & 0,0014 SEK/TKBT \\
\cline { 2 - 3 } & $>20 \mathrm{~T}$. & 0,0154 SEK/TKBT \\
\hline
\end{tabular}

Tabla 173. Canon por acceso de la red ferroviaria Trafikverket.

\begin{tabular}{|l|c|c|c|}
\hline & Nivel alto & Nivel medio & Nivel bajo \\
\hline $\begin{array}{l}\text { Surco trenes de } \\
\text { viajeros }\end{array}$ & 6,30 SEK/tren-km. & 2,30 SEK/tren-km. & 1,90 SEK/tren-km. \\
\hline $\begin{array}{l}\text { Surco trenes de } \\
\text { mercancías }\end{array}$ & 6,30 SEK/tren-km. & 2,30 SEK/tren-km. & 1,90 SEK/tren-km. \\
\hline $\begin{array}{l}\text { Surco trenes de } \\
\text { servicio }\end{array}$ & 6,30 SEK/tren-km. & 2,30 SEK/tren-km. & 1,90 SEK/tren-km. \\
\hline
\end{tabular}

Tabla 174. Canon por reserva de capacidad Trafikverket.

\section{Canon por emisiones.}

Para el material rodante equipado con motores de combustión o de explosión viene determinado por la cantidad de combustible consumido, calculado en litros de combustible líquido o gaseoso en $\mathrm{m}^{3}$. Este canon se reduce si los motores cumplen con la norma de la UE referente a los requisitos de escape para vehículos automotores y locomotoras (tipo IIIA y tipo IIIB).

\begin{tabular}{|l|c|c|c|c|}
\hline \multicolumn{1}{|c|}{ Material rodante } & \multicolumn{2}{|c|}{$\begin{array}{c}\text { Canon para motores de } \\
\text { combustión }\end{array}$} & $\begin{array}{c}\text { Canon para motores de } \\
\text { explosión }\end{array}$ \\
\hline & SEK/litro & SEK/m & SEK/litro & SEK/m $\mathbf{m}^{3}$ \\
\hline Locomotoras & 3,20 & 3,76 & 2,14 & 2,71 \\
\hline Locomotoras tipo III A & 2,07 & 2,43 & 2,07 & 2,43 \\
\hline Locomotoras tipo III B & 1,66 & 1,95 & 1,66 & 1,95 \\
\hline Autopropulsados & 3,13 & 3,68 & 2,07 & 2,62 \\
\hline $\begin{array}{l}\text { Autopropulsados tipo } \\
\text { III A }\end{array}$ & 1,72 & 2,02 & 1,72 & 2,02 \\
\hline $\begin{array}{l}\text { Autopropulsados tipo } \\
\text { III B }\end{array}$ & 1,42 & 1,66 & 1,42 & 1,66 \\
\hline
\end{tabular}

Tabla 175. Canon por emisiones del material rodante Trafikverket.

\footnotetext{
60 SEK: Corona sueca
} 
Existe un canon por tráfico que se aplica a los trenes de mercancías que cruzan el nudo ferroviario de Öresund de 2,980 SEK/tren.

Suiza.

SBB Infraestructura mantiene una red de alrededor de 3.034 kilómetros, de los cuales alrededor de $1.400 \mathrm{~km}$ son de vía doble.

Tiene 393 túneles con una longitud total de unos $250 \mathrm{~km}$ (excluyendo el túnel de base del Gotardo), y casi 5.936 puentes $(90 \mathrm{~km}$ ) y posee 6 plantas hidroeléctricas propiedad de compañías ferroviarias, además de un número de plantas asociadas y siete centros de transformación que suministran potencia de tracción a la infraestructura. La red cubre prácticamente la totalidad de Suiza.

Las principales rutas de tráfico son el eje norte-sur de Schaffhausen / Basilea a Chiasso / Luino, Brig / Domodossola y el eje este-oeste de St. Margrethen / Buchs (St. Gallen) de Genève.

El canon de acceso está formado por los siguientes elementos:

- El precio mínimo.

- El margen de contribución.

- El precio de la energía eléctrica.

- Bonificación por reducción de ruido.

- Bonificación por equipamiento con ECTS.

El precio mínimo es aplicado para todo tipo de tráfico y se establece teniendo en cuanta los costes marginales y los diferentes costes de infraestructura, la demanda y el impacto medioambiental de los vehículos usados. Se establece el precio mínimo para cada categoría de ruta basándose en la información proporcionada por los administradores de la infraestructura, y la divide de acuerdo con la causa de cada coste:

a) Por tren-kilómetro (precio mínimo de surcos).

b) Por tren, basado en desgaste causado por los vehículos del tren. 
El precio mínimo varía en función de los siguientes factores de precios, recargos y descuentos:

a) Factor precio para cada trayecto de tren relacionado con la demanda.

b) Factor precio para cada trayecto de tren relacionado con la calidad.

c) Demanda.

d) Recargos y descuentos para el impacto ambiental causado por los vehículos utilizados.

e) Descuento para viajes en rutas equipadas con ETCS.

f) Descuento para circulaciones que optimizan la línea respecto a la capacidad.

El margen de contribución para servicios no franquiciados de viajeros es de 0,0027 CHF61-km, excepto en material rodante "vacío". En el caso de servicios franquiciados se calcula sobre la base de los ingresos de tráfico, incluyendo los generados por la venta de billetes, reservas, suplementos y el transporte de equipaje

El margen de contribución para los trenes de pasajeros franquiciados está determinado por la autoridad de franquicia de la siguiente manera:

a) Para los servicios reservados, 18 meses antes del inicio del respectivo año calendario, después de consultar con los administradores de infraestructuras, usuarios de la red y los clientes.

b) Para todos los demás servicios, en el momento de concesión de la licencia, sobre la base de la aplicación. Si la franquicia se concede por un período superior a cinco años, es conveniente prever para la revisión periódica y la realineación del margen de contribución.

El precio de la electricidad se incrementa en un $20 \%$ durante los períodos "punta" y se reducen en un $40 \%$ entre las $22: 00$ y las 6: 00 . Si los usuarios de la red renuncian a la instalación y calibración de equipos de medición para el consumo de electricidad en las unidades de tracción, los administradores de infraestructuras están en libertad para fijar las tasas para cada categoría de trenes basado en las mediciones de muestras.

${ }^{61}$ CHF: Francos suizos. 
Las empresas ferroviarias que operan los trenes de mercancías equipados con frenos de disco, frenos de tambor o bloques de freno de material compuesto tienen derecho a reclamar un bono de bajo nivel de ruido de:

a) 0,01 CHF por eje-kilómetro para los vehículos con un diámetro de la rueda de menos de 50 centímetros.

b) 0,02 CHF por eje-kilómetro para los vehículos equipados con bloques de freno de material compuesto o frenos de tambor y con un diámetro de la rueda de menos de 50 centímetros.

c) 0,03 CHF por eje-kilómetro para los vehículos equipados con frenos de disco y con un diámetro de rueda de 50 centímetros o más.

Se concede un descuento de $25.000 \mathrm{CHF}$ anual por ETCS instalado para los servicios realizados en los tramos convertidos al sistema.

LFP (Línea Figueres Perpignan).

Gestiona el tramo internacional entre España y Francia que fue anteriormente gestionada por TP Ferro por medio de concesión por 51 años. Esta concesión fue aprobada por el Reino de España y la República Francesa en 2003 y rubricada a través del contrato de concesión el 17 de febrero de 2004 (BOE 175 de 21/7/2004), autorizando a TP Ferro a actuar como Gestor de Infraestructuras Ferroviarias, de acuerdo con la Directiva $2001 / 14 / C E$ y con lo establecido en las normas y especificaciones legales aplicables en el territorio de ambos estados concedentes, de la "Sección Internacional" objeto de la concesión.

El canon por reserva de capacidad es considerado como un pago a cuenta del canon final, una vez utilizado el surco reservado. En caso de no ser utilizado el surco, el importe de la reserva no es reembolsable. A continuación, se muestran las tablas donde se indica el importe del canon a aplicar ante la solicitud de reserva de capacidad estándar/ especial o urgente y a los trenes de mercancías especiales:

\begin{tabular}{|l|c|c|c|}
\hline Tipo de tren & Hora valle & Hora media & Hora punta \\
\hline Viajeros & $137 €$ & $164 €$ & $274 €$ \\
\hline Mercancías & \multicolumn{3}{|c|}{$60 €$} \\
\hline Locomotoras aisladas & \multicolumn{3}{|c|}{$60 €$} \\
\hline
\end{tabular}

Tabla 176. Canon por reserva de capacidad estándar y especial TP Ferro. 


\begin{tabular}{|l|c|}
\hline \multicolumn{1}{|c|}{ Tipo de tren } & Canon \\
\cline { 1 - 1 } Viajeros & $912 €$ \\
\cline { 1 - 1 } Mercancías & $288 €$ \\
\hline
\end{tabular}

Tabla 177. Canon por reserva de capacidad urgente TP Ferro.

\begin{tabular}{|c|c|}
\hline Tipo de tren & Canon \\
\hline Mercancías especiales & $326 €$ \\
\hline
\end{tabular}

Tabla 178. Canon por reserva de capacidad trenes de mercancías especiales TP Ferro.

Para el cálculo del componente por uso de la infraestructura sólo se considera una tipología de trenes de viajeros, grupo 1, trenes de alta velocidad que efectúan servicios de larga distancia (>400 km) y caracterizados por una velocidad de concepción superior a $250 \mathrm{~km} / \mathrm{h}$.

Se dividen en cuatro categorías:

- Categoría 1.1: Trenes con capacidad inferior a 300 plazas sentadas.

- Categoría 1.2: Trenes con capacidad comprendida entre 301 y 410 plazas sentadas.

- Categoría 1.3: Trenes con capacidad comprendida entre 411 y 510 plazas sentadas.

- Categoría 1.4: Trenes con capacidad superior a 510 plazas sentadas.

En la tabla siguiente se muestra el canon a aplicar a los trenes de viajeros:

\begin{tabular}{|c|c|c|c|}
\hline \multicolumn{4}{|c|}{ Grupo 1 (Trenes de viajeros) } \\
\hline Categoría tren & Hora valle & Hora media & Hora punta \\
\hline 1.1 & $960,34 €$ & $1.160,84 €$ & $1.582,95 €$ \\
\hline 1.2 & $1.308,58 €$ & $1.582,95 €$ & $2.158,07 €$ \\
\hline 1.3 & $1.625,17 €$ & $1.962,85 €$ & $2.680,45 €$ \\
\hline 1.4 & $2.031,58 €$ & $2.473,22 €$ & $3.385,94 €$ \\
\hline
\end{tabular}

Tabla 179. Canon por circulación de trenes de viajeros TP Ferro.

Los trenes de mercancías, grupo 2, se dividen en tres categorías:

- Categoría 2.1: Trenes convencionales.

- Categoría 2.2: Trenes de transporte de automóviles.

- Categoría 2.3: Trenes de transporte combinado.

La categoría se asigna dependiendo del número de vagones con la misma finalidad $(\geq 60 \%)$. 
En la tabla siguiente se muestra el canon a aplicar a los trenes de mercancías:

\begin{tabular}{|c|c|}
\hline \multicolumn{2}{|c|}{ Grupo 2 (Trenes de mercancías) } \\
\hline Categoría tren & Canon \\
\hline 2.1 & $639,05 €$ \\
\hline 2.2 & $918,29 €$ \\
\hline 2.3 & $894,43 €$ \\
\hline
\end{tabular}

Tabla 180. Canon por circulación de trenes de mercancías TP Ferro.

Las otras composiciones contempladas son las locomotoras aisladas (grupo 3) y los trenes de mercancías especiales (grupo 4).

En la tabla siguiente se muestra el canon para locomotoras aisladas y para trenes de mercancías especiales:

\begin{tabular}{|l|l|}
\hline \multicolumn{1}{|c|}{ Grupo } & \multicolumn{1}{|c|}{ Canon } \\
\hline Grupo 3 (Locomotoras aisladas) & $896,66 €$ \\
\hline Grupo 4 (Trenes de mercancías especiales) & A determinar por TP FERRO \\
\hline
\end{tabular}

Tabla 181. Canon por circulación locomotoras aisladas y trenes de mercancías TP Ferro. 


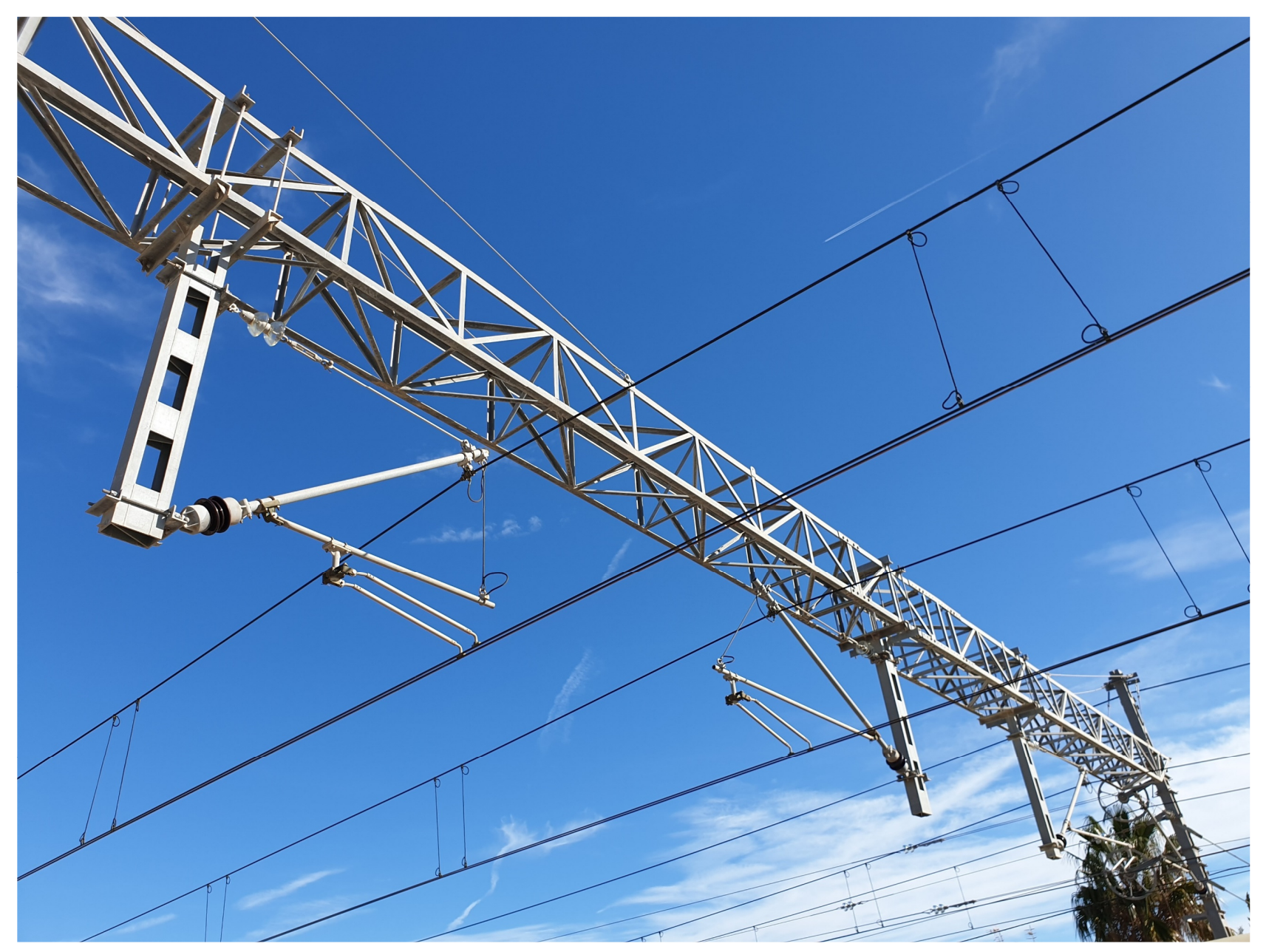

